Aus der Klinik für Unfallchirurgie,Orthopädie und Plastische Chirurgie ( Prof. Dr. med. W. Lehmann)

der Medizinischen Fakultät der Universität Göttingen

\title{
Die Modulation der Skelettmuskelzelle unter dem Einfluss einer horizontalen Ganzkörpervibration in östrogendefizienten Ratten
}

\section{INAUGURAL-DISSERTATION}

zur Erlangung des Doktorgrades

der Medizinischen Fakultät der Georg-August-Universität zu Göttingen

\author{
vorgelegt von \\ Cordula Sauerhoff
}

aus

Gelsenkirchen

Göttingen 2017 
Dekan: Herr Prof. Dr. med. Heyo Kroemer

\section{Betreuungsausschuss:}

Betreuerin: Prof. Dr. med. E. K. Stürmer

Ko-Betreuer/in: Prof. Dr. Dr. med. F.-J. Kramer

\section{Prüfungskommission:}

Referent/in: Prof. Dr. med. E. K. Stürmer

Ko-Referent/in: Prof. Dr. Dr. med. F.-J. Kramer

Drittreferent/in: Prof. Dr. M. Schön

Datum der mündlichen Prüfung: 11.04.2018 
Widmung: 
Hiermit erkläre ich, die Dissertation mit dem Titel „Die Modulation der Skelettmuskelzelle unter dem Einfluss einer horizontalen Ganzkörpervibration in östrogendefizienten Ratten“ eigenständig angefertigt und keine anderen als die von mir angegebenen Quellen und Hilfsmittel verwendet zu haben.

Münster, den 25.09.2017

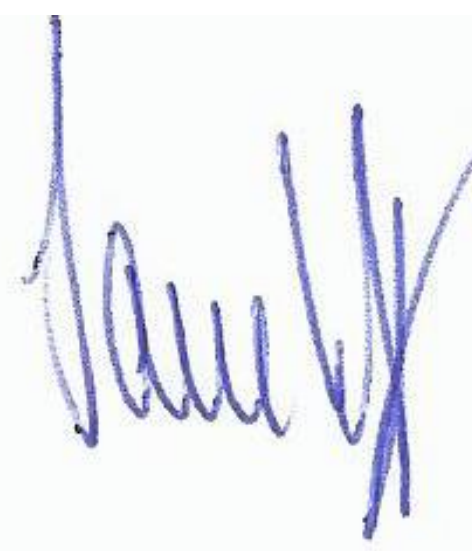




\section{Inhaltsverzeichnis}

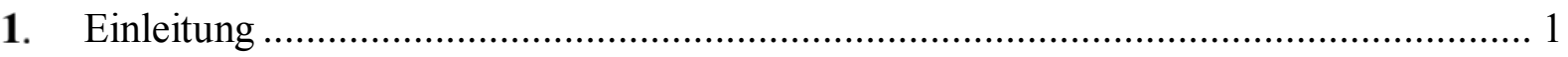

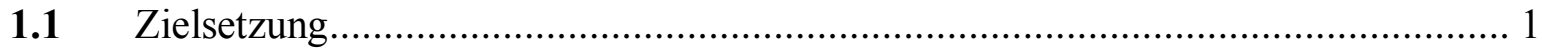

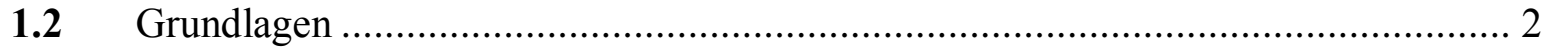

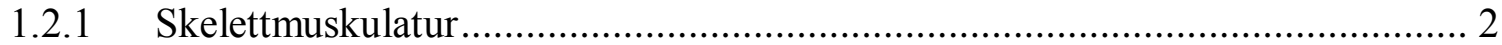

1.2.2 Zellulärer Aufbau einer Skelettmuskelzelle.................................................. 3

1.2.3 Aufbau von Myofibrillen .......................................................................... 4

1.2.4 Fasertypen der Skelettmuskulatur ................................................................ 5

1.2.5 Einflüsse auf die Plastizität der Muskelfasertypen ......................................... 7

1.2.6 Angiogenese und Kapillaren im Skelettmuskel .......................................... 8

1.2.7 Stoffwechselvorgänge in Skelettmuskelzellen............................................. 9

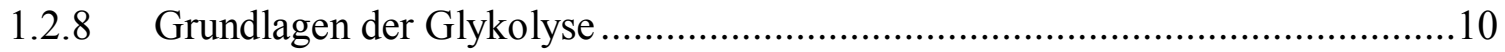

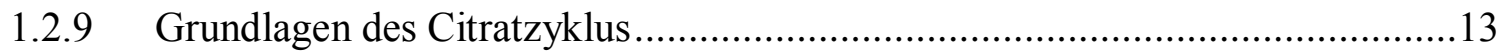

1.2.10 Grundlagen der Atmungskette...............................................................

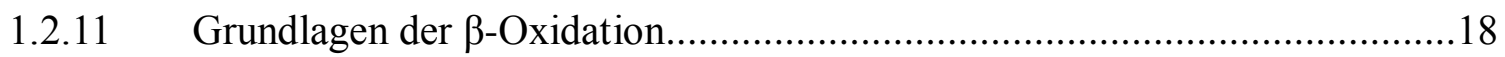

1.2.12 Einfluss von Östrogenen auf die Skelettmuskulatur..................................21

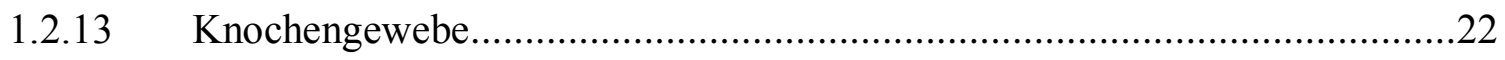

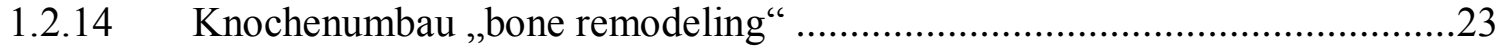

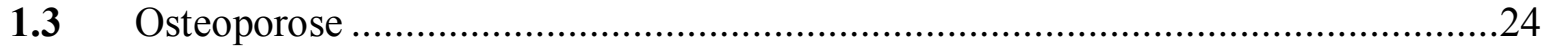

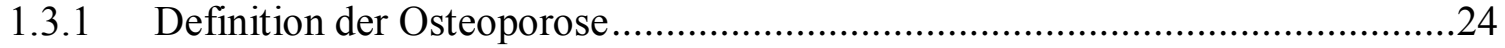

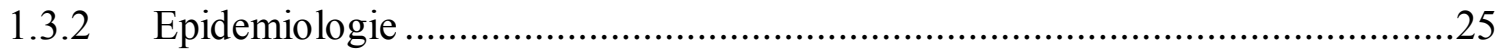

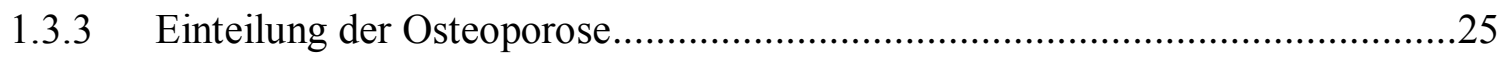

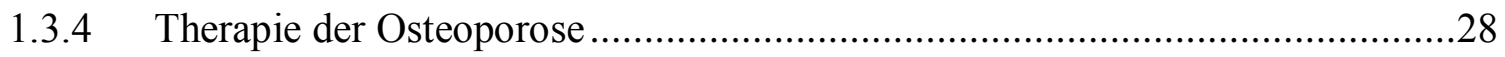

1.3.5 Der Einfluss von Östrogen auf die Osteoporose ..........................................29

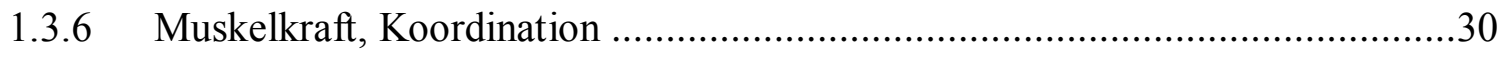

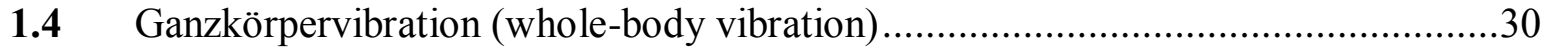

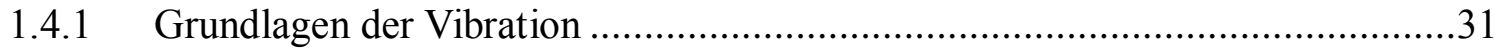

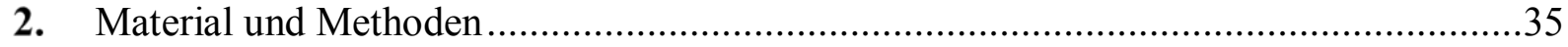

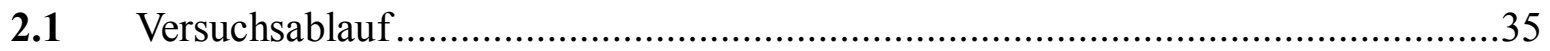




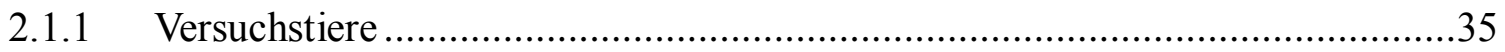

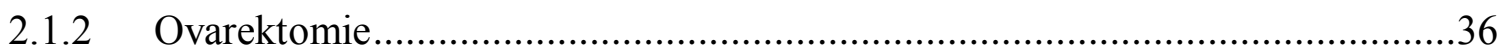

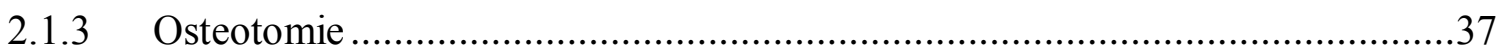

2.1.4 Horizontale Ganzkörpervibration (whole-body vibration; WBV) .....................37

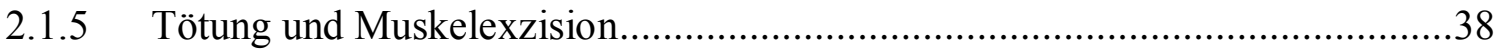

2.1.6 Aufarbeitung der Muskulatur zur Gewinnung der Histologie ..........................39

2.1.7 Analyse der Muskelzellen auf Kapillardichte und Stoffwechsel ......................39

2.1.8 ATPase-Färbung kombiniert mit Diaphorase für Rattenproben ......................40

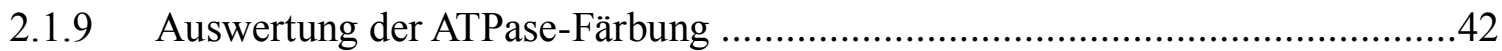

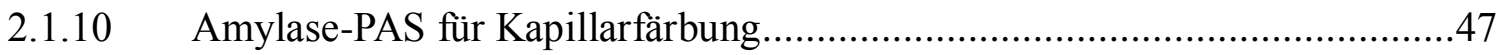

2.1.11 Auswertung der Amylase-PAS-Färbung .................................................48

2.1.12 Aufarbeitung der Muskulatur für Enzym-Analysen ..................................49

2.1.13 Bestimmung der Laktatdehydrogenase-Aktivität ......................................50

2.1.14 Bestimmung der Citrat-Synthase-Aktivität.............................................51

2.1.15 Bestimmung der Komplex I-Aktivität ....................................................53

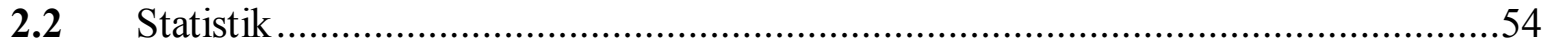

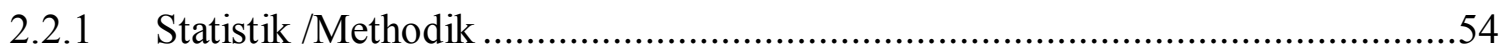

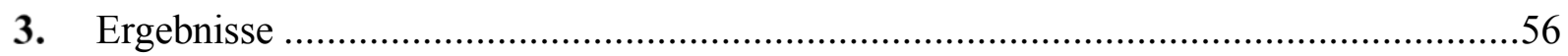

3.1 Gewichtsbestimmungen der Tiere, der untersuchten Muskeln und der Uteri ..........56

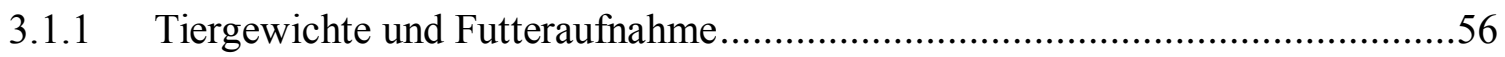

3.1.2 Muskelgewichte der Mm. gastrocnemii und Mm. solei ................................58

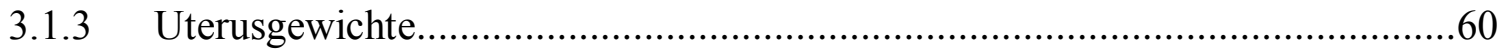

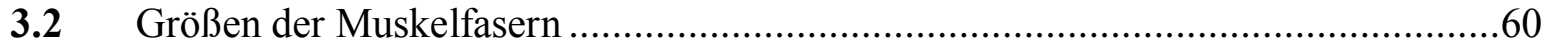

3.2.1 Analysen der Querschnittsflächen der Muskeln ..........................................61

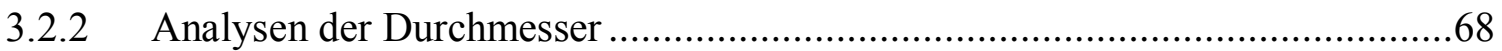

3.2.3 Verhältnisse der glykolytischen und oxidativen Zellen im M. longissimus .......80

3.3 Verteilung der Kapillaren in den Muskelfasern der Mm. gastrocnemii, longissimi

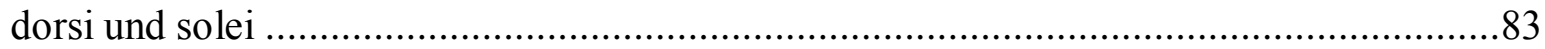

3.4 Aktivität der Enzyme in den Muskelproben....................................................89

3.4.1 Ergebnisse für die Laktatdehydrogenase ....................................................90

3.4.2 Ergebnisse für das Enzym Citrat-Synthase ..................................................92

3.4.3 Ergebnisse für den Komplex I ................................................................ 93

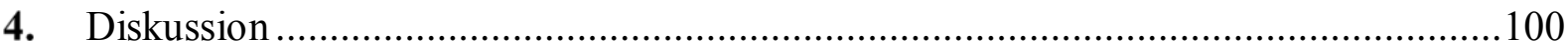

4.1 Ratten als Tiermodell für Osteoporose ........................................................ 100 
4.2 Analysen der Muskelgewichte für den M. gastrocnemius und M. soleus unter

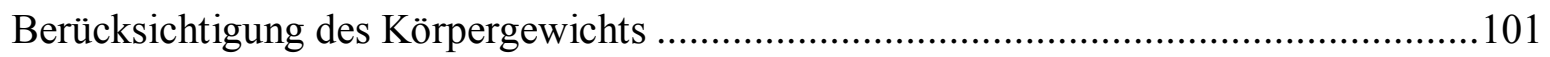

4.3 Analysen der Muskelflächen, Muskeldurchmesser und Muskelfasertypen ...........103

4.4 Analysen der Zell- und Kapillardichte im Muskel ..........................................106

4.5 Laktatdehydrogenase (LDH)-, die Citrat-Synthase (CS)- und der Komplex I- Gehalt in den Mm. gastrocnemii, Mm. solei und Mm. longissimi dorsi ................................... 107

4.6 Der Einfluss der horizontalen Ganzkörpervibration auf die Ratten-Tibia .............109

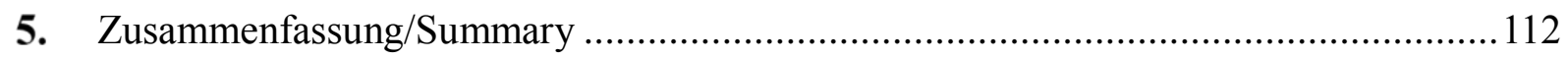

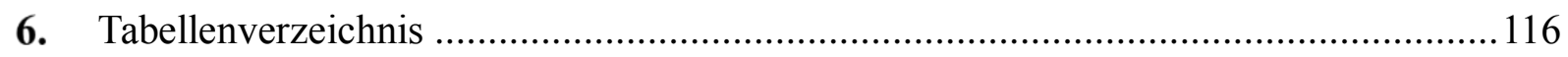

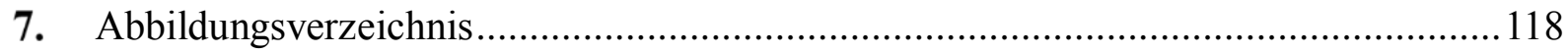

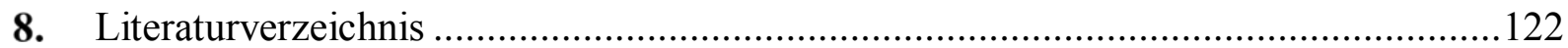




\section{Abkürzungsverzeichnis}

$\begin{array}{ll}\text { A-Bande } & \text { Anisotroper Abschnitt eines Sarkomers } \\ \text { Abb. } & \text { Abbildung } \\ \text { ADP } & \text { Adenosindiphosphat } \\ \text { AK } & \text { Alizarin-Komplexon } \\ \text { AMP } & \text { Adenosinmonophosphat } \\ \text { ANOVA } & \text { Analysis of Variance } \\ \text { ATP } & \text { Adenosintriphosphat } \\ \text { ATPase } & \text { Adenosintriphosphatase } \\ \text { a } & \text { Alpha } \\ \text { BCA } & \text { Bicinchoninic acid } \\ \text { BMD } & \text { Bone mineral densitiy } \\ \text { BMS } & \text { Biomechanische Muskel-Stimulation } \\ \text { BMU } & \text { Basic multicellular unit } \\ \text { BMP } & \text { Bone morphogenetic proteins } \\ \text { BSA } & \text { Bovine serum albumin } \\ \text { Bzw. } & \text { Beziehungsweise } \\ \beta & \text { Beta } \\ \text { C } & \text { Kohlenstoffatom } \\ { }^{\circ} \mathrm{C} & \text { Grad Celsius } \\ \text { CaCl } 2 & \text { Calcium-Chlorid } \\ \text { CG } & \text { Calcein-Grün } \\ \text { cm } & \text { Zentimeter } \\ \text { CO } 2 & \text { Kohlenstoffdioxid } \\ \text { CO-A } & \text { Coenzym-A } \\ \text { COCl } & \text { Kobalt-Chlorid } \\ \text { CS } & \text { Citrat-Synthase } \\ \text { D } & \text { Spezifische Schichtdicke } \\ \text { Dest. } & \text { Destilliert } \\ \text { DTNB } & \text { Dithiobis-2-Nitrobenzoesäure } \\ \text { DVC } & \text { Digital video casette } \\ \text { DVO } & \text { Dachverband Osteologie e.V. } \\ \end{array}$


DXA Dual-Röntgen-Absorptiometrie
$\Delta$
Delta
E
Extinktion
EDTA Ethylendiamintetraacetat
EGTA Ethylenglycol-bis(aminoethylether)- $N, N, N^{\prime}, N^{\prime}-$
tetraessigsäure
Et al. Und andere
ETF Elektronen-Transferierendes Flavoprotein
e.V. Eingetragener Verein
$\varepsilon$
Etta

FAD Flavin-Adenin-Dinukleotid (oxidiert)

FADH Flavin-Adenin-Dinucleotid (reduziert)

g Erdbeschleunigung/Ortsfaktor

g Gramm

$\gamma \quad$ Gamma

GDP Guanosindiphosphat

Ggf. Gegebenenfalls

$\mathrm{GmbH} \quad$ Gesellschaft mit beschränkter Haftung

GTP Guanosintriphosphat

GLUTs Glukosetransporter

$\mathrm{H}^{+} \quad$ Proton

$\mathrm{H}_{2} \mathrm{O} \quad$ Wasser

$\mathrm{HCl} \quad$ Salzsäure

$\mathrm{H}$-Streifen Hensen-Streifen

$\mathrm{Hz} \quad$ Hertz

I-Bande Isotroper Streifen

IGF-1 Insulin-like growth factor-1

ILUSA Illinois United States of America

Inc Incorporated

K $1 \quad$ Komplex I

KCL Kalium-Chlorid

$\mathrm{kJ} / \mathrm{mol} \quad$ Kilogramm-Joule/ Mol

$\mathrm{K}_{2} \mathrm{~S}_{2} \mathrm{O}_{5} \quad$ Kaliumdisulfit

L-Malat Linksdrehende Apfelsäure 


\begin{tabular}{|c|c|}
\hline LDH & Laktatdehydrogenase \\
\hline LPL & Lipoprotein-Lipase \\
\hline M & Mol \\
\hline M. & Musculus \\
\hline Mm. & Musculi \\
\hline $\mathrm{mM}$ & Mili-Mol \\
\hline $\mathrm{mm}$ & Milimeter \\
\hline $\mathrm{mm}^{2}$ & Quadrat-Milimeter \\
\hline mATPase & Myosin-Adenosintriphosphatase \\
\hline $\mathrm{MHC}$ & Myosin heavy chain \\
\hline M-Streifen & Mittel-Streifen \\
\hline mTOR & Mammalian target of Rapamycin \\
\hline N & Newton \\
\hline NAD & Nikotinamidadenindinukleotid (oxidiert) \\
\hline $\mathrm{NADH}$ & Nikotinamidadenindinukleotid (reduziert) \\
\hline $\mathrm{NaOH}$ & Natriumhydroxid \\
\hline NIS- & Nikon Imaging Software Advanced Research \\
\hline \multicolumn{2}{|l|}{ Elements } \\
\hline \multicolumn{2}{|l|}{ AR } \\
\hline Nitro-BT & Nitroblau Tetrazoliumchlorid \\
\hline $\mathrm{nm}$ & Nano-Meter \\
\hline N.Y. & New York \\
\hline o. & Oder \\
\hline $\mathrm{OH}$ & Hydroxyl-Gruppe \\
\hline OPG & Osteoprotegerin \\
\hline ovX & Ovarektomiert \\
\hline PAS & Periodoc acid-Schiff Reaction \\
\hline PFK & Phosphofruktokinase \\
\hline $\mathrm{pH}$ & potentia Hydrogenii \\
\hline PTH & Parathormon \\
\hline Coenzym Q & Ubiquinon \\
\hline RANKL & Receptor Activator of NF-kB Ligand \\
\hline Rpm & Rounds per minute \\
\hline SERM & Selektive Östrogenrezeptor-Modulatoren \\
\hline
\end{tabular}




\begin{tabular}{ll} 
SHAM & Scheinoperiert \\
s.o. & Siehe oben \\
$\mathrm{SO}_{2}$ & Schwefelwasser \\
T.M. & Trade Mark \\
TVR & Tonischer Vibrations-Reflex \\
u. & Und \\
u.a. & unter anderem \\
U/g & Units pro Gramm \\
USA & United States of America \\
V & Volumen \\
v.a. & vor allem \\
VEGF & Vascular endothelial growth factor \\
WBV & whole-body vibration \\
WHO & World Health Organization \\
$\mu$ l & Mikro-Liter \\
$\mu m$ & Mikro-Meter \\
ZTE & Zentrale Experimentelle Tiereinrichtung \\
Z-Streifen & Zwischen-Streifen \\
\hline
\end{tabular}




\section{Einleitung}

\subsection{Zielsetzung}

Der Inhalt dieser Arbeit ist die Analyse, inwieweit die Skelettmuskulatur in die systemische Erkrankung der Osteoporose involviert ist. Der Einfluss beziehungsweise auch der Zusammenhang zwischen dem Verlust an Knochendichte und dem Verlust an Muskelmasse und Muskelkraft ist bis zum heutigen Tag nur unzureichend untersucht und verstanden worden. Dabei ist es offensichtlich, dass die Muskelarbeit einen entscheidenden Beitrag an der Knochenstärke und Knochenmasse leistet (Wolfe 2006). Selbst die Arbeit, die die Skelettmuskeln zum Tragen eines erhöhten Körpergewichtes erbringen müssen, korreliert mit einer erhöhten Masse an Knochengewebe.

Die Muskulatur des Menschens beginnt, ab einem Alter von ungefähr 30 Jahren an Kraft zu verlieren, wobei das Knochengewebe noch an die ,jungen“ Muskeln angepasst ist. Der Knochen wird aber durch diesen beginnenden Alterungsprozess des Muskelapparates nicht mehr ausreichend belastet, so dass dieser konsekutiv an Stärke und Masse verliert (Frost 1997). Diesen Mechanismus zukünftig positiv und effektiv durch Muskelarbeit in Form einer Ganzkörpervibration (whole-body vibration) beeinflussen $\mathrm{zu}$ können, ist die zentrale Fragestellung der vorliegenden Arbeit. Wir untersuchten dafür den Einfluss der Ganzkörpervibration auf Skelettmuskeln an östrogen-defizienten Ratten, wobei wir das Ziel verfolgten, die optimale Vibrations-Frequenz bei horizontaler Ausrichtung der Vibration ausfindig zu machen.

Die Ganzkörpervibration scheint für die Zukunft eine sinnvolle nicht-pharmakologische, prophylaktische und therapeutische Maßnahme für die Osteoporose zu sein (Rubin et al. 2006), denn diese Methode des Muskeltrainings ist sogar bei schwachen oder immobilen Personen anwendbar. Ebenso ist es eine minimale Trainingsmethode, die zu den erwünschten Ergebnissen, einer Steigerung der Muskelkraft und somit auch der Knochendichte führen kann. Unklar ist noch, welche Art (vertikal, horizontal, sinusoidal) und welche Frequenz der Vibration die bestmögliche Anwendungsweise für eine optimale Stimulation der Muskel- und Knochenzellen darstellt (Fritton et al. 2000). In der vorliegenden Arbeit untersuchten wir zur Bestimmung der optimalen Vibrationsart und Frequenz die Skelettmuskelzellen auf ihren Fasertyp beziehungsweise auf ihren Metabolismus, auf ihre Kapillardichte, auf das Muskelgewicht und auf verschiedene zum Zellstoffwechsel gehörende Enzyme. 


\subsection{Grundlagen}

\subsubsection{Skelettmuskulatur}

Die Entwicklung der Skelettmuskulatur scheint bei allen Wirbeltieren nach einem gemeinsamen Modell abzulaufen (Kablar und Rudnicki 2000). Mit Hilfe dieser Aussage lässt sich also annehmen, dass wir unsere Ergebnisse von weiblichen Sprague Dawley-Ratten auf andere Vertebraten übertragen können.

Die quergestreifte Muskulatur beziehungsweise die Skelettmuskulatur macht mit ihren über 300 Muskeln etwa 40\% des Körpergewichtes aus und ist mit dem höchsten Anteil an Gewebe am Säugetierorganismus beteiligt, sie hat in Ruhe einen Sauerstoffverbrauch von 20\% (Hick und Hartmann 2006). Sie wird in den meisten Fällen willentlich innerviert, ihre Stärke liegt vor allem darin, für ein kurzes Zeitintervall eine große Kraft zu entwickeln. Darüber hinaus können die Skelettmuskeln durch ihre Fixierung am Knochen bei aktiven Bewegungen und durch ihre Wirkung gegen die Schwerkraft wichtige Haltefunktionen erfüllen (Pette und Staron 2000). Eine Schwäche der quergestreiften Muskulatur ist jedoch ihre schnelle Erschöpfbarkeit.

Ein Muskel besteht aus Muskelzellen und kollagenfaserigen Bindegewebe, diese sind zu einem komplexen, hierarchischen System angeordnet. Die Funktionseinheit der Muskulatur, die sogenannten Primärbündel, setzen sich aus mehreren parallel verlaufenden Muskelzellen zusammen. Diese Muskelzellen sind vom Perimysium internum umhüllt. Zwischen den einzelnen Muskelzellen verlaufen jeweils zarte Bindegewebsfasern, die auch benachbarte Muskelzellen miteinander im Verbund halten, hierbei handelt es sich um das Endomysium, in dem das reiche Kapillarnetz der Muskelzellen zu finden ist. Mehrere Primärbündel stellen wiederum ein Sekundärbündel (Fleischfaser) dar, welches vom Perimysium externum umgeben wird. In seiner Gesamtheit wird ein Muskel vom Epimysium und als äußerste Schicht von einer Faszie eingeschlossen (Abb.1).

Für den Feinaufbau der Skelettmuskelzelle ist charakteristisch, dass die einzelnen Zellen einige Zentimeter lang sind und einen Durchmesser zwischen 40-100 (selten auch bis 500) $\mu \mathrm{m}$ haben (Welsch 2010). Weil die Muskelzellen lang und schmal sind, werden sie gewöhnlich als Muskelfasern bezeichnet (Moore 2007). Eine Skelettmuskelzelle ist eine relativ lange, vielkernige Zelle. Die Zunahme des Skelettmuskels an Länge und Breite verläuft an das Skelettwachstum angepasst, die spezifische Größe eines Muskels hängt dabei jeweils von der zu verrichtenden Arbeit ab. Beim Menschen entsteht das Wachstum eines quergestreiften Muskels durch die Vergrößerung des Durchmessers einer Muskelzelle. Diese 
Vergrößerung wird durch eine vermehrte Synthese von Myofilamenten erreicht. Zu den Myofilamenten gehören beispielsweise Aktin, Myosin und Troponin (Moore 2007).

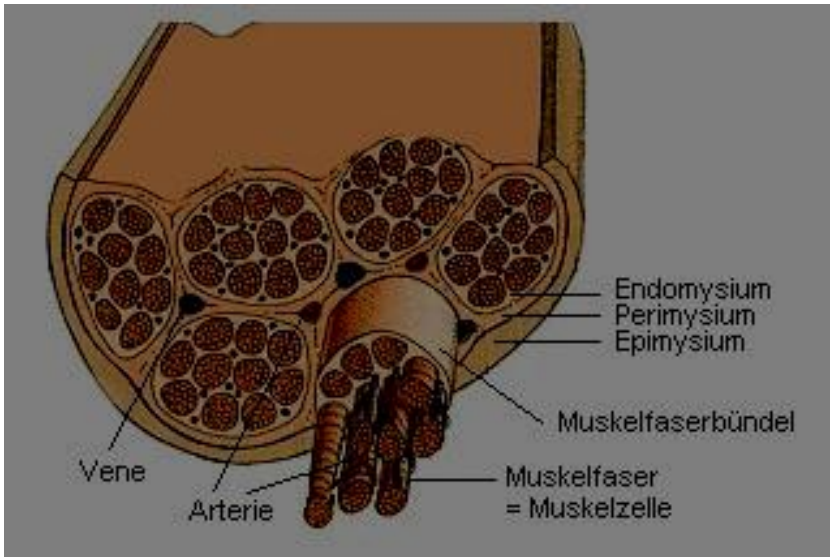

Abbildung 1: Aufbau der Muskulatur

\subsubsection{Zellulärer Aufbau einer Skelettmuskelzelle}

Bei der Betrachtung einer Skelettmuskelfaser unter einem Lichtmikroskop fällt eine besondere Querstreifung dieser Zelle auf. Diese beruht auf der regelmäßigen Anordnung von kontraktilen Proteinen, bei denen es sich um Aktin und Myosin handelt (Hick und Hartmann 2006). Es liegen hunderte von 0,5-1 $\mu \mathrm{m}$ dicken Myofibrillen, die aus Aktin und Myosin bestehen, im Zytoplasma (Sarkoplasma bei der Muskelzelle) dicht aneinander. In der Peripherie der Skelettmuskelzelle liegen mehrere längliche Zellkerne, etwa 20-40 pro mm der Zelllänge. Das Vorliegen von derart vielen (zum Teil mehreren hundert) Zellkernen, lässt sich durch die Entwicklung der Skelettmuskelzelle erklären, bei der mehrere einkernige Vorläuferzellen (Myoblasten) zu einem Synzytium verschmelzen (Welsch 2010). Im Sarkoplasma befinden sich darüber hinaus das endoplasmatische Retikulum (sarkoplasmatisches Retikulum), eine große Anzahl von Mitochondrien (Sarkosomen), Glykogen, Lysosomen, Golgi-Apparaten, Lipidtröpfchen und andere sarkoplasmatische Einschlüsse (Hick und Hartmann 2006). Gesondert zu erwähnen ist das Myoglobin als sauerstoffbindendes Protein, das frei im Sarkoplasma vorliegt. Die Skelettmuskelzelle besitzt eine Zellmembran, die auch Sarkolemm genannt wird, diese zieht sich fingerförmig bis weit in das Sarkoplasma hinein (Welsch 2010). 


\subsubsection{Aufbau von Myofibrillen}

Wie bereits erwähnt, ist das Charakteristische der Skelettmuskelzelle ihre mikroskopische Querstreifung. Der Eindruck der Querstreifung wird durch die kontinuierliche Abfolge von hellen und dunklen Banden entlang der Myofibrillen erzeugt. Die dunklen Anteile werden ABanden und die hellen Anteile werden I-Banden genannt. Die I-Banden verkürzen sich bei Kontraktion und es findet sich in jeder I-Bande mittig angeordnet ein Z-Streifen (Zwischenstreifen). Die A-Banden, die in ihrer Länge bei Kontraktion konstant bleiben, besitzen in ihrer Mitte einen H-Streifen (Hensen-Streifen), in dessen Mitte wiederum ein dunkler M-Streifen liegt. Die einzelnen Myofibrillen bestehen aus den kontraktilen Proteinen Aktin und Myosin und werden in ca. $2 \mu \mathrm{m}$ lange Sarkomere unterteilt. Im lichtmikroskopischen Bild lässt sich das an den sogenannten Z-Scheiben beziehungsweise im Schnittbild an den Z-Streifen erkennen. Bei den Z-Streifen handelt es sich um Haltestrukturen aus Proteinen (Hick und Hartmann 2006). Das Segment zwischen zwei Z-Streifen ist ein Sarkomer, das die kleinste kontraktile Einheit der Myofibrille darstellt (Abb. 2). Im Sarkomer finden sich regelmäßig angeordnete dünne und dicke Filamente. Die dünnen Filamente bestehen aus Aktin, Tropomyosin und Troponin und sind ca. $7 \mathrm{~nm}$ dick und $1 \mu \mathrm{m}$ lang. Den Hauptbestanteil der dicken Filamente macht das Myosin II aus, Myosin II ist ca. $15 \mathrm{~nm}$ dick und 1,5 $\mu \mathrm{m}$ lang. Für jede Kontraktion der Muskelzelle oder auch für die Zellteilung liefert das Myosin II die benötigte Kraft. Die dünnen und dicken Filamente liegen im Sarkomer im Verhältnis 2:1 vor (Welsch 2010).

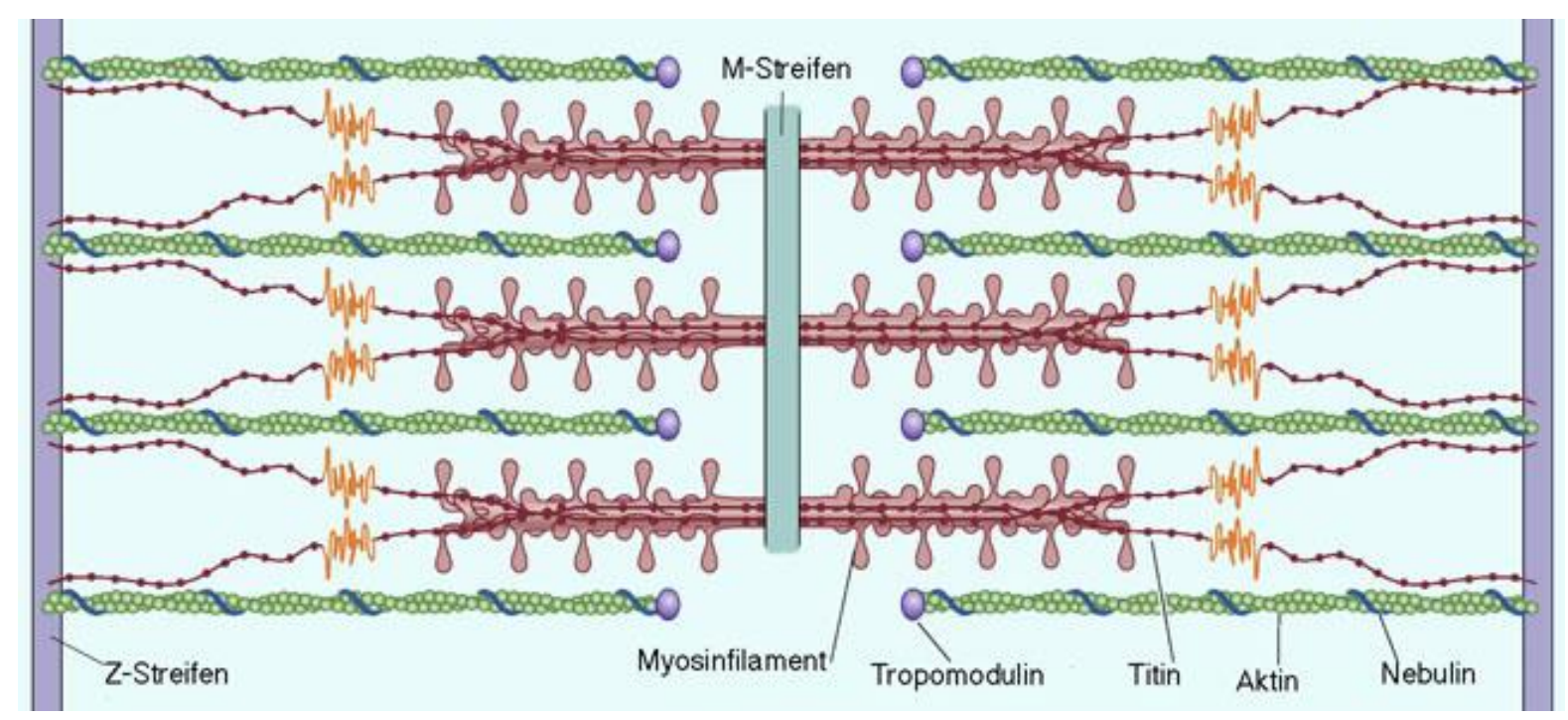

Abbildung 2: Sarkomeraufbau 


\subsubsection{Fasertypen der Skelettmuskulatur}

Bei den Skelettmuskeln handelt es sich um ein heterogenes Gewebe; die meisten, insbesondere die humanen, sind aus verschiedenartigen Fasertypen aufgebaut. Die Fasertypen lassen sich histochemisch, biochemisch, morphologisch oder physiologisch klassifizieren. Es gibt eine Vielzahl von Einteilungsmöglichkeiten für die Muskelfasern, im Folgenden werden einige Muskelfaser-Typisierungen vorgestellt. Ursprünglich unterteilte man die Muskelfasern nach der Geschwindigkeit, in der sie sich kontrahieren. Durch histologische Untersuchungen kann man eine Korrelation zwischen der Myosin-ATPase und der Geschwindigkeit der Muskelverkürzung erkennen. So kann man zwischen langsamen Fasern (Typ-I-Faser) und schnellen Fasern (Typ-II-Faser) unterscheiden. Morphologisch korreliert diese Unterscheidung mit der Tatsache, dass langsame Typ-I-Fasern rot sind und schnelle Typ-IIFasern weiß erscheinen. Die langsame Typ-I-Faser erhält ihre Rotfärbung durch einen, im Gegensatz zu der schnellen Typ-II-Faser, hohen Gehalt an Myoglobin und einer hohen Kapillardichte. Der höhere Myoglobingehalt und auch die höhere Kapillardichte tragen zu einer größeren oxidativen Kapazität der Muskelfaser bei (Scott et al. 2001). Beim Menschen werden die Muskelfasern in drei Haupttypen eingeteilt, hierbei gibt es die langsamen Typ-I-, die schnellen Typ-IIA- und Typ-IID-Fasern (Pette und Staron 2000).

In der Regel werden die Fasertypen nach histochemischer Anfärbung der MyosinAdenosintriphosphatase (mATPase), nach Identifikation der Isoformen der schweren Myosinketten und nach biochemischer Bestimmung von metabolischen Enzymen eingeteilt (Scott et al. 2001). Die oben genannten Untersuchungsmethoden und Messungen der kontraktilen Eigenschaften von einzelnen Fasern zeigen, dass es sehr wohl Unterschiede im molekularen Aufbau der Myofibrillen, im Zellmetabolismus und in ihrer Kontraktionsgeschwindigkeit gibt. Ebenso enthält jeder Fasertyp eine spezifische, von einem eigenen Gen kodierte Isoform der schweren Kette des Myosinmoleküls, Typ I die MHCI, Typ IIA die MHCIIa und Typ IID die MHCIId (MHC = myosin heavy chain) (Pette und Staron 2000).

Es ist bekannt, dass schnelle Fasern eine zwei- bis dreimal höhere Aktivität an ATPase, im Vergleich zu langsamen Fasern haben. Jedoch wird diese Tatsache durch eine ATPase Färbung nicht dargestellt, die Intensitätsunterschiede in der Färbung beruhen auf verschieden pH-WertSensitivitäten der Muskelzellen (Scott et al. 2001).

In der biochemischen Klassifikation werden die Stoffwechselunterschiede in den Muskelfasertypen aufgedeckt. Es liegt entweder ein aerober/ oxidativer oder ein anaerober/ 
glykolytischer Stoffwechsel der Zelle vor. Dementsprechend klassifizieren wir drei verschiedene Muskelfasertypen:

- Fast-twitch glycolytic (FG)

- $\quad$ Fast-twitch oxidative (FOG)

- Slow-twitch oxidative (SO)

In der vorliegenden Arbeit werden die fast-twitch oxidativen und die slow-twitch oxidativen Muskelfasern zusammengefasst.

Typ-I- und Typ-IIA-Fasern weisen überwiegend einen aeroben-oxidativen Metabolismus auf, wohingegen Typ-IID-Fasern über einen größtenteils anaeroben-glykolytischen Energieumsatz verfügen. Diese Unterschiede im Zellstoffwechsel legen nahe, warum Typ-I- und Typ-IIAFasern für eine ausdauernde und Typ-IID-Fasern für eine rasche und zeitlich kurze Muskelarbeit sinnvoll sind. Das gemeinsame Vorliegen der unterschiedlichen Fasertypen scheint im Rahmen einer metabolischen Symbiose als sinnvoll (Pette und Staron 2000). Höchstwahrscheinlich wird das in den Muskelfasern, die über einen glykolytischen Metabolismus verfügen, gebildete Laktat direkt von angrenzenden aerob-oxidativen metabolisierenden Muskelfasern aufgenommen und endoxidiert (Pette und Staron 2000).

In der vorliegenden Arbeit konnten wir mittels einer ATPase-Färbung nach Horak (s. 2.1.8) diese Stoffwechselunterschiede in den untersuchten Muskelzellen darstellen und unter dem Lichtmikroskop deren Anzahl, Verteilungsmuster, Durchmesser und Flächen bestimmen. Dabei wird lediglich zwischen Zellen mit einem anaerob-/glykolytischen und einem aerob/oxidativen Stoffwechsel unterschieden.

Für die Fragestellung ist dabei besonders interessant, dass bei normaler, ruhiger Muskelausdauerarbeit die aeroben-oxidativen Typ-I-Fasern und nur bei großer, schneller und kurzer Muskelarbeit die anaeroben Typ-IID-Fasern genutzt werden. Demzufolge sind die Ergebnisse unseres Versuches explizit abhängig von der zu verrichtenden Muskelarbeit (horizontale Ganzkörpervibration, WBV).

Tabelle 1: Übersicht zu den verschieden Muskelfaserklassifikationen

\begin{tabular}{|c|c|c|}
\hline Muskelfasertyp I & Muskelfasertyp IIA & Muskelfasertyp IID \\
\hline \multicolumn{2}{|c|}{ - Aerober-/ oxidativer Metabolismus } & $\begin{array}{l}\text { - Anaerob-/ } \\
\text { glykolytischer } \\
\text { Metabolismus }\end{array}$ \\
\hline \multicolumn{2}{|c|}{ - Ausdauernde, ruhige Muskelarbeit } & $\begin{array}{l}\text { - Kraftvolle, schnelle, } \\
\text { kurze Muskelarbeit }\end{array}$ \\
\hline
\end{tabular}




\begin{tabular}{|l|ll|}
\hline $\begin{array}{l}\text { ATPase-Färbung: dunklere Färbung der } \\
\text { Muskelzellen }\end{array}$ & $\begin{array}{l}\text { ATPase-Färbung: } \\
\text { hellere Färbungen } \\
\text { der Muskelzellen }\end{array}$ \\
\hline$\bullet$ Durchmesser und Flächen i. d. R klein & $\begin{array}{l}\text { Durchmesser und } \\
\text { Flächen i. d. R. groß }\end{array}$ \\
\hline
\end{tabular}

\subsubsection{Einflüsse auf die Plastizität der Muskelfasertypen}

Bei den Muskelfasertypen liegen nicht nur „reine“ Typen vor, die nur eine Myosinisoform besitzen, sondern es gibt auch Muskelfasern, die über mehrere Myosinisoformen verfügen. Muskelzellen, die mehrere Myosinisoformen besitzen, stellen Übergangsfasern dar. Übergangsfasern können unter dem Einfluss exogener Faktoren in der Lage sein, ihren Phänotyp zu ändern. Ein exogener Faktor kann eine langfristig veränderte Leistungsanforderung an die Muskelfaser sein, dabei wird sich nicht nur das Expressionsmuster von Aktin und Myosin ändern, sondern es kommt auch zu einer Modulierung, beziehungsweise zum Wechsel des Zellmetabolismus. Demnach finden Fasertypübergänge statt (Pette und Staron 2000). Diese phänotypische Plastizität des Muskels beruht auf qualitativen und quantitativen Änderungen der Genexpression (Pette und Staron 2000).

Beim Fasertypübergang können die Typ-IIA-Fasern in die langsameren Typ-I-Fasern oder in die schnelleren Typ-IID-Fasern übergehen. Am meisten gesteigert werden die Fasertypübergänge durch neuromuskuläre Aktivität beziehungsweise Inaktivität. Diese lässt sich beispielsweise durch vermehrte kontraktile Muskelarbeit (Ausdauertraining), durch mechanische Beanspruchung (Dehnung), durch chronisch niederfrequente elektrische Stimulation, aber auch durch verminderte kontraktile Muskelarbeit wie Immobilisation, Schwerelosigkeit oder Denervation verändern beziehungsweise modulieren. Reduzierte Muskelarbeit führt also $\mathrm{zu}$ Fasertypübergängen von schnelleren (glykolytischen) zu langsameren (oxidativen) Fasern und eine erhöhte muskuläre Arbeit begünstigt Übergänge von langsameren (oxidativen) hin zu schnelleren (glykolytischen) Fasertypen (Pette und Staron 2000). Unter isometrischen, ballistischen Kontraktionen lassen sich Zeiten von $60 \mathrm{~ms}$ für schnelle und Zeiten von 140 ms für langsame Fasertypen festhalten (Tidow und Wiemann 1993).

Ebenso müssen hormonelle Einflüsse auf die Induktion zu Fasertypübergängen berücksichtigt werden. Eine sehr wichtige Funktion kommt hierbei dem Schilddrüsenhormon Thyroxin zu. Erkennen lässt sich dies an der Tatsache daran, dass ein erhöhter Thyroxin Wert (Hyperthyreose) einen Fasertypübergang von langsameren (oxidativen) zu schnelleren 
(glykolytischen) Fasertypen unterstützt. Dazu gegensinnig verhalten sich die Fasertypübergänge beim Vorliegen eines erniedrigten Thyroxin Werts (Hypothyreose) (Pette und Staron 2000).

Die Vorgänge der Fasertypübergänge lassen sich, wie bereits oben erwähnt, auch in der Enzymausstattung der Muskelzellen beziehungsweise an deren Zellmetabolismus erkennen. Es lässt sich die Regel aufstellen, dass eine vermehrte Muskelarbeit die Kapazität an aerobenoxidativen Stoffwechselvorgängen erhöht und dass eine verminderte Arbeit der Muskeln den anaeroben-glykolytischen Stoffwechsel quantitativ steigert.

\subsubsection{Angiogenese und Kapillaren im Skelettmuskel}

Die Verteilung beziehungsweise die Angiogenese von Kapillaren in Skelettmuskeln unterliegt jeweils dem Verbrauch und dem Bedarf an Sauerstoff. Bei erhöhtem Bedarf an Sauerstoff in der Muskelzelle nimmt mittelfristig die Anzahl der Kapillaren zu. Die Anzahl und Verteilung dieser Zunahme der Blutversorgung, ist einerseits abhängig von der Muskelfaserart, andererseits von der Art, in der der Muskel seine Arbeit verrichtet (Egginton 2011). Es liegen lokale Regulationsmechanismen vor, die entscheiden, ob neue Kapillaren im Bereich von glykolytischen oder oxidativen Muskelfasern ausgebildet werden (Egginton 2011). Dass sich die Anzahl von Kapillaren durch vermehrte muskuläre Arbeit verändert, hatte schon Professor Dr. August Krogh zu Beginn des 21. Jahrhunderts als den „kapillarmotorischen Regulationsmechanismus“ beschrieben (Krogh 1924). Krogh legte dabei sein Interesse auf den Aufbau der Kapillarwand, welches unser heutiges Verständnis von dem Wachstum von Kapillaren prägte (Egginton 2011). Bei erhöhter Muskelaktivität scheinen perivaskuläre Zellen und Stromazellen, wie beispielsweise Makrophagen, Perizyten und Fibroblasten, als Reaktion chemische, stimulierende Signale an den vaskulären endothelialen Wachstumsfaktor (VEGF) zu senden (Egginton 2011). Ebenso sind hämodynamische Faktoren wie Scherkäfte und Dehnungszustand der Muskeln wichtige Einflüsse auf die Modulation des muskulokapillären Systems.

Allerdings ist bekannt, dass im Allgemeinen die Aktivität der Angiogenese, in ausgewachsenen Organen und Organismen eher niedrig ausgeprägt ist. Eine Ausnahme stellen dabei die Reproduktionsorgane bei weiblichen Tieren und Menschen dar (Findlay 1986). Die Regulation der Angiogenese in reproduktiven Geweben erfolgt über Steroidhormone, wobei hier das 17- $\beta$ Östradiol die führende Rolle einnimmt (Simon et al. 1986). Der Östrogeneinfluss ist dabei bezogen auf kardiovaskuläre Erkrankungen ein schützender Faktor für Frauen in ihrer fertilen Lebensphase. Mehrere Studien belegen, dass der Einfluss von 
Östradiol die Aktivität von Endothelzellen steigert und es konsekutiv zu einer vermehrten Angiogenese kommt. So konnte eine Studie mit östrogendefizienten Kaninchen zeigen, dass nach der intramuskulären Gabe von 17- $\beta$ Östradiol die Angiogenese und die Perfusion im Muskel gesteigert wurden (Kyriakides et al. 2001). Ebenso konnte in der histologischen Aufarbeitung der Muskulatur eine Zunahme der Kapillardichte festgestellt werden (Kyriakides et al. 2001). In der vorliegenden Arbeit wurde die Verteilung der Kapillaren und ihre Dichte mittels PAS-Färbung dargestellt (s. 2.1.10).

\subsubsection{Stoffwechselvorgänge in Skelettmuskelzellen}

Keine einzige Muskelkontraktion wäre ohne das Vorhandensein von Adenosintriphosphat (ATP) möglich, so dass die zentrale Aufgabe des Muskelstoffwechsels die Gewinnung von ATP ist. Der Skelettmuskel hat drei verschiedene Wege, um die Bereitstellung von ATP zu bewerkstelligen: 1. die direkte Phosphorylierung, 2. die Glykolyse und 3. die oxidative Phosphorylierung. Die direkte Phosphorylierung dient zur kurzfristigen und raschen Erhöhung des ATP Gehalts zu Beginn einer Kontraktion, wobei diese Reakion auch nur für 10-20 Sekunden mit ihrer Leistungsfähigkeit ausreicht (Schmidt et al. 2010). In dieser Reaktion wird das Phosphat vom Kreatinphosphat auf das Adenosindiphosphat (ADP) übertragen, welches so zum dem benötigten Adenosintriphosphat (ATP) wird. Bei länger anhaltender Muskelarbeit wird zunächst über die anaerobe Glykolyse ATP neu gewonnen. Dies ist maximal über wenige Minuten für die Muskelzelle zu schaffen (Schmidt et al. 2010). Dieser Weg ATP zu gewinnen, erschöpft sich schon bereits nach 30 Sekunden, in denen das Maximum der anaeroben Glykolyse schon erreicht sein kann.

Darüber hinaus fällt vermehrt Laktat an, das zu einer metabolischen Azidose und zu einer verminderten Leistungsfähigkeit führt. Befindet sich der Muskel in einer ausdauernden Tätigkeit, so setzt nach 30-60 Sekunden die oxidative Phosphorylierung als Form der aeroben ATP-Gewinnung ein. Es handelt sich um einen obligat aeroben Prozess. Die Energie, die zur Synthese von ATP gebraucht wird, wird aus der Oxidation von Kohlenhydraten oder Fetten bezogen. Man spricht von einem Fließgleichgewicht (steady state) wenn die Neusynthese von ATP und der Verbrauch von ATP eine ausgeglichene Bilanz ergeben. Wir wissen, dass bei sportlichen Dauerleistungen ein um den Faktor 100 erhöhter Verbrauch an ATP vorliegt. Für diesen erhöhten Verbrauch wird auch eine gesteigerte ATP Neusynthese mittels oxidativer Phosphorylierung erforderlich, und so steigt der Abbau von Fettsäuren und Glykogen an 
(Schmidt et al. 2010). Bei einer kurzfristigen, maximalen Muskelarbeit werden vor allem die direkte Phosphorylierung und die Glykolyse bzw. Glykogenolyse genutzt. Der aeroben oxidativen Phosphorylierung kommt dabei nur eine untergeordnete Rolle zu (Pette und Staron 2000).

\subsubsection{Grundlagen der Glykolyse}

In der Glykolyse findet der Abbau von Glucose zu Pyruvat statt. Es werden sämtliche Kohlenhydrate in dieser Weise zu Pyruvat abgebaut. Alle Schritte der Glykolyse laufen im Zytoplasma ab, ohne das weitere Zellorganellen benötigt werden, so dass auch einfache Einzeller die Fähigkeit zur Glykolyse besitzen. Der Abbau von Zucker wurde schon seit Ende des 19. Jahrhunderts wissenschaftlich untersucht, alle Schritte und Enzyme der Glykolyse kennen wir aber erst seit 1940.

In der Glykolyse kann Glukose zu Pyruvat (aerobe Glykolyse) oder zu Laktat (anaerobe Glykolyse) abgebaut werden. Für die Glykolyse wird kein Sauerstoff benötigt, wobei das in der aeroben Glykolyse gewonnene Pyruvat nur durch die Atmungskette weiter abgebaut werden kann. Dies ist die Begründung, warum wir also von der aeroben Glykolyse im Vergleich zur anaeroben Glykolyse sprechen, letztere kommt gänzlich ohne Sauerstoff aus.

Neben der Aufgabe, durch den Abbau von Glukose Energie bereitzustellen (in Form von ATP bzw. in Form von $\mathrm{NADH} / \mathrm{H}^{+}$, welches in der Atmungskette auch in ATP umgesetzt wird), entstehen durch die Glykolyse auch wichtige Bestandteile für die Biosynthesen (wie das Acetyl-CoA, das aus Pyruvat entstanden ist), wie zum Beispiel Fettsäuren und Cholesterin (Horn et al. 2005). Wenn Glukose abgebaut wird, werden Bindungen aufgespalten; dabei wird Energie für die Zelle frei. Unter dem Aspekt der Energiebilanz können wir die Glykolyse in zwei Abschnitte einteilen. Für den ersten Abschnitt der Glykolyse, der 5 Reaktionen umfasst, werden 2 ATP aufgewendet. Als Ergebnis erhalten wir pro Molekül Glukose zwei Moleküle Glyceral-3-Phosphat. Im zweiten Abschnitt des Glukose-Abbaus wird Energie gewonnen. Durch wiederum fünf Reaktionen werden zwei Moleküle $\mathrm{NADH} / \mathrm{H}^{+}$, vier Moleküle ATP und zwei Moleküle Pyruvat generiert. In der Bilanz gewinnt die Zelle also pro Molekül Glukose, das zu Pyruvat abgebaut wird, zwei ATP. Es handelt sich im Vergleich zum Energiegewinn der Atmungskette jedoch nur um einen kleinen Energiezuwachs, aber die Glykolyse bietet der Zelle die Möglichkeit, auch bei Hypoxie ihren Energiehaushalt aufrechtzuerhalten. Besteht keine Hypoxie, so wird das Pyruvat in der Atmungskette vollständig zu $\mathrm{CO}_{2}$ und $\mathrm{H}_{2} \mathrm{O}$ 
oxidiert. Unter Hypoxie kommt es zur Reduktion des Pyruvats, so dass Laktat, welches in das Blut abgegeben wird, entsteht.

Betrachten wir nun die erste Phase der Glykolyse etwas genauer, die Glukose wird mit ihren sechs Kohlenstoffatomen unter der Zufuhr von Energie in zwei phosphorylierte Zucker mit je drei Kohlenstoffatomen gespalten. Der Abbau der Glukose beginnt mit ihrer Aufnahme, über Glukosetransporter (GLUTs) in die Zelle. In die Zelle aufgenommen, wird die Glukose von dem Enzym Hexokinase phosphoryliert. Für diesen Vorgang wird das erste ATP benötigt. Im nächsten Schritt wird die Glukose von der Glukose-6-Phosphat-Isomerase in das Fruktose-6Phosphat überführt. Als nächstes erscheint das wichtigste regulative Enzym der Glykolyse, die Phosphofruktokinase (PFK). Die PFK phosphoryliert das Fruktose-6-Phosphat am $\mathrm{C}_{1}$ Atom, so dass nun ein Fruktose-1,6-Bisphosphat vorliegt. Auch für die zweite Phosphorylierung wurde ein ATP verbraucht. Der Sinn des zweiten Phosphats erklärt sich durch den nächsten Schritt der Glykolyse, in dem der $\mathrm{C}_{6}$-Zucker in zwei $\mathrm{C}_{3}$-Zucker (Triosen), die dann jeweils mit einen Phosphat versehen sind, gespalten wird. Das spaltende Enzym ist die Aldolase, die das Fruktose-1,6-Bisphosphat in Glyceral-3-Phosphat und Glyceron-3Phosphat zerlegt. Da für die weiteren Glykolyse Schritte nur das Glyceral-3-Phosphat, welches sehr schnell abgebaut wird, relevant ist, wird das Glyceron-3-Phosphat durch die Triosephosphat-Isomerase ebenfalls zum Glyceral-3-Phosphat umgewandelt. Mit dem nächsten Schritt beginnt die zweite, energieerzeugende Phase der Glykolyse.

Die zweite Phase arbeitet mit zwei Molekülen Glyceral-3-Phosphat, die aus einem Molekül Glukose entstanden sind, das heißt, dass nun alle Reaktionen doppelt ablaufen (Abb. 3). Erst dadurch wird die Glykolyse in ihrer Bilanz zum Energielieferanten. Zunächst wird das Glyceral-3-Phosphat von der Glyceral-3-Phosphat-Dehydrogenase zum 1,3-Bisphosphoglycerat oxidiert. An das $\mathrm{C}_{1}$-Atom wird ebenfalls ein Phosphat durch dieses Enzym gesetzt. Das Besondere an diesem Phosphat ist, dass es nicht aus einem ATP stammt, sondern einen organischen Ursprung besitzt (Horn et al. 2005). Darüber hinaus wurde durch die Oxidation ein sehr energiereiches Anhydrid aus Carbonsäure und Phosphorsäure geschaffen. Diese Energie wird nun im nächsten Schritt direkt genutzt, indem die Anhydridbindung wieder gespalten wird und so aus einem (Adenosindiphosphat) ADP ein ATP entsteht. Das im Schritt zuvor zugeführte Phosphat wird also von der 3-Phosphoglycerat-Kinase auf ein ADP übertragen, aus dem 1,3 Bisphosphoglycerat wird so das 3-Phosphoglycerat. Genau an diesem Punkt wird erstmalig in der Glykolyse Energie in Form von 2 ATP pro Molekül Glukose gewonnen (Horn et al. 2005). 
Für den nächsten Schritt wird durch die Phosphoglycerat-Mutase das Phosphat vom $\mathrm{C}_{3}$-Atom an das $\mathrm{C}_{2}$-Atom umgelagert, es ensteht also das 2-Phosphoglycerat. Von dem 2Phosphoglycerat wird dann Wasser abgespalten, dies geschieht mit Hilfe der Enolase. Als Ergebnis erhalten wir das Phosphoenolpyruvat. Dieser Schritt ist energetisch sinnvoll, da das Phosphoenolpyruvat bedeutend energiereicher als ATP ist und es zur Umwandlung von ADP zu ATP fähig ist. Im letzten Schritt der Glykolyse wird das Phosphat vom Phosphoenolpyruvat abgespalten, diese Reaktion übernimmt die Pyruvatkinase. Dieses abgespaltene Phosphat wird dann auf ein ADP übertragen, so dass ATP entsteht (Abb. 3). Es enstehen im letzten Schritt der Glykolyse also ATP und Pyruvat, genauer gesagt entstehen pro Molekül Glukose 2 ATP und 2 Moleküle Pyruvat, und es werden zusätzlich noch mehr als $30 \mathrm{~kJ} / \mathrm{mol}$ Energie in diesem Schritt frei (Horn et al. 2005). 


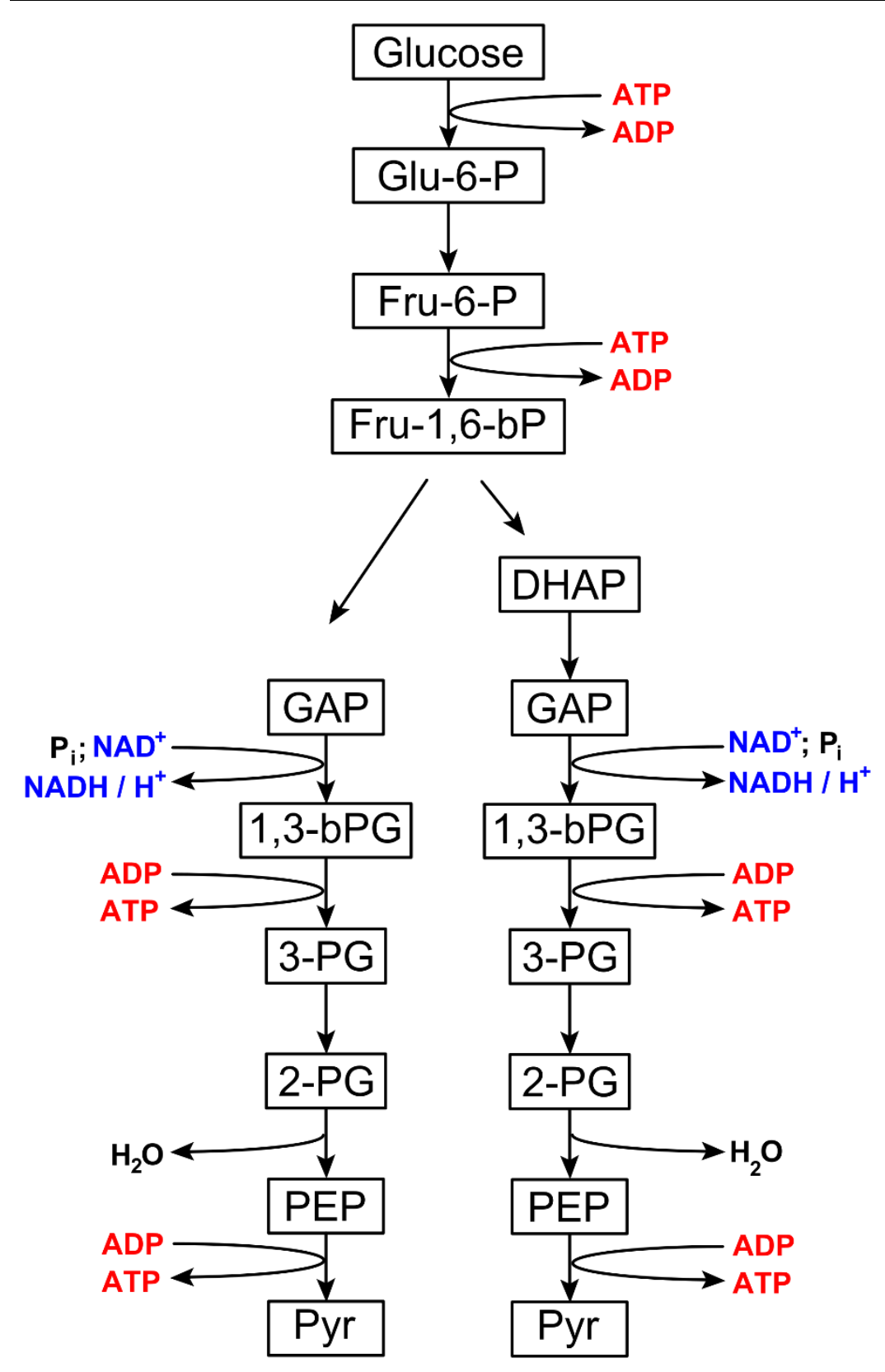

Abbildung 3: Reaktionsfolge in der Glykolyse

\subsubsection{Grundlagen des Citratzyklus}

Im Abbau und auch in der Biosynthese von verschiedenen biochemischen Stoffklassen, wie Kohlenhydraten, Lipiden und Aminosäuren, stellt der Citratzyklus eine gemeinsame Strecke auf dem Weg zur Energiegewinnung dar. Der Citratzyklus kann ausschließlich in den Mitochondrien der Zellen ablaufen, so dass jede Zelle- bis auf Erythrozythen- zum Citratzyklus befähigt ist (Krebs und Johnson 1937). Werden die Abbauprodukte aus dem Kohlenhydrat-, dem Lipid- und/ oder dem Aminosäurestoffwechsel dem Citratzyklus 
zugeführt, so werden diese komplett verstoffwechselt und anschließend der Atmungskette zugeführt. Da das Mitochondrium in seiner Matrix alle für die Atmungskette notwendigen Enzyme aufweist, ist die Lokalisation des Citratzyklus im Mitochondrium sehr sinnvoll. Der Vorteil ist dabei, dass durch die direkte Nähe, eine präzise aufeinander abgestimmte Abfolge des Citratzyklus und der Atmungskette stattfinden kann. Außerdem gehört ein Enzym (Komplex II) sowohl zur Atmungskette, als auch zum Citratzyklus (Krebs und Johnson 1937). Die Abbauprodukte, die im Zyklus verstoffwechselt werden, liegen hauptsächlich in Form von Acetyl-CoA in der Zelle vor, welches in diesem Zyklus zu zwei Molekülen $\mathrm{CO}_{2}$, acht Wasserstoffatomen und in Energie, in Form von GTP (Guanosintriphosphat) umgewandelt wird. Daneben entstehen noch Reduktionsäquivalenten in Form von NADH/ $\mathrm{H}^{+}$(NikotinamidAdenin-Dinukleotid) und $\mathrm{FADH}_{2}$ (Flavin-Adenin-Dinukleotid). Diese Reduktionsäquivalenten stellen dabei die Hauptlieferanten von Energie, in Form von ATP für die Atmungskette dar (Horn et al. 2005). Beim Citratzyklus handelt es sich um einen Ablauf von acht Reaktionen, nach denen der Zyklus erneut mit dem Startmolekül Oxalacetat beginnt. Der Zyklus kann nur in Anwesenheit von Acetyl-CoA und des Enzyms Citrat-Synthase starten. Anhand der Citrat-Synthase, deren Aktivität als molekularer Marker interpretiert werden darf, lässt sich die Enzymaktivität der Mitochondrien abschätzen (Opalka et al. 2004). Ebenso ist bekannt, dass die Citrat-Synthase mit der Anzahl von Mitochondrien korreliert (Krasnianski et al. 2005).

Als Endprodukt der Glykolyse ensteht Pyruvat, welches vom Zytosol in das Mitochodrium übertreten kann. Im Mitochondrium wird dann das Pyruvat durch die Pyruvatdehydrogenase $\mathrm{zu}$ Acetyl-CoA $+\mathrm{H}_{2} \mathrm{O}$ dehydriert, wobei ein $\mathrm{CO}_{2}$ abgegeben wird. Nun liegt das Acetyl-CoA für den Citratzyklus vor, dessen Reaktionen sich zunächst in zwei Kompartimente unterteilen. Im ersten Abschnitt ensteht aus Citrat Succinat, dabei wird der Rest des Acetyls in zwei Moleküle $\mathrm{CO}_{2}$ abgebaut, welche einfach als eine Art Abfallprodukt abgeatmet werden. Der zweite Abschnitt ist die Regeneration vom Succinat zum Oxalacetat (Horn et al. 2005).

In beiden Anteilen des Zyklus wird Energie gewonnen, einerseits direkt in Form von GTP oder andererseits in Form von $\mathrm{NADH} / \mathrm{H}^{+}$und $\mathrm{FADH}_{2}$. In der ersten Reaktion setzt sich der Acetylrest des Acetyl-CoAs an das Oxalacetat. Diese Reaktion wird durch die Citrat-Synthase katalysiert und ist dabei stark exergon $(=-38 \mathrm{~kJ} / \mathrm{mol})$. Da generell nur eine kleine Menge an Oxalacetat vorliegt, und natürlich trotzdem diese Reaktion, und damit der Zyklus ablaufen können soll, wird eine stark exergone Reaktion benötigt. Als Ergebnis liegt dann das Citrat vor, an welchem in einer zweiten Reaktion obligat eine Hydroxyl $(\mathrm{OH})$-Gruppe umgesetzt wird. Durch diese Umsetzung der Hydroxyl-Gruppe liegt dann nicht mehr ein tertiärer 
Alkohol vor, der nicht mehr oxidierbar gewesen wäre, sondern es liegt ein sekundärer Alkohol vor, der sehr wohl noch oxidiert werden kann (Horn et al. 2005). So wird aus dem Citrat mit Hilfe des Enzyms Aconitase-Hydratase, welches zunächst eine Abspaltung von $\mathrm{H}_{2} \mathrm{O}$ (Dehydratisierung) und dann eine Wiederanlagerung (Hydratisierung) an anderer Stelle des Moleküls bewirkt, das Isocitrat. Im nächsten Schritt des Zyklus erfährt das Isocitrat eine oxidative Decarboxylierung zum $\alpha$-Ketogluterat. Vorangetrieben wird diese Reaktion von der Isocitrat-Dehydrogenase. Hervorzuheben ist, dass an dieser Stelle des Zyklus zum ersten Mal Energie gewonnen wird, dabei wird $\mathrm{NAD}^{+}$zu NADH/ $\mathrm{H}^{+}$, unter zusätzlicher Abspaltung von $\mathrm{CO}_{2}$, umgesetzt. Danach kommt es zu einer erneuten oxidativen Decarboxylierung des $\alpha$ Ketogluterats zu Succinyl-CoA, wobei wieder NAD ${ }^{+}$zu NADH/ $\mathrm{H}^{+}+\mathrm{CO}_{2}$ gespalten wird. Die in $\mathrm{NADH} / \mathrm{H}^{+}$gespeicherte Energie wird an dieser Stelle zur Thioesterbindung des in der Reaktion entstandenen Succinyl-CoAs genutzt beziehungsweise die Energie wird in dieser Bindung kurzfristig gespeichert. Das $\alpha$-Ketogluterat wird in dieser Reaktion durch die $\alpha$ Ketogluterat-Dehydrogenase zum Succinyl-CoA umgesetzt.

Im nächsten Schritt wird aus dem Succinyl-CoA mittels der Succinat-Thiokinase Succinat, ebenso wird durch die Succinat-Thiokinase ein GDP (Guanosindiphosphat) zu dem energiereichen GTP, welches vom Energiegehalt mit einem ATP zu vergleichen ist (Horn et al 2005). Die für die Bildung von GTP benötigte Energie stammt aus der Hydrolyse der Thiosterbindung vom Succinyl-CoA. Nach diesem Schritt ist das erste Kompartiment des Citratzyklus abgeschlossen, in den dann folgenden Reaktionen ist die Wiederherstellung des Oxalacetats das Ziel, wofür ein Sauerstoffatom in das Molekül eingebracht werden muss. Zunächst wird das Succinat durch die Succinat-Dehydrogenase zu Fumarat dehydriert. In diesem Schritt steckt nicht genügend Energie um ein $\mathrm{NAD}^{+} \mathrm{zu}$ reduzieren, daher wird an dieser Stelle ein $\mathrm{FAD}$ zu $\mathrm{FADH}_{2}$ reduziert. Interessanterweise gehört das an die innere Mitochondrienmembran gebundene Enzym Succinat-Dehydrogenase nicht nur zum Citratzyklus, sondern es gehört zur Atmungskette. Die Succinat-Dehydrogenase entspricht dem Komplex II der Atmungskette, der Elektonen vom $\mathrm{FADH}_{2}$ über sein Eisen-SchwefelZentrum auf das Ubichinon übertragen kann (Horn et al. 2005). Aus dem Fumarat wird durch die Anlagerung von $\mathrm{H} 2 \mathrm{O}$ mit Hilfe der Fumarat-Hydratase das L-Malat. Das Malat wird dann im nächsten und letzten Reaktionsschritt zu Oxalacetat, die Reaktion wird durch die MalatDehydrogenase forciert, wobei $\mathrm{NAD}^{+}$mittels übertragener Elektronen zu NADH/H${ }^{+}$wird (Horn et al. 2005). Zusammengefasst handelt es sich beim Citratzyklus um einen zum Katabolismus und zum Anabolismus befähigten Prozess. Unter dem katabolen Aspekt lassen sich die Endoxidationen von Kohlenhydraten, Aminosäuren und Lipiden aufzeigen, und unter 
dem Aspekt eines anabolen Prozesses stellen Zwischenstufen des Zyklus Vorstufen für die Biosynthesen von beispielsweise Glukose, Aminosäuren, Häm und Fettsäuren dar.

\subsubsection{Grundlagen der Atmungskette}

Unser heutiges Verständnis für den Ablauf und den Sinn der Atmungskette verdanken wir dem Biochemiker und Nobelpreisträger Peter Mitchell. Er formulierte 1961 die chemiosmotische Theorie, in der er dem Protonengradienten die tragende Rolle in der ATP-Synthese zuschreibt. Ebenso stellt er in dieser Theorie die hintereinander geschalteten Reaktionen der Atmungskette dar (Mitchell 1961). Die Grundlage der Atmungskette liegt in der wissenschaftlichen Aussage, dass jede von einer Zelle zu verrichtende Arbeit nur durch einen Elektronenfluss bei Redoxreaktionen möglich ist. Die Atmungskette ist die von allen oxidativen Stoffwechselprozessen genutzte letzte Passage zur Energiegewinnung. Dafür werden in dieser Elektronen aufgenommen. Die Atmungskette besteht aus vier Komplexen, wobei von einigen Autoren die ATP-Synthase als fünfter Komplex mit eingeschlossen wird (Horn et al. 2005). Die Elektronen gehören den im oxidativen Stoffwechsel reduzierten Reduktionsäquivalenten $\left(\mathrm{NADH} / \mathrm{H}^{+}\right.$und $\left.\mathrm{FADH}_{2}\right)$ an. Durch die Energie, die diese Elektronen besitzen, baut sich ein Protonengradient während der Atmungskette auf, der zur ATP-Synthese dient. Genauer gesagt, folgen diese Elektronen einer Kette von Redoxstufen hin zum Sauerstoff, auf welchen sie übertragen werden. Der Sauerstoff wird so zu Wasser reduziert (Horn et al. 2005). In den einzelnen Redoxstufen wird von den Elektronen Energie abgeben. Aus dieser Ernergie wird ein Protonengradient geschaffen, der über der inneren Mitochondrienmembran liegt. Mit Hilfe dieses Gradienten kann aus ADP ein ATP entstehen (Horn et al. 2005). Die Reaktionen der Atmungskette laufen obligat in der inneren Mitochondrienmembran ab, da hier die einzelnen Komplexe und die ATP-Synthase lokalisiert sind. Elektronen werden einerseits von Elektronentransportern zur Atmungskette gebracht, andererseits bringen die Reduktionsäquivalente $\left(\mathrm{NADH} / \mathrm{H}^{+}\right.$und $\left.\mathrm{FADH}_{2}\right)$ ihre Elektronen in die Atmungskette mit ein (Horn et al. 2005). Betrachten wir zunächst die vier Komplexe der Atmungskette (Abb. 4): Auf den ersten Komplex (Komplex I) werden alle NADHs, die in der Zelle entstanden sind, übertragen. Dafür muss das $\mathrm{NADH} / \mathrm{H}^{+}$an die NADH-Bindungstelle im Mitochondrium gelangen und NADH, welches sich noch im Zytosol befindet, in das Mitochondrium aufgenommen werden. Es handelt sich bei Komplex I um den größten Komplex der Atmungskette, der die NADH-Hydrogenase darstellt. Durch die NADH- 
Hydrogenase wird die Übertragung von Wasserstoffatomen auf das Ubichinon vorangetrieben (Horn et al. 2005). Das Ubichinon ist ein beweglicher Wasserstoff-Überträger (Horn et al. 2005), durch den die Wasserstoffatome von Komplex I, Komplex II, ETF (ElektronenTransferierendes Flavoprotein) und von den übrigen Flavoproteinen auf den Komplex III übergeben werden. Nachdem das $\mathrm{NADH} / \mathrm{H}^{+}$zu NAD ${ }^{+}$oxidiert worden ist, kann der Komplex I als Protonenpumpe vier Wasserstoffatome von der Mitochondrien-Matrixseite in den Bereich zwischen innerer und äußerer Mitochondrienmembran befördern (Horn et al. 2005). Der zweite Komplex (Komplex II) der Atmungskette ist uns schon bekannt aus dem Citratzyklus; er entspricht der Succinat-Dehydrogenase. In der Atmungskette ist er für die Aufnahme der Elektronen aus dem Reduktionsäquivalent $\mathrm{FADH}_{2}$ zuständig. Der Komplex II ist nicht in der Lage, als Protonenpumpe zu agieren, und kann somit keinen Beitrag zum Protonengradienten leisten (Horn et al. 2005). Wird das Succinat zu Fumerat oxidiert, so wird der Wasserstoff zuerst auf einen Eisen-Schwefelkomplex übertragen und anschließend findet die Übertragung auf das Cytochrom b statt, welches dann den Wasserstoff an das schon erwähnte Ubichinon weitergibt. Nach der Aufnahme von Wasserstoff wird das Ubichinon zu Ubichinol reduziert (Horn et al. 2005). Schließlich übernimmt der Komplex III (Cytochromc-Reduktase) die Elektronen vom Ubichinol und gibt diese nacheinander an zwei Cytochrome c weiter. Der Komplex III benötigt dafür einen komplexen Ablauf von Reaktionen, da das Ubichinol zwei Elektronen bewegt, obwohl die Cytochrome c jeweils nur ein Elektron transportieren können (Horn et al. 2005). Das Cytochrom c ist ein mobiler und im Wasser löslicher Elektronen-Transporter, der die Elektronen von Komplex III auf den Komplex IV überträgt (Abb.4). Darüber hinaus kann der Komplex III auch wieder als eine Protonenpumpe vier Wasserstoffatome, in den unter Komplex I beschriebenen Bereich der Mitochondrienmembran befördern, und ist somit an dem Aufbau des Protonengradienten beteiligt. Der oben genannte letzte Komplex der Atmungskette (Komplex IV) ist die Cytochrom Oxidase. Es handelt sich beim Komplex IV ebenfalls um eine Protonenpumpe, die aber, im Gegensatz zum Komplex I und III, nur zwei Protonen in den Raum zwischen innerer und äußerer Mitochondrienmembran bewegt (Horn et al. 2005). Die Elektronen, die aus den verschiedenen Stoffwechselprozessen stammen, sind nun zu Sauerstoff umgesetzt worden, wobei die Energie der Elektronen zum Aufbau des Protonengradienten genutzt worden ist. Diese Energie wird am Ende der Atmungskette unter anderem für die Bildung von ATP aus ADP mittels der ATP-Synthase benötigt (Abb. 4). 


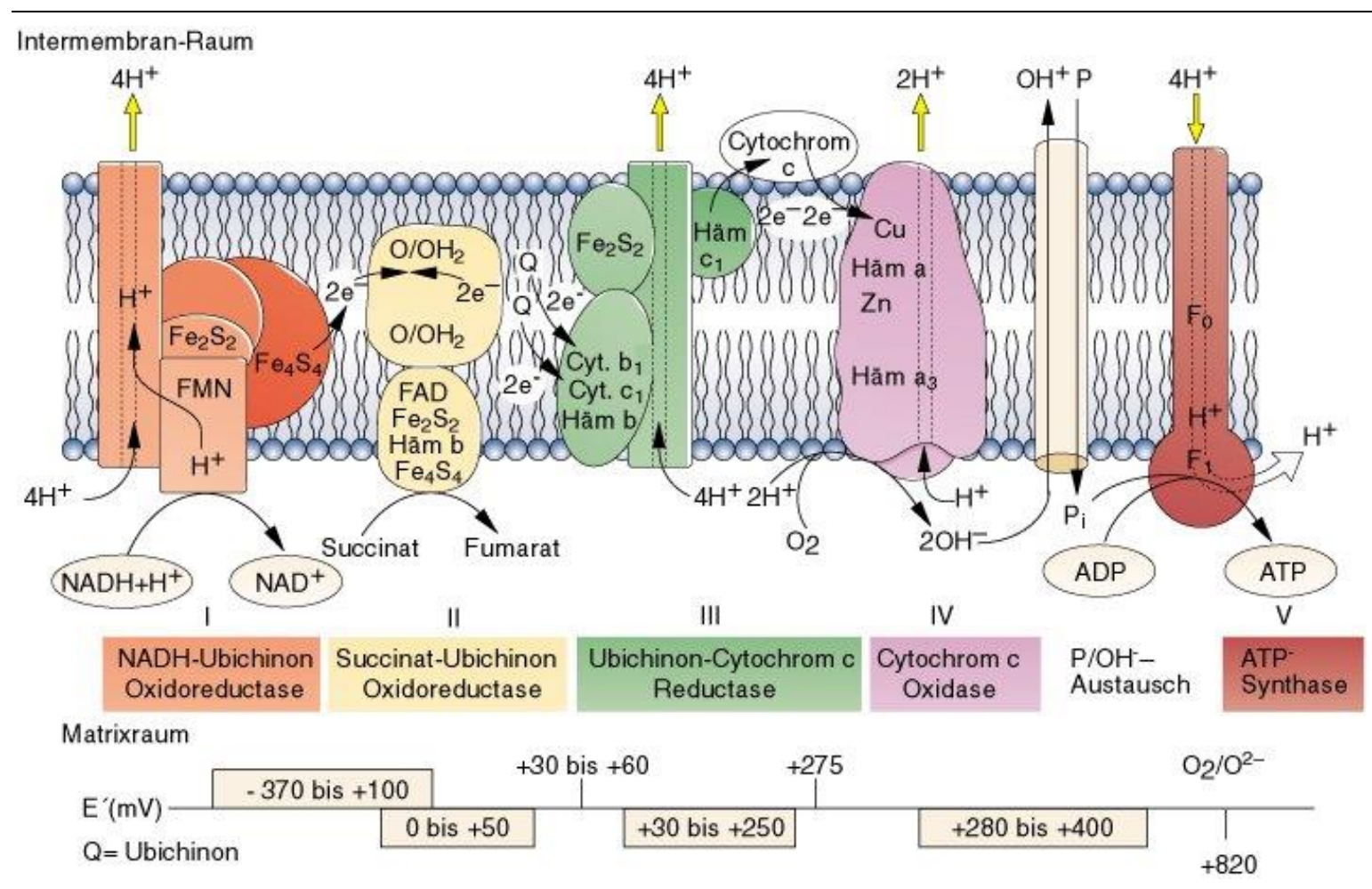

Abbildung 4: Übersicht über die Atmungskette

\subsubsection{Grundlagen der $\beta$-Oxidation}

Die grundlegenden Erkenntnisse der ß-Oxidation gehen auf Georg Franz Koop zurück, der sich 1904 über den Abbau der Fettsäuren im Tierkörper im Fach Physiologische Chemie habilitierte. Seine Formulierung der ß-Oxidation war noch nicht die entgültige, erst weitere 50 Jahre später konnte Feodor Lynen den Ablauf der ß-Oxidation so darstellen, wie er unserem heutigem Wissensstand entspricht (Decker 2005). Dazu befähigt sind allerdings nur die Zellen, die mit Mitochondrien, in denen die $\beta$-Oxidation unter obligat aeroben Bedingungen abläuft, ausgestattet sind. Demnach verfügen Erythrozyten nicht über die Fähigkeit, Fettsäuren abbauen zu können. Auch neuronale Zellen sind nicht in der Lage die Fettsäuren in Energie umzusetzen. Dies lässt sich mit der Funktion der Blut-Hirn-Schranke begründen, die einen Übergang der Fettsäuren ins Gehirn nicht erlaubt. Spezielle Organe wie beispielsweise die Leber, das Herz und die quergestreifte Muskulatur nutzen zum Teil mehr als 50\% ihres Energiebedarfs aus dem Abbau von Fettsäuren (Horn et al. 2005).

Der Skelettmuskel beginnt unter zu verrichtender Arbeit, wenn es sich um eine ausdauernde Arbeit handelt, nach circa 30-60 Sekunden, sein ATP aus der oxidativen Phosphorylierung zu beziehen. Dabei kann der Muskel die Energie, die er zur Synthese von ATP benötigt, entweder aus einer Oxidation von Kohlenhydraten oder aus einer Oxidation von Fettsäuren beziehen 
(Schmidt et al 2010). Wenn zur Energiebereitstellung nun Fettsäuren genutzt werden sollen, so müssen diese zunächst im Zytosol der Zelle aktiviert werden. Zuständig für die Aktivierung, die in zwei Schritten abläuft, ist das Coenzym A. Im ersten Schritt lagern sich die Fettsäuren und ein ATP aneinander, dadurch kommt es beim ATP zu einer Abspaltung von Pyrophosphat (Abb. 5). Neben dem Pyrophosphat bildet sich ein, aus Phosphorsäure und Fettsäure bestehend, gemischtes Säureanhydrid (Acyl-Adenylat). Im zweiten Schritt wird aus dem Acyl-Adenylat das Acyl-CoA, indem das AMP (Adenosinmonophosphat) durch das Coenzym A aus seiner Bindungstelle verdrängt wird. Beide Reaktionen werden durch das Enzym Acyl-CoA-Synthetase forciert. Nach diesen zwei Schritten gilt die Fettsäure, die zu Acyl-CoA geworden ist, als aktiviert. Für den weiteren oxidativen Abbau des Acyl-CoAs muss dieses aktiv in das Mitochondrium befördert werden, da aktivierte Fettsäuren nicht mehr die Fähigkeit besitzen Membranen zu passieren (Horn et al. 2005). Der aktive Transport vom Acyl-CoA in das Innere des Mitochondriums findet an der inneren Mitochondrienmembran mit Hilfe des Enzyms Carnitin-Acyl-Transferase I statt. Durch die Carnitin-Acyl-Transferase I wird der Acyl-Anteil des Acyl-CoAs auf das Carnitin übertragen, so dass dann das Enzym Carnitin-Acylcarnitin-Translokase das gebildete Acyl-Carnitin an den Zielort, das Innere des Mitochondriums, bringen kann. Ab diesem Schritt kommt es unweigerlich zur $\beta$-Oxidation des Acyl-Anteils. Der Regulationsvorgang der $\beta$-Oxidation wirkt am Transportprozess. Präzisiert, kommt es zur Hemmung der Carnitin-Acyl-Transferase I durch das Malonyl-CoA. In dem Mitochondrium wird dann der Acyl-Anteil auf ein Coenzym A, welches dem Mitochondrium angehört, übertragen. Es folgen vier weitere Reaktionen, die die eigentliche $\beta$-Oxidation darstellt. Als Bilanz ergeben sich pro oxidiertem Acyl-Rest $2 \mathrm{NADH} / \mathrm{H}^{+}$, ein $\mathrm{FADH}_{2}$, ein Acetyl-CoA und ein Acyl-CoA.

Für die Grundlagen der $\beta$-Oxidation wird zur Vereinfachung in den folgenden Erläuterungen der einzelnen Reaktionen nur auf den Abbau einer geradzahligen und gesättigten Fettsäure eingegangen. Im ersten Schritt werden von dem Acyl-CoA durch das Enzym Acyl-CoADehydrogenase zwei Wasserstoffatome abgespalten, so dass als Produkt Enoyl-CoA ensteht. Daneben kann durch diese Reaktion ein FAD zu einem $\mathrm{FADH}_{2}$ reduziert werden. Der zweite Reaktionsschritt stellt eine Hydratisierung des Enoyl-CoAs dar. Getragen wird diese Reaktion vom Enzym Enoyl-CoA-Hydratase und wir erhalten als Produkt dieser Reaktion ein L- $\beta$ Hydroxyacyl-CoA. Im dritten Schritt werden erneut zwei Wasserstoffatome abgespalten, so dass das $\beta$-Ketoacyl-CoA gebildet wird. Der Sinn hinter dieser erneuten Dehydrierung besteht in der Ausbildung einer für die $\beta$-Oxidation notwendigen Keto-Gruppe. Die Katalysation übernimmt in diesem Schritt das Enzym L- $\beta$-Hydroxyacyl-CoA-Dehydrogenase und da in 
dieser Reaktion genügend Energie freigesetzt wird, kann ein $\mathrm{NAD}$ zu einem $\mathrm{NADH} / \mathrm{H}^{+}$ reduziert werden. Die vierte und letzte Reaktion wird durch das Enzym Thiolase bewerkstelligt, welche mittels einer Anlagerung von Schwefel das Acetyl-CoA vom KetoacylCoA abspalten kann. Dies ist also einer der verschiedenen Stoffwechselprozesse, an dessen Ende ein Acetyl-CoA steht, welches dann in den Citratzyklus zur weiteren Energiegewinnung übergehen kann. An dieser Stelle ist die $\beta$-Oxidation noch nicht abgeschlossen, denn durch die vier Reaktionen hat sich das Acyl-CoA lediglich um zwei Kohlenstoffatome verkürzt. Das verkürzte Acyl-CoA wird nun wieder der ersten Reaktion zugeführt und der Ablauf der einzelnen vier Schritte wiederholt sich bis zum kompletten Abbau der Fettsäuren (Horn et al. 2005).

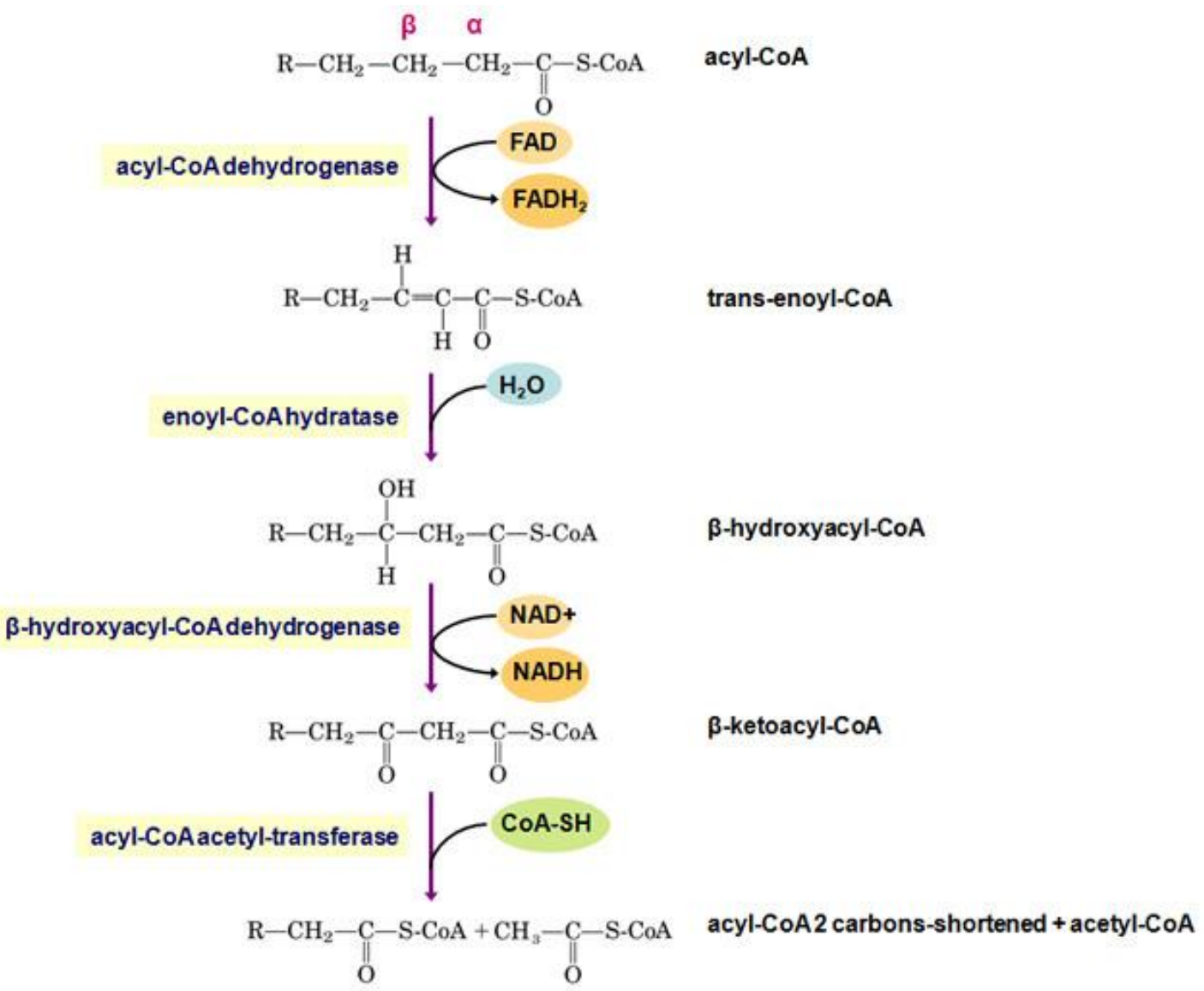

Abbildung 5: Schema der ß-Oxidation von Fettsäuren. 


\subsubsection{Einfluss von Östrogenen auf die Skelettmuskulatur}

Anhand von (klinischen) Studien konnte bereits vielfach belegt werden, dass ein atrophierter Skelletmuskel durch eine Vielzahl von Faktoren wieder an Muskelkraft gewinnen kann. Unter diese Faktoren fallen: Mechanische Stimulationen, Zytokine, Hormone und Wachstumsfaktoren, die über den mTOR (Mammalian target of rapamycin)-Signalweg das Muskelwachstum stimulieren (Sitnick et al 2006). Welchen Einfluss Östrogene auf die Skelettmuskulatur haben, ist derzeit unzureichend untersucht. Da es sich jedoch ebenfalls um mesenchymales Gewebe handelt, kann ein ähnlicher Effekt des Östrogens wie auf das Knochengewebe postuliert werden. Die Muskulatur unterliegt auch dem sich verändernden Hormonstatus der (postmenopausalen) Frau, so dass dieser Einfluss auf die Fähigkeiten der Muskelplastizität und auf die Muskelgröße hat (McClung et al. 2006). Der Skelettmuskel verfügt in seinen reifen Myozyten und in Vorläufer-Zellen über Östrogenrezeptoren, die dementsprechend sensitiv gegenüber dem hormonalen Einfluss sind (Kahlert et al. 1997). Durch das Fehlen von Östrogen kommt es zu einer Stoffwechselsituation, in der sich eine gesteigerte Zirkulation von Wachstumsfaktoren und ein veränderter Energiehaushalt einstellen (Fisher et al. 1998). Diese Veränderungen lassen sich im Tiermodell anhand von gesteigertem Körpergewicht, Muskelgewichten und Organgewichten belegen (Fisher et al. 1998), wobei diese Veränderungen nicht mit einer Verbesserung der Muskelleistung einhergehen. Vielmehr ist diese Gewichtszunahme durch Lipideinlagerungen bedingt. Die Muskelkraft nimmt mit dem Beginn der Menopause ab. Durch die Substitution von Östrogenen resultiert ein Muskelerhalt, eventuell sogar ein Muskelaufbau (Phillips et al. 1993). Phillips konnte zeigen, dass es zwischen der Muskelkraft von jungen Männern und prämenopausalen Frauen keine signifikanten Unterschiede gibt, es jedoch nach dem Eintritt der Frauen in die Menopause zu einem starken Abfall der Muskelleistung kommt. Dieser Verlust an Muskelkraft kann mit einer Hormonersatztherapie, dass heißt durch eine Östrogensubstitition, ausgeglichen werden (Phillips et al 1993). Zudem beschreibt er einen direkten Zusammenhang zwischen dem Abfallen der Muskelkraft und der rapiden Zunahme an Frakturen des distalen Radius (explizit an Colles-Frakturen) bei postmenopausalen Frauen (Phillips et al 1993). Das Fehlen von Östrogenen scheint frühzeitiger eine Auswirkung auf den Sklettmuskel zu haben als auf das Knochengewebe, wobei zum jetzigen Zeitpunkt unklar ist, welche der beiden Effekte gravierender ist (Warren et al. 1996) und welchen Anteil sie am vermehrten Auftreten von Fragilitätsfrakturen bei Osteoporose haben. 


\subsubsection{Knochengewebe}

Das Knochengewebe ist bei verhältnismäßig geringem Eigengewicht des Bindegewebes besonders stabil und belastbar. Zu den Funktionen des Knochens gehören einerseits die Stützund Schutzfunktion des Bewegungsapparates, und andererseits hat das Knochengewebe eine zentrale metabolische Funktion. So ist das Knochengewebe u. a. der Speicher von 99\% des sich im Körper befindlichen Calciums. Ebenso werden Magnesium-, Phosphor-, Natrium- und andere Ionen im Knochengewebe gespeichert. Um die spezifischen Eigenschaften des Knochens verstehen zu können, soll die Zusammensetzung der Knochenmatrix genauer betrachten werden. Die Knochenmatrix weist ca. 35\% organisches Material auf, wobei es sich überwiegend um Kollagenfasern (Typ I), Knochenprotein und Proteoglykan handelt. Mit einem prozentualen Anteil von 65\% machen die mineralischen Substanzen bzw. die anorganischen Salze die Knochenmatrix aus. Das Calcium liegt in der Form von Calciumsalz, welches in die Knochenmatrix eingelagert wird, vor. Durch diese Komponenten der Knochenmatrix lassen sich die hohen Torsions- und Biegemöglichkeiten des Knochengewebes erklären (Welsch 2010). Wichtig zu beachten ist, dass sich das Knochengewebe, bestehend aus organischen und anorganischen Bestandteilen, in einem ständigen Umwandlungsprozess befindet. Induziert bzw. moduliert wird dieser Umwandlungsprozess durch hormonale, nutritive und metabolische Einflüsse (Welsch 2010). Bei der makroskopischen Betrachtung der Knochenstruktur ist es möglich, zwei verschiedene Architekturen zu unterscheiden. Entweder handelt es sich um einen kompakten oder um einen spongiösen Knochen, wobei die Übergänge von der einen Knochenbauweise in die andere ohne scharfe Trennlinie erfolgen (Welsch 2010). Der kompakte Knochenanteil wird Substantia corticalis genannt, dieser Anteil umgibt als solide, stabile Struktur den Skelettknochen. Die Substantia corticalis ist reich mit Blutgefäßen ausgestattet. Der spongiöse Anteil des Skelettknochens befindet sich im Inneren des Knochens und bildet ein dreidimensionales System von feinen, sich verzweigenden Knochenbälckchen bzw. Trabekeln. In den Zwischenräumen dieses Trabekelsystems befinden sich weite Räume, die mit blutbildendem Gewebe oder Fettgewebe gefüllt sind, Blutgefäße sind in diesem System nicht vorhanden. Die Ausrichtung der Trabekel erfolgt nicht zufällig, sondern sie ergibt sich aus den biomechanischen Anforderungen, die dem Knochengewebe gestellt werden. Die Ausrichtung der Trabekel erfolgt parallel zur größten Druckbeanspruchung, dies gilt zum Beispiel für die Wirbelkörper, oder sie erfolgt parallel zur Biegebeanspruchung, wie es am proximalen Femurende der Fall ist. 
1892 wurde dieses Prinzip von dem Berliner Anatomen und Chirurgen Julius D. Wolff als „Wolff-Transformationsgesetz“ in seinem Werk „Das Gesetz der Transformation der Knochen" formuliert. Es hat die Kernaussage, dass mechanische Kräfte für die spezifische Architektur der Knochen verantwortlich sind. Da es sich um Kräfte handelt, sind diese mathematisch beschreibbar (Wolff 2010).

\subsubsection{Knochenumbau „bone remodeling“}

Der Knochen steht das ganze Leben über in einem kontinuierlichen Umbauprozess, pro Jahr werden 18\% des gesamten Skelettcalciums umgesetzt (Welsch 2010). Der Knochenumbau besteht aus drei aufeinander folgenden Phasen. In der ersten Phase wird der Knochen von den Osteoklasten abgebaut, im Folgenden ersetzen die Osteoblasten das zuvor abgebaute Knochenvolumen (Hadjidakis und Androulakis 2006). Selbst kleinste Veränderungen im Beanspruchungsprofil der Knochen induzieren Umbaumaßnahmen im Skelett. Hierbei stehen für die Wahrnehmung der veränderten Bedingungen die Osteozyten als Mechanosensoren im Vordergrund. Für den aktiven Umbau treten dann wieder Osteoblasten und Osteoklasten in Aktion. Diese arbeiten dafür in einer gut organisierten Gruppe, als basic multicellular unit (BMU) zusammen. In der Substancia corticalis arbeiten sich Osteoklasten, einem Bohrkopf ähnlich, in das Knochengewebe vor. Dies schaffen sie zum Teil mit einer Geschwindigkeit von bis zu $50 \mu \mathrm{m}$ pro Tag. Im Gegensatz dazu bleiben die Osteoklasten in der Substancia spongiosa nur an der Oberfläche, an der sie sich auch nur langsam vorwärts bewegen (Welsch 2010). Es stellt sich die Frage, inwieweit diese Umbauvorgänge des Knochengewebes reguliert werden. Die Regulierung erfolgt auf jeden Fall systemisch, so wie auch lokal (Hadjidakis und Androulakis 2006). Wichtigstes Instrument der Regulierung stellt dabei die mechanische Beanspruchung des Knochens dar, mit der eine ausgeglichene Bilanz des Umbaus erreicht wird. Einflussnehmend auf diese Regulierung sind beispielsweise Hormone. So kann Östrogen die von Osteoblasten induzierte Rekrutierung der Osteoklasten hemmen, so dass es in diesem Fall zu keiner weiteren Knochenresorption kommt (Lüllmann-Rauch 2009). Im Fall der Osteoporose ist bei zusätzlicher reduzierter Aktivität der Osteoblasten die Resorption der Knochenmasse gesteigert, so dass ein Verlust an Knochengewebe als Resultat vorliegt (Corrado et al. 2013). Anhand von Studien wurde nachgewiesen, dass ein mechanischer Stimulus die Syntheseleistung in Osteoblasten ansteigen lässt (Tanaka et al. 2003; Kaspar et al. 2000). Es kommt zu einer Modulierung der Osteocalcin-Produktion 
(Kaspar et al. 2000), zu einer Veränderung der Mineralisierung und der Knochenmatrixproteine (Wozniak et al.2000), sowie zu einer Signalübertragung zwischen Osteoblasten und Osteozyten (Yellowley et al. 2000). Zusammengefasst liegen vier Vorgänge im Knochengewebe beim Vorliegen einer mechanischen Stimulation vor: Der Prozess der Mechanotransduktion im Knochen, geschieht in vier Schritten 1. mechanische Ankopplung 2. biochemische Ankopplung, 3. Signalübertragung und 4. Antwort der Effektorzellen (Duncan und Turner 1995).

\subsection{Osteoporose}

\subsubsection{Definition der Osteoporose}

Die Osteoporose ist eine systemische Skeletterkrankung, welche durch eine niedrige Knochenmasse und Verfall der Mikroarchitektur des Knochengewebes, einhergehend mit erhöhter Knochenbrüchigkeit und erhöhtem Frakturrisiko, charakterisiert ist.

Mit diesen Worten ist 2001 die Definition der Osteoporose durch das National Institutes of Health Consensus Development Panel on Osteoporosis formuliert worden.

Wobei sich die klinische Diagnose der Osteoporose, laut DVO-Leitlinie 2014 zur Prophylaxe und Therapie der Osteoporose bei Erwachsenen (Dachverband Osteologie e.V.), auf eine geringe Knochendichte als essentielle Komponente der Osteoporose stützt. Das heißt, dass es sich auch ohne das Vorliegen von Frakturen, um Osteoporose handeln kann. Liegen oder lagen bereits eine oder mehrere Frakturen, aufgrund von Osteoporose vor, sprechen wir von einer manifesten Osteoporose.

Laut Definition der WHO (World Health Organization) liegt eine Osteoporose vor, wenn sich die Dichte des Knochens 2,5 Standardabweichungen unter dem Mittelwert der Knochendichte skelettgesunder Erwachsener zwischen dem zwanzigsten und vierzigsten Lebensjahr (TScore) befindet (Tab. 2).

Tabelle 2: WHO-Diagnosekriterien Osteoporose

WHO-Diagnosekriterien Osteoporose

Normale Knochendichte

T-Score $>-1,0 \mathrm{SD}$

Osteopenie

T-Score $>-1,0$ und $<-2,5$ SD

Osteoporose

T-Score $\geq-2,5$ SD

Schwere (manifeste) Osteoporose

T-Score $\geq-2,5$ mit Fraktur 


\subsubsection{Epidemiologie}

Bei der Osteoporose handelt es sich um die häufigste generalisierte Skeletterkrankung mit einer erheblichen Unter- und Fehlversorgung in Deutschland (Baum und Peters 2009). Die Osteoporose ist nicht nur als individuelles Krankheitsbild der betroffenen Personen mit zum Teil irreversiblen Einschränkungen der Lebensqualität $\mathrm{zu}$ sehen, sondern auch als medizinische und ökonomische Aufgabe unserer Gesellschaft. Die Häufigkeit von Osteoporose liegt Hochrechnungen zufolge in Deutschland bei 25,8\% der Bevölkerung über fünfzig Jahre, das entspricht etwa 7,8 Millionen Menschen. Mit zunehmendem Lebensalter steigt der Anteil der Betroffenen: Jenseits des 75. Lebensjahres liegt der Anteil bei ca. 60\% (Häussler et al. 2007).

Die Folgen der Osteoporose sind häufige Frakturen an typischen Lokalisationen wie an den Wirbelkörpern, am Handgelenk oder an der Hüfte. Wirbelkörperfrakturen sind überwiegend auf Osteoporose zurückzuführen, wohingegen periphere Frakturen genau auf Unfallmechanismen, exogene und endogene Ursachen hin untersucht werden müssen, um nicht eine osteoporose bedingte Fraktur als traumatische Fraktur zu interpretieren.

\subsubsection{Einteilung der Osteoporose}

Für die Einteilung der Osteoporose müssen wir vier verschiedene Formen berücksichtigen. Es muss unterschieden werden zwischen der primären Osteoporose, der sekundären Osteoporose, Erkrankungen, die mit Osteoporose assoziiert sein können und heriditären Erkrankungen (Tab. 4). In 95\% der Fälle liegt die primäre Osteoporose vor, deren Ätiologie ungeklärt ist (Tab. 3). Diese Form umfasst die postmenopausale Osteoporose (Synonym: Typ IOsteoporose), die senile Osteoporose (Synonym: Typ II-Osteoporose) und die seltene idiopathische Osteoporose junger Menschen.

Tabelle 3: Merkmale der primären Osteoporose Typen, Herold 2010

\begin{tabular}{|l|l|l|}
\hline Merkmale & $\begin{array}{l}\text { Osteoporose-Typ I } \\
\text { (postmenopausal) }\end{array}$ & $\begin{array}{l}\text { Osteoporose-Typ II } \\
\text { (senil) }\end{array}$ \\
\hline Alter (Jahre) & $50-70$ & $>70$ \\
\hline Geschlecht (w:m) & Frauen & $(\mathrm{w}: \mathrm{m} / 2: 1)$ \\
\hline Knochenverlust & Stärker trabekulär als kortikal & $\begin{array}{l}\text { Gleichermaßen trabekulär } \\
\text { und kortikal }\end{array}$ \\
\hline
\end{tabular}




\begin{tabular}{|l|l|l|}
\hline Häufigste Frakturen & Wirbelkörper & $\begin{array}{l}\text { Femur-Schenkelhals, Radius, } \\
\text { Humerus, Wirbelkörper, }\end{array}$ \\
\hline Ätiologische Faktoren & Östrogenmangel & $\begin{array}{l}\text { Alterungssprozess, Beweg- } \\
\text { ungsmangel, ev. Mangel an } \\
\text { Kalzium u./ o. Vitamin D }\end{array}$ \\
\hline
\end{tabular}

Bei bis zu 5\% aller Osteoporose-Patienten liegt eine Sekundäre Osteoporose vor, die im Gegensatz zur primären Osteoporose durch spezielle Grunderkrankungen erklärbar ist. Die Ursachen für diese Form sind vielfältig. So können endokrine Ursachen, wie ein Hyperkortisolismus, ein Hypogonadismus, eine Hyperthyreose, ein primärer Hyperparathyreoidismus u. a., die Grundlage der sekundären Osteoporose sein (Herold 2010). Daraus entsteht zum Beispiel bei einem Cushing-Syndrom und oder einer manifesten Hyperthyreose zusätzlich ein starkes Frakturrisiko (relatives Risiko 2- bis 3-fach). Des Weiteren werden Absorptionsstörungen, wie das Malabsorptionssyndrom und der Zustand nach Magenresektionen oder nach Magenteilresektionen (Billroth II-Operationen), als Ursachen aufgeführt (Leitlinie Osteoporose 2014). Ebenso ist Immobilität ein mäßiger Risikofaktor (relatives Risiko 1,5- bis 2-fach). Als immobil gelten schon Patienten mit einer Gehstrecke von unter 100 Metern (Leitlinie Osteoporose 2014). Es werden auch die iatrogenen bzw. medikamentösen Auslöser, die zur Osteoporose führen, zu der sekundären Form gezählt. Hierunter fallen Langzeittherapien mit verschiedenen Medikamenten: Kortikosteroide, Glitazone, Protonenpumpenhemmer, Aromatasehemmer, Antiandrogene, Antiepileptika (Herold 2010). Weitere wichtige Medikamentengruppen sind: Sedativa, Neuroleptika, orthostatische Dysregulation auslösende Medikamente und Antidepressiva. Für die Einnahme von Protonenpumpenhemmern ist anzumerken, dass erst bei mehrjähriger Einnahme ein Frakturisiko besteht (Leitlinie Osteoporose 2014).

Es gibt multiple Risikofaktoren, eine primäre Osteoporose und osteoporotische Frakturen zu entwickeln. Man unterscheidet hierbei therapeutisch nicht beeinflussbare von therapeutisch beeinflussbaren Faktoren. $\mathrm{Zu}$ den therapeutisch nicht beeinflussbaren Faktoren rechnet man vor allem das Alter, das Geschlecht und die genetischen Anlagen eines Patienten. Die beeinflussbaren Faktoren werden durch einen Mangel an Geschlechtshormonen bzw. durch ein Östrogendefizit, durch körperliche Inaktivität/ Immobilität, durch Ernährungsdefizite wie einem Mangel an Calcium oder Vitamin D und auch durch Untergewicht bzw. durch Kachexie, durch starken Nikotinabusus und durch multiple Stürze gebildet (Herold 2010). Einer der wichtigsten Faktoren ist das Alter, das maßgeblich das Frakturrisiko für beide 
Geschlechter determiniert. Mit jeder Dekade verdoppelt sich etwa das Frakturrisiko für Wirbelkörper (Leitlinie Osteoporose 2014). Es scheint plausibel, dass mit zunehmendem Alter eine Verschlechterung der biomechanischen Faktoren der Knochenarchitektur und der Knochenqualität eintritt (Leitlinie Osteoporose 2014).

Die Osteoporose weist auch metabolische Charakteristika auf, an Hand derer wir zwei verschiedene Patientenkollektive ermitteln können. Das erste Patientenkollektiv wird durch sogenannte Fast-loser-Patienten gebildet. Bei diesen Patienten beträgt der Verlust an trabekulärer Knochendichte mehr als 3\% pro Jahr. Es ist ein Knochenmassenverlust bei einem gesteigerten Umbau (high turnover). Typische fast-loser-Patienten sind Frauen in ihrer frühen postmenopausalen Lebensphase, das heißt sie befinden sich in ihren ersten zehn Jahren nach der Menopause. Das zweite Kollektiv wird dementsprechend von slow-loser-Patienten gebildet. Der Verlust an trabekulärer Knochendichte liegt unter 3\% pro Jahr, wobei ein Knochenmassenverlust bei einem reduzierten Umbau (low turnover) vorliegt. Typische slowloser-Patienten sind Frauen, die sich seit über zehn Jahren in der Menopause befinden (Herold 2010).

Tabelle 4: Einteilung der Osteoporose nach ihrer Ätiologie, Herold 2010

- 1. Primäre Osteoporose (95\%)

- Idiopathische Osteoporose junger Menschen (selten)

- $\quad$ Postmenopausale Osteoporose (= Typ I-Osteoporose)

- $\quad$ Senile Osteoporose (= Typ II-Osteoporose)

- 2. Sekundäre Osteoporose (5\%)

- Endokrine Ursachen

- Malabsorptionssyndrom, Zustand nach Gastrektomie

- Immobilisation

- Iatrogen/ medikamentös

- 3. Erkrankungen, die mit Osteoporose assoziiert sein können

- Rheumathoide Arthritis, Morbus Crohn, Typ I Diabetes, Epilepsie 
- 4. Heriditäre Erkrankungen

- Osteogenesis imperfecta, Ehlers-Danlos-Syndrom, Marfan-Syndrom, Homozysteinurie

Im Fokus der experimentellen Untersuchungen dieser Arbeit steht die durch Östrogenmangel induzierte primäre Osteoporose. Um dies abzubilden, wird das weltweit etablierte mature model of osteoporosis, mit drei Monate alten ovarektomierte Sprague Dawley-Ratten genutzt.

\subsubsection{Therapie der Osteoporose}

Für die Therapie der Östeoporose gilt zunächst, dass kausal oder symptomatisch beziehungsweise auch protektiv gehandelt werden kann und muss. Kausal bedeutet, dass ggf. eine Kortikosteroidtherapie reduziert oder Testosteron beim Hypogonadismus substituiert wird. Die symptomatische Therapie ist sehr vielfältig und beinhaltet beispielsweise die Verbesserung und Steigerung von Motorik, Koordination, Muskelkraft, Mobilisation, die Vermeidung von Stürzen und ggf. die Nutzung von Hilfsmitteln, die die Mobilisation der Patienten unterstützt.

Für die Steigerung der Mobilisation existieren aktuell Möglichkeiten an speziellen krankengymnastischen Therapien, an Rehabilitationssport und an Ganzkörpervibration (WBV) teilzunehmen. Den unter Osteoporose leidenden Patienten sollten nach Möglichkeit keine sturzfördernden Medikamente wie Sedativa, Benzodiazepine, Antihypertonika, Neuroleptika oder Antidepressiva verabreicht werden. Die Serum Spiegel von Kalzium und Vitamin D sollten für die Patienten optimiert werden. Auch sollten die Patienten Untergewicht vermeiden und kein Nikotin konsumieren.

Den Patienten wird eine medikamentöse Therapie der Osteoporose empfohlen, wenn das 10Jahresrisiko für Wirbelkörper- und proximale Femurfrakturen über 30\% liegt (Leitlinie Osteoporose 2014), folgende Medikamentenklassen finden in der Osteoporose Therapie ihre Anwendung (Herold 2010):

1. Bisphosphonate, die die Osteoklasten in ihrer resorptiven Aktivität hemmen [Alendronat ${ }^{\circledR}$, Ibandronat ${ }^{\circledR}$ ].

2. Strontiumranelat, das einen stimulierenden Effekt auf die Osteoblasten und einen hemmenden Effekt auf die Osteoklasten besitzt. 
3. Selektive Östrogenrezeptor-Modulatoren (SERM), die eine östrogenähnliche protektive Wirkung auf das Knochengewebe haben [Raloxifen $\left.{ }^{\circledR}\right]$.

4. Denosumab, der als monoklonaler Antikörper die Osteoklasten hemmt.

5. Parathormon (PTH), dass, bei subkutaner Anwendung, den Aufbau von Knochengewebe induziert [Forsteo $®$ ].

6. Östrogene, die im Einzelfall ihre Anwendung bei postmenopausalen Frauen finden, haben eine hemmende Wirkung auf Osteoklasten.

Die besten Behandlungsergebnisse für postmenopausale Frauen, die an der Senkung von Frakturen gemessen werden, lassen sich mit den Medikamenten/ Wirkstoffen: Alendronat ${ }^{\circledR}$, Ibandronat ${ }^{\circledR}$, Risedronat ${ }^{\circledR}$, Zoledronat ${ }^{\circledR}$, Östrogene, Teriparatid und Strontiumranelat erzielen (Leitlinie Ostoporose 2014).

\subsubsection{Der Einfluss von Östrogen auf die Osteoporose}

Der generelle Mechanismus zur Entstehung einer Osteoporose beruht auf einem Ungleichgewicht der Osteoklasten- und der Osteoblastenfunktion. Wichtige Kriterien für die Effektivität ihrer Funktionen sind Aktivität, Rekrutierung, Stimulierbarkeit und Lebensdauer. Diese genannten Kriterien unterliegen einer Vielzahl von möglichen Modulationen, die durch Hormone oder Zytokine beeinflusst werden.

Damit Östrogene ihre Wirkung auf das Knochengewebe entfalten können, müssen Osteoblasten, Osteozyten und Osteoklasten Östrogenrezeptoren aufweisen. Die Knochenzellen tragen $\alpha$ - und $\beta$-Östrogenrezeptoren, wobei dem $\alpha$-Östrogenrezeptor anscheinend die tragende Rolle im Knochenstoffwechsel zukommt (Lee et al. 2003). Durch eine verminderte Östrogensynthese postmenopausal kommt es zwar zunächst zu einer gesteigerten Rekrutierung von Osteoblasten und Osteoklasten, wodurch wir ein Gleichgewicht dieser in ihren Funktionen erwarten würden. Diese Annahme ist jedoch falsch, da bei den Osteoblasten gleichzeitig eine erhöhte Induktion zur Apoptose eingeleitet wird, und im Gegensatz dazu die Lebensdauer der Osteoklasten prolongiert wird. Zudem sinkt die Osteoprotegerin (OPG)-Synthese, und es steigt die RANKL-Synthese der Osteoblasten. Als gemeinsamen Effekt hinterlassen diese Modulationen durch Östrogenmangel einen Verlust an Knochenmasse. Es ist erwiesen, dass das Östrogendefizit der Postmenopause ursächlich für 
die erhöhte Osteoporoseinzidenz bei postmenopausalen Frauen verantwortlich ist (Govindarajan et al. 2014).

In einer klinischen Studie mit 124 offensichtlich ansonsten gesunden postmenopausalen Frauen konnte gezeigt werden, dass zum einen eine Dauer der fertilen Lebensphase unter 30 Jahren bzw. das Einsetzen der Menopause vor dem 45. Lebensjahr zu einer verminderten Knochenmasse führen kann. Diese Studie konnte die endogene Östrogen-Präsenz in der fertilen Lebensphase als einen signifikanten Schutzfaktor bezüglich der Entwicklung einer Osteoporose belegen (Sioka et al. 2010).

\subsubsection{Muskelkraft, Koordination}

Der Dachverband Osteologie empfiehlt in seiner Leitlinie von 2014 eine regelmäßige körperliche Aktivität. Es soll dabei das Ziel einer genügenden Muskelkraft und einer sicheren Koordination verfolgt werden. In einer Studie mit 33 postmenopausalen Frauen konnte gezeigt werden, dass ein Walking-Training von 30 Minuten dreimal pro Woche über 7 Monate einen präventiven Einfluss auf die Knochendichte hat. Gegenstand der Untersuchung waren in dieser Studie die lumbalen Wirbelkörper, an denen die Knochendichte (BMD) gemessen wurde (Hatori et al. 1993).

\subsection{Ganzkörpervibration (whole body vibration)}

Die Ganzkörpervibration (WBV) als Form einer Bewegungstherapie ist noch ein relativ junger Ansatz zum Knochen- und Muskelerhalt und wird heutzutage zum Teil als Trainingseinheit für Athleten, als sportmedizinische Therapie und als Maßnahme zur physischen Rehabilitation genutzt (Nordlund und Thorstensson 2007). Vor allem in den letzten Jahren lässt sich anhand von vielfältigen Studien erahnen, dass sich ein großer medizinischer Nutzen hinter dieser Art von Bewegungstherapie verbirgt. Gerade durch ein passives Ansprechen der Muskeln, welches sich effektiv für einige Minuten pro Vibrationssitzung, mehrmals in der Woche einfach wiederholen lässt, entsteht ein Vorteil gegenüber der herkömmlichen Bewegungstherapie (Mayer et al. 2007). Ziel der derzeitigen Untersuchungen ist es, die exakte Dosis der Belastung (WBV) einerseits für den muskuloskelettalen Bewegungsapparat und andererseits für die Therapie der Osteoporose zu 
bestimmen. Studien mit postmenopausalen Frauen die eine Osteoporose oder eine Osteopenie aufweisen, belegen einen signifikanten Anstieg der Knochendichte (BMD) unter dem Einfluss einer Ganzkörpervibration (Slatkovska et al. 2010).

Dem Östrogendefizit der postmenopausalen Frau kommt eine starke Bedeutung in Bezug auf den Heilungsprozess einer knöchernen Fraktur zu. Die Frakturheilung ist verzögert und zudem geschieht das Wiedererlangen der Muskelaktivität langsamer als bei der prämenopausalen Frau (Namkung-Matthai 2001 et al.; Sitnick et al. 2006). Deshalb wird die Ganzkörpervibration als eine nicht-invasive und nicht-pharmakologische Therapie zum Aufbau und Erhalt des Muskel- und Knochengewebes bei Osteoporose eingesetzt (Rubin et al. 2006).

Wenn die Ganzkörpervibration klassifiziert wird, fällt diese eindeutig in die Bewegungstherapien (Mayer et al. 2007 Die WBV hat für die Patienten einen Vorteil: Man muss keine aktiven, anstrengenden Bewegungen durchführen, sondern wird passiv bewegt. Bedenken für jegliche Art der Bewegungstherapie bestehen nur bei älteren Patienten, die zum Teil schwer zu körperlichen Übungen zu motivieren sind oder, die aus Angst vor Stürzen an keinen Trainingseinheiten teilnehmen würden. Gerade für diese Gruppe an Patienten, die in ihrer Anzahl in den nächsten Jahren noch wachsen wird, scheint die WBV eine sichere und effektive Methode zu sein, um Knochensubstanz- und Muskelaktivitätsverlust vorbeugen zu können. Unter den Indikationen für die Ganzkörpervibrationen lassen sich Kraft- und Leistungsminderungen bei u.a. Immobilisationen, Diabetes, altersassoziierten Gehstörungen, Muskelatrophien, Osteoporose, Rheumatischen Erkrankungen und neurologischen Grunderkrankungen wie zum Beispiel der Multiplen Sklerose finden. $\mathrm{Zu}$ den Kontraindikationen zählen u.a. Gravidität, Epilepsie, frisch implantierte Endoprothesen, frische Frakturen oder Thrombosen.

\subsubsection{Grundlagen der Vibration}

Eine Vibration stellt eine mechanische Schwingung (Oszillation) dar, die hörbar und/ oder fühlbar ist, wobei die Schwingung als eine Funktion, die eine physikalische Zustandsgröße in Abhängigkeit von der Zeit ist, definiert wird (Bundesminesterium für Arbeit und Soziales 2002). Jede Schwingung weist spezifische Merkmale in ihrer Periodendauer, in ihrer Frequenz, in ihrer Form der Schwingung, in ihrer Amplitudenhöhe, in ihrer Rhythmik und in 
ihrer Schwingungsebene auf. Die spezifischen Parameter lassen eine Dosierung der Ganzkörpervibration zu.

Es werden zum heutigen Zeitpunkt regelmäßige Sinusschwingungen und dreidimensionale Zufallsschwingungen für therapeutische Zwecke genutzt (Mayer et al. 2007). Bereits 1943 konnte der Psychologe Rohracher eine gewisse Muskeleigenschwingung von 7-13 Hz belegen (Rohracher 1962), diese Entdeckung wurde dann von Gallasch und Kenner aufgegriffen, die wiederum die Muskeleigenschwingung als eine Übertragung des Herzschlages auf die Knochen und die Muskulatur interpretierten (Gallasch und Kenner 1997). Eine tragende Rolle in der Einführung der biomechanischen Muskelstimulation (BMS) kommt Vladimir Nasarov und ebenso der Forschungsgruppe um G.D. Whedon zu. Die Forschungsgruppe um G.D. Whedon konnten schon 1949 eine positive Wirkung von Osszilationen auf den Erhalt von Muskelmasse und Muskelkraft, auf den Knochenumbau und auf die orthostatische Blutdruckregulation dokumentieren (Whedon et al. 1949). Ebenso ließen sich bei Sportlern eine Verbesserung der Muskelkraft und der Koordination belegen (Haas et al. 2004; Mahieu et al. 2006).

Wird ein Muskel einer Vibration von über $20 \mathrm{~Hz}$ ausgesetzt, so wird eine tonische Kontraktion induziert. Es kommt zur Auslösung des „Tonischen Vibrationsreflex“ (TVR), der eine Kraftsteigerung im Muskel bewirkt. Bei dem sogenannten „Tonischen Vibrationsreflex“ werden durch die Vibration Hautrezeptoren, Sehnenrezeptoren und Muskelspindelrezeptoren in ihren Aktivitätszustand versetzt. Durch diesen Aktivitätszustand werden Signale an die aufsteigenden Bahnen des Rückenmarks und an die zuführenden Nervenbahnen gesendet, so dass mono- und polysynaptische Reflexbögen, die dann für die Muskelkontraktion verantwortlich sind, ausgelöst werden. Des Weiteren wissen wir, dass bei Vibrationen unter $20 \mathrm{~Hz}$ der Muskel in einen Entspannungszustand übergeht (Mayer et al. 2007). In tierexperimentellen Studien ließen sich auch Zunahmen des Knochengewebes durch die Anwendung von Ganzkörpervibrationen darstellen, so wurden von der Forschungsgruppe Oxlund et al. östrogendefiziente Ratten bei $45 \mathrm{~Hz}$ für 30 Minuten pro Tag ganzkörpervibriert und es stellte sich unter dieser Hertz-Zahl eine Zunahme der Knochenmasse ein (Oxlund et al. 2003). In einer für 6 Wochen angelegten Studie mit geschlechtsreifen Mäusen, die pro Tag für 15 Minuten einer hochfrequenten Ganzkörpervibration $(90 \mathrm{~Hz})$ bei extrem niedriger Amplitude zugeführt wurden, konnten Xie et al. zeigen, dass diese mechanische Stimulation zu einer signifikanten Zunahme der Flächendurchmesser der Muskelfasern (Typ I und Typ II ) im untersuchten M. soleus führte (Xie et al. 2008). Ebenso konnte diese Studie belegen, dass der oben beschriebene mechanische Stimulus eine Zunahme des Volumens der 
Knochentrabekel und der Dichte der Corticalis an der Tibia-Metaphyse bedingte (Xie et al. 2008). Diese Studie verbessert also unser Verständnis dafür, dass Knochen und Muskulatur auf mechanische Stimulation anabol reagieren. Xie et al. gehen nach ihrer Datenlage davon aus, dass einzig allein eine Zunahme der Knochenqualität und der Muskelfasergröße während der Wachstumsphase durch gezieltes Training/ Stimulanz zu einer effektiven und langfristigen Prävention von Sarkopenie und osteoporosebedingten Frakturen führen kann (Xie et al. 2008). Xie et al. arbeiteten ausschließlich mit Tieren, die sich in der Wachstumsphase befanden; im Vergleich zur vorliegenden Arbeit fehlt der Aspekt des Einflusses einer mechanischen Stimulation auf Knochen- und Muskelgewebe unter Östrogendefizienz bei ausgewachsenen Individuen.

Verschueren et al. untersuchten 70 postmenopausale Frauen zwischen dem 58. und 74. Lebensjahr, diese Frauen waren gesund und nahmen keine den Knochenstoffwechsel beeinflussenden Medikamente ein. Die Frauen wurden in drei Gruppen geteilt: Die erste Gruppe nahm an einem Ganzkörpervibrations-Training (35-40 Hz; 2,28- 5,09 g) inklusive statischer und dynamischer Knie-Extensoren-Übungen teil, die zweite Gruppe führte ein reines Training der Knie-Extensoren mit im Verlauf zunehmenden Widerständen durch, die dritte Gruppe diente als Kontrollgruppe, für die es keine Trainingseinheiten gab. Gruppe eins und zwei trainierten 3-mal pro Woche über 6 Monate. Kontrollpunkt der Studie war die gemessene Knochendichte des Hüftknochens zu Beginn der Studie und nach 6 Monaten (DXA). Isometrische und dynamische Muskelkraft wurde mittels einem Dynamometer gemessen. Die Frauen mit dem Vibrationstraining konnten ihre isometrische und dynamische Muskelkraft um 15\% und 16\% verbessern, und die BMD des Hüftknochens hatte signifikant um 0,93\% $(\mathrm{p}<0,05)$ zugenommen. Die Zunahme der BMD zeigte statistisch keinen Bezug zur Steigerung der Muskelkraft. Dies lässt den Schluss zu, dass Veränderungen des Knochens nicht vorwiegend durch Kontraktionen der Muskulatur vermittelt werden (Verschueren et al. 2004). In Gruppe 2 und 3 traten keine Veränderungen der BMD des Hüftknochens auf (-0,6\% und $-0,62 \%)$. Verschueren betont, dass die Ergebnisse dieser Studie nicht verallgemeinert werden dürfen, da es sich um gesunde und freiwillige Teilnehmerinnen gehandelt hat, die nicht dem Durchschnitt der Population in ihrer Altersgruppe entsprechen. Die Gruppe um Verschueren empfahl deshalb zukünftig mehr Studien, die die Ganzkörpervibration auch über einen längeren Zeitraum untersuchen durchzuführen, um so einen Effekt in der Prävention und Therapie der Osteoporose belegen zu können (Verschueren et al. 2004).

Wie sich eine Ganzkörpervibration bei dem Vorliegen einer Osteoporose auf das Knochengewebe auswirkt, ist ausführlich untersucht und in der Literatur beschrieben worden. 
Auswirkungen einer Ganzkörpervibration auf die Skelettmuskulatur bei einer vorliegenden Osteoporose sind hingegen nur unzureichend untersucht, so dass Literatur zu diesem Thema fehlt. 


\section{Material und Methoden}

\subsection{Versuchsablauf}

Das Versuchsvorhaben wurde mit 90 weibliche Ratten (Sprague Dawley, Alter: 3 Monate) durchgeführt. Diese wurden in 6 Gruppen a 15 Tieren randomisiert geteilt. Nach einer Woche, in der sich die Ratten als gesund dargestellt und sich in der Tierexperimentellen Einrichtung der Universitätsmedizin Göttingen eingewöhnt hatten, erfolgte bei 5 Gruppen die Ovarektomie, um eine, durch Östrogenmangel induzierte Osteoporose, zu induzieren. Die 6. Grupp wurde SHAM-operiert (Gruppe 1: Tier 1-15) Nach der Ovarektomie entwickelte sich in einem Zeitraum von 8 Wochen bei den Gruppen 2-6 eine Osteoporose.

Zur Analyse der Knochenbruchheilung, die Gegenstand eines anderen Dissertationsprojektes ist, wurde nach diesen 8 Wochen an allen Tieren eine beidseitige Osteotomie der TibiaeMethaphysen mit direkter Osteosynthesen-T-Platten-Versorgung durchgeführt. Die Tiere erholten sich rasch nach diesen Operationen, so dass am 5. postoperativen Tag mit einer WBV in horizontaler Ausrichtung begonnen wurde. Die Vibrationen erfolgten in der für die jeweilige Gruppe spezifischen Frequenz $(30 \mathrm{~Hz} ; 50 \mathrm{~Hz} ; 70 \mathrm{~Hz}$ oder $90 \mathrm{~Hz})$ mit einer Amplitude von $0,5 \mathrm{~mm}$, täglich für jeweils 15 Minuten, über insgesamt 30 Tage. Für diese Ganzkörpervibration verwendeten wir eine an unsere Versuchsbedingungen spezifisch angepasste neu entwickelte Vibrationsplattform. Am Versuchsende wurden die Ratten durch Dekapitation nach vorheriger $\mathrm{CO}_{2}$-Sedierung getötet. Es wurden für die vorliegende Arbeit die Musculi longissimi dorsi, Musculi gastrocnemii und Musculi solei sowie für weitere Dissertationsanalysen Blutbestandteile, Uteri, Tibiae, Oberschenkelknochen und Wirbelkörper entnommen.

\subsubsection{Versuchstiere}

3 Monate alte weibliche Sprague Dawley-Ratten wurden über Harlan Winkelmann GmbH in Borchen, Deutschland, bezogen. Die Haltung der Versuchsratten erfolgte über den gesamten experimentellen Versuchsablauf in der Zentralen Tierexperimentellen Einrichtung (ZTE) der Universitätsmedizin Göttingen. 90 weiblichen Ratten wurden mit vier bis fünf Tiere pro Käfig vom Typ Makrolon ${ }^{\circledR}$ IV gehalten.Sie wurden mit 1500 g Standardfutternahrung pro Käfig und pro Woche (10mm-Pellets, Sniff Special Diet, Soest, Germany) und regelmäßig mit 
Wasser versorgt (ad libitum). Das Restfutter wurde einmal pro Woche gewogen und dokumentiert, um die aufgenommene Futtermenge zu bestimmen.

$\mathrm{Zu}$ den Haltungsbedingungen zählten eine Umgebungstemperatur von $22+/-1^{\circ} \mathrm{C}$ mit einer relativen Luftfeuchtigkeit von 55\%, sowie eine Tageslichtrhythmik von 12 Stunden. Jeweils montags wurden die Ratten einzeln gewogen, um den Gewichtsverlauf zu dokumentieren. Die Tierversuche für unser Forschungsprojekt, wurden nach den Richtlinien des deutschen Tierschutzgesetzes durchgeführt und waren durch die Bezirksregierung Braunschweig (33.42502-04-011/07) genehmigt.

\subsubsection{Ovarektomie}

Vor Durchführung der beidseitigen Ovarektomie hatten die Tiere hatten ein durchschnittliches Körpergewicht von 250g. Zur Operation wurden sie zunächst mit $\mathrm{CO}_{2}$ sediert. Nach ca. 15 Sekunden unter $\mathrm{CO}_{2}$ Inhalation trat die Sedation der Tiere ein und es konnte eine intraperitoneale Gabe von Ketamin (115 mg/kg KG, Hostaket ${ }^{\circledR}$, Firma Hoechst, Bad Soden) und Xylazin (7,5 mg/kg KG, Rompun ${ }^{\circledR}$, Firma Beyer, Leverkusen) im Verhältnis 3:1, als Anaesthesie durchgeführt werden. Die Dosierung des Ketamin-Xylazin Gemisches betrug $0,001 \mathrm{ml} / \mathrm{g} \mathrm{KG}$. Perioperativ erhielten die Ratten ein subkutanes Flüssigkeitsdepot von $3 \mathrm{ml}$ $0,9 \% \mathrm{NaCl}$.

Zur Vorbereitung der Operation wurden die Tiere im lateralen Bereich unterhalb des Rippenbogens bis zu den Hinterläufen rasiert und die Haut anschließend desinfiziert. Danach wurde die Haut dorsal unterhalb des Rippenbogens beidseits inzidiert, das Peritoneum dargestellt und die Bauchhöhle eröffnet. Nach dem Aufsuchen der Adnexe konnte die Tuba uterina mit begleitenden Gefäßen legiert und die Arterie ovarica abgesetzt werden, so dass die Ovarien komplikationslos entnommen werden konnten. Nach Ausschluss von Blutungen wurde das Peritoneum verschlossen, die Bauchmuskulatur mit Vicrylnähten versorgt und die Haut mit Klammernahtmaterial verschlossen. Haut und Klammern wurden abschließend noch einmal desinfiziert. Die Ovarektomie wurde beidseits durchgeführt, um die Tiere in einen hormonell postmenopausalen Zustand mit Tendenz zur Osteoporose zu versetzen. 


\subsubsection{Osteotomie}

Zur Untersuchung der Frakturheilung wurden die Ratten 10 Wochen nach der Ovarektomie beidseits tibial osteotomiert. Dazu wurden sie auf die gleiche Weise narkotisiert, wie zur Ovarektomie (s. 2.1.2). Die Analysen der Frakturheilung erfolgt in Rahmen der Dissertation von Frau Peggy Lieberwirth.

\subsubsection{Horizontale Ganzkörpervibration (whole body vibration; WBV)}

Zur WBV werden folgende Geräte eingesetzt:

- Vibrationsgerät: Vibriertisch VTG; Drehstrom-Vibrationsmotor HVL/HVE; Vibrationsspektrum: 30 bis $100 \mathrm{~Hz}$; Amplitude 0,5 mm horizontal; Vibra Maschinenfabrik Schultheis, Offenbach, Deutschland

- Vibrationskäfig: Kunststoffmaterial, 50×50×25 cm, Dekorationsabteilung der UMG, Deutschland.

- Gerät zur Frequenzdetektion: Schwingweitenmessgerät (SWM 3000), REO Elektronik AG, Elsau, Schweiz.

Der Versuch, zum Einfluss einer horizontalen WBV auf das muskuloskelletale System bei Osteoporose, beinhaltete 6 Tierversuchsgruppen mit je 15 Tieren (perioperativ verendete Tiere ließen die Gruppengröße auf 14 Tiere reduzieren).

Gruppe 1) Nicht-ovarektomierte Tiere; SHAM

Gruppe 2) ovarektomierte Tiere ohne WBV; OVX

Gruppe 3) ovarektomierte Tiere und einer bei $30 \mathrm{~Hz} W B V ; O V X+30 \mathrm{~Hz}$

Gruppe 4) ovarektomierte Tiere und einer bei $50 \mathrm{~Hz} \mathrm{WBV;} \mathrm{OVX+50} \mathrm{Hz}$

Gruppe 5) ovarektomierte Tiere und einer bei $70 \mathrm{~Hz} \mathrm{WBV;} \mathrm{OVX+70} \mathrm{Hz}$

Gruppe 6) ovarektomierte Tiere und einer bei $90 \mathrm{~Hz} \mathrm{WBV;} \mathrm{OVX+90} \mathrm{Hz}$

Für diese Ganzkörpervibration wurde eine an die Versuchsbedingungen spezifisch angepasste, neu entwickelte Vibrationsmaschine (Vibra Maschinenfabrik Schultheis, Offenbach, Deutschland) verwendet. $\mathrm{Ab}$ dem 5. Tag nach der Osteotomie begann die Ganzkörpervibration der Ratten in der oben aufgeführten Gruppeneinteilung. Die Tiere wurden über einen Zeitraum von 30 Tagen einem pro Tag je 15 minütigen Vibrationsdurchlauf ausgesetzt. Dazu wurden 7 bis 8 Tiere in einen $\mathrm{zu}$ der Vibrationsmaschine spezialangefertigten Käfig (50x50x25 cm) platziert. Während der Vibration bewegten sich die 
Ratten frei, und es wurde darauf geachtet, dass sie sich kontinuierlich in direktem Kontakt mit dem Boden des Vibrationskäfigs befanden.

Die Ratten, die sich in den nicht zu vibrierenden Gruppen 1 und 2 befanden, wurden, abgesehen von der Vibrationstherapie, unter denselben Bedingungen gehalten.

\subsubsection{Tötung und Muskelexzision}

Am 35. Tag nach der Osteotomie wurden die Versuchstiere durch Dekapitation getötet. Die Tiere erhielten zunächst, wie unter 2.1.2 beschrieben, eine $\mathrm{CO}_{2}$-Sedierung. In tiefer Sedierung wurden die Ratten durch Dekapitation getötet. Die Tierkörper wurden direkt nach der Dekapitation und nach dem Auffangen des Blutes seziert. Die dafür ausgewählten Muskeln waren der Musculus longissimus dorsi, der Musculus gastrocnemius und der Musculus soleus. Jedem Tierkörper wurden die genannten Muskeln bilateral entfernt. Zur Muskulaturentnahme wurde zuerst das Tierfell, dann Cutis und Subcutis am Unterschenkel und im Rückenbereich entfernt, so dass der Muskulus soleus und der Muskulus gastrocnemius der dorsalen Unterschenkelmuskulatur und der Muskulus longissimus dorsi als Rückenmuskel exakt präpariert und entnommen werden konnten. Die beiden Muskeln des dorsalen Unterschenkels wurden einzeln gewogen. Im Anschluss wurde der Musculus gastrocnemius sagital halbiert, um im Folgenden nur mit dem halbierten Muskel zu arbeiten. Der Musculus soleus wurde im Ganzen weiter verwendet. Vom Musculus longissimus dorsi wurde nur eine partielle Exzision entnommen.

Für die histologischen Untersuchungen wurden randomisiert die drei genannten Muskeln einer Körperhälfte verwendet; die kontralateralen Muskeln wurden auf ihre enzymatische Aktivität hin untersucht (s. 2.1.10). Die Proben für die Muskelenzym-Analysen wurden direkt in flüssigen Stickstoff getaucht und anschließend bei $-80{ }^{\circ} \mathrm{C}$ gefroren aufbewahrt. Die Muskeln für die histologischen Untersuchungen wurden mit Talkum versehen, in flüssigen Stickstoff gegeben, um danach in Aluminiumfolie eingewickelt bei $-80^{\circ} \mathrm{C}$ konserviert $\mathrm{zu}$ werden.

Zusäzlich zu den Muskeln wurde via medianer Laparotomie der Uterus entnommen, das Gewicht ermittelt und dokumentiert. Die Knochen, die Grundlage andererer Dissertationsarbeiten sind, wurden ebenfalls präpariert. 


\subsubsection{Aufarbeitung der Muskulatur zur Gewinnung der Histologie}

Nach Kollektion aller, bei $-80{ }^{\circ} \mathrm{C}$ für die histologische Untersuchung gefrorenen Muskelpräparate wurden diese mit einem Mikrotom-Cryostat (Leica, Frigocut 2800E, Nussloch, Deutschland) in einer Stärke von $12 \mu \mathrm{m}$ geschnitten. Die so hergestellten Querschnittsflächen der Muskeln wurden auf einen Objektträger übertragen, mussten für zwei Stunden bei Raumtemperatur trocknen und wurden danach in einem Setzkasten bei $-20{ }^{\circ} \mathrm{C}$ aufbewahrt. Pro Muskel wurden im Durchschnitt 10 Querschnittsflächen mit einer Stärke von $12 \mu \mathrm{m}$ angefertigt.

\subsubsection{Analyse der Muskelzellen auf Kapillardichte und Stoffwechsel}

In diesen Analysen ging es um die Modulation der Skelettmuskelzellen, unter dem Einfluss einer horizontalen WBV bei Ratten mit durch Ovarektomie induziertem Östrogenmangel. Daher wurde die quergestreifte Skelettmuskulatur auf Unterschiede in der Expression von Muskelzellgröße, Kapillardichte und auf die Klassifikation der Stoffwechselarten untersucht. Nach ihrem Stoffwechselverhalten lassen sich die Skelettmuskelzellen in fast-twitch glykolytische, in fast-twitch oxidative und in slow-twitch oxidative Zellen spezifizieren. Wobei die fast- und slow-twitch oxidativen Zellen in der vorliegenden Analyse zusammengefasst wurden.

Die Auswertung der Querschnittsflächen erfolgte mit einem Lichtmikroskop (Mikroskop Eclipse E 600 (Nikon, N.Y. 11747-3064, U.S.A.; 10fache Vergrößerung) und einem Bildverarbeitungsprogramm (NIS-Elements AR 4.00.08 (Nikon, N.Y. 11747-3064, U.S.A.), welches uns ermöglichte auch mit live Bildern, Muskelzellen auf ihren Stoffwechsel und ihre Kapillardichte hin zu untersuchen. An das Mikroskop wurde eine Kamera (DVC, Thorlabs Inc, Newton, New Jersey, U.S.A.) angeschlossen, mit der die Bildaufnahmen digitalisiert werden konnten.

Mit der Amylase-PAS-Färbung wurde das Verhältnis zwischen Muskelfaseranzahl und Anzahl der Kapillaren bestimmt, die ATPase-Färbung ließ Rückschlüsse auf einzelne Muskelfasergrößen und Verhältnissen zu. 


\subsubsection{ATPase-Färbung kombiniert mit Diaphorase für Rattenproben}

Zur Analyse der Muskelfasern in den Querschnittsflächen verwendeten wir eine ATPaseFärbung nach der Horak-Methode, Halle, Deutschland; 1988. Durch diese lassen sich die Stoffwechselarten der einzelnen Zellen in oxydative- und glykolytische Energiegewinnung differenzieren. Die Angaben zur Herstellung der einzelnen Lösungen, gelten für jeweils $12 \mu \mathrm{m}$ dicke Schnitte.

Im Folgenden sind die einzelnen Arbeitsschritte zur ATPase-Färbung aufgezeigt:

1. Fixierlösung nach Meier (eingefüllt in Küvetten):

- 1,5 g Paraformaldehyd (1\%, Merck)

- $3 \mathrm{~g} \mathrm{CaCl}_{2}$ (-6-hydrat)

- $9 \mathrm{~g}$ Saccharose

- $150 \mathrm{ml}$ destilliertes Wasser

Kurz vor der Verwendung wurde ein $\mathrm{pH}$ Wert von 6,3- 6,6 eingestellt. Dafür wurden wenige $\mu 1 \mathrm{NaOH}$ beziehungsweise $\mathrm{HCl}$ genutzt.

Die Einwirkung der Lösung erfolgte über 1 Minute

2. Aufbewahrung in Aqua dest. für 5 Minuten

3. Erneute Aufbewahrung in Aqua dest. für 5 Minuten

4. Diaphoraseinkubation:

- Diaphorase-Inkubationslösung in einem $50 \mathrm{ml}$ Becherglas:

- 20 mg NADH (disodium salt, grad 2,98\% Böhringer)

- $3,2 \mathrm{ml}$ Phosphatpuffer $(0,1 \mathrm{M} / \mathrm{pH} 7,4)$

- $4 \mathrm{ml}$ Nitro-BT

- $4,8 \mathrm{ml}$ Aqua dest.

Die mit Diaphorase-Inkubationslösung betropften Objektträger werden über 60 Minuten bei $37{ }^{\circ} \mathrm{C}$ in eine feuchte Kammer gelegt.

5. Aufbewahrung in Aqua dest. über 15 Minuten

6. Saure Vorinkubation in den Küvetten:

- $15 \mathrm{ml} \mathrm{CaCl}_{2}$-Stammlösung

- $\quad$ 0,6 ml konzentrierte Essigsäure

- $135 \mathrm{ml}$ Aqua dest.

Ebenfalls wurde hier kurz vor der Verwendung ein $\mathrm{pH}$ Wert von 4,2 eingestellt bevor die saure Vorinkubation über 15 Minuten einwirken konnte. 
7. Tris- $\mathrm{CaCl}_{2}$-Lösung in den Küvetten

- $\quad 1,82 \mathrm{~g}$ Tris (Tris-(hydroxymethyl)-aminomethan $99,9 \%, \mathrm{M}=121,4 \mathrm{~g} / \mathrm{mol}$ )

- $15 \mathrm{ml} \mathrm{CaCl}_{2}$-Stammlösung

- $135 \mathrm{ml}$ Aqua dest.

Es wurde ein $\mathrm{pH}$ Wert von 7,8 zeitnah vor der Verwendung eingestellt. Die Lösung wirkte für 2 Minuten ein.

8. ATPase Inkubationslösung in den Küvetten

- $555 \mathrm{mg} \mathrm{KCl}(\mathrm{M}=75 \mathrm{~g} / \mathrm{mol})$

- $228 \mathrm{mg}$ ATP (Adenosin-5' - Triphosphat, $\mathrm{M}=551,2 \mathrm{~g} / \mathrm{mol}$ )

- $135 \mathrm{ml}$ Glycinpuffer

- $15 \mathrm{ml} \mathrm{CaCl}_{2}$-Stammlösung

Die $15 \mathrm{ml} \mathrm{CaCl}$-Stammlösung war als letzte Lösung hinzuzufügen, da sonst eine ATPBlockade einsetzt. Die ATPase Inkubationslösung wurde in die Küvetten gefüllt und diese wurden dann für 30 Minuten bei $37^{\circ} \mathrm{C}$ in einen Trockenschrank gestellt. In diesem Arbeitsschritt wurde zeitnah vor der Verwendung ein $\mathrm{pH}$ Wert von 9,4 eingestellt.

9. 1. $\mathrm{CaCl}_{2}$-Waschlösung über 30 Sekunden

10. 2. $\mathrm{CaCl}_{2}$-Waschlösung über 30 Sekunden

11. 3. $\mathrm{CaCl}_{2}$-Waschlösung über 30 Sekunden

12. Kobaltchlorid-Lösung in den Küvetten

- 3 g Kobaltchlorid $\left(\mathrm{CoCl}_{2} \times 6 \mathrm{H}_{2} \mathrm{O}\right)$

- $150 \mathrm{ml}$ Aqua dest.

Die Kobaltchloridlösung wirkte über 3 Minuten ein.

13. 1. Spülung mit Aqua dest. für 45 Sekunden

14. 2. Spülung mit Aqua dest. für 45 Sekunden

15. 3. Spülung mit Aqua dest. für 45 Sekunden

16. Ammoniumsulfidlösung in den Küvetten

- $\quad 0,3 \mathrm{ml}$ Ammoniumsulfid (40\%)

- $150 \mathrm{ml}$ Aqua dest.

Mit der Ammoniumsulfidlösung wurde aufgrund ihrer Toxizität ausschließlich unter dem Abzug gearbeitet, die Lösung wirkte über 3 Minuten ein.

17. Spülung der Objektträger unter fließendem Leitungswasser für 10 Minuten

18. Spülung der Objektträger in Aqua dest. für 5 Minuten. 


\subsubsection{Auswertung der ATPase Färbung}

Für die Auswertung der ATPase Färbung war es wichtig, optisch dunkel gefärbte Fasern, die oft klein waren, von schwach angefärbten, in der Regel großen Fasern differenzieren zu können (Abb. 6). Während bei den kleinen, dunkel angefärbten Muskelfasern ein langsamer oxidativer oder ein schneller oxdativer-glykolytischer Stoffwechsel vorliegt, liegt bei den oft sehr großen, schwach angefärbten Muskelfasern ein schneller glykolytischer Stoffwechsel vor.

Die Muskelfasern mit einem schnellen und langsamen oxidativen Stoffwechsel wurden in der vorliegenden Analyse zusammen erfasst. Eine eindeutige Differenzierung zwischen schnellen und langsamen oxidativen Stoffwechsel anhand der Farbstufen lässt die angewandte Färbung nicht zu. Pro Querschnittsfläche wurden 90 Muskelfasern mit einer oxidativen Energiegewinnung und 90 Muskelfasern mit einer glykolytischen Energiegewinnung erfasst. Zur Messung dieser insgesamt 180 Muskelfasern pro Querschnittsfläche, wurden randomisiert drei $1 \mathrm{~mm}^{2}$ große Felder bestimmt, in denen dann jeweils 30 oxidative Muskelfasern und 30 glykolytische Muskelfasern gezählt und auf ihre jeweilige Gesamtfläche gemessen wurden. Im Musculus soleus wurden ausschließlich Muskelfasern mit einer oxidativen Energiegewinnung gemessen, da dieser Muskel hauptsächlich über oxidative Muskelfasern verfügt (Abb. 7). Die Bildverarbeitung erfolgte mit dem Programm NIS-Elements AR 4.00.08 (Nikon, N.Y. 11747-3064, U.S.A.), und für die Datenverarbeitung wurde das Tabellenkalkulationsprogramm Excel Microsoft-Office genutzt. 


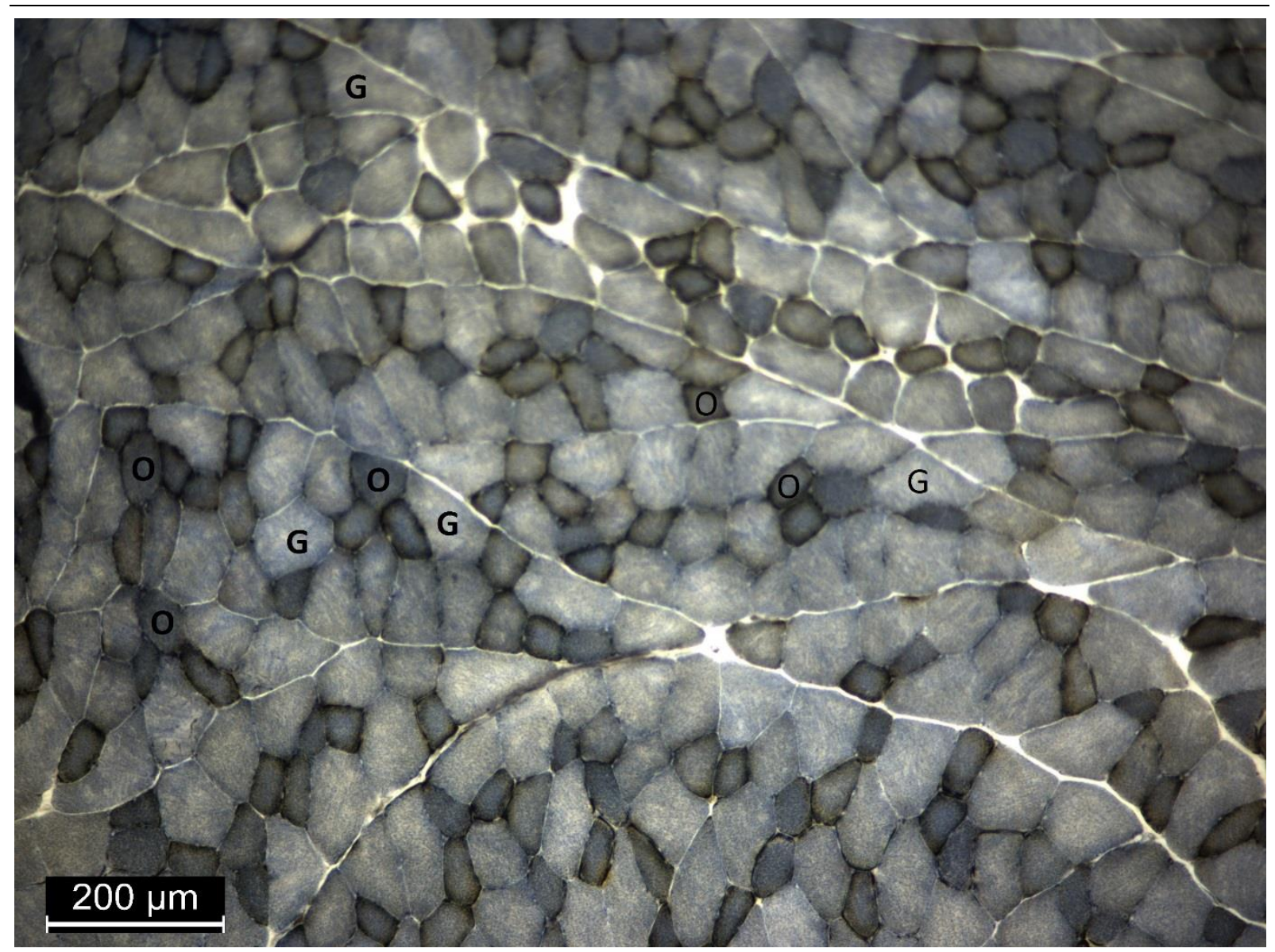

Abb. 6: ATPase-Färbung M. gastrocnemius (Ratte 02; SHAM)

- $\mathrm{G}=$ glykolytische Zellen

- $\mathrm{O}=$ oxidative Zellen 


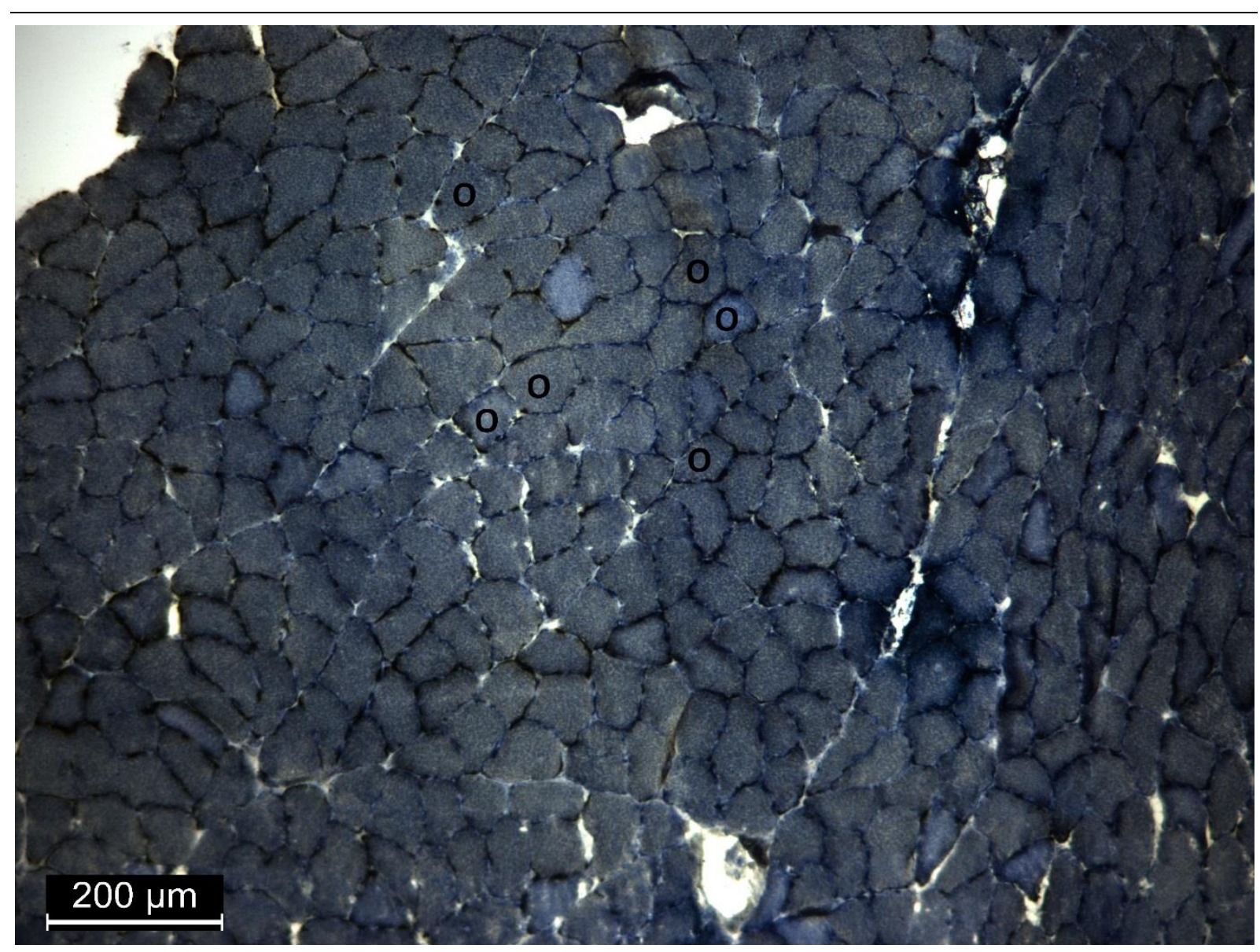

Abb. 7: ATPase-Färbung M. solues (Ratte 11; SHAM)

- $\mathrm{O}=$ oxidative Zellen 


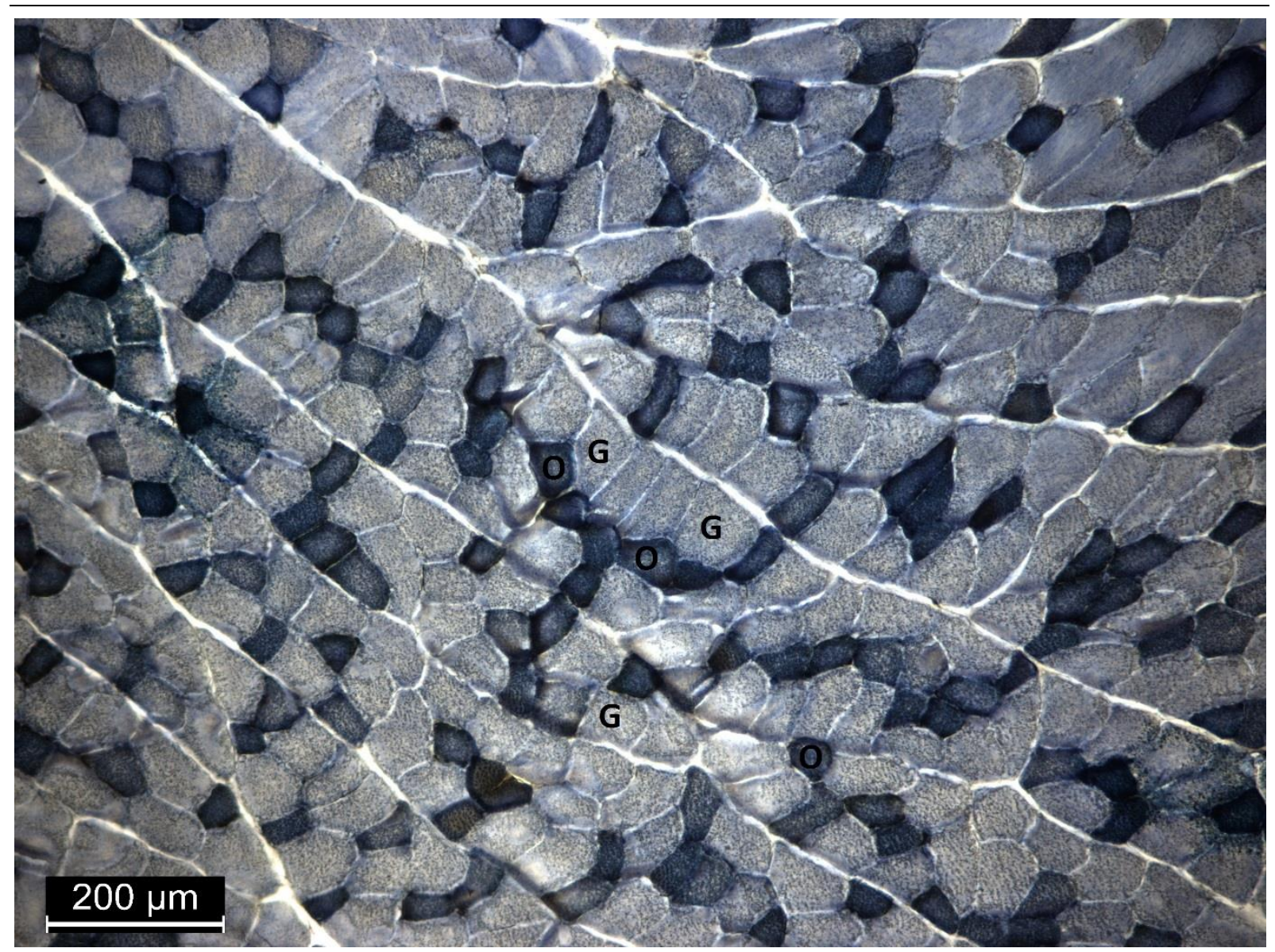

Abb.8: ATPase-Färbung M. longissimus dorsi (Ratte 46; OVX+30 Hz)

- $\mathrm{G}=$ glylolytische Zellen

- $\mathrm{O}=$ oxidative Zellen 


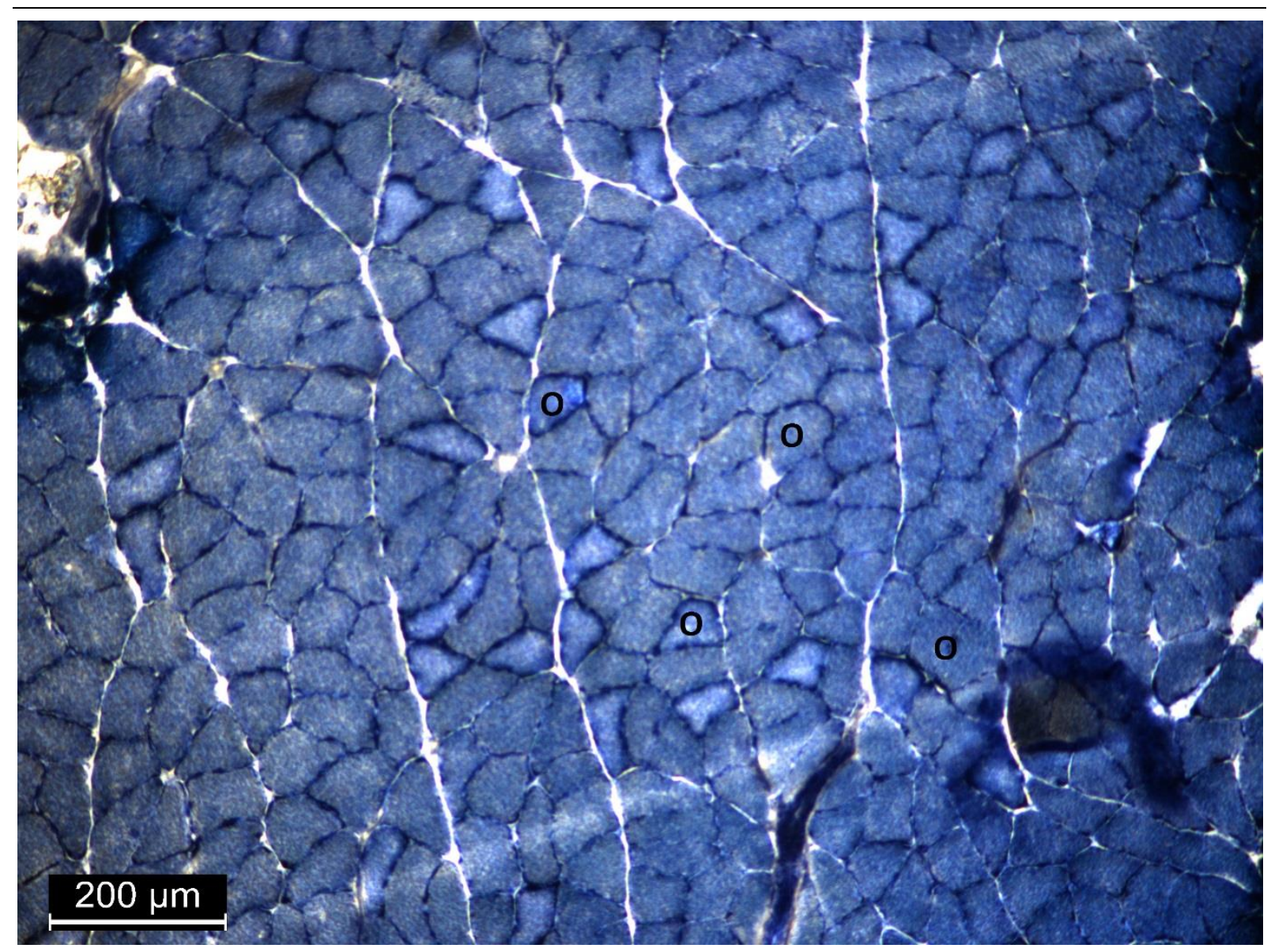

Abb. 9: ATPase-Färbung M. soleus (Ratte 45; OVX+30 Hz)

- $\mathrm{O}=$ oxidative Zellen 


\subsubsection{Amylase-PAS für Kapillarfärbung}

Zur Analyse der Muskelzellkapillaren beziehungsweise zur Analyse der Zellkapillar-Anzahl wurde eine Amylase-PAS-Färbung, nach der Horak-Methode, Halle, Deutschland, 1988 genutzt, mit der sich die einzelnen Kapillaren deutlich darstellen lassen (Abb. 10). Die Angaben zur Herstellung der Färbung verstehen sich auf $12 \mu \mathrm{m}$ dicke Schnitte.

Im Folgenden sind die einzelnen Arbeitsschritte zur Durchführung der Amylase-PASFärbung aufgezeigt:

1. Fixierungslösung:

- $128 \mathrm{ml}$ Ethanol (95-100\%)

- $24 \mathrm{ml}$ Chloroform

- $8 \mathrm{ml}$ Essigsäure (99\%)

Die Fixierlösung wurde immer frisch hergestellt. Die Lösung wurde in die Küvetten, mit den zu färbenden Objektträgern gefüllt. Die Küvetten wurden dann eine Stunde im Kühlschrank bei ca. $8{ }^{\circ} \mathrm{C}$, danach für 10 Minuten bei Raumtemperatur aufbewahrt.

2. Spülung mit Aqua dest. (10mal).

3. $\alpha$-Amylaselösung:

- $500 \mathrm{mg} \alpha$-Amylase

- $160 \mathrm{ml}$ Aqua dest.

Die $\alpha$-Amylaselösung wurde ebenfalls immer frisch angesetzt, da bei Aufbewahrung eine Extinktionsabnahme (Hydrolyse der Stärkelösung) messbar ist. Die Lösung konnte dann über 25 Minuten bei einer Temperatur von $37^{\circ} \mathrm{C}$ einwirken.

4. Spülung mit Aqua dest. (10mal).

5. Perjodsäure:

- $\quad 1,5$ g Perjodsäure

- $150 \mathrm{ml}$ Aqua dest.

Mit ebenfalls frisch hergestellter Perjodsäure wurden die Küvetten aufgefüllt, und die Perjodsäure konnte über 30 Minuten chemisch einwirken.

6. Spülung mit Aqua dest. (10mal).

7. Schiff's Reagenz (CARL ROTH GMBH und CO.KG, Karlsruhe, Deutschland) (Wir benutzten diese fertig zubereitet.)

- $0,1 \mathrm{~g}$ Fuchsin

- $100 \mathrm{ml}$ Aqua dest. 
- 1 g Natriumsulfit

- $1 \mathrm{ml}$ konzentrierte Salzsäure

Das Schiffsche Reagenz entsteht durch mehrere Arbeitsschritte. Als erstes wird Fuchsin unter Erwärmung in Aqua dest. gelöst. Nach dem Abkühlen wird das Natriumsulfit und die konzentrierte Salzsäure hinzugegeben. Die Lösung muss sich entfärben. Die obigen Mengenangaben verstehen sich für die Hersstellung von $100 \mathrm{ml}$ Schiff's Reagenz. Die Objektträger wurden für 25 Minuten mit der Schiff's Reagenz behandelt.

8. $\mathrm{SO}_{2}$-Wasser:

- $600 \mathrm{ml}$ Aqua dest.

- $30 \mathrm{ml}$ Kaliumdisulfit-Lösung $\left(\mathrm{K}_{2} \mathrm{~S}_{2} \mathrm{O}_{5}\right.$-Lösung, 10\%)

- $30 \mathrm{ml} \mathrm{HCl}$

Das $\mathrm{SO}_{2}$-Wasser wurde für 30 Minuten in die Küvetten eingefüllt.

9. Spülung unter fließendem Leitungswasser, über 10 Minuten.

10. Spülung mit Aqua dest. für 3 Minuten.

Im darauffolgenden Arbeitsschritt wurden Deckgläschen mittels Klebstoff (Aquafex Merck) auf die Objektträger aufgebracht, was Voraussetzung für die lichtmikroskopische Auswertung war.

\subsubsection{Auswertung der Amylase-PAS-Färbung}

Die Auswertung der angefertigten Schnittpräparate erfolgte für alle drei Muskeln nach einem standardisierten Schema. Dabei wurden zunächst pro Schnitt an drei randomisierten $1 \mathrm{~mm}^{2}$ großen Flächen die Muskelfasern und die Kapillaren gezählt. Diese Zählungen wurden durchgängig für alle Präparate durchgeführt, da so gleichzeitig über die pro Schnitt je ausgewählten drei Flächen eine Validierung erfolgen konnte. Zur Analyse wurde ein Lichtmikroskop, welches mit dem Bildverarbeitungsprogramm korrespondierte, eingesetzt. Die Bildverarbeitung erfolgte mit dem Programm NIS-Elements AR 4.00.08 (Nikon, N.Y. 11747-3064, U.S.A.) Für die Datenverarbeitung wurde das Tabellenkalkulationsprogramm Excel Microsoft-Office genutzt. 


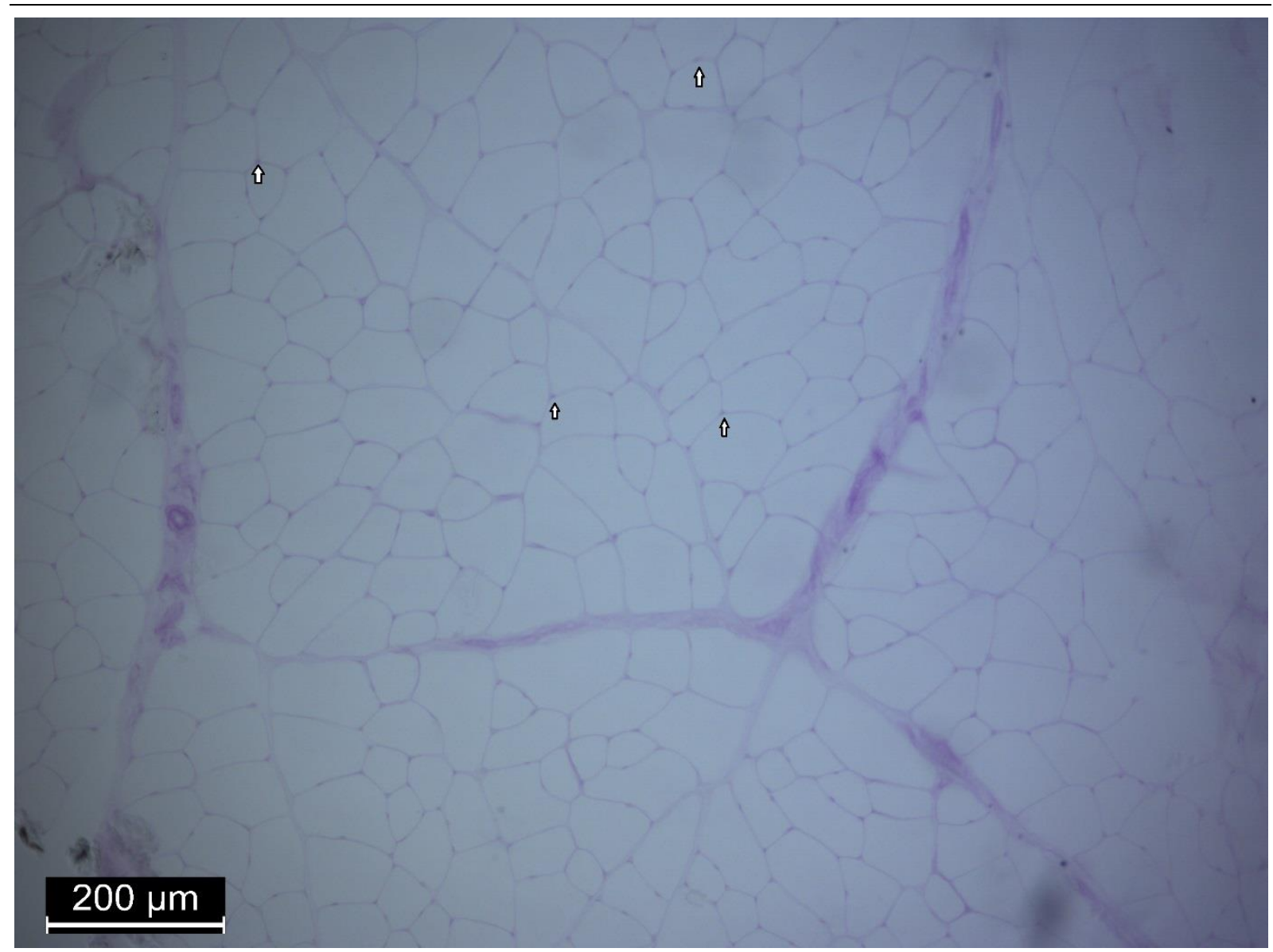

Abb. 10: PAS-Färbung M. gastrocnemius (Ratte 14; SHAM)

- 仓 deutet auf Kapillaren

\subsubsection{Aufarbeitung der Muskulatur für Enzym-Analysen}

Zur Vorbereitung der Enzym-Analysen wurden die bei $-80{ }^{\circ} \mathrm{C}$ gefrorenen Muskeln einer einheitlichen Prozedur unterzogen: Zunächst wurden 100-150 mg pro Muskel für die Analysen abgewogen. Nach der exakten Gewichtsbestimmung wurde dieser Muskelteil in eine spezielle Kapsel, in der eine mechanische Zerkleinerung des Muskelgewebes mittels Mikro-Dismembrator S (Sartorius, Göttingen, Deutschland) durchgeführt wurde, überführt. Nach 30 Sekunden bei 2500 rounds per minute (rpm) lag das Muskelgewebe in einer Art Pulver vor. Diesem noch gefrorenem Pulver wurde dann zur Verdünnung und Lösung ein Chappel-Perry Medium (0,1 M KCL; 0,05 M Tris; 0,01 M $\mathrm{MgCl}_{2} \times 6 \mathrm{H}_{2} \mathrm{O}, 1 \mathrm{mM}$ EGTA; $\mathrm{pH}$ 7,5) zugefügt. Das so gewonnene Homogenat wurde in Röhrchen aliquotiert. Danach konnten die einzelnen spezifischen Enzym-Analysen für die Glykolyse, für den Citrat-Kreislauf und für die Atmungskette gestartet werden. 


\subsubsection{Bestimmung der Laktatdehydrogenase-Aktivität}

Die Aktivität der Laktatdehydrogenase-Aktivität (LDH) (Abb. 11) wurde über das in der Reaktion freigesetzte $\mathrm{NAD}^{+}$ermittelt.

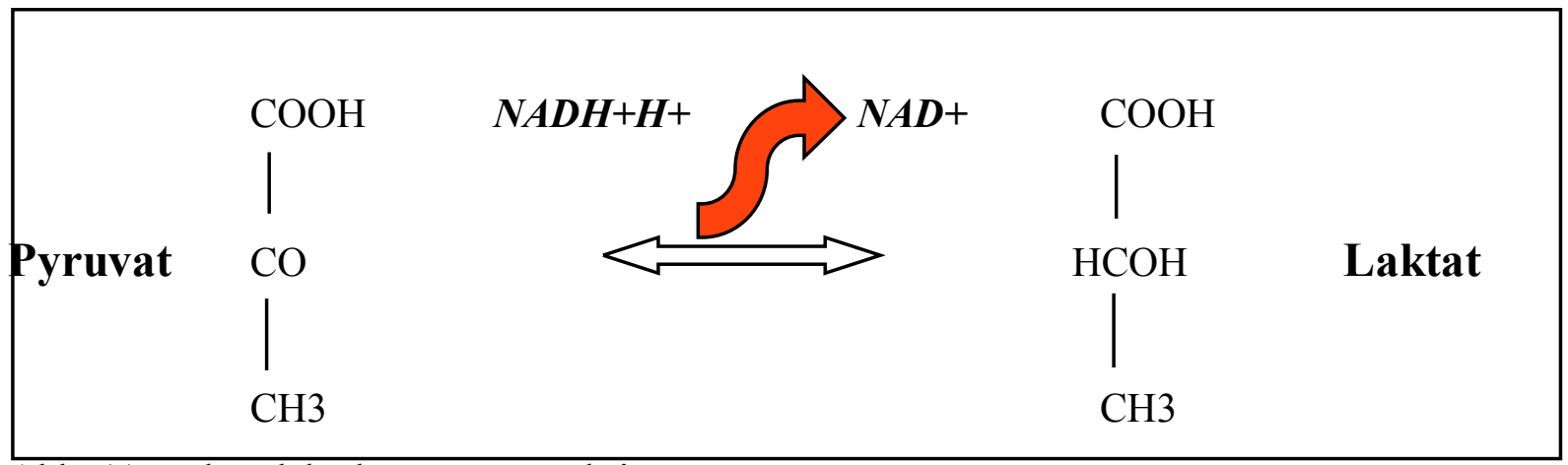

Abb. 11: Laktatdehydrogenase Reaktion

Zur Analyse der Laktatdehydrogenase-Aktivität in den Muskelproben wurden die in 2.1.10 beschriebenen Homogenate genutzt. Dieses Homogenat musste zunächst ggf. mit weiterem Chappel-Perry-Medium (0,1 M KCL; 0,05 M Tris; 0,01 M $\mathrm{MgCl}_{2} \times 6 \mathrm{H}_{2} \mathrm{O}, 1 \mathrm{mM}$ EGTA; pH 7,5) im Verhältnis 1:100 verdünnt werden. Im Versuch wurde mit 2 Proben, einmal $20 \mu 1$ Homogenat und einmal ohne Homogenat (als Leerwert gearbeitet. Dazu wurden zwei Lösungen nach folgendem Schema in Halbmikroküvetten hergestellt:

Leerwert-Testansatz:

- $\quad$ 0,05 M Tris-HCL bei einem pH-Wert von 7,4: $935 \mu 1$

- $\quad 0,25$ M EDTA: $20 \mu 1$

- 10 mM NADH: $15 \mu 1$

Homogenat-Testansatz:

- 0,05 M Tris-HCL bei einem pH-Wert von 7,4: $915 \mu 1$

- $\quad 0,25$ M EDTA: $20 \mu 1$

- 10 mM NADH: $15 \mu 1$

- es erfolgte die Zugabe des Homogenats: $20 \mu 1$

Die hergestellten Lösungen wurden im nächsten Schritt für 10 Minuten bei $30^{\circ} \mathrm{C}$ in ihrer zum Photometer gehörenden Küvette vorinkubiert. Nach 10 Minuten Vorinkubation wurde durch das Hinzufügen von je $30 \mu 1$ Pyruvat $(40 \mathrm{mM})$ die Reaktion eingeleitet. Dann erfolgte über 5 Minuten bei $30{ }^{\circ} \mathrm{C}$ die Messung bei $365 \mathrm{~nm}$ im Photometer (LP6, Hach Lange GmbH; Düsseldorf, Deutschland). Mit den so ermittelten Ergebnissen konnte dann die 
Laktatdehydrogenase-Aktivität berechnet werden. Es wurde folgende Formel für die Berechnung genutzt:

$$
\begin{aligned}
& (\Delta \mathrm{E}-\Delta \mathrm{E} \text {-Leerwert }) \times 1000 \mu \mathrm{l} \times \text { Verdünnung } \\
& \mathrm{d} \times \varepsilon \times 5 \text { Minuten } \times 20 \mu \mathrm{l} \quad \varepsilon=6,2 \mathrm{mM}^{-1} \mathrm{x} \mathrm{cm}^{-1}
\end{aligned}
$$

Erläuterungen zu verwendeten Formel:

- $\Delta \mathrm{E}$ war die Extinktion

- $\quad 1000 \mu 1$ entsprachen dem Küvettenvolumen

- V entsprach dem Verdünnungszustand des Homogenats

- d entsprach der spezifischen Schichtdicke

- $\varepsilon$ entsprach dem millimolaren Extinktionskoeffizienten $\left(\varepsilon=6,2 \mathrm{mM}^{-1} \mathrm{x} \mathrm{cm}^{-1}\right)$

- Die 5 Minuten stellten die Inkubationszeit dar

- Die $20 \mu 1$ entsprachen der Menge an Homogenat

Die ermittelte Aktivität konnte somit in Units pro Gramm Muskel (U/g) umgerechnet werden. In einem weiteren Arbeitsschritt wurden die Units pro Gramm Proteingehalt (U/g Protein) bestimmt. Für diesen weiteren Arbeitsschritt wurde das Protein Assey Kit eingesetzt. Je $25 \mu 1$ des Homogenats wurden auf Photometerplatten pipettiert und $200 \mu 1$ der im Protein Assay Kit enthaltenen Arbeitsreagenz zugefügt. Eine gute Verteilung und Vermischung der Arbeitsreagenz mit dem Homogenat wurde durch ein Rütteln der Platten über 30 Sekunden erreicht. Danach blieben die Platten abgedeckt und ruhten für 30 Minuten bei einer Temperatur von $37^{\circ} \mathrm{C}$. Vor der Messung mittels Photometer mussten die Platten wieder auf Raumtemperatur abkühlen. Dann erst konnten die Messungen bei $562 \mathrm{~nm}$ durchgeführt werden. Der beschriebenen Vorgang wurde gleichzeitig mit einer Standard-Albumin-Lösung (bovine serum albumin, BSA) als Kontrolle durchgeführt, um einen stabilen Referenzwert zu haben.

\subsubsection{Bestimmung der Citrat-Synthase-Aktivität}

Die Bestimmung der Aktivität der Citrat-Synthase erfolgte über die zeitabhängige Konzentrationsänderung der in der Citrat-Synthase-Reaktion freigesetzten Coenzym A-Moleküle. Zur Analyse der Citrat-Synthase-Aktivität wurde ebenfalls das angefertigte Homogenat aus den 
Muskelproben verwendet. Das Homogenat musste ggf. mit dem Chappel-Perry-Medium (0,1 M KCL; 0,05 M Tris; 0,01 M $\mathrm{MgCl}_{2} \times 6 \mathrm{H}_{2} \mathrm{O}, 1 \mathrm{mM}$ EGTA; $\mathrm{pH}$ 7,5) im Verhätnis 1:3 verdünnt werden. Auch in diesem Versuchsablauf wurde mit 2 Proben, mit $20 \mu 1$ Homogenat und ohne Homogenat als Leerwert gearbeitet. Zwei Lösungen wurden nach folgendem Schema in Halbmikroküvetten hergestellt:

Leerwert-Testansatz:

- Tris Mannitol-Puffer bei einem pH-Wert von: 7,4: $830 \mu 1$

- $\operatorname{Triton}(5,1 \%): 20 \mu 1$

- Dithiobis(2-Nitrobenzoic Acid), 2 mM (DTNB): $50 \mu 1$

- Acetyl-CoA, 2 mM: $50 \mu 1$

Homogenat Testansatz:

- Tris Mannitol-Puffer bei einem pH-Wert von: 7,4: $810 \mu 1$

- $\operatorname{Triton}(5,1 \%): 20 \mu 1$

- Dithiobis(2-Nitrobenzoic Acid), 2 mM (DTNB): $50 \mu 1$

- Acetyl-CoA, $2 \mathrm{mM}: 50 \mu 1$

- Zugabe des Homogenats: $20 \mu 1$

Die hergestellten Lösungen wurden im nächsten Schritt für 10 Minuten bei $30{ }^{\circ} \mathrm{C}$ in ihrer zum Photometer gehörenden Küvette vorinkubiert. Nach diesen 10 Minuten der Vorinkubation wurde durch Hinzufügen von je $50 \mu$ Oxalacetat $(10 \mathrm{mM})$ die Reaktion eingeleitet. Dann erfolgte über 5 Minuten bei $30^{\circ} \mathrm{C}$ die Messung der Kinetik bei $405 \mathrm{~nm}$ im Photometer (LP6, Dr. Lange GmbH; Düsseldorf, Deutschland). Mit den so ermittelten Ergebnissen konnte dann die Citrat-Synthase-Aktivität berechnet werden. Es wurde folgende Formel für die Berechnung genutzt:

$(\Delta \mathrm{Ecs}-\Delta \mathrm{E}$-Leerwert $) \times 1000 \mu 1 \times$ Volumen

$\mathrm{d} \times \varepsilon \times 5$ Minuten $\mathrm{x} 20 \mu \mathrm{l} \quad \varepsilon=13,6 \mathrm{mM}^{-1} \mathrm{x} \mathrm{cm}^{-1}$

Erläuterungen zur verwendeten Formel:

- $\Delta \mathrm{E}$ war die Extinktion

- $1000 \mu 1$ entsprachen dem Küvettenvolumen

- V entsprach dem Verdünnungszustand des Homogenats 
- d entsprach der spezifischen Schichtdicke

- $\varepsilon$ entsprach dem millimolaren Extinktionskoeffizienten $\left(\varepsilon=6,2 \mathrm{mM}^{-1} \mathrm{x} \mathrm{cm}^{-1}\right)$

- Die 5 Minuten stellten die Inkubationszeit dar

- Die $20 \mu 1$ entsprachen der Menge an Homogenat

Mit Hilfe des BCA TM Protein Assay Kits (Pierce, Rockford, ILUSA) konnten, wie unter der Aktivitätsbestimmung der Laktatdehydrogenase beschrieben, die ermittelte Aktivität in Units pro Gramm Muskel (U/g) der Citrat-Synthase, auch in Units pro Gramm Protein-gehalt (U/g Protein) bestimmt werden.

\subsubsection{Bestimmung der Komplex I-Aktivität}

Zur Analyse der Komplex I-Aktivität wurde die Reduzierung der NADH-Konzentration, jeweils mit und ohne Zusatz des Komplex I-Inhibitors Rotenon bestimmt. Das Homogenat war auch hier das Substrat. Ebenfalls wurden wiederum zwei Proben mit $20 \mu 1$ Homogenat und ohne es (Leerwert) eingesetzt. Zwei Lösungen wurden nach folgendem Schema in Halbmikroküvetten hergestellt:

Leerwert-Testansatz:

- Messpuffer: Tris $10 \mathrm{mM}$ bei einem pH-Wert von 7,4; KCL $50 \mathrm{mM}$; EDTA 1 mM: $920 \mu 1$

- Kaliumcyanid $50 \mathrm{mM}: 20 \mu 1$

- Antimycin A $50 \mu \mathrm{M}: 20 \mu 1$

Homogenat-Testansatz:

- Messpuffer: Tris $10 \mathrm{mM}$ bei einem pH-Wert von 7,4; KCL 50 mM; EDTA 1 mM: $900 \mu 1$

- Kaliumcyanid $50 \mathrm{mM}: 20 \mu 1$

- Antimycin A $50 \mu \mathrm{M}: 20 \mu 1$

- Zugabe des Homogenats: $20 \mu 1$

Die hergestellten Lösungen wurden im nächsten Schritt für 10 Minuten bei $30^{\circ} \mathrm{C}$ in ihrer zum Photometer gehörenden Küvette vorinkubiert. Nach diesen 10 Minuten der Vorinkubation wurde durch das Hinzufügen von Co-Enzym Q (6 mM) $20 \mu 1$ und NADH (10 mM) die 
Reaktion eingeleitet. Dann erfolgte über 10 Minuten bei $30^{\circ} \mathrm{C}$ die Messung der Kinetik bei 365 nm im Photometer (LP6, Dr. Lange GmbH; Düsseldorf, Deutschland). Nach Beendigung dieses Messvorgangs wurde sofort Rotenon als Komplex I-Inhibitor in die Lösungen gegeben. Anschließend wurde die nun gehemmte Kinetik nach erneuten 10 Minuten bei $30{ }^{\circ} \mathrm{C}$ gemessen. Mit den so ermittelten Ergebnissen konnte dann rechnerisch die Citrat-SynthaseAktivität bestimmt werden. Es wurde dafür folgende Formel für die Berechnung genutzt:

( $\Delta \mathrm{E}$ ohne Rotenon- $\Delta \mathrm{E}$ mit Rotenon̄) $\times 1000 \mu 1 \times$ Verdünnung

$\mathrm{d} \times \varepsilon \times 10$ Minuten $\mathrm{x} 20 \mu \mathrm{l} \quad \varepsilon=6,22 \mathrm{mM}^{-1} \mathrm{x} \mathrm{cm}^{-1}$

Erläuterungen zur verwendeten Formel:

- $\Delta \mathrm{E}$ war die Extinktion (mit und ohne Rotenon)

- $\quad 1000 \mu 1$ entsprachen dem Küvettenvolumen

- V entsprach dem Verdünnungszustand des Homogenats

- d entsprach der spezifischen Schichtdicke

- $\varepsilon$ entsprach dem millimolaren Extinktionskoeffizienten $\left(\varepsilon=6,2 \mathrm{mM}^{-1} \mathrm{x} \mathrm{cm}^{-1}\right)$

- Die 10 Minuten stellten die Inkubationszeit dar

- Die $20 \mu 1$ entsprachen der Menge an Homogenat

Mit Hilfe des BCA TM Protein Assay Kits (Pierce, Rockford, ILUSA) konnten, wie unter der Aktivitätsbestimmung der Laktatdehydrogenase beschrieben, die ermittelte Komplex IAktivität in Units pro Gramm Muskel (U/g) auch in Units pro Gramm Proteingehalt (U/g Protein) bestimmen werden.

\subsection{Statistik}

\subsubsection{Statistik /Methodik}

Die ermittelten Daten wurden mit dem Software Programm Prism (Version 4.00a, April 2003, GraphedPad Software Inc., San Diego, USA) statistisch analysiert. Das Programm wurde sowohl für die Analyse der Daten als auch für die graphische Darstellung der gewonnenen Ergebnisse genutzt. 
Um die Daten hinsichtlich ihrer Aussagekraft statistisch zu bewerten, wurde auf die One-way Analysis of Variance (one-way ANOVA), welche Vergleiche zwischen Mittelwerten von zwei oder mehr Proben erlaubt, genutzt. Das Signifikanzniveau liegt ausschließlich bei einem pWert von $<0,05$. Liegen nach einer Datenanalyse mittels ANOVA signifikante Werte vor, so gilt das benutze Model, beziehungsweise der benutzte Test als Zeichen für dessen Validität. Zur exakteren Betrachtung der signifikanten Unterschiede zwischen den untersuchten Gruppen wurde nach der one-way ANOVA der Tukey-Kramer post-hoch Test durchgeführt. Das Signifikanzniveau bestand bei einem $\mathrm{p}$-Wert von $<0,05$. 


\section{Ergebnisse}

\subsection{Gewichtsbestimmungen der Tiere, der untersuchten Muskeln und der Uteri}

\subsubsection{Tiergewichte und Futteraufnahme}

\section{Tiergewichte}

Das Gewicht der Ratten wurde zu Beginn jeder Versuchswoche bestimmt, wobei in der folgenden Tabellen 5 nur die Tiergewichte der Woche 1,8 und 13 bzw. die Tage 7, 63 und 98 nach Versuchsbeginn dargestellt sind. Dies entspricht den Zeitpunkten der Ovarektomie, der Osteotomie und der Tötung.

Tabelle 5: Tiergewichte der Gruppen SHAM, OVX, OVX $30 \mathrm{~Hz}$, OVX $50 \mathrm{~Hz}$, OVX $70 \mathrm{~Hz}$ und OVX $90 \mathrm{~Hz}[\mathrm{~g}]$;

\begin{tabular}{|l|l|l|l|l|l|l|}
\hline & SHAM & OVX & OVX 30 Hz & OVX 50 Hz & OVX 70 Hz & OVX 90 Hz \\
\hline $\begin{array}{l}\text { Ovar- } \\
\text { ektomie } \\
\text { (Tag 7) } \\
\text { MW/ Std } \\
\text { (g) }\end{array}$ & $\mathbf{2 3 9} \pm 12,31$ & $\mathbf{2 4 7} \pm 14,7$ & $\mathbf{2 4 2} \pm 12,87$ & $\mathbf{2 3 6} \pm 10,1$ & $\mathbf{2 3 0} \pm 5,58$ & $\mathbf{2 4 6} \pm 9,76$ \\
\hline $\begin{array}{l}\text { Osteotomie } \\
\text { (Tag } \mathbf{6 3}) \\
\text { MW/ Std } \\
\text { (g) }\end{array}$ & $\mathbf{2 7 1} \pm 24,1$ & $\mathbf{3 4 1} \pm 14,58$ & $\mathbf{3 2 8} \pm 23,01$ & $\mathbf{3 3 4} \pm 15,18$ & $\mathbf{3 2 4} \pm 13,69$ & $\mathbf{3 3 5} \pm 15,83$ \\
\hline $\begin{array}{l}\text { Tötung } \\
\text { (Tag 98) } \\
\text { MW/ Std } \\
\text { (g) }\end{array}$ & $\mathbf{2 7 4} \pm 16,1$ & $\mathbf{3 3 2} \pm 15,38$ & $\mathbf{3 1 7} \pm 22,58$ & $\begin{array}{l}\mathbf{3 2 2} \pm 15,34 \\
{[*}\end{array}$ & $\begin{array}{l}\mathbf{3 1 2} \pm 13,67 \\
{[*]}\end{array}$ & $\begin{array}{l}\text { 317 } \pm 14,04 \\
{[*]}\end{array}$ \\
\hline
\end{tabular}


Futteraufnahme:

Am Ende jeder Versuchswoche wurde die in dieser Woche von den Tieren aufgenommenen Futtermenge in den jeweiligen Gruppen (SHAM, OVX, OVX $+30 \mathrm{~Hz}, \mathrm{OVX}+50 \mathrm{~Hz}$, $\mathrm{OVX}+70 \mathrm{~Hz}$ und $\mathrm{OVX}+90 \mathrm{~Hz}$ ) auf die einzelnen Tiere umgerechnet. Die so für jedes Tier ermittelte durchschnittliche Futtermenge pro Tag ist in der Tabelle 6 dargestellt. Das Körpergewicht und die Futtermengen sind Bestand anderer Dissertationsarbeiten.

Tabelle 6: Durchschnittliche tägliche Futteraufnahme der Ratten (Gramm (g) pro Ratte pro Tag)

\begin{tabular}{|c|c|c|c|c|c|c|}
\hline & SHAM & OVX & OVX $30 \mathrm{~Hz}$ & OVX $50 \mathrm{~Hz}$ & OVX $70 \mathrm{~Hz}$ & OVX $90 \mathrm{~Hz}$ \\
\hline $\begin{array}{l}\text { Ovar- } \\
\text { ektomie } \\
\text { (Tag 7) } \\
\text { MW/ Std } \\
(\text { g) }\end{array}$ & $\begin{array}{l}\mathbf{1 7 , 4 7}= \\
1,04\end{array}$ & $\pm \begin{array}{l}\mathbf{1 6 , 7 3} \\
0,90\end{array}$ & $\mathbf{1 7 , 8} \pm 1,74$ & $\begin{array}{ll}\mathbf{1 7 , 3 6} & \pm \\
0,82 & \end{array}$ & $\begin{array}{ll}\mathbf{1 4 , 5 5} & \pm \\
1,05 & \end{array}$ & $\begin{array}{ll}\mathbf{1 3 , 9 6} & \pm \\
0,29 & \end{array}$ \\
\hline $\begin{array}{l}\text { Osteotomie } \\
\text { (Tag 63) } \\
\text { MW/ Std } \\
\text { (g) }\end{array}$ & $\begin{array}{l}\mathbf{1 5 , 8 7}= \\
2,41\end{array}$ & $\pm \mathbf{1 6 , 9} \pm 2,11$ & $\begin{array}{l}\mathbf{1 8 , 0 0} \quad \pm \\
6,27\end{array}$ & $\begin{array}{l}\mathbf{1 8 , 0 5} \\
7,96\end{array}$ & $\begin{array}{l}\mathbf{1 7 , 8 2} \\
6,74\end{array}$ & $\begin{array}{ll}\mathbf{1 9}, 33 & \pm \\
6,53 & \end{array}$ \\
\hline $\begin{array}{l}\text { Tötung } \\
\text { (Tag 98) } \\
\text { MW/ Std } \\
\text { (g) }\end{array}$ & $\begin{array}{l}\mathbf{1 6 , 4 6}= \\
1,70\end{array}$ & $\pm \begin{array}{l}\mathbf{1 8}, \mathbf{7 8} \\
0,43\end{array}$ & $\begin{array}{ll}\mathbf{1 8 , 0 2} & \pm \\
0,33 & \end{array}$ & $\begin{array}{l}\mathbf{1 8 , 1 1} \quad \pm \\
0,28\end{array}$ & $\begin{array}{ll}\mathbf{1 8}, \mathbf{1 8} & \pm \\
1,33 & \end{array}$ & $17,87 \pm 0,50$ \\
\hline
\end{tabular}




\subsubsection{Muskelgewichte der Mm. gastrocnemii und Mm. solei}

Die Muskelgewichte, auf denen die vorliegenden Diagramme basieren, sind nach der Tötung der Tiere ermittelt worden. Es liegen keine Werte für den M. longissimus dorsi vor, da dieser von uns nicht in toto exstirpiert wurde.

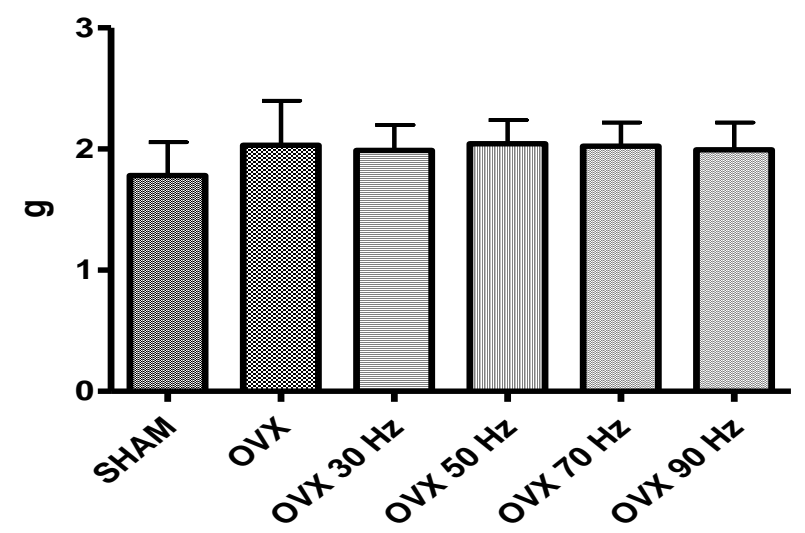

Abb. 12: Gewicht des M. gastrocnemius in [g] der Ratten nach 30 Tagen WBV; Darstellung der $\mathrm{MW} \pm / \mathrm{Std}$

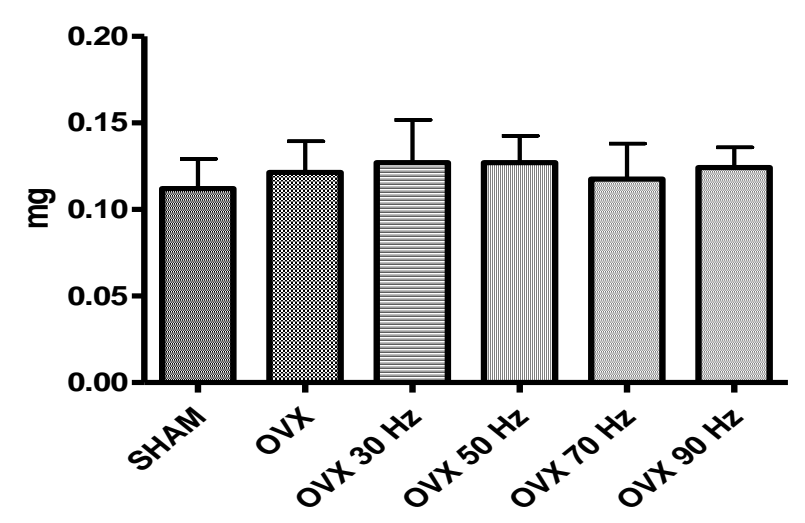

Abb. 13: Gewicht des M. soleus in Gramm [g] der Ratten nach 30 Tagen WBV;

Darstellung der MW \pm / Std 
Gewichte der Muskeln im Verhältnis zum Körpergewicht

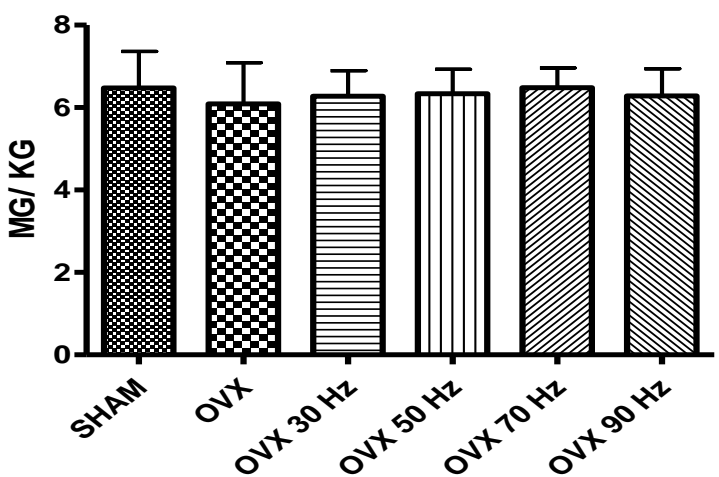

Abb. 14: Gewicht des M. gastrocnemius in [g] im Verhältnis zum Körpergewicht in [g] der Ratten nach 30 Tagen WBV; Darstellung der MW \pm /Std

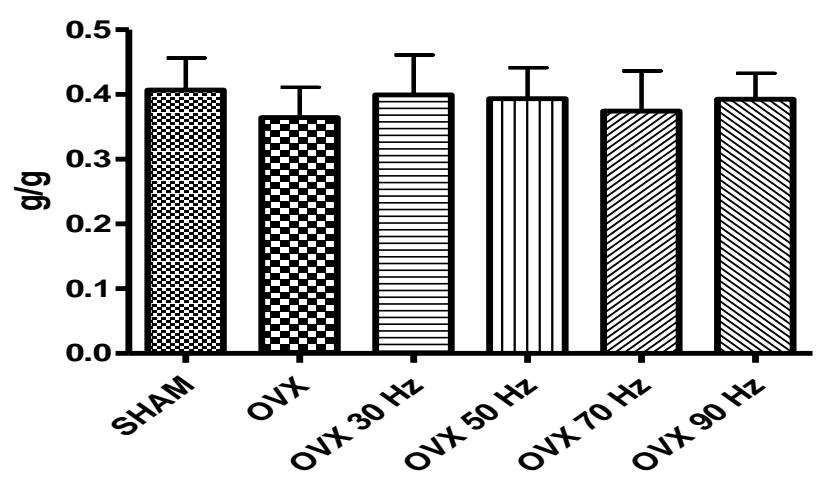

Abb. 15: Gewichte des M soleus in [g] im Verhältnis zum Körpergewicht in [g] der Ratten nach 30 Tagen WBV; Darstellung der MW $\pm /$ Std

Werden die ermittelten Gewichtswerte für die beiden Muskeln in das Verhältnis zum Körpergewicht der Tiere gesetzt, so ergeben sich zwischen den verschiedenen Gruppen für beide Muskeln keine signifikanten Unterschiede (Abbildung 14 und 15). Die gesunde Kontrollgruppe (SHAM) weist den höchsten Wert, die osteoporotische Gruppe den geringsten Wert auf. 


\subsubsection{Uterusgewichte}

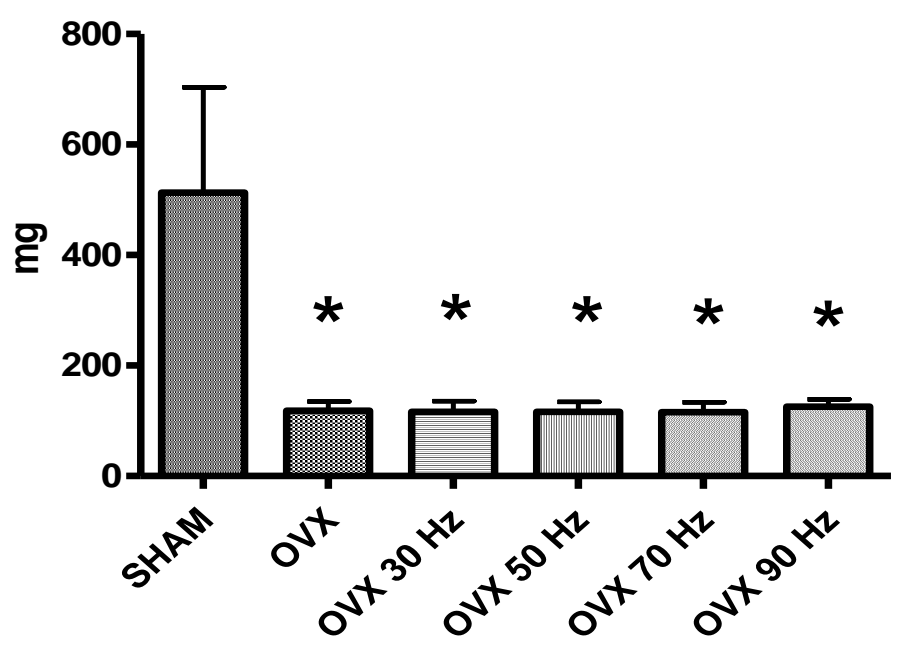

Abb. 16: Gewichte der Ratten-Uteri am Tag der Tötung in [mg] (Tag 98); der Ratten nach 30 Tagen WBV; Darstellung der MW \pm Std; * $p<0,05$ vs SHAM

Die Analyse der Uterusgewichte ergab signifikant höhere Messwerte in der SHAM-Gruppe gegenüber allen ovarektomierten Gruppen OVX, OVX $+30 \mathrm{~Hz}, \mathrm{OVX}+50 \mathrm{~Hz}, \mathrm{OVX}+70 \mathrm{~Hz}$, $\mathrm{OVX}+90 \mathrm{~Hz}$ (Abb 16). Das erniedrigte Uterusgewicht in den ovarektomierten Tieren können wir als das Ergebnis eines erfolgreich induzierten Östrogendefizits interpretieren. Zwischen den jeweils ovarektomierten Tieren gibt es keine signifikanten Unterschiede.

\subsection{Größen der Muskelfasern}

Für die Bestimmung der Muskelfasergröße wurden Flächen und Durchmesser genutzt. Histologisch war dies mit Hilfe der ATPase-Färbung nach Horak möglich. Die Größenbestimmung der Muskelzellen wurden für den M. gastrocnemius, M. longissimus dorsi und den M. soleus vorgenommen und wurde in Bezug zu ihrem Metabolismus, zum Muskelgewicht und zum Körpergewicht gesetzt. 


\subsubsection{Analysen der Querschnittsflächen der Muskeln}

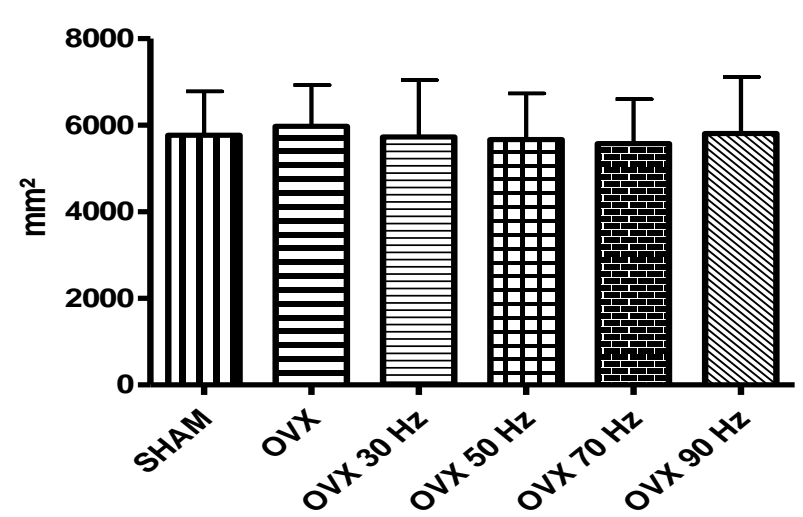

Abb. 17: Fläche der glykolytischen Muskelfasern im M. gastrocnemius in $\left[\mathrm{mm}^{2}\right]$ der Ratten nach 30 Tagen WBV; Darstellung der MW $\pm /$ Std

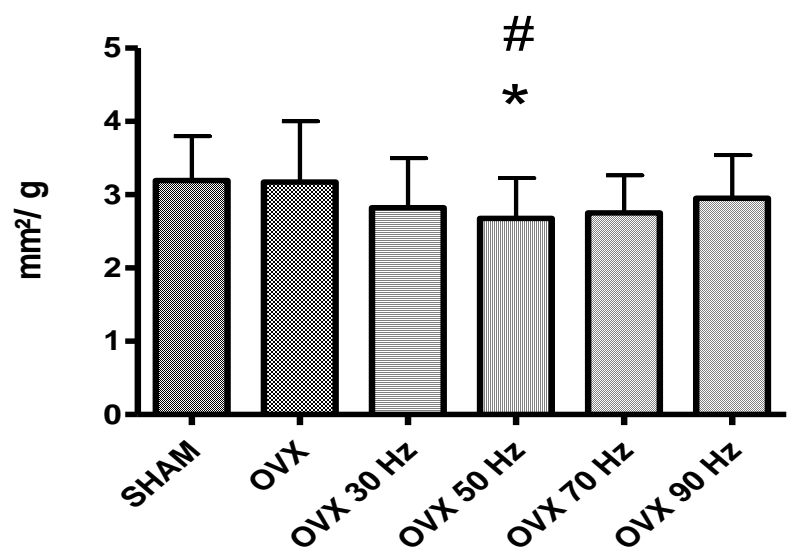

Abb. 18: Fläche der glykolytischen Muskelfasern in $\left[\mathrm{mm}^{2}\right]$ im Verhältnis zum Gewicht des M. gastrocnemius in [g] der Ratten nach 30 Tagen WBV; Darstellung der MW $\pm /$ Std ; * $\mathrm{p}<0,05$ vs SHAM; \# $\mathrm{p}<0,05$ vs OVX 


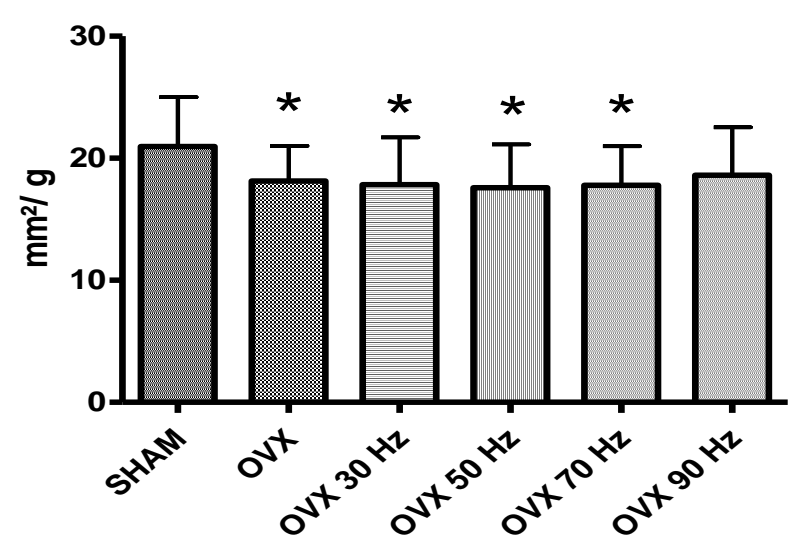

Abb. 19: Verhältnis der Fläche der glykolytischen Muskelfasern des M. gastrocmemius $\left[\mathrm{mm}^{2}\right]$ im Verhältnis zum Körpergewicht der Ratten [g]; der Ratten nach 30 Tagen WBV; Darstellung der MW $\pm /$ Std; * $\mathrm{p}<0,05$ vs SHAM

Die Größe der Muskelfaserflächen zeigt keine signifikanten Unterschiede (Abb. 17). Stellt man einen Bezug zwischen Muskelfaserflächen und Muskelgewicht her, treten signifikante Unterschiede der Gruppe OVX $+50 \mathrm{~Hz}$ im Vergleich zur osteoporotischen Kontrollgruppe (OVX) und Positiv-Kontrolle (SHAM) auf (Abb. 18).

In Bezug zum Körpergewicht können wir folgende Ergebnisse für die Größe der glykolytischen Muskelfaserfläche formulieren: Es zeigen sich Signifikanzen zu der SHAM-Gruppe durch die Gruppen, die ovarektomiert und bei 30, 50 beziehungsweise bei 70 Hertz (OVX, $\mathrm{OVX}+30 \mathrm{~Hz}, \mathrm{OVX}+50 \mathrm{~Hz}, \mathrm{OVX}+70 \mathrm{~Hz}$ ) vibriert worden sind (Abb. 19). 


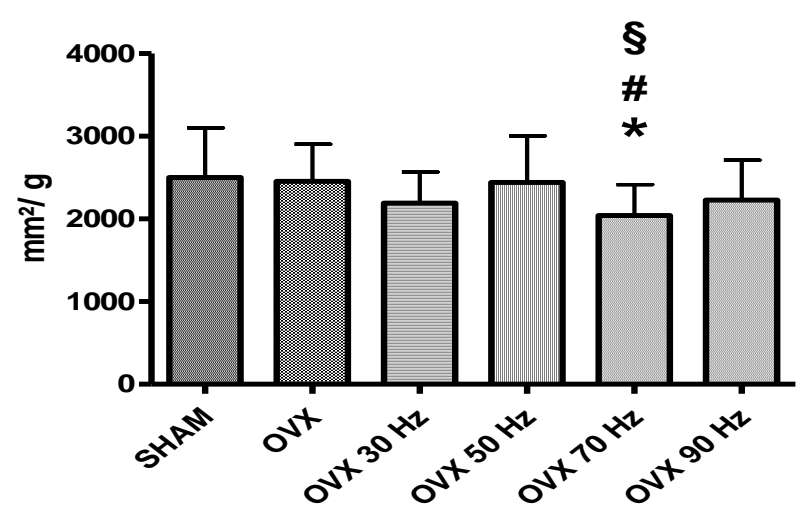

Abb. 20: Flächen der oxidativen Muskelfasern im M. gastrocnemius $\left[\mathrm{mm}^{2}\right]$ der Ratten nach 30 Tagen WBV; Darstellung der MW \pm Std; * $\mathrm{p}<0,05$ vs SHAM; $\#<0,05$ vs OVX; $\S<0,05$ vs OVX $+50 \mathrm{~Hz}$

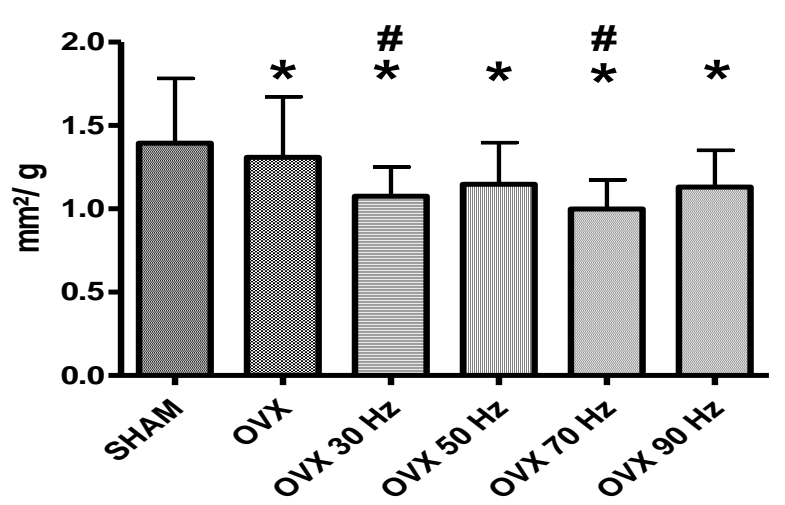

Abb. 21: Flächen der oxidativen Muskelfasern im M. gastrocnemius $\left[\mathrm{mm}^{2}\right]$ im Verhältnis zum Gewicht des M. gastrocnemius in [g] der Ratten nach 30 Tagen WBV; Darstellung der MW $\pm /$ Std; * $p<0,05$ vs SHAM; \#<0,05 vs OVX

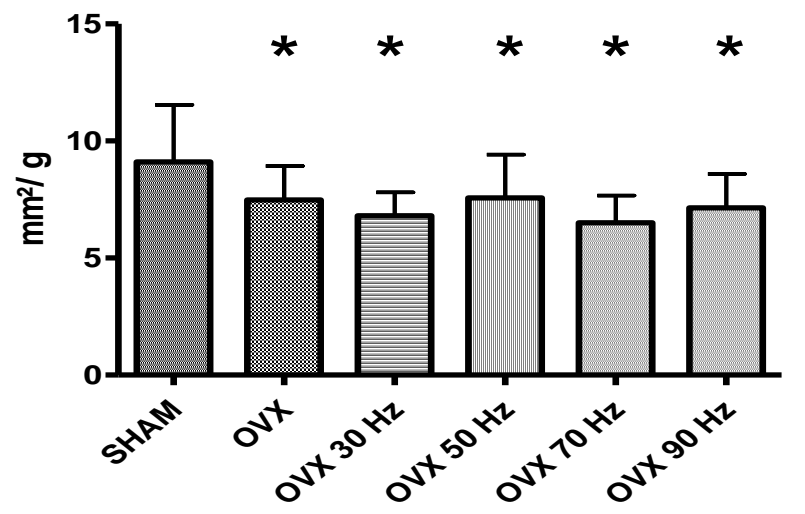

Abb. 22: Flächen der oxidativen Muskelfasern im M. gastrocnemius $\left[\mathrm{mm}^{2}\right] \mathrm{im}$ Verhältnis zum Körpergewicht in [g] der Ratten nach 30 Tagen WBV; Darstellung der MW $\pm / \mathrm{Std} ; * \mathrm{p}<0,05$ vs SHAM 
Die Flächen der oxidativen Muskelfasern im M. gastrocnemius ist bei den bei 70 Hertz vibrierten Tieren (Gruppe OVX+70 Hz) im Vergleich zur SHAM-Gruppe, der OVX-Gruppe und der OVX+50 Hz-Gruppe signifikant erniedrigt (Abb. 20). Ebenfalls bestehen signifikante Unterschiede hinsichtlich der oxidativen Muskelfaserflächen in Bezug auf das Muskelgewicht. So sind die Flächen-Gewicht-Relationen der Gruppen: OVX, OVX+30 Hz, $\mathrm{OVX}+50 \mathrm{~Hz}, \mathrm{OVX}+70 \mathrm{~Hz}, \mathrm{OVX}+90 \mathrm{~Hz}$ signifikant im Vergleich zur SHAM-Gruppe vermindert. Auch unterscheiden sich die Muskelgewichte der Gruppen OVX+30 Hz und OVX $+70 \mathrm{~Hz}$ zur Gruppe OVX signifikant (Abb. 21).

Wird der ermittelte Wert der oxidativen Muskelfaserflächen in Bezug zum Körpergewicht der Tiere gesetzt, so ist dieses Verhältnis bei der SHAM-Gruppe im Vergleich zu allen anderen Versuchsgruppen signifikant größer, unabhängig vom WBV-Regime (Abb. 22).

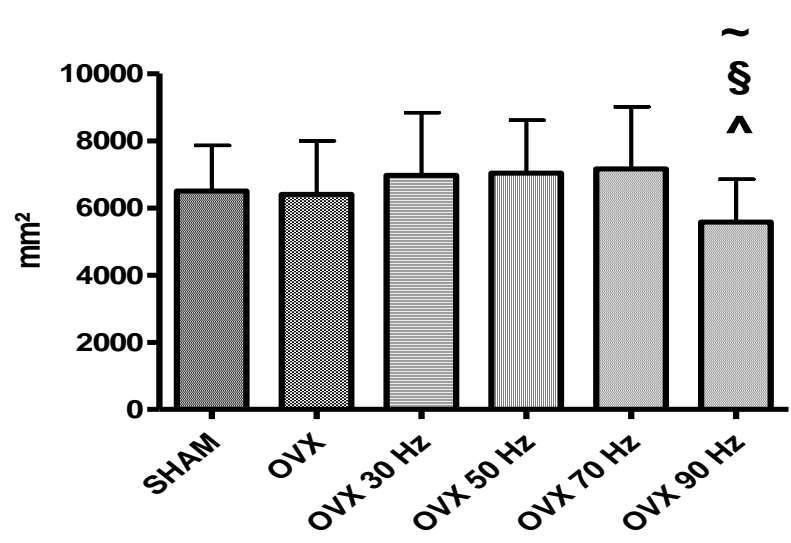

Abb. 23: Flächen der glykolytischen Muskelfasern $\left[\mathrm{mm}^{2}\right]$ im M. longissimus dorsi der Ratten nach 30 Tagen WBV; Darstellung der $\mathrm{MW} \pm / \mathrm{Std} ;{ }^{\wedge} \mathrm{p}<0,05$ vs $\mathrm{OVX}+30 \mathrm{~Hz} ; \S \mathrm{p}<0,05$ vs $\mathrm{OVX}+50 \mathrm{~Hz} ; \sim \mathrm{p}<0,05$ vs $\mathrm{OVX}+70 \mathrm{~Hz}$ 


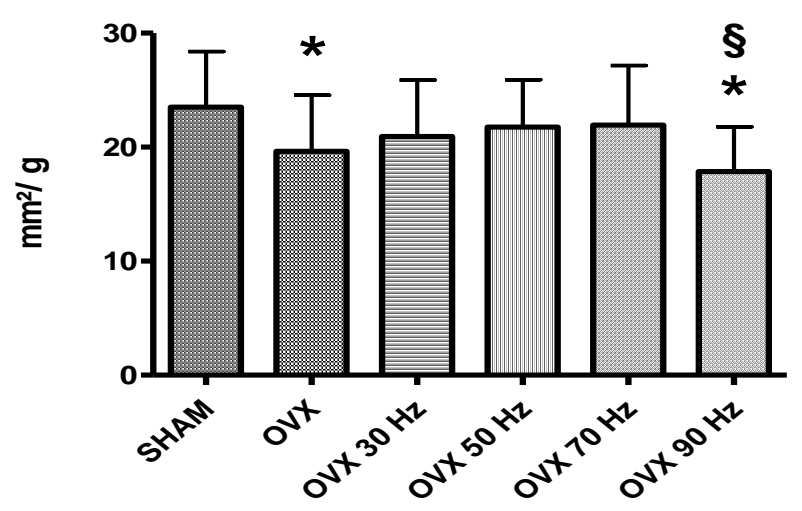

Abb. 24: Verhältnis der Flächen der glykolytischen Muskelfasern $\left[\mathrm{mm}^{2}\right]$ des M. longissimus dorsi im Verhältnis zum Körpergewicht [g] der Ratten nach 30 Tagen WBV; Darstellung der MW $\pm /$ Std; * p $<0,05$ vs SHAM; $\S \mathrm{p}<0,05$ vs $\mathrm{OVX}+50 \mathrm{~Hz} ; \sim \mathrm{p}<0,05 \mathrm{vs} \mathrm{OVX}+70 \mathrm{~Hz}$

In der Auswertung der glykolytischen Flächen im M. longissimus dorsi fallen die signifikant erhöhten Werte für die Gruppen $\mathrm{OVX}+30 \mathrm{~Hz}, \mathrm{OVX}+50 \mathrm{~Hz}$ und $\mathrm{OVX}+70 \mathrm{~Hz}$ im Vergleich zur Gruppe OVX $+90 \mathrm{~Hz}$ auf (Abb. 23). Wird die glykolytische Fläche mit dem Körpergewicht in Beziehung gesetzt, so ist der Wert der Gruppe SHAM signifikant gegenüber den Gruppen OVX und OVX $+90 \mathrm{~Hz}$ erhöht. Die Gruppen OVX $+50 \mathrm{~Hz}$ und OVX $+70 \mathrm{~Hz}$ liegen auf dem Niveau der SHAM-Gruppe und ihre Werte sind signifikant gegenüber der Gruppe OVX+90 Hz erhöht (Abb. 24).

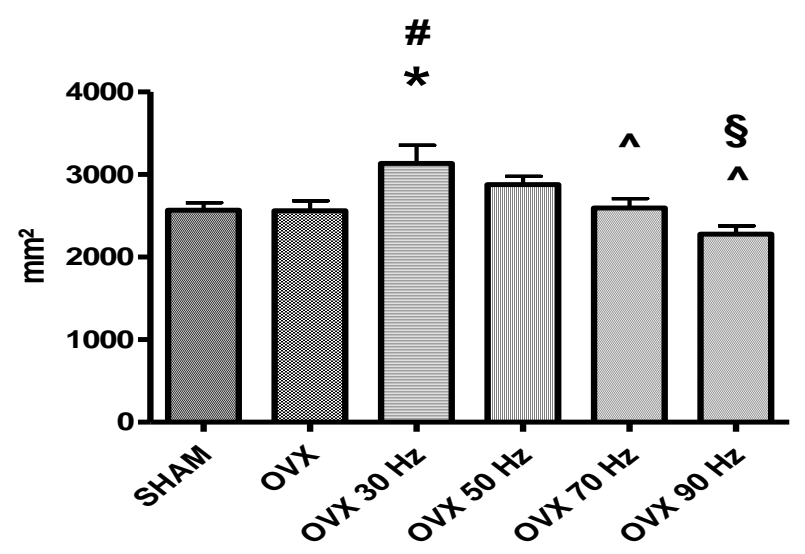

Abb. 25: Fläche der oxidativen Muskelfasern des M. longissimus dorsi $\left[\mathrm{mm}^{2}\right]$ der Ratten nach 30 Tagen WBV; Darstellung der MW $\pm /$ Std; * p $<0,05$ vs SHAM; \# $\mathrm{p}<0,05$ vs OVX; $\wedge$ p $<0,05$ vs OVX+30 Hz; $\S \mathrm{p}<0,05$ vs $\mathrm{OVX}+50 \mathrm{~Hz}$ 


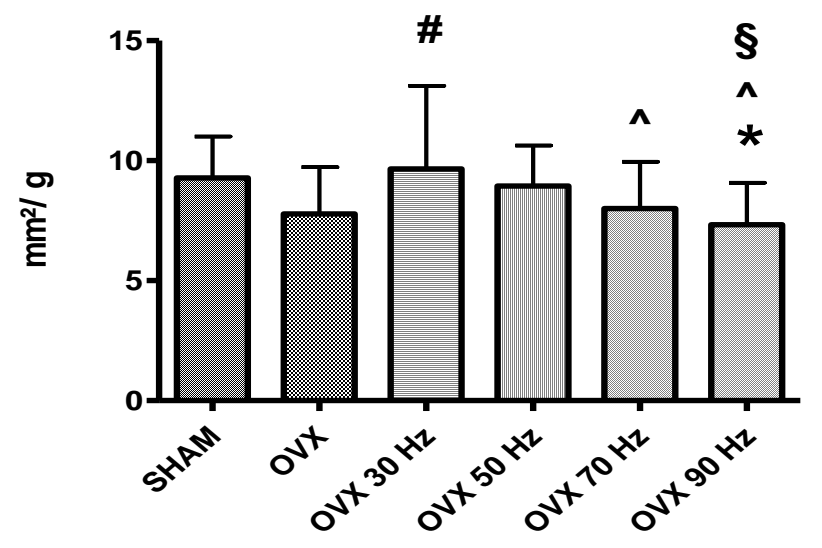

Abb. 26: Verhältnis der Fläche der oxidativen Muskelfasern $\left[\mathrm{mm}^{2}\right]$ des $\mathrm{M}$. longissimus dorsi im Verhältnis zum Körpergewicht [g] der Ratten nach 30 Tagen WBV; Darstellung der MW $\pm /$ Std; * p < 0,05 vs SHAM; \# p $<0,05$ vs OVX; ^ $\mathrm{p}<0,05$ vs OVX $+30 \mathrm{~Hz} ; \S \mathrm{p}<0,05$ vs OVX $+50 \mathrm{~Hz}$

In der Analyse der Flächen der oxidativen Muskelfasern im M. longissimus dorsi stellen sich sowohl Signifikanzen in der alleinigen Messung der Flächen als auch in der Beziehung zwischen Flächen und Körpergewicht dar. Für die Flächen, sind die der Gruppen SHAM und OVX in Bezug auf die Gruppe OVX $+30 \mathrm{~Hz}$ signifikant erniedrigt. Signifikant vergrößerte Flächen weisen die Gruppen $\mathrm{OVX}+30 \mathrm{~Hz}$ und $\mathrm{OVX}+50 \mathrm{~Hz}$ gegenüber der Gruppe OVX $+90 \mathrm{~Hz}$ auf. Zusätzlich dazu sind die Werte der Gruppe OVX+30 Hz auch gegenüber der Gruppe OVX+70 Hz signifikant erhöht (Abb. 25).

Für die Muskelflächen in Bezug auf das Körpergewicht zeigt die Analyse, dass die Werte der Gruppe SHAM zu denen der Gruppe OVX+90 Hz signifikant erhöht und die Ergebnisse der Gruppe OVX signifikant zur Gruppe OVX $+30 \mathrm{~Hz}$ erniedrigt sind. Jeweils signifikant erhöht sind die Verhältnisse der Gruppen OVX $+30 \mathrm{~Hz}$ und OVX $+50 \mathrm{~Hz} z u$ der Gruppe OVX+ $90 \mathrm{~Hz}$ sowie die der Gruppe OVX $+30 \mathrm{~Hz}$ zur Gruppe OVX+70 Hz (Abb. 26). Anzumerken ist, dass die Flächen der Muskelfasern des M. longissimus dorsi nicht in Bezug zum Gewicht des Muskels gesetzt werden können, da der Muskel bei der Präparation nicht in toto entnommen wurde, so dass in diesem Fall kein Muskeleigengewicht bestimmt werden konnte. 


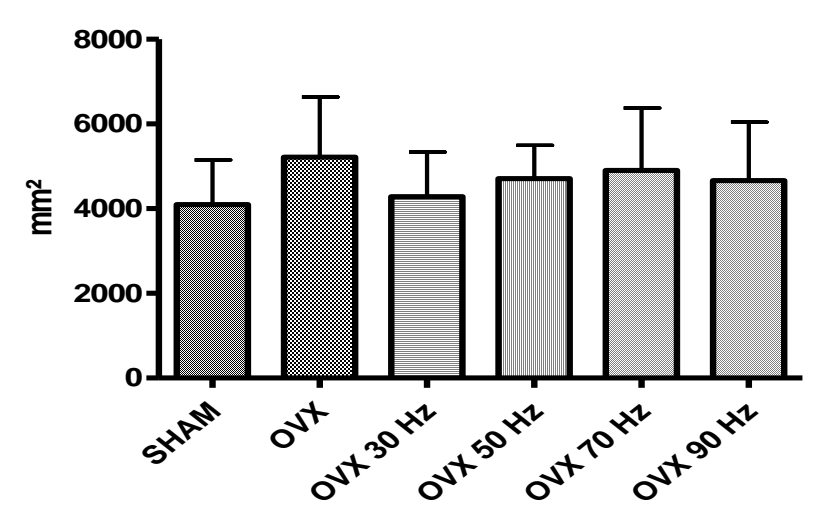

Abb. 27: Fläche der oxidativen Muskelfasern $\left[\mathrm{mm}^{2}\right]$ des M. soleus der Ratten nach 30 Tagen WBV; Darstellung der MW $\pm /$ Std

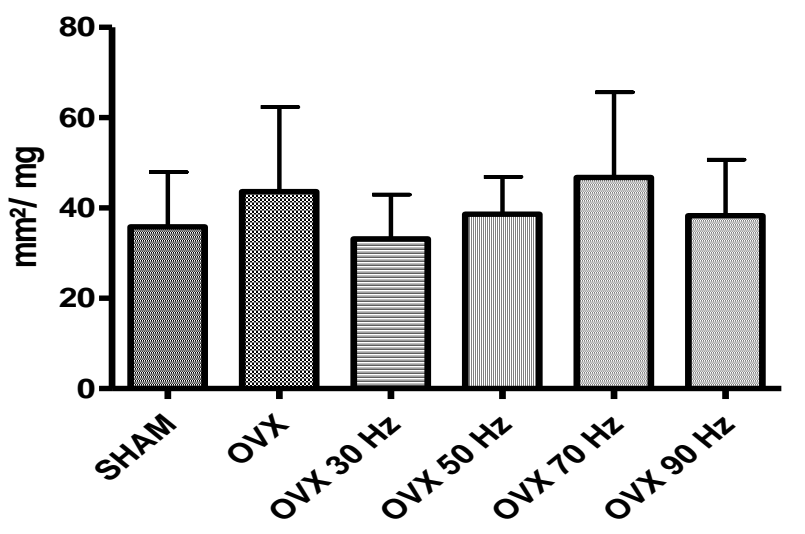

Abb. 28: Fläche der oxidativen Muskelfasergröße $\left[\mathrm{mm}^{2}\right]$ des M. soleus im Verhältnis zu seinem Gewicht [mg] der Ratten nach 30 Tagen WBV; Darstellung der $\mathrm{MW} \pm /$ Std 


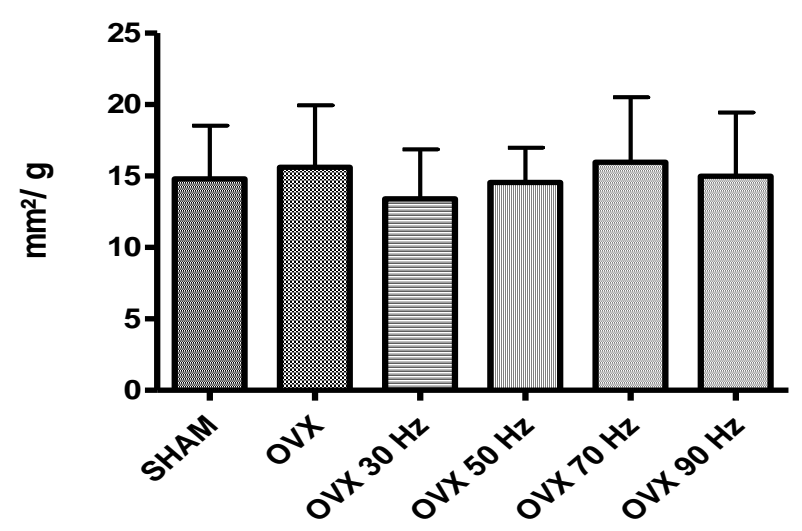

Abb. 29: Fläche der oxidativen Muskelfasergröße des M. soleus $\left[\mathrm{mm}^{2}\right] \mathrm{im}$ Verhältnis zum Körpergewicht [g] der Ratten nach 30 Tagen WBV; Darstellung der $\mathrm{MW} \pm / \mathrm{Std}$

Für die oxidativen Muskelfaserflächen im M. soleus ließen sich in der Analyse, weder unabhängig, noch in Bezug auf das Muskelgewicht oder das Körpergewicht signifikante Unterschiede feststellen (Abb. 27, 28 und 29). Tendenziell zeigen die Gruppen OVX und OVX $+70 \mathrm{~Hz}$, sowohl die größte Fläche, als auch die größten Relationen von Fläche zu Gewicht [Muskeleigengewicht und Körpergewicht].

\subsubsection{Analysen der Durchmesser}

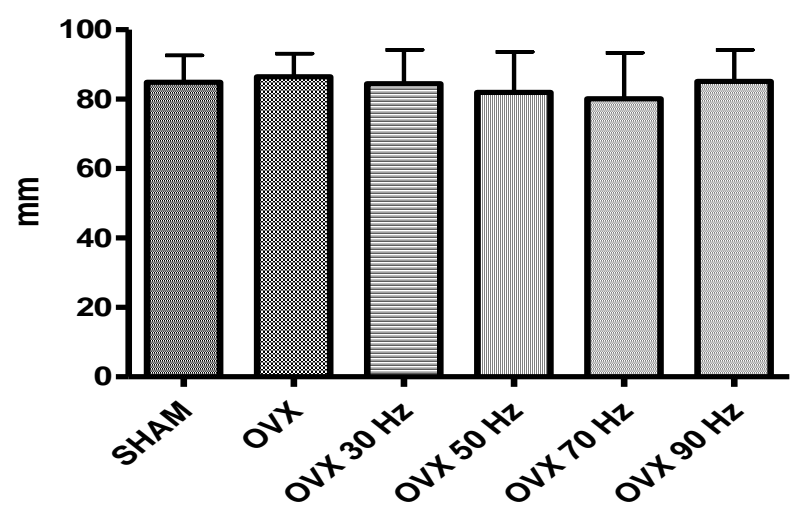

Abb. 30: Durchmesser der glykolytischen Muskelfasern [mm] des

M.gastrocnemius der Ratten nach 30 Tagen WBV; Darstellung der MW $\pm /$ Std 


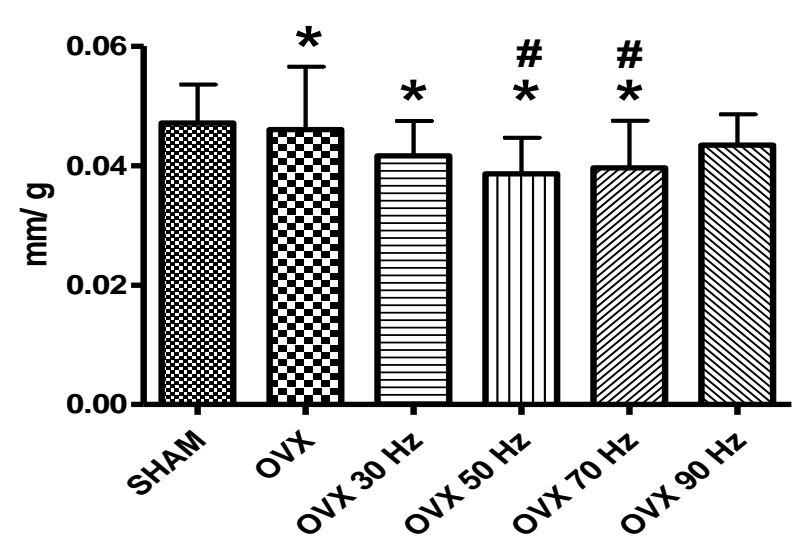

Abb. 31: Verhältnis des Durchmessers der glykolytischen Muskelfasern [mm]des M. gastrocnemius zu seinem Gewicht [g] der Ratten nach 30 Tagen WBV; Darstellung der MW $\pm /$ Std; * $\mathrm{p}<0,05$ vs SHAM; \# $\mathrm{p}<0,05$ vs OVX

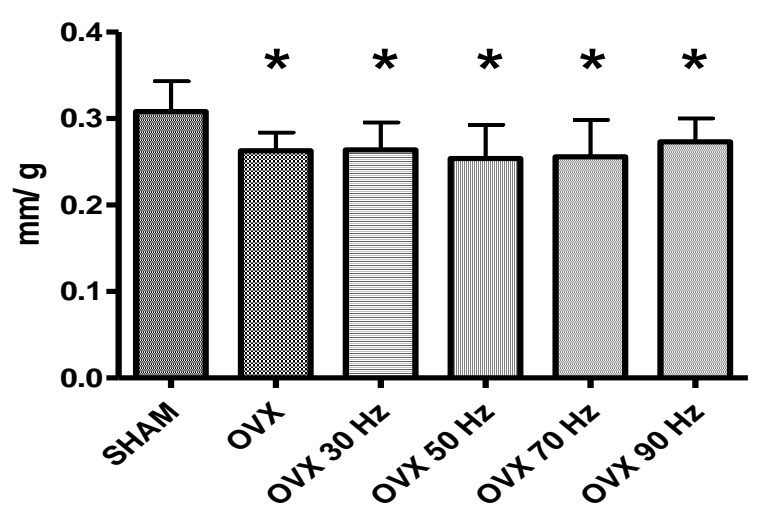

Abb. 32: Verhältnis des Durchmessers der glykolytischen Muskelfasern [mm] des M. gastrocnemius zum Körpergewicht [g] Darstellung der MW \pm Std; * p < 0,05 vs SHAM

Bei der Analyse der Durchmesser der glykolytischen Muskelfasern des M. gastrocnemius lässt sich festhalten, dass nur in Bezug auf die Verhältnisse der Faserdurchmesser zu den Gewichten der Muskeln und der Tiere signifikante Unterschiede vorliegen (Abb.31 u. 32). Es liegen keine signifikanten Unterschiede für den Muskeldurchmesser selbst vor (Abb. 30).

In Bezug auf die Verhältnisse Durchmesser pro Gramm des M. gastrocnemius sind die Werte der SHAM Gruppe signifikant erhöht gegenüber den Gruppen OVX, OVX+30 Hz, $\mathrm{OVX}+50 \mathrm{~Hz}, \mathrm{OVX}+70 \mathrm{~Hz}$ und OVX $+90 \mathrm{~Hz}$. Ebenfalls sind die Ergebnisse der OVX Gruppe signifikant $\mathrm{zu}$ den Werten der Gruppen $\mathrm{OVX}+50 \mathrm{~Hz}$ und $\mathrm{OVX}+70 \mathrm{~Hz}$, bezüglich der Durchmessergröße im Verhältnis zum Muskelgewicht erhöht (Abb. 31). Für den 
Muskelfaserdurchmesser bezogen auf das Körpergewicht gilt, dass er für die SHAM-Gruppe gegenüber allen anderen Gruppen signifikant erhöht ist (Abb. 32).

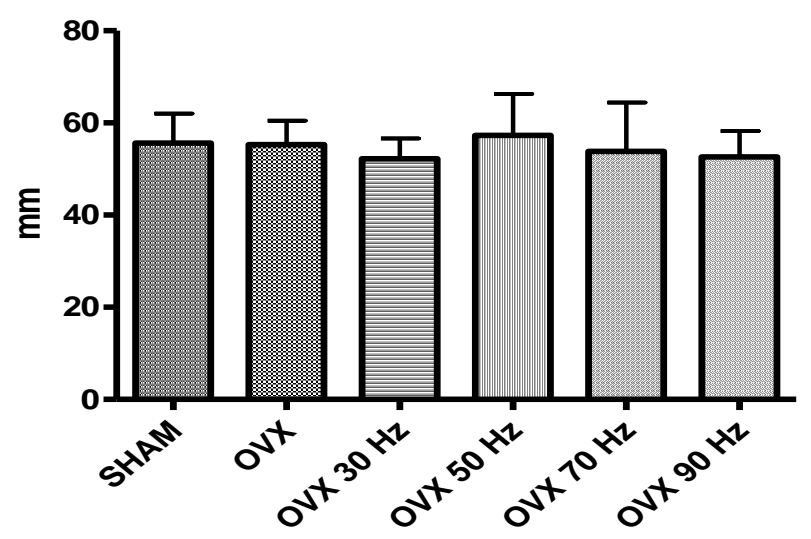

Abb. 33: Durchmesser der oxidativen Muskelfasern [mm] im M.gastrocnemius der Ratten nach 30 Tagen WBV; Darstellung der MW $\pm /$ Std

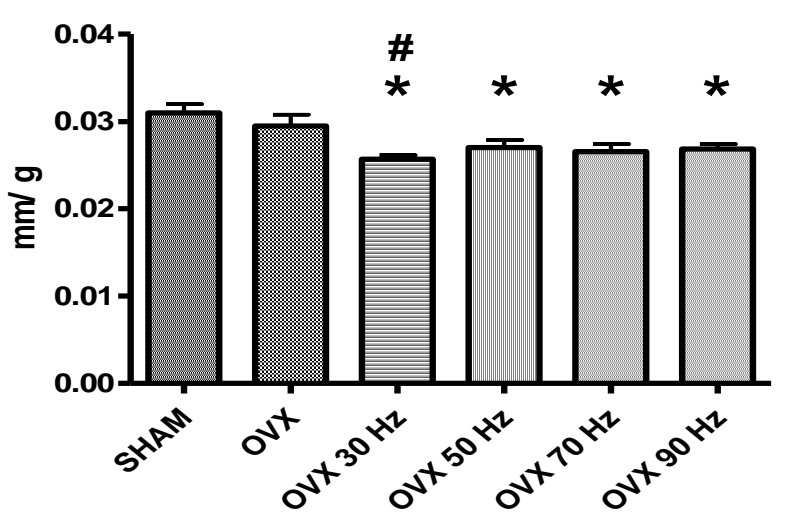

Abb. 34: Verhältnis des Durchmessers der oxidativen Muskelfasern [mm] zum Gewicht des M. gastrocnemius [g] der Ratten nach 30 Tagen WBV; Darstellung der MW $\pm / \mathrm{Std} ; * \mathrm{p}<0,05$ vs SHAM; \# $\mathrm{p}<0,05$ vs OVX 


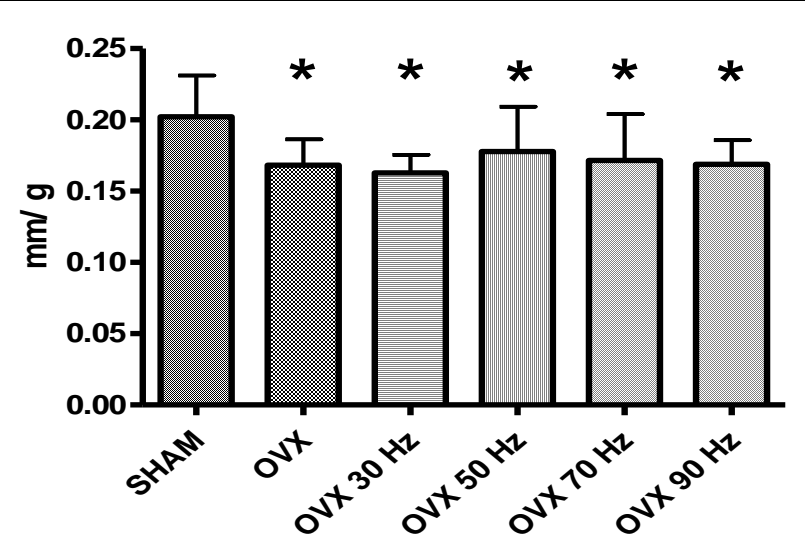

Abb. 35: Verhältnis des Durchmessers der oxidativen Muskelfasern [mm] im M. gastrocnemius zum Körpergewicht [g] der Ratten nach 30 Tagen WBV; Darstellung der MW $\pm / \mathrm{Std} ; * \mathrm{p}<0,05$ vs SHAM

In der Bestimmung des Durchmessers der einzelnen oxidativen Muskelfasern des $\mathrm{M}$. gastrocnemius lassen sich keine signifikanten Unterschiede zwischen den Gruppen ermitteln (Abb. 33). Bezieht man den Durchmesserwert auf das Muskeleigengewicht oder das Körpergewicht, so treten signifikante Unterschiede auf (Abb. 34 u. 35): Der Durchmesser bezogen auf das Gewicht des M. gastrocnemius zeigt eine signifikante Erhöhung der Werte für die SHAM-Gruppe, gegenüber den Gruppen OVX+30 Hz, OVX+50 Hz, OVX+70 Hz und OVX $+90 \mathrm{~Hz}$. Es liegt auch eine signifikante Erhöhung der Werte für die OVX Gruppe bezogen auf die OVX+30 Hz Gruppe vor (Abb. 34). In Bezug zum Körpergewicht stellen sich die Durchmesserwerte der SHAM-Gruppe als signifikant erhöht im Vergleich zu den Gruppen OVX, OVX+30 Hz, OVX+50 Hz, OVX+70 Hz und OVX+90 Hz dar (Abb. 35). 


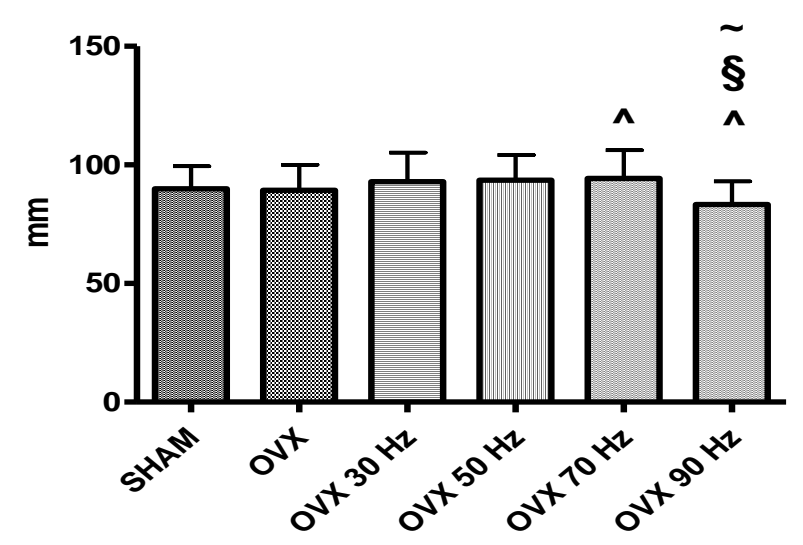

Abb. 36: Durchmesser der glykolytischen Muskelfasern [mm] des M. longissimus dorsi der Ratten nach 30 Tagen WBV; Darstellung der MW $\pm /$ Std; $\wedge \mathrm{p}<0,05$ vs OVX+30 Hz; $\S \mathrm{p}<0,05$ vs OVX $+50 \mathrm{~Hz} ; \sim \mathrm{p}<0,05$ vs $\mathrm{OVX}+70 \mathrm{~Hz}$

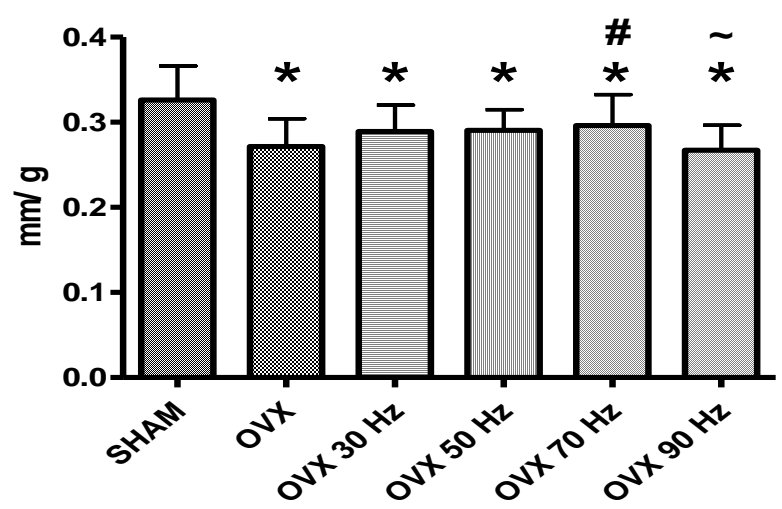

Abb. 37: Größen der glykolytischen Muskelfaserdurchmesser [mm] zum Körpergewicht [g] des M. longissimus dorsi der Ratten nach 30 Tagen WBV; Darstellung der MW $\pm / \mathrm{Std} ; * \mathrm{p}<0,05$ vs SHAM; \# $\mathrm{p}<0,05$ vs OVX; $\sim \mathrm{p}<$ 0,05 vs $\mathrm{OVX}+70 \mathrm{~Hz}$

Für die glykolytischen Muskelfaserdurchmesser des M. longissimus dorsi lassen sich ohne und mit Bezug auf das Körpergewicht signifikante Unterschiede ermitteln. Der Muskelfaserdurchmesser der Gruppe $\mathrm{OVX}+30 \mathrm{~Hz}$ ist einerseits signifikant erniedrig gegenüber der Gruppe $\mathrm{OVX}+70 \mathrm{~Hz}$, andererseits signifikant erhöht gegenüber der Gruppe OVX $+90 \mathrm{~Hz}$. Ebenfalls signifikant erhöht sind die Durchmesser der Gruppen: OVX+50 Hz und OVX+70 Hz gegenüber der Gruppe OVX+90 Hz (Abb. 36). 
Nach Referenzierung des M. longissimus dorsi Muskelfaserdurchmessers auf das Körpergewicht liefert die SHAM-Gruppe signifikant erhöhte Werte gegenüber allen anderen Gruppen. Der Wert der Gruppe OVX ist bezogen auf die Gruppe OVX $+70 \mathrm{~Hz}$ signifikant erniedrigt. Die Ergebnisse der Gruppe OVX $+70 \mathrm{~Hz}$ zeigen sich wiederum signifikant erhöht gegenüber der Gruppe OVX+90 Hz (Abb. 37).

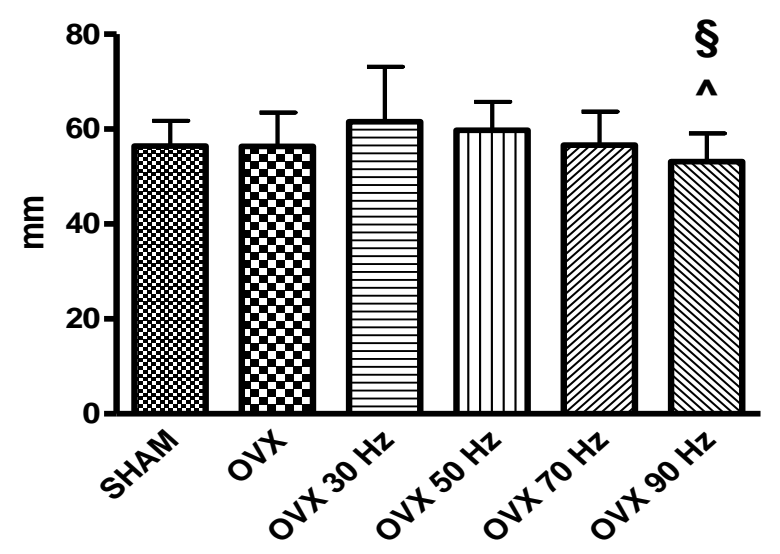

Abb. 38: Durchmesser der oxidativen Muskelfasern des M. longissimus dorsi [mm] der Ratten nach 30 Tagen WBV; Darstellung der $\mathrm{MW} \pm / \mathrm{Std} ; \wedge$ p $<0,05$ vs $\mathrm{OVX}+30 \mathrm{~Hz} ; \S \mathrm{p}<0,05 \mathrm{vs} \mathrm{OVX}+50 \mathrm{~Hz}$

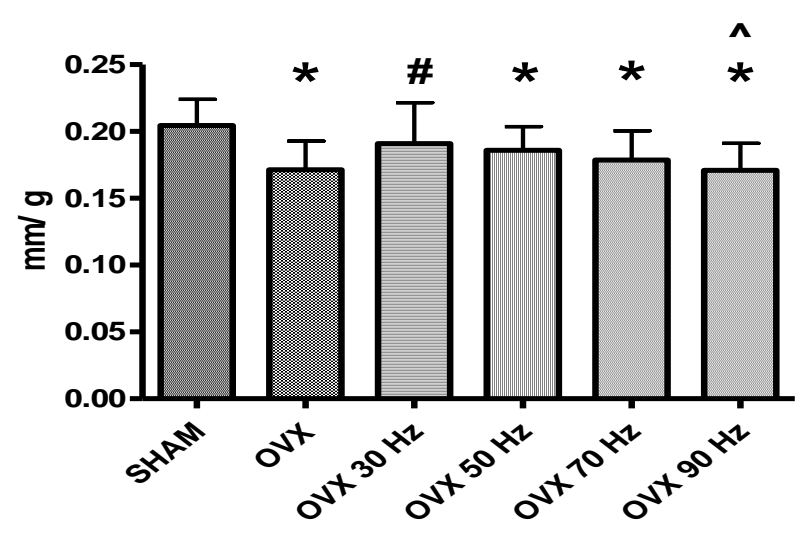

Abb. 39: Durchmesser der oxidativen Muskelfasern [mm] des M. longissimus dorsi im Verhältnis zum Körpergewicht [g] der Ratten nach 30 Tagen WBV; Darstellung der MW $\pm / \mathrm{Std} ; * \mathrm{p}<0,05$ vs SHAM; \# $\mathrm{p}<0,05$ vs OVX; ${ }^{\wedge} \mathrm{p}<$ 0,05 vs $\mathrm{OVX}+30 \mathrm{~Hz}$

Für die Durchmesser der oxidativen Muskelfasern zeigen sich mit und ohne Bezug zum Körpergewicht signifikante Unterschiede. Die Ergebnisse der Gruppen OVX+30 Hz und 
OVX $+50 \mathrm{~Hz}$ signifikant erhöht gegenüber der Gruppe OVX+90 Hz (Abb. 38). In Relation gesetzt zum Körpergewicht sind die Ergebnisse der SHAM-Gruppe signifikant gegenüber den Gruppen OVX, OVX $+50 \mathrm{~Hz}, \mathrm{OVX}+70 \mathrm{~Hz}$ und $\mathrm{OVX}+90 \mathrm{~Hz}$ erhöht. Die Werte der Gruppe OVX sind signifikant erniedrigt gegenüber der Gruppe OVX $+30 \mathrm{~Hz}$. Die Werte der Gruppe OVX $+30 \mathrm{~Hz}$ sind wiederum signifikant erhöht zur Gruppe OVX+90 Hz (Abb. 39).

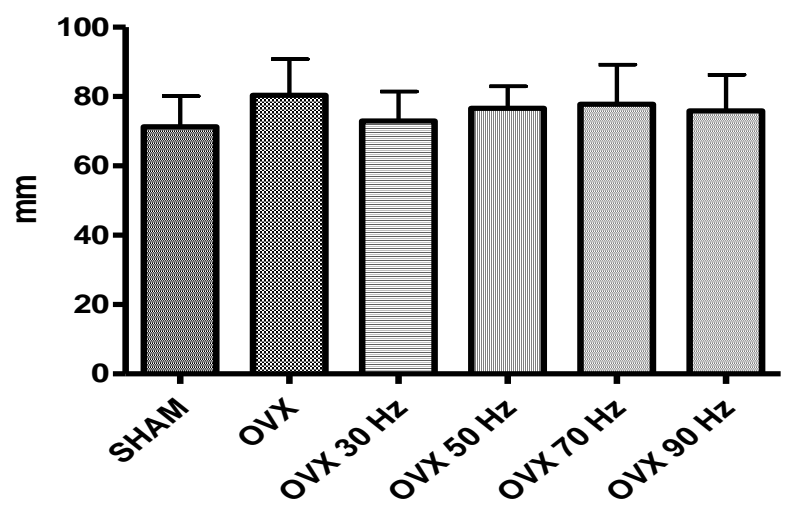

Abb. 40: Durchmesser der oxidativen Muskelfasern [mm] im M. soleus der Ratten nach 30 Tagen WBV; Darstellung der MW $\pm /$ Std

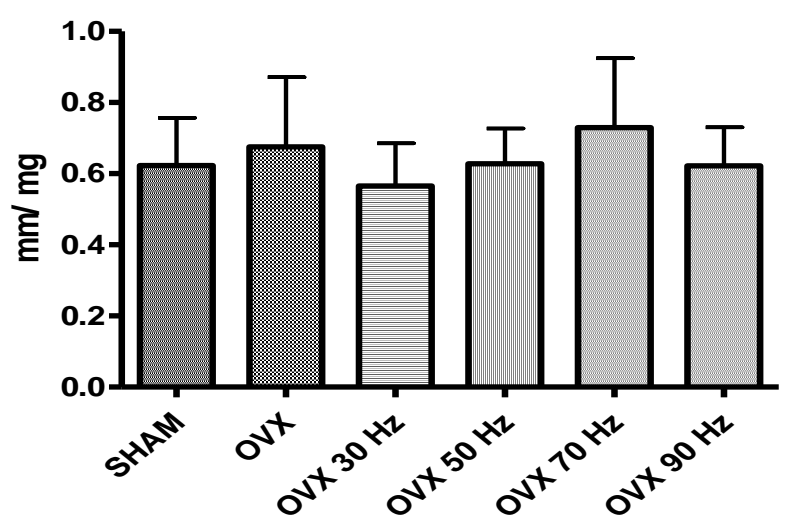

Abb. 41: Durchmesser der oxidativen Muskelfasern [mm] des M. soleus im Verhältnis $\mathrm{zu}$ seinem Gewicht [mg] der Ratten nach 30 Tagen WBV; Darstellung der MW $\pm /$ Std 


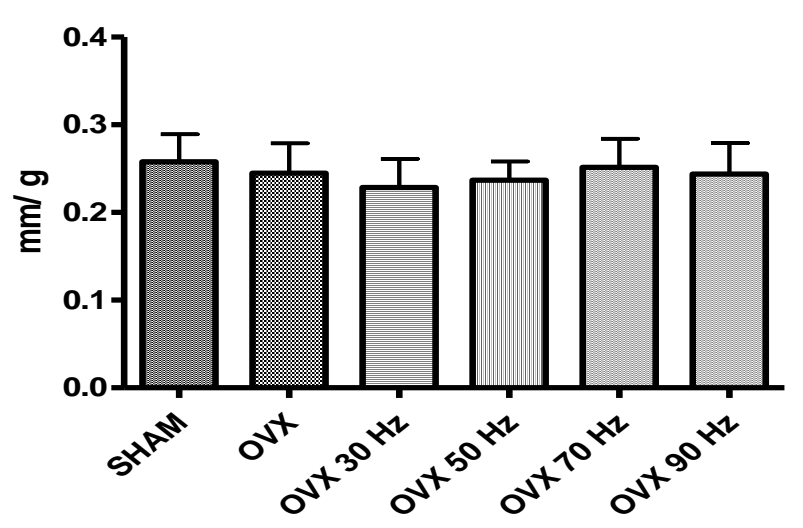

Abb. 42: Durchmesser der oxidativen Muskelfasern [mm] des M. soleus im Verhältnis zum Körpergewicht [g] der Ratten nach 30 Tagen WBV; Darstellung der $\mathrm{MW} \pm /$ Std

Bezüglich der Werte für den Durchmesser der oxidativen Muskelfasern des M. soleus lassen sich keine signifikanten Unterschiede zwischen den Gruppen ermitteln, dies gilt für die Ergebnisse ohne und mit Bezug zum Gewicht des Muskels beziehungsweise zum Körpergewicht (Abb. 40,41 u. 42).

Tabelle 7: Flächen und Durchmesser, glykolytischer und oxidativer Muskelfasern, der Mm. gastrocnemii der Ratten nach 30 Tagen WBV; Darstellung der MW $\pm /$ Std

\begin{tabular}{|c|c|c|c|c|c|c|}
\hline & SHAM & OVX & $\begin{array}{l}\mathrm{OVX}+ \\
30 \mathrm{~Hz}\end{array}$ & $\begin{array}{l}\text { OVX+ } \\
50 \mathrm{~Hz}\end{array}$ & $\begin{array}{l}\text { OVX+ } \\
70 \mathrm{~Hz}\end{array}$ & $\begin{array}{l}\mathrm{OVX}+ \\
90 \mathrm{~Hz}\end{array}$ \\
\hline $\begin{array}{l}\text { Glykoly- } \\
\text { tische } \\
\text { Fläche } \\
{\left[\mathrm{mm}^{2}\right]}\end{array}$ & $\begin{array}{c}5771 \\
\pm \\
1011\end{array}$ & $\begin{array}{c}5957 \\
\pm \\
953\end{array}$ & $\begin{array}{c}5728 \\
\pm \\
1318\end{array}$ & $\begin{array}{c}5672 \\
\pm \\
1062\end{array}$ & $\begin{array}{c}5578 \\
\pm \\
1023\end{array}$ & $\begin{array}{c}5811 \\
\pm \\
1303\end{array}$ \\
\hline $\begin{array}{l}\text { Glykoly- } \\
\text { tischer } \\
\text { Durchmes- } \\
\text { ser [mm] }\end{array}$ & $\begin{array}{c}84,89 \\
\pm \\
7,71\end{array}$ & $\begin{array}{c}86,48 \\
\pm \\
6,66\end{array}$ & $\begin{array}{c}84,47 \\
\pm \\
9,70\end{array}$ & $\begin{array}{c}81,97 \\
\pm \\
11,69\end{array}$ & $\begin{array}{c}80,09 \\
\pm \\
13,29\end{array}$ & $\begin{array}{c}85,09 \\
\pm \\
9,09\end{array}$ \\
\hline $\begin{array}{l}\text { Oxidative } \\
\text { Fläche } \\
{\left[\mathrm{mm}^{2}\right]}\end{array}$ & $\begin{array}{c}2502 \\
\pm \\
599,90\end{array}$ & $\begin{array}{c}2456 \\
\pm \\
449,80\end{array}$ & $\begin{array}{c}2191 \\
\pm \\
377,30\end{array}$ & $\begin{array}{c}2442 \\
\pm \\
561,00\end{array}$ & {$\left[\begin{array}{c}2041 \\
\pm \\
373,80 \\
{[* \# \S]}\end{array}\right.$} & $\begin{array}{c}2228 \\
\pm \\
482,80\end{array}$ \\
\hline
\end{tabular}




\begin{tabular}{|l|c|c|c|c|c|c|}
\hline Oxidativer & 55,66 & 55,3 & 52,26 & 57,28 & 53,82 & 52,63 \\
Durchmes- & \pm & \pm & \pm & \pm & \pm & \pm \\
$\operatorname{ser}[\mathrm{mm}]$ & 6,37 & 5,18 & 4,39 & 8,99 & 10,63 & 5,62 \\
\hline
\end{tabular}
1. * p $<0,05$ vs SHAM
2. $\# \mathbf{p}<0,05$ vs OVX
3. $\S \mathrm{p}<0,05$ vs OVX $+50 \mathrm{~Hz}$

Tabelle 8: Flächen und Durchmesser glykolytischer und oxidativer Muskelfasern der Mm. longissimi dorsi der Ratten nach 30 Tagen WBV; Darstellung der MW $\pm /$ Std

\begin{tabular}{|c|c|c|c|c|c|c|}
\hline & SHAM & ovX & $\begin{array}{l}\mathrm{OVX}+ \\
30 \mathrm{~Hz}\end{array}$ & $\begin{array}{l}\mathrm{OVX}+ \\
50 \mathrm{~Hz}\end{array}$ & $\begin{array}{l}\mathrm{OVX}+ \\
70 \mathrm{~Hz}\end{array}$ & $\begin{array}{l}\text { OVX+ } \\
90 \mathrm{~Hz}\end{array}$ \\
\hline $\begin{array}{l}\text { Glykoly- } \\
\text { tische } \\
\text { Fläche } \\
{\left[\mathrm{mm}^{2}\right]}\end{array}$ & $\begin{array}{c}6501 \\
\pm \\
1364\end{array}$ & $\begin{array}{c}6403 \\
\pm \\
1593\end{array}$ & $\begin{array}{c}6972 \\
\pm \\
1863\end{array}$ & $\begin{array}{c}7039 \\
\pm \\
1576\end{array}$ & $\begin{array}{c}7166 \\
\pm \\
1848\end{array}$ & $\begin{array}{c}5578 \\
\pm \\
1273 \\
{[\wedge \S \sim]}\end{array}$ \\
\hline $\begin{array}{l}\text { Glykoly- } \\
\text { tischer } \\
\text { Durchmes- } \\
\text { ser [mm] }\end{array}$ & $\begin{array}{c}89,95 \\
\pm \\
9,49\end{array}$ & $\begin{array}{c}89,25 \\
\pm \\
10,86\end{array}$ & $\begin{array}{c}92,91 \\
\pm \\
12,24\end{array}$ & $\begin{array}{c}93,58 \\
\pm \\
10,61\end{array}$ & $\begin{array}{c}94,26 \\
\pm \\
11,90 \\
{\left[{ }^{\wedge}\right]}\end{array}$ & $\begin{array}{c}83,33 \\
\pm \\
9,76 \\
{[\wedge \S \sim]}\end{array}$ \\
\hline $\begin{array}{l}\text { Oxidative } \\
\text { Fläche } \\
{\left[\mathrm{mm}^{2}\right]}\end{array}$ & $\begin{array}{c}2567 \\
\pm \\
491,40\end{array}$ & $\begin{array}{c}2562 \\
\pm \\
660,00\end{array}$ & $\begin{array}{l}3134 \\
\pm \\
1213,00 \\
{[* \#]}\end{array}$ & $\begin{array}{c}2879 \\
\pm \\
572,90\end{array}$ & $\begin{array}{l}2595 \\
\pm \\
656,80 \\
{\left[^{\wedge}\right]}\end{array}$ & $\begin{array}{c}2279 \\
\pm \\
538,00 \\
{[\wedge \S]}\end{array}$ \\
\hline $\begin{array}{l}\text { Oxidativer } \\
\text { Durchmes- } \\
\text { ser [mm] }\end{array}$ & $\begin{array}{c}56,46 \\
\pm \\
5,29\end{array}$ & $\begin{array}{c}56,36 \\
\pm \\
7,13\end{array}$ & $\begin{array}{c}61,55 \\
\pm \\
11,64\end{array}$ & $\begin{array}{c}59,80 \\
\pm \\
5,96\end{array}$ & $\begin{array}{c}56,63 \\
\pm \\
7,05\end{array}$ & $\begin{array}{c}53,19 \\
\pm \\
5,89 \\
{[\wedge \S]}\end{array}$ \\
\hline & $\begin{array}{l}1 . \\
2 . \\
3 . \\
4 . \\
5 .\end{array}$ & $\begin{array}{l}0,05 \text { vs } \mathrm{SHA} \\
0,05 \text { vs OVy } \\
0,05 \text { vs OV? } \\
0,05 \text { vs OV } \\
0,05 \text { vs OV: }\end{array}$ & & & & \\
\hline
\end{tabular}


Tabelle 9: Flächen und Durchmesser, oxidativer Muskelfasern, der Mm. solei der Ratten nach 30 Tagen WBV; Darstellung der MW \pm /Std

\begin{tabular}{|c|c|c|c|c|c|c|}
\hline & SHAM & OVX & $\begin{array}{l}\text { OVX+ } \\
30 \mathrm{~Hz}\end{array}$ & $\begin{array}{l}\text { OVX+ } \\
50 \mathrm{~Hz}\end{array}$ & $\begin{array}{l}\text { OVX+ } \\
70 \mathrm{~Hz}\end{array}$ & $\begin{array}{l}\text { OVX+ } \\
90 \mathrm{~Hz}\end{array}$ \\
\hline $\begin{array}{l}\text { Oxidative } \\
\text { Fläche } \\
{\left[\mathrm{mm}^{2}\right]}\end{array}$ & $\begin{array}{c}4097 \\
\pm \\
1052\end{array}$ & $\begin{array}{c}5219 \\
\pm \\
1419\end{array}$ & $\begin{array}{c}4284 \\
\pm \\
1051\end{array}$ & $\begin{array}{c}4711 \\
\pm \\
782,4\end{array}$ & $\begin{array}{c}4902 \\
\pm \\
1476\end{array}$ & $\begin{array}{c}4664 \\
\pm \\
1379\end{array}$ \\
\hline $\begin{array}{l}\text { Oxidativer } \\
\text { Durchmes- } \\
\text { ser [mm] }\end{array}$ & $\begin{array}{c}71,29 \\
\pm \\
8,86\end{array}$ & $\begin{array}{c}80,41 \\
\pm \\
10,41\end{array}$ & $\begin{array}{c}72,98 \\
\pm \\
8,43\end{array}$ & $\begin{array}{c}76,62 \\
\pm \\
6,31\end{array}$ & $\begin{array}{c}77,79 \\
\pm \\
11,40\end{array}$ & $\begin{array}{c}75,87 \\
\pm \\
10,41\end{array}$ \\
\hline
\end{tabular}

Tabelle 10: Glykolytische Muskelfasern des M. gastrocnemius. Flächen und Gewichte der Ratten nach 30 Tagen WBV; Darstellung der MW $\pm /$ Std

\begin{tabular}{|c|c|c|c|c|c|c|}
\hline & SHAM & OVX & $\begin{array}{l}\text { OVX+ } \\
30 \mathrm{~Hz}\end{array}$ & $\begin{array}{l}\text { OVX+ } \\
50 \mathrm{~Hz}\end{array}$ & $\begin{array}{l}\text { OVX+ } \\
70 \mathrm{~Hz}\end{array}$ & $\begin{array}{l}\text { OVX+ } \\
90 \mathrm{~Hz}\end{array}$ \\
\hline $\begin{array}{l}\text { Fläche/ } \\
\text { Muskelge- } \\
\text { wicht } \\
{\left[\mathrm{mm}^{2} / \mathrm{g}\right]}\end{array}$ & $\begin{array}{c}3,194 \\
\pm \\
0,6036\end{array}$ & $\begin{array}{c}3,174 \\
\pm \\
0,8289\end{array}$ & $\begin{array}{c}2,823 \\
\pm \\
0,6751\end{array}$ & $\begin{array}{c}2,677 \\
\pm \\
0,5502 \\
{[* \#]}\end{array}$ & $\begin{array}{c}2,754 \\
\pm \\
0,5119\end{array}$ & $\begin{array}{c}2,951 \\
\pm \\
0,5869\end{array}$ \\
\hline $\begin{array}{l}\text { Durchmes- } \\
\text { ser/ } \\
\text { Muskelge- } \\
\text { wicht } \\
{[\mathrm{mm} / \mathrm{g}]}\end{array}$ & $\begin{array}{l}0,04711 \\
\pm \\
0,006443\end{array}$ & $\begin{array}{l}0,04602 \\
\pm \\
0,01054 \\
{[*]}\end{array}$ & $\begin{array}{l}0,04164 \\
\quad \pm \\
0,005833 \\
{[*]}\end{array}$ & $\begin{array}{l}0,03861 \\
\quad \pm \\
0,006061 \\
{[* \#]}\end{array}$ & $\begin{array}{l}0,03960 \\
\quad \pm \\
0,007931 \\
{[* \#]}\end{array}$ & $\begin{array}{c}0,04343 \\
\pm \\
0,005144\end{array}$ \\
\hline $\begin{array}{l}\text { Fläche/ } \\
\text { Körperge- } \\
\text { wicht } \\
{\left[\mathrm{mm}^{2} / \mathrm{g}\right]}\end{array}$ & $\begin{array}{c}20,96 \\
\pm \\
4,062\end{array}$ & $\begin{array}{l}18,14 \\
\pm \\
2,879 \\
{[*]}\end{array}$ & $\begin{array}{l}17,84 \\
\quad \pm \\
3,864 \\
{[*]}\end{array}$ & $\begin{array}{l}17,58 \\
\pm \\
3,547 \\
{[*]}\end{array}$ & $\begin{array}{l}17,80 \\
\quad \pm \\
3,198 \\
{[*]}\end{array}$ & $\begin{array}{c}18,62 \\
\pm \\
3,909\end{array}$ \\
\hline $\begin{array}{l}\text { Durchmes- } \\
\text { ser/ } \\
\text { Körperge- } \\
\text { wicht } \\
{[\mathrm{mm} / \mathrm{g}]}\end{array}$ & $\begin{array}{l}0,3080 \\
\pm \\
0,03500\end{array}$ & $\begin{array}{l}0,2627 \\
\pm \\
0,02128 \\
{[*]}\end{array}$ & $\begin{array}{l}0,2637 \\
\quad \pm \\
0,03167 \\
{[*]}\end{array}$ & $\begin{array}{l}0,2538 \\
\pm \\
0,03906 \\
{[*]}\end{array}$ & $\begin{array}{l}0,2559 \\
\pm \\
0,04272 \\
{[*]}\end{array}$ & $\begin{array}{l}0,2731 \\
\pm \\
0,02717 \\
{[*]}\end{array}$ \\
\hline
\end{tabular}


Tabelle 11: Oxidative Muskelfasern des M. gastrocnemius. Flächen und Gewichte der Ratten nach 30 Tagen WBV; Darstellung der MW $\pm /$ Std

\begin{tabular}{|c|c|c|c|c|c|c|}
\hline & SHAM & OVX & $\begin{array}{l}\text { OVX+ } \\
30 \mathrm{~Hz}\end{array}$ & $\begin{array}{l}\mathrm{OVX}+ \\
50 \mathrm{~Hz}\end{array}$ & $\begin{array}{l}\text { OVX+ } \\
70 \mathrm{~Hz}\end{array}$ & $\begin{array}{l}\text { OVX+ } \\
90 \mathrm{~Hz}\end{array}$ \\
\hline $\begin{array}{l}\text { Fläche/ } \\
\text { Muskelge- } \\
\text { wicht } \\
{\left[\mathrm{mm}^{2} / \mathrm{g}\right]}\end{array}$ & $\begin{array}{c}1,394 \\
\pm \\
0,389\end{array}$ & $\begin{array}{l}1,308 \\
\quad \pm \\
0,364 \\
{[*]}\end{array}$ & $\begin{array}{c}1,075 \\
\pm \\
0,176 \\
{[* \#]}\end{array}$ & $\begin{array}{l}1,147 \\
\pm \\
0,250 \\
{[*]}\end{array}$ & $\begin{array}{c}0,999 \\
\pm \\
0,176 \\
{[* \#]}\end{array}$ & $\begin{array}{l}1,131 \\
\quad \pm \\
0,220 \\
{[*]}\end{array}$ \\
\hline $\begin{array}{l}\text { Durchmes- } \\
\text { ser/ } \\
\text { Muskelge- } \\
\text { wicht } \\
{[\mathrm{mm} / \mathrm{g}]}\end{array}$ & $\begin{array}{c}0,031 \\
\pm \\
0,005\end{array}$ & $\begin{array}{c}0,029 \\
\pm \\
0,007\end{array}$ & {$\left[\begin{array}{c}0,026 \\
\pm \\
0,002 \\
{[* \#]}\end{array}\right.$} & $\begin{array}{l}0,027 \\
\pm \\
0,005 \\
{[*]}\end{array}$ & $\begin{array}{l}0,027 \\
\pm \\
0,005 \\
{[*]}\end{array}$ & $\begin{array}{l}0,027 \\
\quad \pm \\
0,003 \\
{[*]}\end{array}$ \\
\hline $\begin{array}{l}\text { Fläche/ } \\
\text { Körperge- } \\
\text { wicht } \\
{\left[\mathrm{mm}^{2} / \mathrm{g}\right]}\end{array}$ & $\begin{array}{c}9,108 \\
\pm \\
2,434\end{array}$ & $\begin{array}{l}7,475 \\
\quad \pm \\
1,450 \\
{[*]}\end{array}$ & $\begin{array}{l}6,810 \\
\pm \\
0,997 \\
{[*]}\end{array}$ & $\begin{array}{l}7,574 \\
\quad \pm \\
1,844 \\
{[*]}\end{array}$ & $\begin{array}{l}6,511 \\
\pm \\
1,160 \\
{[*]}\end{array}$ & $\begin{array}{l}7,139 \\
\pm \\
1,449 \\
{[*]}\end{array}$ \\
\hline $\begin{array}{l}\text { Durchmes- } \\
\text { ser/ } \\
\text { Körperge- } \\
\text { wicht } \\
{[\mathrm{mm} / \mathrm{g}]}\end{array}$ & $\begin{array}{c}0,202 \\
\pm \\
0,029\end{array}$ & $\begin{array}{l}0,168 \\
\pm \\
0,018 \\
{[*]}\end{array}$ & $\begin{array}{l}0,163 \\
\quad \pm \\
0,013 \\
{[*]}\end{array}$ & $\begin{array}{l}0,178 \\
\pm \\
0,032 \\
{[*]}\end{array}$ & $\begin{array}{l}0,172 \\
\pm \\
0,033 \\
{[*]}\end{array}$ & $\begin{array}{l}0,169 \\
\pm \\
0,017 \\
{[*]}\end{array}$ \\
\hline
\end{tabular}

Tabelle 12: Oxidative Muskelfasern des M. soleus. Flächen und Gewichte der Ratten nach 30 Tagen WBV; Darstellung der MW $\pm /$ Std

\begin{tabular}{|c|c|c|c|c|c|c|}
\hline & SHAM & OVX & $\begin{array}{l}\mathrm{OVX}+ \\
30 \mathrm{~Hz}\end{array}$ & $\begin{array}{l}\mathrm{OVX}+ \\
50 \mathrm{~Hz}\end{array}$ & $\begin{array}{l}\text { OVX+ } \\
70 \mathrm{~Hz}\end{array}$ & $\begin{array}{l}\text { OVX+ } \\
90 \mathrm{~Hz}\end{array}$ \\
\hline $\begin{array}{l}\text { Fläche/ } \\
\text { Muskelge- } \\
\text { wicht } \\
{\left[\mathrm{mm}^{2} / \mathrm{g}\right]}\end{array}$ & $\begin{array}{c}35847 \\
\pm \\
12110\end{array}$ & $\begin{array}{c}43619 \\
\pm \\
18767\end{array}$ & $\begin{array}{c}33157 \\
\pm \\
9837\end{array}$ & $\begin{array}{c}38614 \\
\pm \\
8266\end{array}$ & $\begin{array}{c}46741 \\
\pm \\
18874\end{array}$ & $\begin{array}{c}38326 \\
\pm \\
12395\end{array}$ \\
\hline
\end{tabular}




\begin{tabular}{|c|c|c|c|c|c|c|}
\hline $\begin{array}{l}\text { Durchmes- } \\
\text { ser/ } \\
\text { Muskelge- } \\
\text { wicht } \\
{[\mathrm{mm} / \mathrm{g}]}\end{array}$ & $\begin{array}{c}622,800 \\
\pm \\
134,500\end{array}$ & $\begin{array}{c}675,600 \\
\pm \\
195,300\end{array}$ & $\begin{array}{l}565,300 \\
\pm \\
119,900\end{array}$ & $\begin{array}{c}628,000 \\
\pm \\
99,200\end{array}$ & $\begin{array}{c}729,600 \\
\pm \\
194,700\end{array}$ & $\begin{array}{c}622,000 \\
\pm \\
108,00\end{array}$ \\
\hline $\begin{array}{l}\text { Fläche/ } \\
\text { Körperge- } \\
\text { wicht } \\
{\left[\mathrm{mm}^{2} / \mathrm{g}\right]}\end{array}$ & $\begin{array}{c}14,800 \\
\pm \\
3,724\end{array}$ & $\begin{array}{c}15,610 \\
\pm \\
4,342\end{array}$ & $\begin{array}{c}13,410 \\
\pm \\
3,453\end{array}$ & $\begin{array}{c}14,550 \\
\pm \\
2,446\end{array}$ & $\begin{array}{c}15,960 \\
\pm \\
4,551\end{array}$ & $\begin{array}{c}15,000 \\
\pm \\
4,458\end{array}$ \\
\hline $\begin{array}{l}\text { Durchmes- } \\
\text { ser/ } \\
\text { Körperge- } \\
\text { wicht } \\
{[\mathrm{mm} / \mathrm{g}]}\end{array}$ & $\begin{array}{c}0,258 \\
\pm \\
0,031\end{array}$ & $\begin{array}{c}0,245 \\
\pm \\
0,034\end{array}$ & $\begin{array}{c}0,228 \\
\pm \\
0,033\end{array}$ & $\begin{array}{c}0,237 \\
\pm \\
0,022\end{array}$ & $\begin{array}{c}0,251 \\
\pm \\
0,328\end{array}$ & $\begin{array}{c}0,244 \\
\pm \\
0,035\end{array}$ \\
\hline
\end{tabular}

Tabelle 13: Glykolytische Muskelfasern des M. longissimus dorsi der Ratten nach 30 Tagen WBV; Darstellung der MW $\pm /$ Std

\begin{tabular}{|c|c|c|c|c|c|c|}
\hline & SHAM & OVX & $\begin{array}{l}\mathrm{OVX}+ \\
30 \mathrm{~Hz}\end{array}$ & $\begin{array}{l}\mathrm{OVX}+ \\
50 \mathrm{~Hz}\end{array}$ & $\begin{array}{l}\text { OVX+ } \\
70 \mathrm{~Hz}\end{array}$ & $\begin{array}{l}\text { OVX+ } \\
90 \mathrm{~Hz}\end{array}$ \\
\hline $\begin{array}{l}\text { Fläche/ } \\
\text { Körperge- } \\
\text { wicht } \\
{\left[\mathrm{mm}^{2} / \mathrm{g}\right]}\end{array}$ & $\begin{array}{c}22,530 \\
\pm \\
4,877\end{array}$ & $\begin{array}{l}19,640 \\
\quad \pm \\
4,913 \\
{[*]}\end{array}$ & $\begin{array}{c}20,950 \\
\pm \\
4,946\end{array}$ & $\begin{array}{c}21,750 \\
\pm \\
4,169\end{array}$ & $\begin{array}{c}21,930 \\
\pm \\
5,231\end{array}$ & $\begin{array}{c}17,860 \\
\pm \\
3,914 \\
{[* \S \sim]}\end{array}$ \\
\hline $\begin{array}{l}\text { Durchmes- } \\
\text { ser/ } \\
\text { Körperge- } \\
\text { wicht } \\
{[\mathrm{mm} / \mathrm{g}]}\end{array}$ & $\begin{array}{c}0,326 \\
\pm \\
0,040\end{array}$ & $\begin{array}{l}0,272 \\
\quad \pm \\
0,033 \\
{[*]}\end{array}$ & $\begin{array}{c}0,289 \\
\pm \\
0,031 \\
{[*]}\end{array}$ & $\begin{array}{l}0,290 \\
\quad \pm \\
0,025 \\
{[*]}\end{array}$ & {$\left[\begin{array}{c}0,296 \\
\pm \\
0,036 \\
{[* \#]}\end{array}\right.$} & $\begin{array}{c}0,267 \\
\pm \\
0,029 \\
{[*]}\end{array}$ \\
\hline & $\begin{array}{l}1 . \\
2 . \\
3 . \\
4 .\end{array}$ & $\begin{array}{l}0,05 \text { vs SHA } \\
0,05 \text { vs OVy } \\
0,05 \text { vs OVy } \\
0,05 \text { vs OVy }\end{array}$ & & & & \\
\hline
\end{tabular}


Tabelle 14: Oxidative Muskelfasern des M. longissimus dorsi der Ratten nach 30 Tagen WBV; Darstellung der MW $\pm /$ Std

\begin{tabular}{|c|c|c|c|c|c|c|}
\hline & SHAM & OVX & $\begin{array}{l}\text { OVX+ } \\
30 \mathrm{~Hz}\end{array}$ & $\begin{array}{l}\text { OVX+ } \\
50 \mathrm{~Hz}\end{array}$ & $\begin{array}{l}\text { OVX+ } \\
70 \mathrm{~Hz}\end{array}$ & $\begin{array}{l}\text { OVX+ } \\
90 \mathrm{~Hz}\end{array}$ \\
\hline $\begin{array}{l}\text { Fläche/ } \\
\text { Körperge- } \\
\text { wicht } \\
{\left[\mathrm{mm}^{2} / \mathrm{g}\right]}\end{array}$ & $\begin{array}{c}9,287 \\
\pm \\
1,741\end{array}$ & $\begin{array}{c}7,783 \\
\pm \\
1,948\end{array}$ & $\begin{array}{l}9,653 \\
\quad \pm \\
3,461 \\
{[\#]}\end{array}$ & $\begin{array}{c}8,941 \\
\pm \\
1,696\end{array}$ & $\begin{array}{l}8,006 \\
\pm \\
1,945 \\
{[\wedge]}\end{array}$ & $\begin{array}{l}7,325 \\
\pm \\
1,758 \\
{[\wedge * \S]}\end{array}$ \\
\hline $\begin{array}{l}\text { Durchmes- } \\
\text { ser/ } \\
\text { Körperge- } \\
\text { wicht } \\
{[\mathrm{mm} / \mathrm{g}]}\end{array}$ & $\begin{array}{c}0,205 \\
\pm \\
0,020\end{array}$ & $\begin{array}{l}0,171 \\
\pm \\
0,021 \\
{[*]}\end{array}$ & $\begin{array}{l}0,191 \\
\quad \pm \\
0,031 \\
{[\#]}\end{array}$ & $\begin{array}{l}0,186 \\
\quad \pm \\
0,018 \\
{[*]}\end{array}$ & $\begin{array}{l}0,179 \\
\quad \pm \\
0,022 \\
{[*]}\end{array}$ & {$\left[\begin{array}{c}0,171 \\
\pm \\
0,020 \\
{[* \wedge]}\end{array}\right.$} \\
\hline & $\begin{array}{l}1 . \\
2 . \\
3 . \\
4 .\end{array}$ & $\begin{array}{l}0,05 \text { vs } S H \\
0,05 \text { vs } O \\
0,05 \text { vs } O \\
0,05 \text { vs } O\end{array}$ & & & & \\
\hline
\end{tabular}

\subsubsection{Verhältnisse der glykolytischen und oxidativen Zellen im M.}

\section{longissimus}

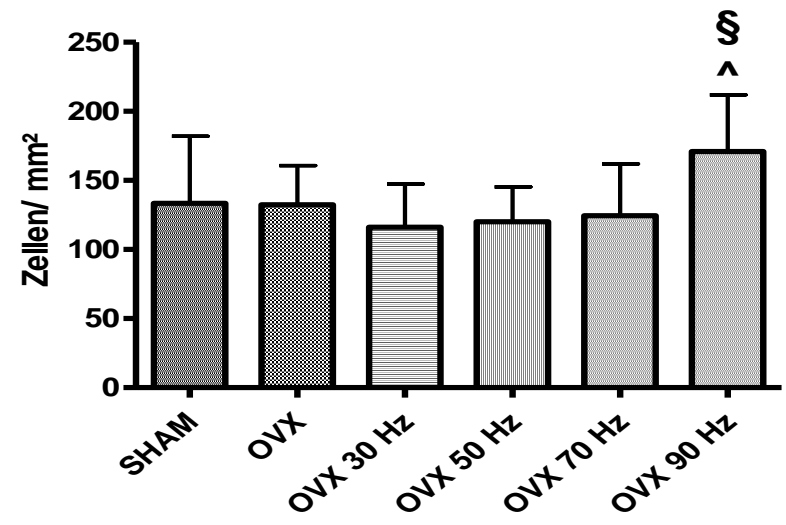

Abb. 43: Anzahl der glykolytischen Zellen pro $\mathrm{mm}^{2}$ des M. longissimus dorsi der Ratten nach 30 Tagen WBV; Darstellung der $\mathrm{MW} \pm / \mathrm{Std} ;{ }^{\wedge} \mathrm{p}<0,05$ vs $\mathrm{OVX}+30 \mathrm{~Hz} ; \S \mathrm{p}<0,05 \mathrm{vs} \mathrm{OVX}+50 \mathrm{~Hz}$ 


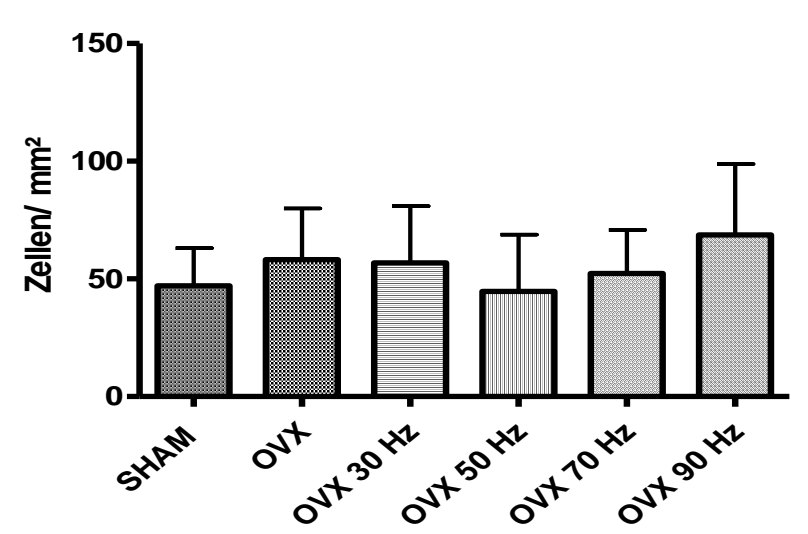

Abb. 44: Anzahl der oxidativen Zellen pro $\mathrm{mm}^{2}$ des M. longissimus dorsi; der Ratten nach 30 Tagen WBV; Darstellung der MW $\pm /$ Std

In der Analyse der Anzahl der glykolytischen Zellen pro $\mathrm{mm}^{2} \mathrm{M}$. longissimus dorsi ist die Zellzahl in den Gruppen OVX $+30 \mathrm{~Hz}$ und $\mathrm{OVX}+50 \mathrm{~Hz}$ signifikant erniedrigt gegenüber der Zellzahl der Gruppe OVX+90 Hz (Abb. 43). Bei der Anzahl der oxidativen Zellen pro mm² M. longissimus dorsi lassen sich keine signifikanten Unterschiede zwischen den verschiedenen Gruppen nachweisen, wobei auch hier die gleiche Tendenz der Gruppe $\mathrm{OVX}+90 \mathrm{~Hz}$ mit einer höheren Zellzahl im Vergleich zu den Gruppen OVX+30 Hz und OVX $+50 \mathrm{~Hz}$ besteht (Abb. 44).

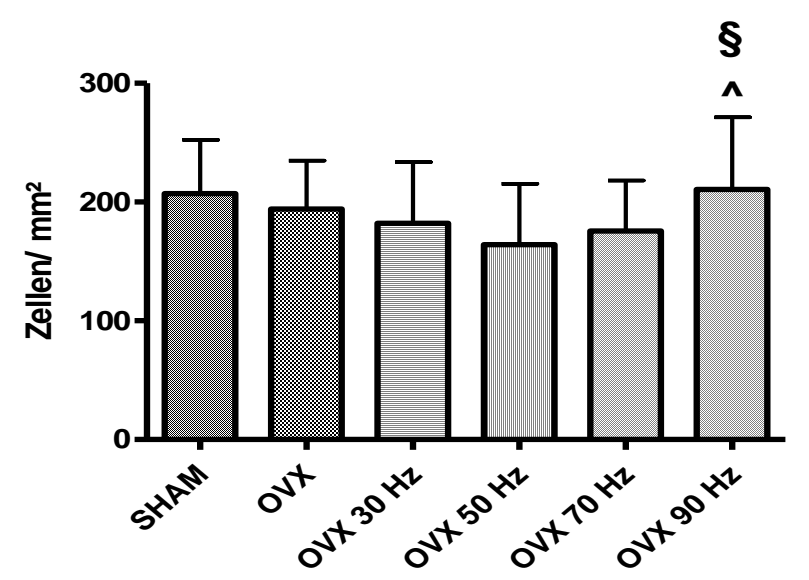

Abb. 45: Anzahl der Gesamtzellzahl pro $\mathrm{mm}^{2}$ des M. longissimus dorsi der Ratten nach 30 Tagen WBV; Darstellung der $\mathrm{MW} \pm / \mathrm{Std} ;{ }^{\wedge} \mathrm{p}<0,05$ vs $\mathrm{OVX}+30 \mathrm{~Hz} ; \S \mathrm{p}<0,05 \mathrm{vs} \mathrm{OVX}+50 \mathrm{~Hz}$ 
Bei der Analyse der Gesamtzellzahl pro $\mathrm{mm}^{2}$ M. longissimus dorsi sind die Werte der Gruppen $\mathrm{OVX}+30 \mathrm{~Hz}$ und $\mathrm{OVX}+50 \mathrm{~Hz}$ jeweils signifikant gegenüber den Werten der Gruppe OVX $+90 \mathrm{~Hz}$ erniedrigt (Abb. 45).

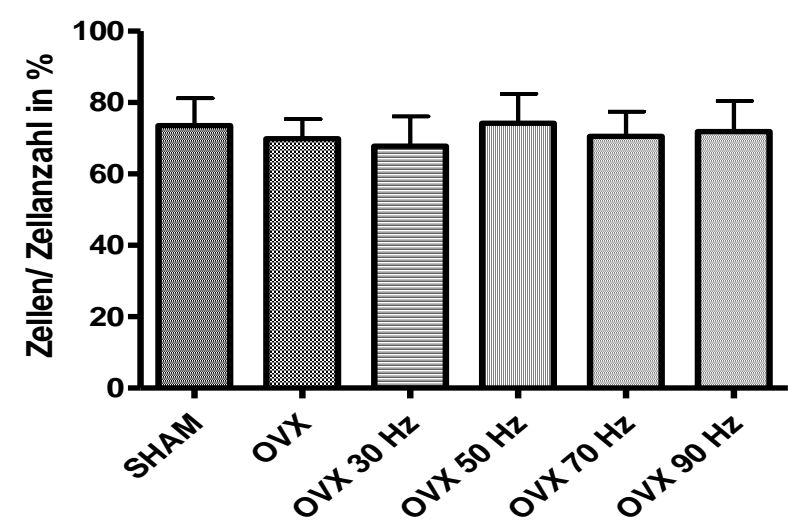

Abb. 46: Anteil der glykolytischen Zellen an der Gesamtzellzahl in [\%] pro $\mathrm{mm}^{2}$ des M. longissimus dorsi der Ratten nach 30 Tagen WBV; Darstellung der MW \pm /Std

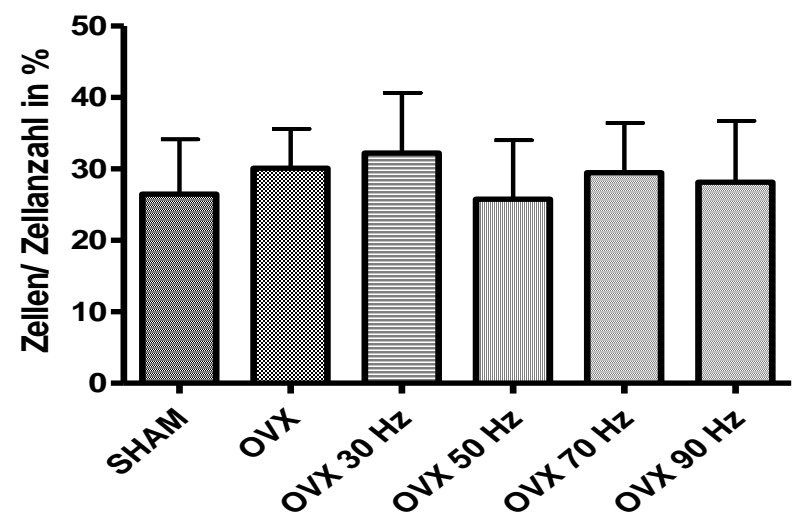

Abb. 47: Anteil der oxidativen Zellen an der Gesamtzellzahl in [\%] pro $\mathrm{mm}^{2}$ des $\mathrm{M}$. longissimus dorsi der Ratten nach 30 Tagen WBV; Darstellung der MW $\pm /$ Std

Es zeigen sich keine signifikanten Unterschiede zwischen den Gruppen sowohl beim Anteil der glykolytischen als auch, aufgrund einer hohen Standardabweichung, beim Anteil der oxidativen Zellen an der Gesamtzellzahl pro $\mathrm{mm}^{2}$ des M. longissimus dorsi (Abb. $46 \mathrm{u}$. 47). Hier besteht bei der Gruppe OVX $+30 \mathrm{~Hz}$ eine Tendenz zum erhöhten Anteil oxidativer Zellen, bei der Gruppe OVX+50 Hz eine zum erniedrigten Anteil. 
Tabelle 15: Verhältnisse der glykolytischen und oxidativen Zellen des M. longissimus dorsi pro $\mathrm{mm}^{2}$ der Ratten nach 30 Tagen WBV; Darstellung der MW $\pm /$ Std

\begin{tabular}{|c|c|c|c|c|c|c|}
\hline & SHAM & $\begin{array}{l}\text { OVX } \\
\text { Darstellung } \\
\text { der } \quad \mathrm{MW} / \\
\text { Std }\end{array}$ & $\begin{array}{l}\mathrm{OVX}+ \\
30 \mathrm{~Hz}\end{array}$ & $\begin{array}{l}\mathrm{OVX}+ \\
50 \mathrm{~Hz}\end{array}$ & $\begin{array}{l}\text { OVX+ } \\
70 \mathrm{~Hz}\end{array}$ & $\begin{array}{l}\text { OVX+ } \\
90 \mathrm{~Hz}\end{array}$ \\
\hline $\begin{array}{l}\text { Glykoly- } \\
\text { tische } \\
\text { Zellen/ } \mathrm{mm}^{2}\end{array}$ & $\begin{array}{c}133,4 \\
\pm \\
48,65\end{array}$ & $\begin{array}{c}132,4 \\
\pm \\
28,29\end{array}$ & $\begin{array}{l}116,1 \\
\pm \\
31,36\end{array}$ & $\begin{array}{c}120,2 \\
\pm \\
25,22\end{array}$ & $\begin{array}{c}124,5 \\
\pm \\
37,61\end{array}$ & $\begin{array}{c}170,9 \\
\pm \\
41,15 \\
{[\wedge \S]}\end{array}$ \\
\hline $\begin{array}{l}\text { Glykoly- } \\
\text { tische } \\
\text { Zellen/ } \\
\text { Zellzahl/ } \\
\mathrm{mm}^{2}\end{array}$ & $\begin{array}{c}73,54 \\
\pm \\
7,690\end{array}$ & $\begin{array}{c}68,89 \\
\pm \\
5,518\end{array}$ & $\begin{array}{c}67,77 \\
\pm \\
8,391\end{array}$ & $\begin{array}{l}74,21 \\
\pm \\
8,248\end{array}$ & $\begin{array}{c}70,50 \\
\pm \\
6,942\end{array}$ & $\begin{array}{c}71,86 \\
\pm \\
8,589\end{array}$ \\
\hline $\begin{array}{l}\text { Oxidative } \\
\text { Zellen/ } \mathrm{mm}^{2} \\
{[\%]}\end{array}$ & $\begin{array}{c}47,10 \\
\pm \\
15,96\end{array}$ & $\begin{array}{c}58,20 \\
\pm \\
21,76\end{array}$ & $\begin{array}{l}56,82 \\
\pm \\
24,17\end{array}$ & $\begin{array}{c}44,73 \\
\pm \\
24,13\end{array}$ & $\begin{array}{c}52.36 \\
\pm \\
18,45\end{array}$ & $\begin{array}{c}68,70 \\
\pm \\
30,06\end{array}$ \\
\hline $\begin{array}{l}\text { Oxidative } \\
\text { Zellen/ } \\
\text { Zellzahl/ } \\
\mathrm{mm}^{2}[\%]\end{array}$ & $\begin{array}{c}26,46 \\
\pm \\
7,690\end{array}$ & $\begin{array}{c}30,11 \\
\pm \\
5,518\end{array}$ & $\begin{array}{c}32,23 \\
\pm \\
8,391\end{array}$ & $\begin{array}{c}25,79 \\
\pm \\
8,248\end{array}$ & $\begin{array}{c}25,90 \\
\pm \\
6,942\end{array}$ & $\begin{array}{l}28,14 \\
\pm \\
8,589\end{array}$ \\
\hline
\end{tabular}

\subsection{Verteilung der Kapillaren in den Muskelfasern der Mm.}

\section{gastrocnemii, longissimi dorsi und solei}

Für die Bestimmung der Anzahl von Kapillaren beziehungsweise deren Verteilung in den untersuchten Muskeln wurden histologische Schnitte, die zuvor mittels Amylase-PASFärbung behandelt worden waren. Pro histologischem Schnitt eines Muskels wurden je drei Flächen a $1 \mathrm{~mm}^{2}$ ausgezählt. 


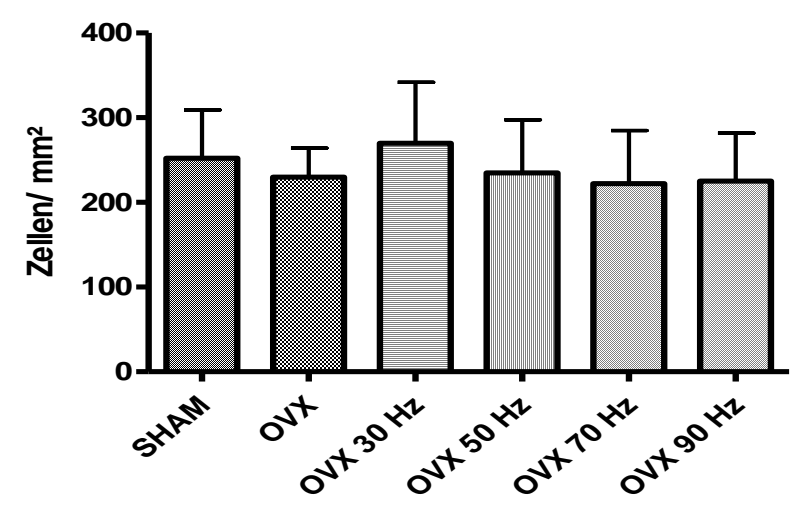

Abb. 48: Anzahl der Muskelfasern pro $\mathrm{mm}^{2}$ des M. gastrocnemius der Ratten nach 30 Tagen WBV; Darstellung der $\mathrm{MW} \pm / \mathrm{Std}$

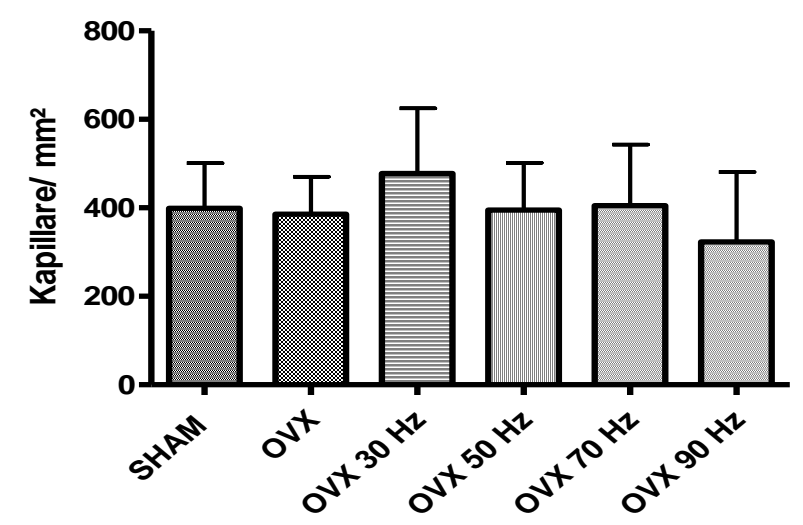

Abb. 49: Anzahl der Kapillaren pro $\mathrm{mm}^{2}$ des M. gastrocnemius der Ratten nach 30 Tagen WBV; Darstellung der MW $\pm /$ Std

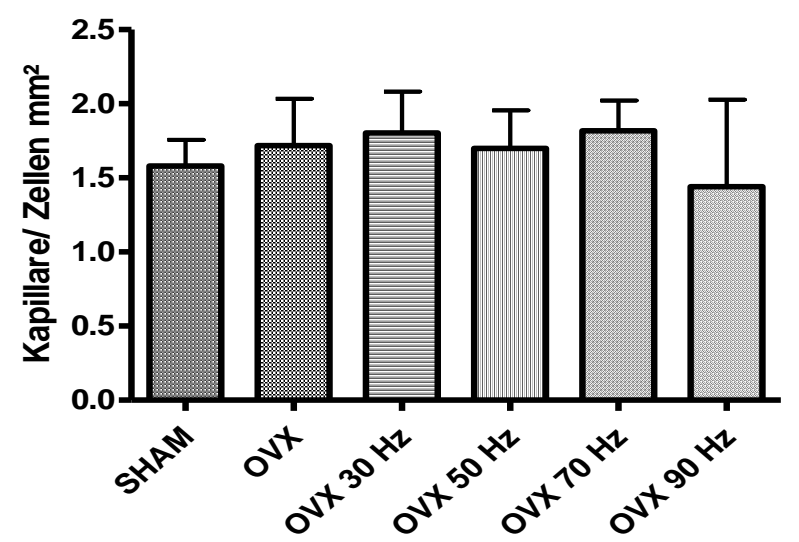

Abb. 50: Verhältnis der Kapillaren zur Gesamtzellzahl pro $\mathrm{mm}^{2}$ des $\mathrm{M}$. gastrocnemius der Ratten nach 30 Tagen WBV; Darstellung der MW $\pm /$ Std 
In der Analyse der für die Kapillaren und Muskelfasern ermittelten Werte treten keine signifikanten Unterschiede, bezogen auf die Anzahl beziehungsweise auf deren Verhältnis zueinander, auf (Abb. 48, 49 u. 50). Tendenziell zeigt die Gruppe OVX+30 Hz sowohl für die Anzahl der Muskelfasern pro $\mathrm{mm}^{2}$ als auch für die Kapillaren des M. gastrocnemius die höchsten Werte.

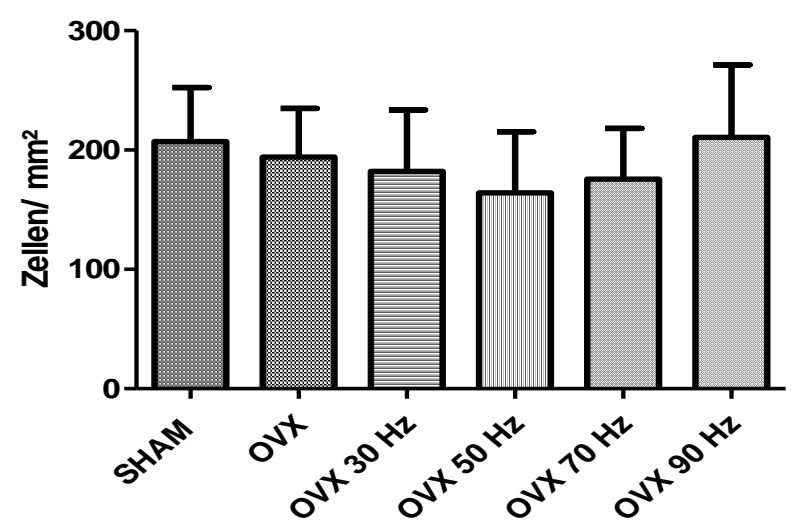

Abb. 51: Anzahl der Zellen pro $\mathrm{mm}^{2}$ des M. longissimus dorsi der Ratten nach 30 Tagen WBV; Darstellung der MW $\pm /$ Std

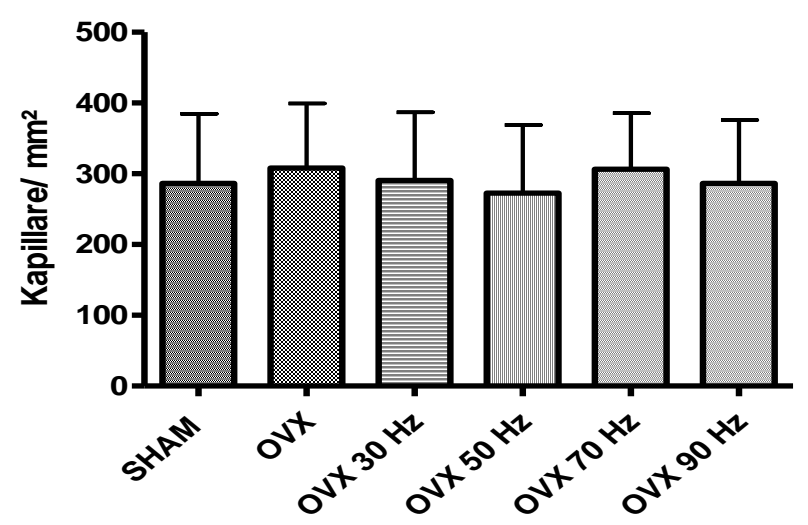

Abb. 52: Anzahl der Kapillaren pro $\mathrm{mm}^{2}$ des M. longissimus dorsi der Ratten nach 30 Tagen WBV; Darstellung der $\mathrm{MW} \pm / \mathrm{Std}$ 


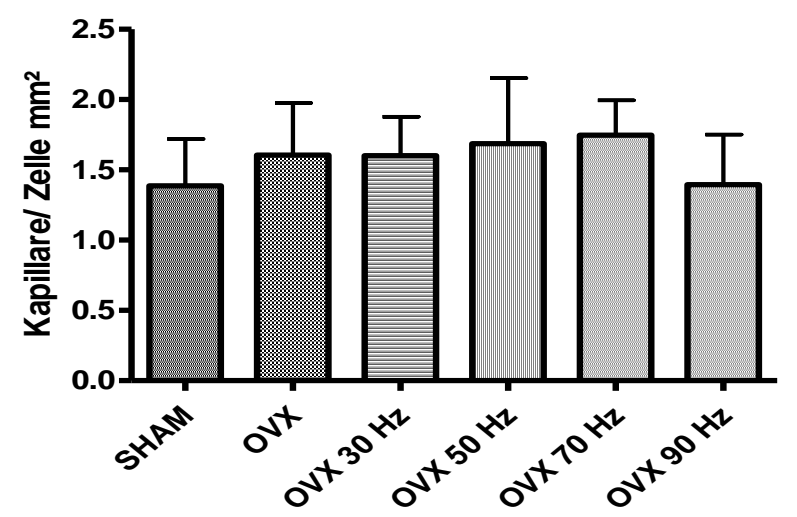

Abb. 53: Verhältnis der Kapillaren zur Gesamtzellzahl pro $\mathrm{mm}^{2}$ des $\mathrm{M}$. longissimus dorsi der Ratten nach 30 Tagen WBV; Darstellung der MW $\pm /$ Std

In der Analyse der für die Kapillaren und Muskelfasern pro $\mathrm{mm}^{2}$ des M. longissimus dorsi ermittelten Werte treten keine signifikanten Unterschiede zwischen den Gruppen, bezogen auf die Anzahl beziehungsweise auf deren Verhältnis zueinander, auf (Abb. 51, 52 u. 53). Hier zeigt die Gruppe OVX+70 Hz tendenziell die höchsten Werte.

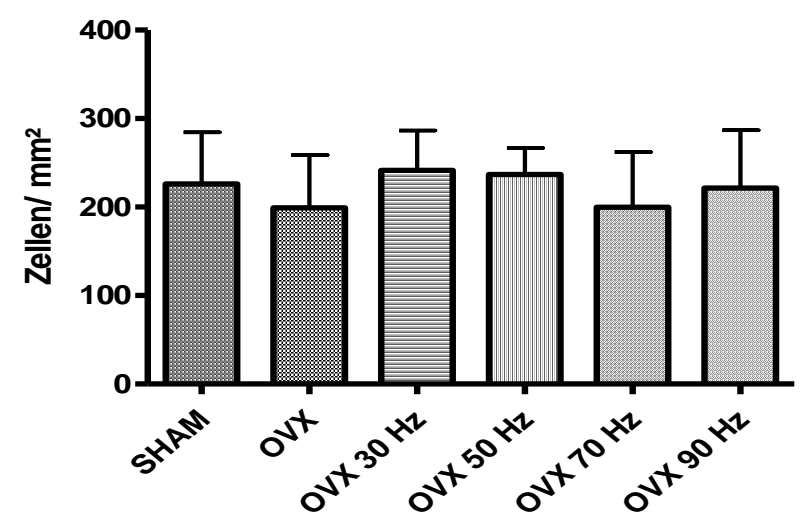

Abb. 54: Anzahl der Muskelzellen pro $\mathrm{mm}^{2}$ des M. soleus der Ratten nach 30 Tagen WBV; Darstellung der MW $\pm /$ Std 


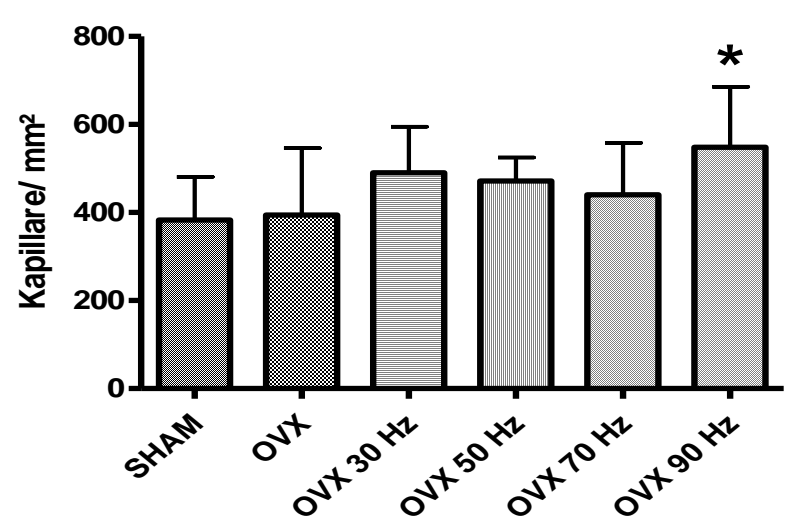

Abb. 55: Anzahl der Kapillaren pro $\mathrm{mm}^{2}$ des M. soleus der Ratten nach 30 Tagen WBV; Darstellung der MW $\pm /$ Std; $\mathrm{p}<0,05$ vs SHAM

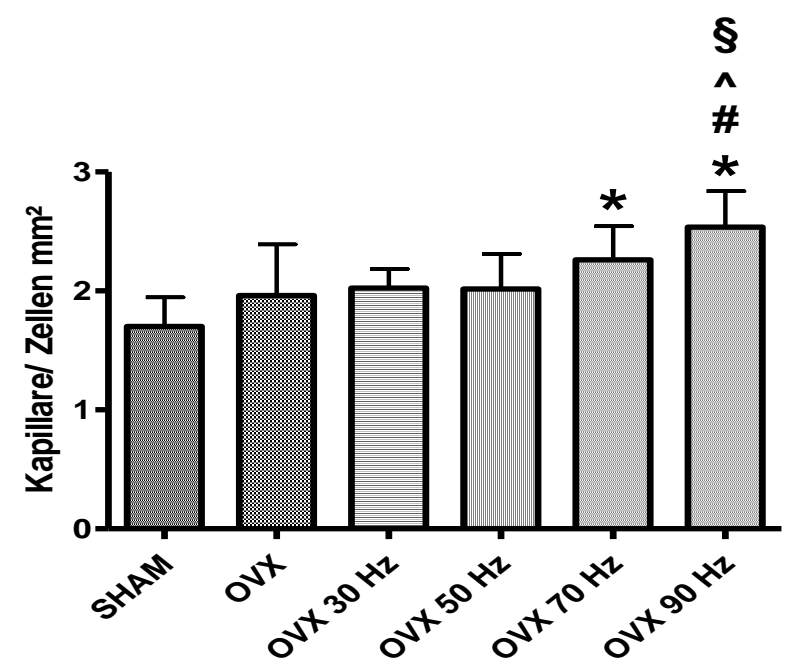

Abb. 56: Verhältnis der Kapillaren zur Gesamtzellzahl pro $\mathrm{mm}^{2}$ des M. soleus der Ratten nach 30 Tagen WBV; Darstellung der MW $\pm /$ Std; * $\mathrm{p}<0,05$ vs SHAM; \# $\mathrm{p}<0,05$ vs OVX; $\wedge$ p $<0,05$ vs OVX+30 Hz; $\S p<0,05$ vs $\mathrm{OVX}+50 \mathrm{~Hz}$

In der Analyse der für die Kapillaren und Muskelfasern pro $\mathrm{mm}^{2}$ des $\mathrm{M}$. soleus ermittelten Werte treten signifikante Unterschiede für die Anzahl der Kapillaren und für das Verhältnis von Kapillaren zu den Zellen auf (Abb. 55 u. 56). So ist die Anzahl der Kapillaren in der Gruppe OVX+90 Hz signifikant gegenüber denen der SHAM-Gruppe erhöht (Abb. 55). Ebenfalls gilt für die Gruppe $\mathrm{OVX}+90 \mathrm{~Hz}$, dass die Werte für das Verhältnis von Kapillaren $\mathrm{zu}$ den Zellen signifikant gegenüber den Gruppen SHAM, OVX, OVX $+30 \mathrm{~Hz}$ und $\mathrm{OVX}+50 \mathrm{~Hz}$ erhöht sind. Das Verhältnis der Kapillaren pro Zelle ist in der Gruppe OVX $+70 \mathrm{~Hz}$ signifikant bezogen auf die SHAM-Gruppe erhöht (Abb. 56). 
Tabelle 16: Zellen pro $\mathrm{mm}^{2}$, Kapillaren pro $\mathrm{mm}^{2}$, Kapillaren pro Zelle pro $\mathrm{mm}^{2}$ für die $\mathrm{Mm}$. gastrocnemius, longissimus dorsi und soleus der Ratten nach 30 Tagen WBV; Darstellung der $\mathrm{MW} \pm / \mathrm{Std}$

\begin{tabular}{|c|c|c|c|c|c|c|}
\hline & SHAM & OVX & $\begin{array}{l}\mathrm{OVX}+ \\
30 \mathrm{~Hz}\end{array}$ & $\begin{array}{l}\mathrm{OVX}+ \\
50 \mathrm{~Hz}\end{array}$ & $\begin{array}{l}\text { OVX+ } \\
70 \mathrm{~Hz}\end{array}$ & $\begin{array}{l}\text { OVX+ } \\
90 \mathrm{~Hz}\end{array}$ \\
\hline \multicolumn{7}{|c|}{ M. gastrocnemius } \\
\hline Zellen/ $\mathrm{mm}^{2}$ & $\begin{array}{c}252,1 \\
\pm \\
56,94\end{array}$ & $\begin{array}{c}229,8 \\
\pm \\
34,44\end{array}$ & $\begin{array}{c}269,7 \\
\pm \\
72,17\end{array}$ & $\begin{array}{c}234,8 \\
\pm \\
62,72\end{array}$ & $\begin{array}{c}222,1 \\
\pm \\
62,80\end{array}$ & $\begin{array}{c}225,3 \\
\pm \\
56,60\end{array}$ \\
\hline $\begin{array}{l}\text { Kapillaren/ } \\
\mathrm{mm}^{2}\end{array}$ & $\begin{array}{c}398,9 \\
\pm \\
102,2\end{array}$ & $\begin{array}{c}385,6 \\
\pm \\
84,44\end{array}$ & $\begin{array}{c}477,6 \\
\pm \\
147,7\end{array}$ & $\begin{array}{c}394,7 \\
\pm \\
106,8\end{array}$ & $\begin{array}{c}404,8 \\
\pm \\
138,2\end{array}$ & $\begin{array}{c}323,3 \\
\pm \\
157,5\end{array}$ \\
\hline $\begin{array}{l}\text { Kapillaren/ } \\
\text { Zelle/ } \mathrm{mm}^{2}\end{array}$ & $\begin{array}{c}1,580 \\
\pm \\
0,1765\end{array}$ & $\begin{array}{c}1,718 \\
\pm \\
0,3173\end{array}$ & $\begin{array}{c}1,804 \\
\pm \\
0,2790\end{array}$ & $\begin{array}{c}1,699 \\
\pm \\
0,2567\end{array}$ & $\begin{array}{c}1,819 \\
\pm \\
0,2024\end{array}$ & $\begin{array}{c}1,440 \\
\pm \\
0,5875\end{array}$ \\
\hline \multicolumn{7}{|c|}{ M. longissimus dorsi } \\
\hline Zellen/ $\mathrm{mm}^{2}$ & $\begin{array}{c}207,2 \\
\pm \\
45,16\end{array}$ & $\begin{array}{c}194,1 \\
\pm \\
40,67\end{array}$ & $\begin{array}{c}182,0 \\
\pm \\
51,68\end{array}$ & $\begin{array}{c}164,2 \\
\pm \\
51,26\end{array}$ & $\begin{array}{c}175,6 \\
\pm \\
42,42\end{array}$ & $\begin{array}{c}210,6 \\
\pm \\
60,65\end{array}$ \\
\hline $\begin{array}{l}\text { Kapillaren/ } \\
\mathrm{mm}^{2}\end{array}$ & $\begin{array}{c}286,3 \\
\pm \\
98,64\end{array}$ & $\begin{array}{c}308,3 \\
\pm \\
91,01\end{array}$ & $\begin{array}{c}290,5 \\
\pm \\
96,36\end{array}$ & $\begin{array}{c}272,7 \\
\pm \\
96,09\end{array}$ & $\begin{array}{c}306,4 \\
\pm \\
79,38\end{array}$ & $\begin{array}{c}286,6 \\
\pm \\
89,38\end{array}$ \\
\hline $\begin{array}{l}\text { Kapillaren/ } \\
\text { Zelle/ } \mathrm{mm}^{2}\end{array}$ & $\begin{array}{c}1,386 \\
\pm \\
0,3344\end{array}$ & $\begin{array}{c}1,605 \\
\pm \\
0,3715\end{array}$ & $\begin{array}{c}1,602 \\
\pm \\
0,2766\end{array}$ & $\begin{array}{c}1,687 \\
\pm \\
0,4667\end{array}$ & $\begin{array}{c}1,748 \\
\pm \\
0,2477\end{array}$ & $\begin{array}{c}1,395 \\
\pm \\
0,3556\end{array}$ \\
\hline \multicolumn{7}{|l|}{ M. soleus } \\
\hline Zellen/ $\mathrm{mm}^{2}$ & $\begin{array}{c}226,3 \\
\pm \\
58,03\end{array}$ & $\begin{array}{c}199,0 \\
\pm \\
59,70\end{array}$ & $\begin{array}{c}241,5 \\
\pm \\
45,07\end{array}$ & $\begin{array}{c}236,9 \\
\pm \\
29,95\end{array}$ & $\begin{array}{c}199,7 \\
\pm \\
62,61\end{array}$ & $\begin{array}{c}221,6 \\
\pm \\
65,26\end{array}$ \\
\hline $\begin{array}{l}\text { Kapillaren/ } \\
\mathrm{mm}^{2}\end{array}$ & $\begin{array}{c}382,8 \\
\pm \\
97,89\end{array}$ & $\begin{array}{c}394,1 \\
\pm \\
152,5\end{array}$ & $\begin{array}{c}490,5 \\
\pm \\
104,6\end{array}$ & $\begin{array}{c}471,9 \\
\pm \\
53,41\end{array}$ & $\begin{array}{c}440,6 \\
\pm \\
117,7\end{array}$ & $\begin{array}{l}548,4 \\
\pm \\
137,0[*]\end{array}$ \\
\hline
\end{tabular}




\begin{tabular}{|c|c|c|c|c|c|l|}
\hline Kapillaren/ & 1,702 & 1,961 & 2,024 & 2,016 & 2,260 & 2,536 \\
Zelle/ mm & \pm & \pm & \pm & \pm & \pm & \pm \\
& 0,2430 & 0,4315 & 0,1596 & 0,2964 & $0,2843\left[{ }^{*}\right]$ & 0,3028 \\
& & & & & {$[* \# \wedge \S$} \\
\hline
\end{tabular}

2. \# p $<0,05$ vs OVX

3. $\wedge^{\mathrm{p}}<0,05$ vs $\mathrm{OVX}+30 \mathrm{~Hz}$

4. $\S p<0,05$ vs OVX $+50 \mathrm{~Hz}$

\subsection{Aktivität der Enzyme in den Muskelnproben}

Bei der Bestimmung der Muskelenzyme wurden die für die Stoffwechselaktivität aussagekräftigsten wie die Laktatdehydrogenase (LDH), die Citrat-Synthase (CS) und der Komplex I (K1) analysiert. Die Laktatdehydrogenase ist das wesentliche Enzym des glykolytischen Stoffwechsels, die Citrat-Synthase repräsentiert den Citratzyklus und der Komplex I ist Teil der Atmungskette.

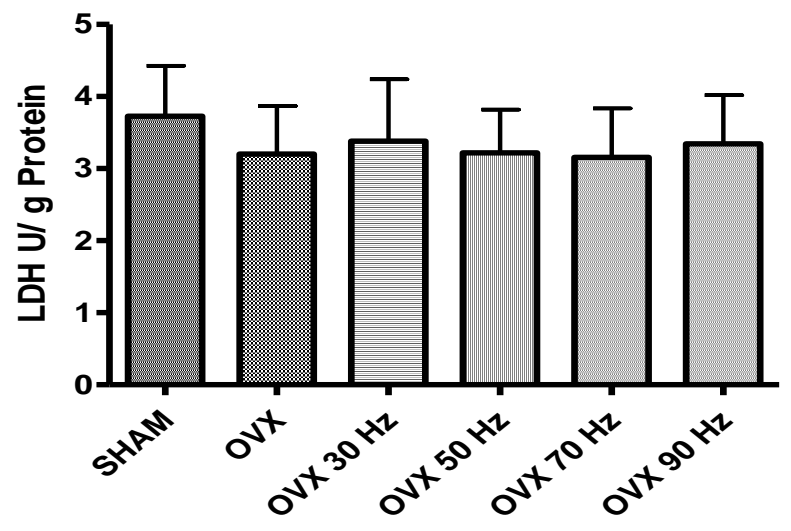

Abb. 57: Aktivität der Lakatatdehydrogenase im M. gastrocnemius

[U/g] der Ratten nach 30 Tagen WBV; Darstellung der MW $\pm /$ Std 


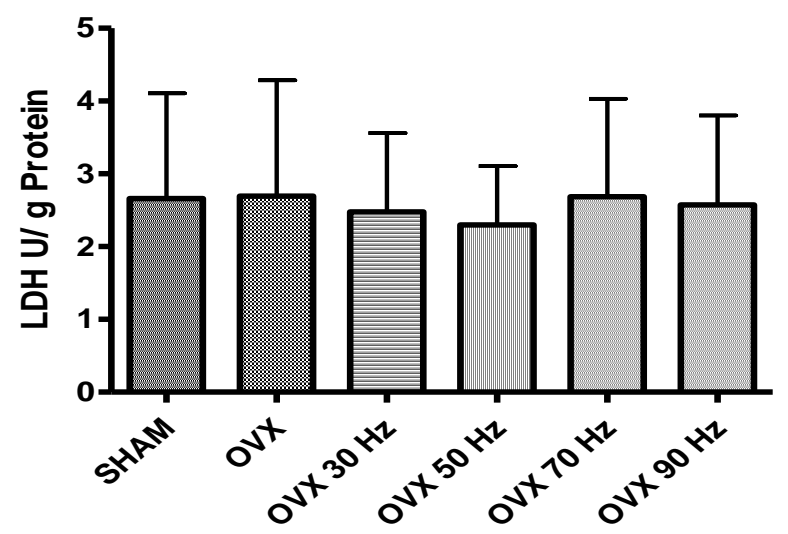

Abb. 58: Aktivität der Laktatdehydrogenase im M. longissimus dorsi [U/g] der Ratten nach 30 Tagen WBV; Darstellung der MW $\pm /$ Std

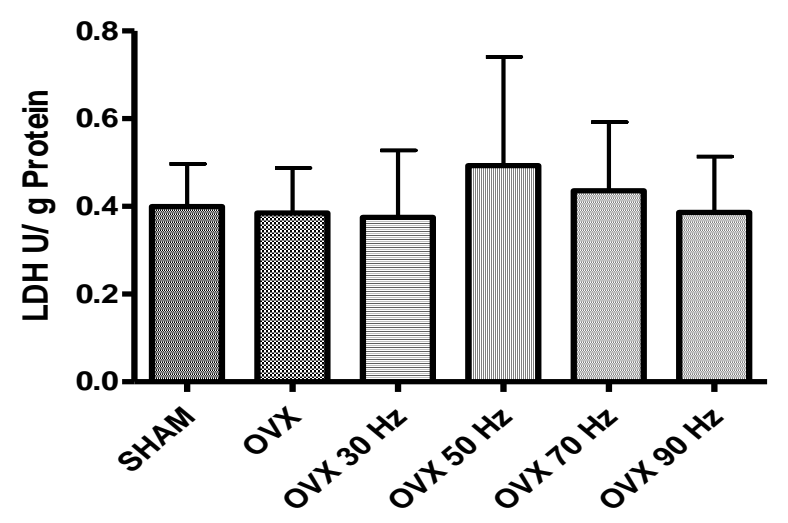

Abb. 59: Aktivität der Laktatdehydrogenase im M. soleus [U/g] der Ratten nach 30 Tagen WBV; Darstellung der MW $\pm /$ Std

\subsubsection{Ergebnisse für die Laktatdehydrogenase}

In der Analyse der Laktatdehydrogenase treten weder zwischen den verschiedenen Muskeln noch unter den verschiedenen Gruppen signifikante Unterschiede auf. Die Werte aller Gruppen weisen hohe Standardabweichungen auf (Abb. 58, 59 u. 60). 


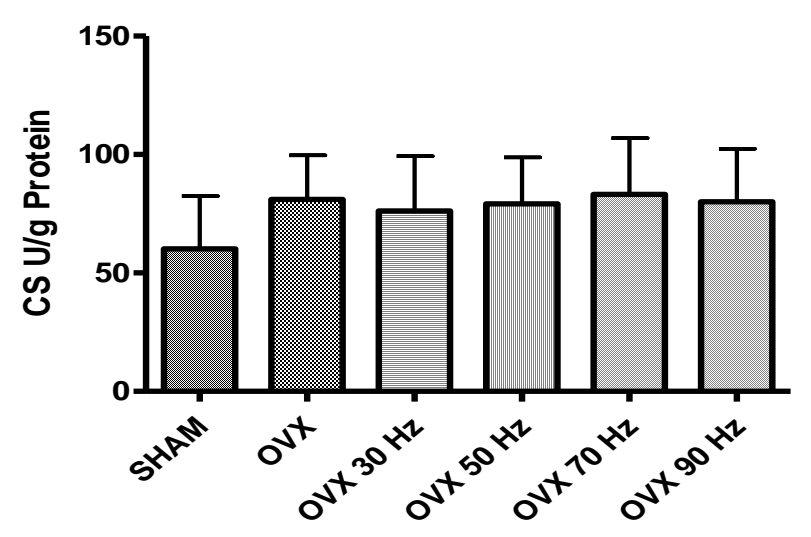

Abb. 60: Aktivität der Citrat-Synthase im M. gastrocnemius

[U/g] der Ratten nach 30 Tagen WBV; Darstellung der MW $\pm /$ Std

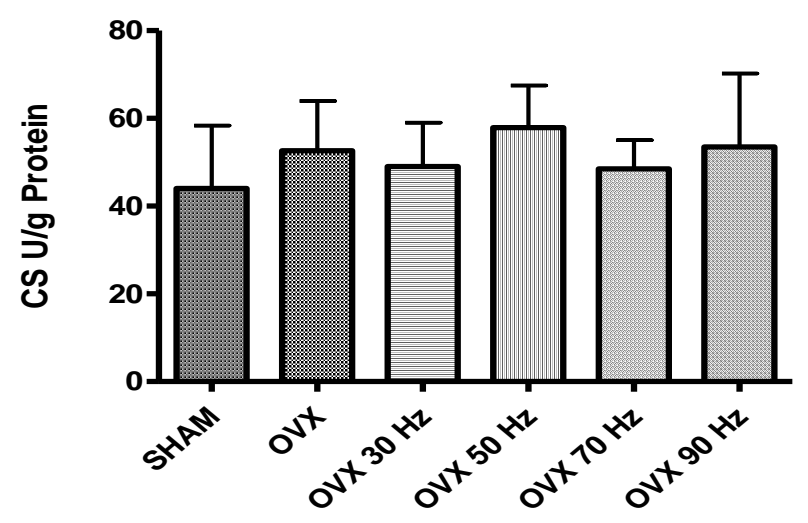

Abb. 61: Aktivität der Citrat-Synthase im M. longissimus dorsi [U/g] der Ratten nach 30 Tagen WBV; Darstellung der MW $\pm /$ Std

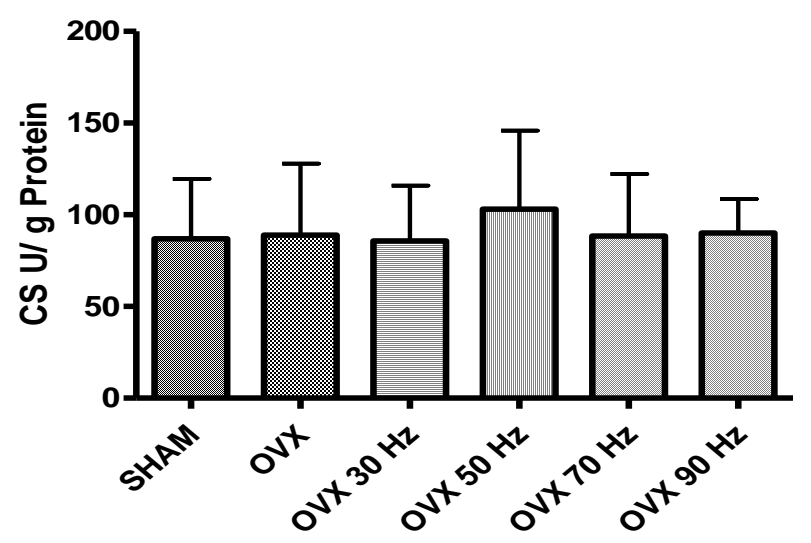

Abb. 62: Aktivität der Citrat-Synthase im M. soleus [U/g] der Ratten nach 30 Tagen WBV; Darstellung der MW $\pm /$ Std 


\subsubsection{Ergebnisse für das Enzym Citrat-Synthase}

In der Analyse der Citrat-Synthase treten weder zwischen den verschiedenen Muskeln noch unter den verschiedenen Gruppen signifikante Unterschiede auf. Bemerkenswert ist, dass die gesunde Kontrollgruppe (SHAM) für die Laktatdehydrogenase und die Citrat-Synthase die tendenziell niedrigsten Werte zeigt. Auch diese Untersuchungen zeigen eine hohe Standardabweichung (Abb. 60, 61 u. 62).

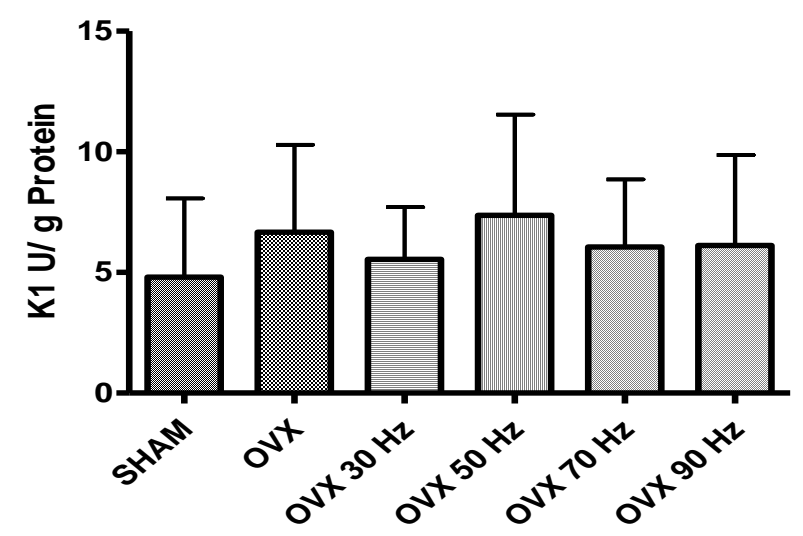

Abb. 63: Aktivität des Komplex I im M. gastrocnemius [U/g] der Ratten nach 30 Tagen WBV; Darstellung der MW $\pm /$ Std

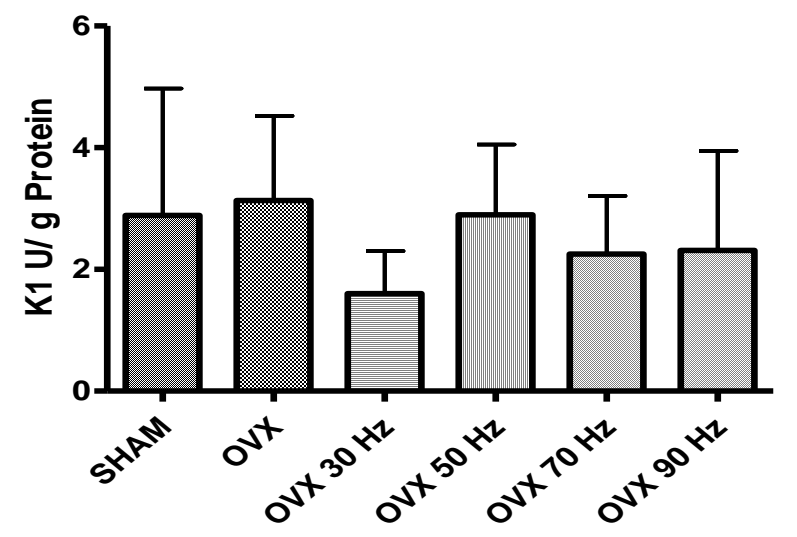

Abb. 64: Aktivität des Komplex I im M. longissimus dorsi [U/g] der Ratten nach 30 Tagen WBV; Darstellung der $\mathrm{MW} \pm /$ Std 


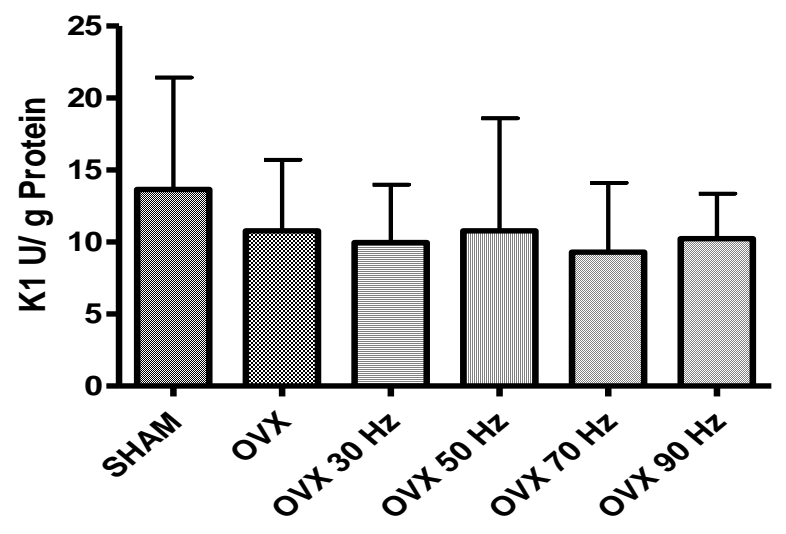

Abb 65: Aktivität des Komplex I im M. soleus [U/g] der Ratten nach 30 Tagen WBV; Darstellung der MW $\pm /$ Std

\subsubsection{Ergebnisse für den Komplex I}

In der Analyse des Komplex I treten weder zwischen den verschiedenen Muskeln noch unter den verschiedenen Gruppen signifikante Unterschiede auf. Es zeigt sich insgesamt ein inhomogenes Bild der Gruppen (Abb. 63, 64 u. 65), wobei hier die Gruppen OVX+30 Hz, $\mathrm{OVX}+70 \mathrm{~Hz}$ und $\mathrm{OVX}+90 \mathrm{~Hz}$ bei allen drei Muskeln sehr niedrige Werte aufweisen. Die Standardabweichung ist beim M. soleus und M. gastrocnemius hoch (Abb. 63 u. 65).

Tabelle 17: Zusammenfassung der Aktivität der Laktatdehydrogenase, der Citrat-Synthase und des Komplexes I [U/g] der Ratten nach 30 Tagen WBV; Darstellung der MW $\pm / \mathrm{Std}$

\begin{tabular}{|c|c|c|c|c|c|c|}
\hline & SHAM & OVX & $\begin{array}{l}\mathrm{OVX}+ \\
30 \mathrm{~Hz}\end{array}$ & $\begin{array}{l}\text { OVX+ } \\
50 \mathrm{~Hz}\end{array}$ & $\begin{array}{l}\mathrm{OVX}+ \\
70 \mathrm{~Hz}\end{array}$ & $\begin{array}{l}\mathrm{OVX}+ \\
90 \mathrm{~Hz}\end{array}$ \\
\hline \multicolumn{7}{|c|}{ Aktivität Laktatdehydrogenase [U/g] } \\
\hline $\begin{array}{l}\text { M. gastroc- } \\
\text { nemius }\end{array}$ & $\begin{array}{c}3,73 \\
\pm \\
0,7\end{array}$ & $\begin{array}{c}3,2 \\
\pm \\
0,67\end{array}$ & $\begin{array}{l}3,38 \pm \\
0,86\end{array}$ & $\begin{array}{c}3,22 \\
\pm \\
0,6\end{array}$ & $\begin{array}{c}3,15 \\
\pm \\
0,68\end{array}$ & $\begin{array}{c}3,34 \\
\pm \\
0,68\end{array}$ \\
\hline $\begin{array}{l}\text { M. } \\
\text { longissimus } \\
\text { dorsi }\end{array}$ & $\begin{array}{c}2,66 \\
\pm \\
1,45\end{array}$ & $\begin{array}{c}2,7 \\
\pm \\
1,59\end{array}$ & $\begin{array}{c}2,48 \\
\pm \\
1,09\end{array}$ & $\begin{array}{r}2,3 \\
\pm \\
0,81\end{array}$ & $\begin{array}{c}2,69 \\
\pm \\
1,35\end{array}$ & $\begin{array}{c}2,57 \\
\pm \\
1,23\end{array}$ \\
\hline M. soleus & $\begin{array}{r}0,4 \\
\pm \\
0,1\end{array}$ & $\begin{array}{c}0,39 \\
\pm \\
0,1\end{array}$ & $\begin{array}{c}0,38 \\
\pm \\
0,15\end{array}$ & $\begin{array}{c}0,49 \\
\pm \\
0,25\end{array}$ & $\begin{array}{c}0,44 \\
\pm \\
0,16\end{array}$ & $\begin{array}{c}0,39 \\
\pm \\
0,13\end{array}$ \\
\hline
\end{tabular}




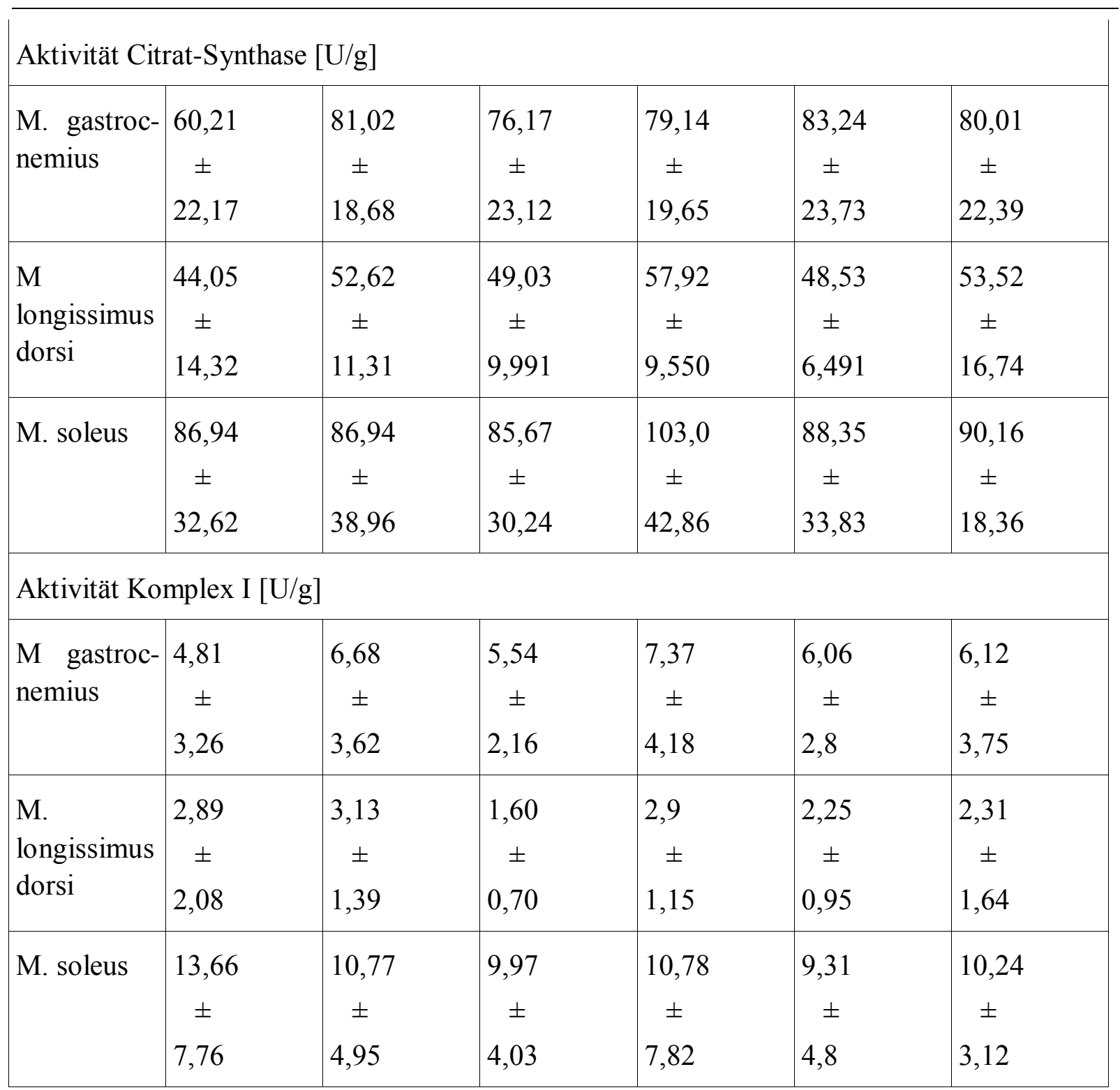




\section{Zusammenfassung der Ergebnisse}

Die nun folgende Tabelle fasst alle Ergebnisse für den M. gastrocnemius, den M. soleus und den M. longissimus dorsi zusammen. Sie soll mittels eines simplen Pfeilschemas die Tendenzen auf einen Blick erfassbar machen. Gewählt wurden folgende Symbole.

$\leftrightarrow \rightarrow=$ keine signifikanten Unterschiede zu SHAM

$\downarrow=$ signifikant niedriger zu SHAM

$=$ signifikant höher zu SHAM

$\Leftrightarrow=$ keine signifikanten Unterschiede zu OVX

$\checkmark=$ signifikant niedriger zu OVX

仓 = signifikant höher zu OVX

$\leftrightarrow=$ keine signifikanten Unterschiede zu:

$\downarrow=$ signifikikant niedriger $\mathrm{zu}$ :

$\uparrow=$ signifikant erhöht $\mathrm{zu}$ :

$\wedge=$ Gruppe $\mathrm{OVX}+30 \mathrm{~Hz}$

$\S=$ Gruppe OVX $+50 \mathrm{~Hz}$

$\sim=$ Gruppe OVX $+70 \mathrm{~Hz}$

$\boldsymbol{\psi}=$ Gruppe $\mathrm{OVX}+90 \mathrm{~Hz}$ 
Tabelle 18: Zusammenfassung aller Ergebnisse für den M. gastrocnemius, den M. soleus und den M. longissimus dorsi in Tendenzen.

\begin{tabular}{|c|c|c|c|c|}
\hline Me & $\begin{array}{l}\text { OVX+ } \\
30 \mathrm{~Hz}\end{array}$ & $\begin{array}{l}\text { OVX+ } \\
50 \mathrm{~Hz}\end{array}$ & $\begin{array}{l}\text { OVX+ } \\
70 \mathrm{~Hz}\end{array}$ & $\begin{array}{l}\text { OVX+ } \\
90 \mathrm{~Hz}\end{array}$ \\
\hline $\begin{array}{l}\text { Fläche der glykolytischen Zellen in } \\
\text { mm² im M. gastrocnemius }^{2}\end{array}$ & $\begin{array}{l}\leftrightarrow \\
\Leftrightarrow \\
\leftrightarrow\end{array}$ & $\begin{array}{l}\leftrightarrow \rightarrow \\
\Leftrightarrow \\
\leftrightarrow\end{array}$ & $\begin{array}{l}\leftrightarrow \rightarrow \\
\Leftrightarrow \\
\leftrightarrow\end{array}$ & $\begin{array}{l}\leftrightarrow \rightarrow \\
\Leftrightarrow \\
\leftrightarrow\end{array}$ \\
\hline $\begin{array}{l}\text { Durchmesser c } \\
\text { in } \mathrm{mm} \text { im } \mathrm{M} . \mathrm{g}\end{array}$ & $\begin{array}{l}\Leftrightarrow \rightarrow \\
\Leftrightarrow \\
\leftrightarrow\end{array}$ & $\begin{array}{l}\Leftrightarrow \rightarrow \\
\Leftrightarrow \\
\leftrightarrow\end{array}$ & $\begin{array}{l}\Leftrightarrow \rightarrow \\
\Leftrightarrow \\
\leftrightarrow\end{array}$ & $\begin{array}{l}\Leftrightarrow \rightarrow \\
\Leftrightarrow \\
\leftrightarrow\end{array}$ \\
\hline Mes & $\begin{array}{l}\text { OVX+ } \\
30 \mathrm{~Hz}\end{array}$ & $\begin{array}{l}\text { OVX+ } \\
50 \mathrm{~Hz}\end{array}$ & $\begin{array}{l}\text { OVX+ } \\
70 \mathrm{~Hz}\end{array}$ & $\begin{array}{l}\text { OVX+ } \\
90 \mathrm{~Hz}\end{array}$ \\
\hline $\begin{array}{l}\text { Fläche der oxidativen Zellen in } \mathbf{m m}^{2} \\
\text { im M. gastrocnemius }\end{array}$ & $\begin{array}{l}\stackrel{\leftrightarrow}{\Leftrightarrow} \\
\Leftrightarrow\end{array}$ & $\begin{array}{l}\Leftrightarrow \rightarrow \\
\Leftrightarrow \\
\leftrightarrow\end{array}$ & $\begin{array}{l}\boldsymbol{\downarrow} * \\
\bigvee \# \\
\downarrow \S\end{array}$ & $\begin{array}{l}\Leftrightarrow \rightarrow \\
\Leftrightarrow \\
\leftrightarrow\end{array}$ \\
\hline $\begin{array}{l}\text { ativen Zellen in } \\
\text { ius }\end{array}$ & $\begin{array}{l}\Leftrightarrow \rightarrow \\
\Leftrightarrow \\
\leftrightarrow\end{array}$ & $\begin{array}{l}\leftrightarrow \rightarrow \\
\Leftrightarrow \\
\leftrightarrow\end{array}$ & $\begin{array}{l}\leftrightarrow \rightarrow \\
\Leftrightarrow \\
\leftrightarrow\end{array}$ & $\begin{array}{l}\leftrightarrow \rightarrow \\
\Leftrightarrow \\
\leftrightarrow\end{array}$ \\
\hline en Zellen in $\mathbf{m m}^{2}$ & $\begin{array}{l}\leftrightarrow \rightarrow \\
\Leftrightarrow \\
\leftrightarrow\end{array}$ & $\begin{array}{l}\leftrightarrow \rightarrow \\
\Leftrightarrow \\
\leftrightarrow\end{array}$ & $\begin{array}{l}\leftrightarrow \rightarrow \\
\Leftrightarrow \\
\leftrightarrow\end{array}$ & $\begin{array}{l}\leftrightarrow \rightarrow \\
\Leftrightarrow \\
\leftrightarrow\end{array}$ \\
\hline $\begin{array}{l}\text { Durchmesser der oxidativen Zellen in } \\
\text { mm im M. soleus }\end{array}$ & $\begin{array}{l}\leftrightarrow \rightarrow \\
\Leftrightarrow \\
\leftrightarrow\end{array}$ & $\begin{array}{l}\leftrightarrow \rightarrow \\
\Leftrightarrow \\
\leftrightarrow\end{array}$ & $\begin{array}{l}\Leftrightarrow \rightarrow \\
\Leftrightarrow \\
\leftrightarrow\end{array}$ & $\begin{array}{l}\Leftrightarrow \rightarrow \\
\Leftrightarrow \\
\leftrightarrow\end{array}$ \\
\hline $\begin{array}{l}\text { Fläche der glykolytischen Zellen in } \\
\text { mm }^{2} \text { im M. longissimus dorsi }\end{array}$ & $\begin{array}{l}\leftrightarrow \rightarrow \\
\Leftrightarrow \\
\leftrightarrow\end{array}$ & $\begin{array}{l}\leftrightarrow \rightarrow \\
\Leftrightarrow \\
\leftrightarrow\end{array}$ & $\begin{array}{l}\leftrightarrow \rightarrow \\
\Leftrightarrow \\
\leftrightarrow\end{array}$ & $\begin{array}{l}\Leftrightarrow \rightarrow \\
\Leftrightarrow \\
\downarrow^{\wedge} \S^{\sim}\end{array}$ \\
\hline $\begin{array}{l}\text { Durchmesser der glykolytischen Zellen } \\
\text { in mm im M. longissimus dorsi }\end{array}$ & $\begin{array}{l}\leftrightarrow \rightarrow \\
\Leftrightarrow \\
\leftrightarrow\end{array}$ & $\begin{array}{l}\Leftrightarrow \rightarrow \\
\Leftrightarrow \\
\leftrightarrow\end{array}$ & $\begin{array}{l}\Leftrightarrow \rightarrow \\
\Leftrightarrow \\
\leftrightarrow\end{array}$ & $\begin{array}{l}\Leftrightarrow \rightarrow \\
\Leftrightarrow \\
\downarrow^{\wedge} \S^{\sim}\end{array}$ \\
\hline $\begin{array}{l}\text { Fläche der oxidativen Zellen in } \mathrm{mm}^{2} \\
\text { im M. longissimus dorsi }\end{array}$ & $\begin{array}{l}\text { 个* } \\
\text { 仓\# } \\
\leftrightarrow\end{array}$ & $\begin{array}{l}\leftrightarrow \rightarrow \\
\Leftrightarrow \\
\leftrightarrow\end{array}$ & $\begin{array}{l}\Leftrightarrow \rightarrow \\
\Leftrightarrow \\
\uparrow^{\wedge}\end{array}$ & $\begin{array}{l}\Leftrightarrow \rightarrow \\
\Leftrightarrow \\
\downarrow^{\wedge} \S\end{array}$ \\
\hline $\begin{array}{l}\text { Durchmesser der oxidativen Zellen in } \\
\text { mm im M. longissimus dorsi }\end{array}$ & $\begin{array}{l}\leftrightarrow \rightarrow \\
\Leftrightarrow \\
\leftrightarrow\end{array}$ & $\begin{array}{l}\leftrightarrow \rightarrow \\
\Leftrightarrow \\
\leftrightarrow\end{array}$ & $\begin{array}{l}\Leftrightarrow \rightarrow \\
\Leftrightarrow \\
\leftrightarrow\end{array}$ & $\begin{array}{l}\Leftrightarrow \rightarrow \\
\Leftrightarrow \\
\downarrow^{\wedge} \S\end{array}$ \\
\hline $\begin{array}{l}\text { Fläche der glykolytischen Zellen in } \\
\text { mm }^{2} \text { im M. gastrocnemius im } \\
\text { Verhältnis zum Muskelgewicht in g }\end{array}$ & $\begin{array}{l}\leftrightarrow \\
\leftrightarrow\end{array}$ & $\begin{array}{l}\boldsymbol{\downarrow} * \\
\sqrt{ } \# \\
\leftrightarrow\end{array}$ & $\begin{array}{l}\leftrightarrow \rightarrow \\
\Leftrightarrow \\
\leftrightarrow\end{array}$ & $\begin{array}{l}\leftrightarrow \rightarrow \\
\Leftrightarrow \\
\leftrightarrow\end{array}$ \\
\hline
\end{tabular}




\begin{tabular}{|c|c|c|c|c|}
\hline $\begin{array}{l}\text { Fläche der glykolytischen Zellen in } \\
\text { mm }^{2} \text { im M. gastrocnemius im } \\
\text { Verhältnis zum Körpergewicht in g }\end{array}$ & $\begin{array}{l}\boldsymbol{\downarrow} * \\
\leftrightarrow\end{array}$ & $\begin{array}{l}\boldsymbol{V}^{*} \\
\leftrightarrow\end{array}$ & $\begin{array}{l}\boldsymbol{\downarrow}^{*} \\
\leftrightarrow\end{array}$ & $\leftrightarrow$ \\
\hline $\begin{array}{l}\text { Durchmesser der glykolytischen Zellen } \\
\text { in mm im M. gastrocnemius im } \\
\text { Verhältnis zum Muskelgewicht in g }\end{array}$ & $\begin{array}{l}\boldsymbol{\downarrow}^{*} \\
\uparrow^{\wedge} \S\end{array}$ & $\begin{array}{l}\boldsymbol{\downarrow} * \\
\leftrightarrow\end{array}$ & $\leftrightarrow$ & $\leftrightarrow$ \\
\hline $\begin{array}{l}\text { Durchmesser der glykolytischen Zellen } \\
\text { in mm im M. gastrocnemius im } \\
\text { Verhältnis zum Körpergewicht in g }\end{array}$ & $\begin{array}{l}\downarrow * \\
\Leftrightarrow \\
\leftrightarrow\end{array}$ & $\begin{array}{l}\downarrow * \\
\Leftrightarrow \\
\leftrightarrow\end{array}$ & $\begin{array}{l}\downarrow * \\
\Leftrightarrow \\
\leftrightarrow\end{array}$ & $\begin{array}{l}\downarrow * \\
\Leftrightarrow \\
\leftrightarrow\end{array}$ \\
\hline $\begin{array}{l}\text { Fläche der oxidativen Zellen in } \mathrm{mm}^{2} \text { im } \\
\text { M. gastrocnemius im Verhältnis zum } \\
\text { Muskelgewicht in } \mathrm{g}\end{array}$ & $\begin{array}{l}\downarrow * \\
\Leftrightarrow \\
\leftrightarrow\end{array}$ & $\begin{array}{l}\boldsymbol{\downarrow} * \\
\Leftrightarrow \\
\leftrightarrow\end{array}$ & $\begin{array}{l}\boldsymbol{\downarrow} * \\
\Leftrightarrow \\
\leftrightarrow\end{array}$ & $\begin{array}{l}\downarrow * \\
\Leftrightarrow \\
\leftrightarrow\end{array}$ \\
\hline ößen & & $\begin{array}{l}\text { OVX+ } \\
50 \mathrm{~Hz}\end{array}$ & & \\
\hline $\begin{array}{l}\text { Fläche der oxidativen Zellen in } \mathrm{mm}^{2} \text { im } \\
\text { M. gastrocnemius im Verhältnis zum } \\
\text { Körpergewicht in } \mathrm{g}\end{array}$ & $\begin{array}{l}\downarrow * \\
\Leftrightarrow \\
\leftrightarrow\end{array}$ & $\begin{array}{l}\boldsymbol{\downarrow} * \\
\Leftrightarrow \\
\leftrightarrow\end{array}$ & $\begin{array}{l}\downarrow * \\
\Leftrightarrow \\
\leftrightarrow\end{array}$ & $\begin{array}{l}\downarrow * \\
\Leftrightarrow \\
\leftrightarrow\end{array}$ \\
\hline $\begin{array}{l}\text { Durchmesser der oxidativen Zellen in } \\
\text { mm im M. gastrocnemius im } \\
\text { Verhältnis zum Muskelgewicht in g }\end{array}$ & $\begin{array}{l}\downarrow * \\
\Leftrightarrow \\
\leftrightarrow\end{array}$ & $\begin{array}{l}\downarrow * \\
\Leftrightarrow \\
\leftrightarrow\end{array}$ & $\begin{array}{l}\downarrow * \\
\Leftrightarrow \\
\leftrightarrow\end{array}$ & $\begin{array}{l}\downarrow * \\
\Leftrightarrow \\
\leftrightarrow\end{array}$ \\
\hline $\begin{array}{l}\text { Durchmesser der oxidativen Zellen in } \\
\text { mm im M. gastrocnemius im } \\
\text { Verhältnis zum Körpergewicht in g }\end{array}$ & $\begin{array}{l}\downarrow * \\
\Leftrightarrow \\
\leftrightarrow\end{array}$ & $\begin{array}{l}\downarrow * \\
\Leftrightarrow \\
\leftrightarrow\end{array}$ & $\begin{array}{l}\downarrow * \\
\Leftrightarrow \\
\leftrightarrow\end{array}$ & $\begin{array}{l}\downarrow * \\
\Leftrightarrow \\
\leftrightarrow\end{array}$ \\
\hline $\begin{array}{l}\text { Fläche der oxidativen Zellen in } \mathrm{mm}^{2} \\
\text { im M. soleus im Verhältnis zum } \\
\text { Muskelgewicht in g }\end{array}$ & $\begin{array}{l}\leftrightarrow \rightarrow \\
\Leftrightarrow \\
\leftrightarrow\end{array}$ & $\begin{array}{l}\leftrightarrow \rightarrow \\
\Leftrightarrow \\
\leftrightarrow\end{array}$ & $\begin{array}{l}\leftrightarrow \rightarrow \\
\Leftrightarrow\end{array}$ & $\begin{array}{l}\leftrightarrow \rightarrow \\
\Leftrightarrow\end{array}$ \\
\hline $\begin{array}{l}\text { Fläche der oxidativen Zellen in } \mathrm{mm}^{2} \\
\text { im M. soleus im Verhältnis zum } \\
\text { Körpergewicht in } \mathrm{g}\end{array}$ & $\begin{array}{l}\leftrightarrow \rightarrow \\
\Leftrightarrow \\
\leftrightarrow\end{array}$ & $\begin{array}{l}\leftrightarrow \rightarrow \\
\leftrightarrow \\
\leftrightarrow\end{array}$ & $\begin{array}{l}\leftrightarrow \rightarrow \\
\Leftrightarrow\end{array}$ & $\begin{array}{l}\leftrightarrow \rightarrow \\
\Leftrightarrow \\
\leftrightarrow\end{array}$ \\
\hline $\begin{array}{l}\text { Durchmesser der oxidativen Zellen in } \\
\text { mm im M. soleus im Verhältnis zum } \\
\text { Muskelgewicht in g }\end{array}$ & $\begin{array}{l}\leftrightarrow \rightarrow \\
\Leftrightarrow \\
\leftrightarrow\end{array}$ & $\begin{array}{l}\leftrightarrow \rightarrow \\
\Leftrightarrow \\
\leftrightarrow\end{array}$ & $\begin{array}{l}\leftrightarrow \rightarrow \\
\Leftrightarrow \\
\leftrightarrow\end{array}$ & $\begin{array}{l}\leftrightarrow \rightarrow \\
\Leftrightarrow \\
\leftrightarrow\end{array}$ \\
\hline $\begin{array}{l}\text { Durchmesser der oxidativen Zellen in } \\
\text { mm im M. soleus im Verhältnis zum } \\
\text { Körpergewicht in } \mathrm{g}\end{array}$ & $\begin{array}{l}\leftrightarrow \rightarrow \\
\Leftrightarrow \\
\leftrightarrow\end{array}$ & $\begin{array}{l}\leftrightarrow \rightarrow \\
\Leftrightarrow \\
\leftrightarrow\end{array}$ & $\begin{array}{l}\Leftrightarrow \rightarrow \\
\Leftrightarrow \\
\leftrightarrow\end{array}$ & $\begin{array}{l}\leftrightarrow \rightarrow \\
\Leftrightarrow\end{array}$ \\
\hline $\begin{array}{l}\text { Fläche der glykolytischen Zellen in } \\
\text { mm }^{2} \text { im M. longissimus dorsi im } \\
\text { Verhältnis zum Körpergewicht in g }\end{array}$ & $\begin{array}{l}\leftrightarrow \rightarrow \\
\Leftrightarrow \\
\leftrightarrow\end{array}$ & $\begin{array}{l}\leftrightarrow \rightarrow \\
\Leftrightarrow \\
\uparrow \sim\end{array}$ & $\begin{array}{l}\leftrightarrow \rightarrow \\
\Leftrightarrow \\
\uparrow \sim\end{array}$ & $\begin{array}{l}\downarrow * \\
\Leftrightarrow \\
\leftrightarrow\end{array}$ \\
\hline $\begin{array}{l}\text { Durchmesser der glykolytischen Zellen } \\
\text { in mm im M. longissimus dorsi im } \\
\text { Verhältnis zum Körpergewicht }\end{array}$ & $\begin{array}{l}\downarrow * \\
\Leftrightarrow \\
\leftrightarrow\end{array}$ & $\begin{array}{l}\downarrow * \\
\Leftrightarrow \\
\leftrightarrow\end{array}$ & $\begin{array}{l}\downarrow * \\
\Leftrightarrow \\
\uparrow \psi\end{array}$ & $\begin{array}{l}\downarrow * \\
\Leftrightarrow \\
\leftrightarrow\end{array}$ \\
\hline
\end{tabular}




\begin{tabular}{|c|c|c|c|c|}
\hline $\begin{array}{l}\text { Fläche der oxidativen Zellen in } \mathrm{mm}^{2} \\
\text { im M. longissimus dorsi im Verhältnis } \\
\text { zum Körpergewicht in } \mathrm{g}\end{array}$ & $\begin{array}{l}\leftrightarrow \rightarrow \\
\Leftrightarrow \\
\uparrow \sim\end{array}$ & $\begin{array}{l}\leftrightarrow \rightarrow \\
\Leftrightarrow \\
\uparrow \varnothing\end{array}$ & $\begin{array}{l}\leftrightarrow \rightarrow \\
\Leftrightarrow \\
\leftrightarrow\end{array}$ & $\begin{array}{l}\downarrow * \\
\Leftrightarrow \\
\leftrightarrow\end{array}$ \\
\hline $\begin{array}{l}\text { Durchmesser der oxidativen } \\
\text { Zel-len in mm im M. } \\
\text { longissimus dorsi im Verhältnis } \\
\text { zum Körpergewicht in g }\end{array}$ & $\begin{array}{l}\leftrightarrow \rightarrow \\
\Leftrightarrow \\
\uparrow\end{array}$ & $\begin{array}{l}\downarrow * \\
\Leftrightarrow \\
\leftrightarrow\end{array}$ & $\begin{array}{l}\downarrow * \\
\Leftrightarrow \\
\leftrightarrow\end{array}$ & $\begin{array}{l}\downarrow * \\
\Leftrightarrow \\
\leftrightarrow\end{array}$ \\
\hline $\begin{array}{l}\text { Anzahl der glykolytischen Zellen pro } \\
\text { mm² im M. longissimus dorsi }^{2}\end{array}$ & $\begin{array}{l}\leftrightarrow \rightarrow \\
\Leftrightarrow \\
\downarrow \varnothing\end{array}$ & $\begin{array}{l}\leftrightarrow \rightarrow \\
\Leftrightarrow \\
\downarrow \varnothing\end{array}$ & $\begin{array}{l}\leftrightarrow \rightarrow \\
\Leftrightarrow \\
\leftrightarrow\end{array}$ & $\begin{array}{l}\leftrightarrow \rightarrow \\
\Leftrightarrow \\
\leftrightarrow\end{array}$ \\
\hline Messgrößen & $\begin{array}{l}\text { OVX+ } \\
30 \mathrm{~Hz}\end{array}$ & $\begin{array}{l}\text { OVX+ } \\
50 \mathrm{~Hz}\end{array}$ & $\begin{array}{l}\text { OVX+ } \\
70 \mathrm{~Hz}\end{array}$ & $\begin{array}{l}\text { OVX+ } \\
90 \mathrm{~Hz}\end{array}$ \\
\hline $\begin{array}{l}\text { Anzahl der oxidativen Zelle pro } \mathrm{mm}^{2} \\
\text { im M. longissimus dorsi }\end{array}$ & $\begin{array}{l}\leftrightarrow \rightarrow \\
\leftrightarrow \\
\leftrightarrow\end{array}$ & $\begin{array}{l}\leftrightarrow \rightarrow \\
\Leftrightarrow \\
\leftrightarrow\end{array}$ & $\begin{array}{l}\leftrightarrow \rightarrow \\
\leftrightarrow \\
\leftrightarrow\end{array}$ & $\begin{array}{l}\leftrightarrow \rightarrow \\
\Leftrightarrow \\
\leftrightarrow\end{array}$ \\
\hline $\begin{array}{l}\text { Anzahl der Zellen pro } \mathrm{mm}^{2} \text { im } \mathrm{M} \text {. } \\
\text { longissimus dorsi }\end{array}$ & $\begin{array}{l}\leftrightarrow \rightarrow \\
\Leftrightarrow \\
\downarrow \varnothing\end{array}$ & $\begin{array}{l}\leftrightarrow \rightarrow \\
\Leftrightarrow \\
\downarrow\end{array}$ & $\begin{array}{l}\leftrightarrow \rightarrow \\
\Leftrightarrow \\
\leftrightarrow\end{array}$ & $\begin{array}{l}\stackrel{\leftrightarrow}{\leftrightarrow} \\
\leftrightarrow \\
\leftrightarrow\end{array}$ \\
\hline $\begin{array}{l}\text { Anzahl der glykolytischen Zellen im } \\
\text { Verhältnis zur gesamten Zellzahl pro } \\
\text { mm² im M. longissimus dorsi }\end{array}$ & $\begin{array}{l}\leftrightarrow \rightarrow \\
\Leftrightarrow \\
\leftrightarrow\end{array}$ & $\begin{array}{l}\leftrightarrow \rightarrow \\
\Leftrightarrow \\
\leftrightarrow\end{array}$ & $\begin{array}{l}\leftrightarrow \rightarrow \\
\Leftrightarrow \\
\leftrightarrow\end{array}$ & $\begin{array}{l}\leftrightarrow \rightarrow \\
\Leftrightarrow \\
\leftrightarrow\end{array}$ \\
\hline $\begin{array}{l}\text { Anzahl der oxidativen Zellen im Ver- } \\
\text { hältnis zur gesamten Zellzahl pro } \text { mm }^{2} \\
\text { im M. longissimus dorsi }\end{array}$ & $\begin{array}{l}\leftrightarrow \rightarrow \\
\leftrightarrow \\
\leftrightarrow\end{array}$ & $\begin{array}{l}\leftrightarrow \rightarrow \\
\Leftrightarrow \\
\leftrightarrow\end{array}$ & $\begin{array}{l}\leftrightarrow \rightarrow \\
\Leftrightarrow \\
\leftrightarrow\end{array}$ & $\begin{array}{l}\leftrightarrow \\
\Leftrightarrow \\
\leftrightarrow\end{array}$ \\
\hline $\begin{array}{l}\text { Anzahl der Muskelzellen pro } \mathrm{mm}^{2} \text { im } \\
\text { M. gastrocnemius }\end{array}$ & $\begin{array}{l}\leftrightarrow \rightarrow \\
\Leftrightarrow \\
\leftrightarrow\end{array}$ & $\begin{array}{l}\Leftrightarrow \rightarrow \\
\Leftrightarrow \\
\leftrightarrow\end{array}$ & $\begin{array}{l}\leftrightarrow \\
\Leftrightarrow \\
\leftrightarrow\end{array}$ & $\begin{array}{l}\leftrightarrow \rightarrow \\
\Leftrightarrow \\
\leftrightarrow\end{array}$ \\
\hline $\begin{array}{l}\text { Anzahl der Kapillaren pro } \mathbf{m m}^{2} \text { im } \mathbf{M} \text {. } \\
\text { gastrocnemius }\end{array}$ & $\begin{array}{l}\leftrightarrow \rightarrow \\
\Leftrightarrow \\
\leftrightarrow\end{array}$ & $\begin{array}{l}\leftrightarrow \rightarrow \\
\Leftrightarrow \\
\leftrightarrow\end{array}$ & $\begin{array}{l}\leftrightarrow \rightarrow \\
\Leftrightarrow \\
\leftrightarrow\end{array}$ & $\begin{array}{l}\stackrel{\leftrightarrow}{\leftrightarrow} \\
\Leftrightarrow \\
\leftrightarrow\end{array}$ \\
\hline $\begin{array}{l}\text { Verhältnis der Kapillaren pro Zelle } \\
\text { pro } \mathrm{mm}^{2} \text { im M. gastrocnemius }\end{array}$ & $\begin{array}{l}\leftrightarrow \rightarrow \\
\Leftrightarrow \\
\leftrightarrow\end{array}$ & $\begin{array}{l}\leftrightarrow \rightarrow \\
\Leftrightarrow \\
\leftrightarrow\end{array}$ & $\begin{array}{l}\Leftrightarrow \rightarrow \\
\Leftrightarrow \\
\leftrightarrow\end{array}$ & $\begin{array}{l}\leftrightarrow \rightarrow \\
\Leftrightarrow \\
\leftrightarrow\end{array}$ \\
\hline $\begin{array}{l}\text { Anzahl der Muskelzellen pro } \mathrm{mm}^{2} \text { im } \\
\text { M. soleus }\end{array}$ & $\begin{array}{l}\leftrightarrow \rightarrow \\
\Leftrightarrow \\
\leftrightarrow\end{array}$ & $\begin{array}{l}\Leftrightarrow \rightarrow \\
\Leftrightarrow \\
\leftrightarrow\end{array}$ & $\begin{array}{l}\leftrightarrow \rightarrow \\
\Leftrightarrow \\
\leftrightarrow\end{array}$ & $\begin{array}{l}\stackrel{\leftrightarrow}{\leftrightarrow} \\
\Leftrightarrow \\
\leftrightarrow\end{array}$ \\
\hline $\begin{array}{l}\text { Anzahl der Kapillaren pro } \mathbf{m m}^{2} \\
\text { im M. soleus }\end{array}$ & $\begin{array}{l}\leftrightarrow \rightarrow \\
\Leftrightarrow \\
\leftrightarrow\end{array}$ & $\begin{array}{l}\leftrightarrow \rightarrow \\
\Leftrightarrow \\
\leftrightarrow\end{array}$ & $\begin{array}{l}\Leftrightarrow \rightarrow \\
\Leftrightarrow \\
\leftrightarrow\end{array}$ & $\begin{array}{l}\boldsymbol{T}^{*} \\
\Leftrightarrow \\
\leftrightarrow\end{array}$ \\
\hline $\begin{array}{l}\text { Verhältnis der Kapillaren pro Zelle } \\
\text { pro } \mathbf{m m}^{2} \text { im M. soleus }\end{array}$ & $\begin{array}{l}\Leftrightarrow \rightarrow \\
\Leftrightarrow \\
\downarrow \varnothing\end{array}$ & $\begin{array}{l}\leftrightarrow \rightarrow \\
\Leftrightarrow \\
\downarrow \varnothing\end{array}$ & $\begin{array}{l}\uparrow^{*} \\
\Leftrightarrow \\
\leftrightarrow\end{array}$ & $\begin{array}{l}\boldsymbol{\uparrow}^{*} \\
\Leftrightarrow \\
\leftrightarrow\end{array}$ \\
\hline
\end{tabular}




\begin{tabular}{|c|c|c|c|c|}
\hline $\begin{array}{l}\text { Anzahl der Muskelzellen pro } \mathrm{mm}^{2} \text { im } \\
\text { M. longissimus dorsi }\end{array}$ & $\begin{array}{l}\leftrightarrow \rightarrow \\
\Leftrightarrow \\
\leftrightarrow\end{array}$ & $\begin{array}{l}\leftrightarrow \rightarrow \\
\Leftrightarrow \\
\leftrightarrow\end{array}$ & $\begin{array}{l}\leftrightarrow \rightarrow \\
\Leftrightarrow \\
\leftrightarrow\end{array}$ & $\begin{array}{l}\leftrightarrow \rightarrow \\
\Leftrightarrow \\
\leftrightarrow\end{array}$ \\
\hline $\begin{array}{l}\text { Anzahl der Kapillaren pro } \mathrm{mm}^{2} \text { im } \mathrm{M} \text {. } \\
\text { longissimus dorsi }\end{array}$ & $\begin{array}{l}\leftrightarrow \rightarrow \\
\Leftrightarrow \\
\leftrightarrow\end{array}$ & $\begin{array}{l}\leftrightarrow \rightarrow \\
\Leftrightarrow \\
\leftrightarrow\end{array}$ & $\begin{array}{l}\leftrightarrow \rightarrow \\
\Leftrightarrow \\
\leftrightarrow\end{array}$ & $\begin{array}{l}\leftrightarrow \rightarrow \\
\Leftrightarrow \\
\leftrightarrow\end{array}$ \\
\hline $\begin{array}{l}\text { Verhältnis der Kapillaren pro Zelle } \\
\text { pro } \mathrm{mm}^{2} \text { im M. longissimus dorsi }\end{array}$ & $\begin{array}{l}\Leftrightarrow \rightarrow \\
\Leftrightarrow \\
\leftrightarrow\end{array}$ & $\begin{array}{l}\leftrightarrow \rightarrow \\
\Leftrightarrow \\
\leftrightarrow\end{array}$ & $\begin{array}{l}\Leftrightarrow \rightarrow \\
\Leftrightarrow \\
\leftrightarrow\end{array}$ & $\begin{array}{l}\Leftrightarrow \rightarrow \\
\Leftrightarrow \\
\leftrightarrow\end{array}$ \\
\hline Messgrößen & $\begin{array}{l}\text { OVX+ } \\
30 \mathrm{~Hz}\end{array}$ & $\begin{array}{l}\text { OVX+ } \\
50 \mathrm{~Hz}\end{array}$ & $\begin{array}{l}\text { OVX+ } \\
70 \mathrm{~Hz}\end{array}$ & $\begin{array}{l}\text { OVX+ } \\
90 \mathrm{~Hz}\end{array}$ \\
\hline $\begin{array}{l}\text { Konzentration der LDH im } \text { M. } \\
\text { gastroc-nemius in U/g }\end{array}$ & $\begin{array}{l}\leftrightarrow \rightarrow \\
\Leftrightarrow \\
\leftrightarrow\end{array}$ & $\begin{array}{l}\leftrightarrow \rightarrow \\
\Leftrightarrow \\
\leftrightarrow\end{array}$ & $\begin{array}{l}\leftrightarrow \rightarrow \\
\Leftrightarrow \\
\leftrightarrow\end{array}$ & $\begin{array}{l}\leftrightarrow \rightarrow \\
\Leftrightarrow \\
\leftrightarrow\end{array}$ \\
\hline $\begin{array}{l}\text { Konzentration der LDH im M. soleus } \\
\text { in U/g }\end{array}$ & $\begin{array}{l}\leftrightarrow \rightarrow \\
\Leftrightarrow \\
\leftrightarrow\end{array}$ & $\begin{array}{l}\leftrightarrow \rightarrow \\
\Leftrightarrow \\
\leftrightarrow\end{array}$ & $\begin{array}{l}\leftrightarrow \rightarrow \\
\Leftrightarrow \\
\leftrightarrow\end{array}$ & $\begin{array}{l}\leftrightarrow \rightarrow \\
\Leftrightarrow \\
\leftrightarrow\end{array}$ \\
\hline $\begin{array}{l}\text { Konzentration der LDH im M. longis- } \\
\text { simus dorsi in U/g }\end{array}$ & $\begin{array}{l}\leftrightarrow \rightarrow \\
\Leftrightarrow \\
\leftrightarrow\end{array}$ & $\begin{array}{l}\leftrightarrow \rightarrow \\
\Leftrightarrow \\
\leftrightarrow\end{array}$ & $\begin{array}{l}\leftrightarrow \rightarrow \\
\Leftrightarrow \\
\leftrightarrow\end{array}$ & $\begin{array}{l}\leftrightarrow \rightarrow \\
\Leftrightarrow \\
\leftrightarrow\end{array}$ \\
\hline $\begin{array}{l}\text { Konzentration der CS im M. gastroc- } \\
\text { nemius in U/g }\end{array}$ & $\begin{array}{l}\leftrightarrow \rightarrow \\
\Leftrightarrow \\
\leftrightarrow\end{array}$ & $\begin{array}{l}\leftrightarrow \rightarrow \\
\Leftrightarrow \\
\leftrightarrow\end{array}$ & $\begin{array}{l}\leftrightarrow \rightarrow \\
\Leftrightarrow \\
\leftrightarrow\end{array}$ & $\begin{array}{l}\leftrightarrow \rightarrow \\
\Leftrightarrow \\
\leftrightarrow\end{array}$ \\
\hline $\begin{array}{l}\text { Konzentration der CS im M. so- } \\
\text { leus in U/g }\end{array}$ & $\begin{array}{l}\leftrightarrow \rightarrow \\
\Leftrightarrow \\
\leftrightarrow\end{array}$ & $\begin{array}{l}\leftrightarrow \rightarrow \\
\Leftrightarrow \\
\leftrightarrow\end{array}$ & $\begin{array}{l}\leftrightarrow \rightarrow \\
\Leftrightarrow \\
\leftrightarrow\end{array}$ & $\begin{array}{l}\leftrightarrow \rightarrow \\
\Leftrightarrow \\
\leftrightarrow\end{array}$ \\
\hline $\begin{array}{l}\text { Konzentration der CS im M. longis- } \\
\text { simus dorsi in U/g }\end{array}$ & $\begin{array}{l}\leftrightarrow \rightarrow \\
\Leftrightarrow \\
\leftrightarrow\end{array}$ & $\begin{array}{l}\Leftrightarrow \rightarrow \\
\Leftrightarrow \\
\leftrightarrow\end{array}$ & $\begin{array}{l}\Leftrightarrow \\
\Leftrightarrow \\
\leftrightarrow\end{array}$ & $\begin{array}{l}\leftrightarrow \\
\Leftrightarrow \\
\leftrightarrow\end{array}$ \\
\hline $\begin{array}{l}\text { Konzentration des Komplexes I im M. } \\
\text { gastrocnemius in U/g }\end{array}$ & $\begin{array}{l}\leftrightarrow \rightarrow \\
\Leftrightarrow \\
\leftrightarrow\end{array}$ & $\begin{array}{l}\leftrightarrow \rightarrow \\
\Leftrightarrow \\
\leftrightarrow\end{array}$ & $\begin{array}{l}\leftrightarrow \rightarrow \\
\Leftrightarrow \\
\leftrightarrow\end{array}$ & $\begin{array}{l}\leftrightarrow \rightarrow \\
\Leftrightarrow \\
\leftrightarrow\end{array}$ \\
\hline $\begin{array}{l}\text { Konzentration des Komplexes I im M. } \\
\text { soleus in U/g }\end{array}$ & $\begin{array}{l}\leftrightarrow \rightarrow \\
\Leftrightarrow \\
\leftrightarrow\end{array}$ & $\begin{array}{l}\leftrightarrow \rightarrow \\
\Leftrightarrow \\
\leftrightarrow\end{array}$ & $\begin{array}{l}\leftrightarrow \rightarrow \\
\Leftrightarrow \\
\leftrightarrow\end{array}$ & $\begin{array}{l}\leftrightarrow \rightarrow \\
\Leftrightarrow \\
\leftrightarrow\end{array}$ \\
\hline $\begin{array}{l}\text { Konzentration des Komplexes I im M. } \\
\text { longissimus dorsi in U/g }\end{array}$ & $\begin{array}{l}\leftrightarrow \rightarrow \\
\Leftrightarrow \\
\leftrightarrow\end{array}$ & $\begin{array}{l}\Leftrightarrow \rightarrow \\
\Leftrightarrow \\
\leftrightarrow\end{array}$ & $\begin{array}{l}\Leftrightarrow \rightarrow \\
\Leftrightarrow \\
\leftrightarrow\end{array}$ & $\begin{array}{l}\Leftrightarrow \rightarrow \\
\Leftrightarrow \\
\leftrightarrow\end{array}$ \\
\hline
\end{tabular}




\section{Diskussion}

\subsection{Ratten als Tiermodell für Osteoporose}

Für das vorliegende Projekt wurden weibliche Sprague Dawley-Ratten, die im ersten Schritt des Forschungsprojektes ovarektomiert wurden, um eine Osteoporose zu induzieren, als Tiermodell eingesetzt. Die Arbeit mit Ratten ist in Bezug auf Osteoporose, die durch einen Östrogenmangel bedingt ist, ein etabliertes Tiermodell. Eine effektive Ovarektomie und damit ein relevanter Östrogenmangel wurden anhand der Uterusgewichte belegt (Abb. 16). Das Gewicht der SHAM-Gruppe bezogen auf die Tiere in den ovarektomierten Gruppen (OVX, $\mathrm{OVX}+30 \mathrm{~Hz}, \mathrm{OVX}+50 \mathrm{~Hz}, \mathrm{OVX}+70 \mathrm{~Hz}, \mathrm{OVX}+90 \mathrm{~Hz}$ ) war signifikant erhöht. Dies ist eine Folge des Östrogenmangels (Komrakova et al. 2010). Zwischen den jeweils ovarektomierten Gruppen gab es keine signifikanten Unterschiede (Tab. 5).

Vorteile in der Nutzung von Ratten als Osteoporosemodell liegen in den niedrigen Anschaffungs- und Haltungskosten, in ihrer guten Verfügbarkeit sowie in ihren biologischen Daten. Zu den biologischen Daten zählt, dass Ratten eine relativ kurze Lebenszeit haben, die es uns erlaubt, mit geschlechtsreifen und skelettreifen Tieren arbeiten zu können, die erst drei Monate alt sind, dass Ratten über ein schnelles Wachstum verfügen, dass sie ein gut definiertes Skelett besitzen, dass sie eine geringe Körpergröße haben und dass sie ein schon bewiesenes gutes Tiermodell für die meisten Osteoporose-Risikofaktoren sind (Turner et al. 2001). Das Rattenmodell stellt jedoch kein absolut optimales Tiermodell für die Osteoporoseforschung des Menschen dar, da nicht alle Bedingungen des menschlichen Organismus erzeugt werden können (Turner et al. 2001). Die größte Problematik besteht darin, dass das Frakturrisiko des menschlichen Knochens nicht auf das Tier übertragbar ist (Turner et al. 2001). Ein weiteres Problem sind die unglaublich vielen Einflussfaktoren auf die Osteoporose, die einzeln oder in einer unbestimmten Anzahl an Kombinations-Varianten auftreten können, so dass es unklar bleibt, ob es irgendwann möglich ist, ein Tiermodel zu finden, dass den Prozess der Osteoporose beim Menschen noch exakter abbilden kann (Turner et al. 2001).

Die Erkenntnis, dass ein Östrogenmangel in der Ratte einen erhöhten Knochenumsatz der Spongiosa verursacht, ließ das Interesse für Tiermodelle mit Ratten für die postmenopausale Osteoporose enorm ansteigen (Wronski et al. 1985). Da Studien zeigten, dass sich aus diesem erhöhten Spongiosaumsatz ein Verlust der Knochenmasse einstellte, ebnete dies dem Rattentiermodell den Weg zur Etablierung (Turner et al. 1994). Der Knochensubstanzverlust nach einer Ovarektomie an skelettreifen Ratten verläuft dem der postmenopausalen Frau sehr 
ähnlich (Turner et al. 2001). Die Ovarektomie induziert bei Ratten schon nach acht bis zehn Wochen eine signifikant verminderte Knochenmineraldichte im Bereich der Lendenwirbelsäule (Miller und Wronski 1993). Weitaus weniger untersucht ist der Einfluss von Östrogenen beziehungsweise von Östrogenmangel auf Skelettmuskelzellen, wobei bekannt ist, dass die Skelettmuskelzellen über Östrogenrezeptoren verfügen und somit östrogensensibel sind (Dahlberg 1982). Deshalb geht man davon aus, dass die Skelettmuskulatur auf das Fehlen von Östrogenen reagiert, eventuell sogar frühzeitiger als das Knochengewebe (Waren et al. 1996). Es konnte gezeigt werden, dass aufgrund eines Östrogenmangels bei Ratten die Kontraktilität im skelettalen Muskel abnimmt. Dies konnte spezifisch für den M. soleus und den M. extensor digitorum longus herausgearbeitet werden (Moran et al. 2006). Ebenso konnten Forschungs-arbeiten belegen, dass Änderungen im Östrogenspiegel von Ratten auch Veränderungen im Verhältnis der Muskelfasertypen hervorrufen (Kadi et al. 2002).

Eine weitere Fragestellung für dieses Tiermodell ist, ob der physiologische Effekt von Östrogenen unterschiedlich auf die Muskulatur von jungen Frauen und älteren Frauen wirkt (Maltais et al. 2009). Auch lässt sich die Überlegung anbringen, ob ein Modell, das mit Tieren arbeitet, die sich größtenteils auf Vorder- und Hinterläufen bewegen auf die Menschen, die sich überwiegend im aufrechten Gang befinden, übertragbar ist. In Zukunft kann nicht genügend Sorgfalt aufgewendet werden, um ein Tiermodell für die Osteoporose zu entwickeln, in dem die exakte Tierart, im exakten Alter, für die exakten Versuche und deren Analysen gefunden werden kann (Turner et al. 2001).

\subsection{Analysen der Muskelgewichte für den M. gastrocnemius und M. soleus unter Berücksichtigung des Körpergewichts}

In den vorliegenden Ergebnissen, konnte festgestellt werden, dass es keine signifikanten Unterschiede in den Muskelgewichten des M. gatrocnemius und des M. soleus zwischen den verschiedenen Gruppen gab (Abb. 13 u. 14). In der Tendenz weist die SHAM-Gruppe die niedrigsten Muskelgewichte auf. Dieses Ergebnis passt $\mathrm{zu}$ bestehenden Forschungsergebnissen, dass die Trockengewichte von Muskeln in ovarektomierten und nicht-ovarektomierten Ratten keine Unterschiede aufweisen (Moran et al. 2006). Allerdings müssen wir in Bezug auf diese Forschungsarbeit berücksichtigen, dass diese Tiere dabei 
keiner Ganzkörpervibration ausgesetzt worden waren. In dem Versuch von Moran et al. ging es um ovarektomierte Tiere, denen mittels eines subkutanen Östrogendepots das 17ßÖstradiol substituiert wurde. Die vorliegenden Ergebnisse sprechen eher dafür, dass weder der Östrogenmangel noch das allerdings verhältnismäßig kurzzeitige Ausdauertraining durch die Ganzkörpervibration signifikante Unterschiede in den Muskelgewichten bewirken konnten. Die Östrogenmangel-Situation durch die Ovarektomie und die erbrachte Muskelarbeit hatten also einen, in der Bilanz ausgleichenden Effekt aufeinander. Diese Annahme deckt sich mit dem Wissen, dass unter einem Östrogenmangel die Muskelmasse in Folge von Flüssigkeitseinlagerungen zunehmen kann, andererseits durch Muskelarbeit, der Stoffwechsel von Muskelzellen positiv verändert wird und Wassereinlagerungen ausgeschwemmt werden (McClung et al. 2006). Betracht man die SHAM- und OVX-Gruppen so kann resümiert werden, dass die Gewichte der untersuchten Muskeln in der SHAM-Gruppe geringer als in der OVX-Gruppe waren. Im Verhältnis zum Körpergewicht sind allerdings die Muskelgewichte der SHAM-Gruppe höher als die der OVX-Gruppe.Hierfür könnte auch eine vermehrte Fetteinlagerung bei letzterer postuliert werden, was allerdings in der vorliegenden Arbeit nicht fokussiert wurde. Es lässt sich also keine eindeutige Aussage hinsichtlich des Effekts des Östrogenmangels oder der horizontalen Ganzkörpervibration auf das Gewicht der untersuchten Muskulatur treffen. Der Östrogenmangel und/ oder die horizontale Ganzköpervibration sind jedoch Effekte, die den gesamten Organismus und nicht nur den Knochen betreffen.

Die Muskelgewichte der Mm. gastrocnemii und Mm. solei der Gruppen untereinander unterscheiden sich, wie bereits oben beschrieben, nicht signifikant. Auch wenn die ermittelten Gewichtswerte ins Verhältnis zum Körpergewicht der Tiere gesetzt werden, ergeben sich zwischen den verschiedenen Gruppen für beide Muskeln keine signifikanten Unterschiede. Tendenzielle Unterschiede sind jedoch in den Ergebnissen erkennbar: So ist das Gewicht vom M. gastrocnemius und M. soleus in der SHAM-Gruppe geringer als in den übrigen Gruppen. Auch das Körpergewicht der Tiere in der SHAM-Gruppe ist im Vergleich zu den anderen Gruppen erniedrigt (Tab.5). Die horizontale WBV und/oder der Östrogenmangel scheint also eine Gewichtszunahme der Muskeln zu bewirken. WBV führt generell zu einer Größenzunahme der Muskelfasern (Stuermer et al. 2010).

Die Ergebnisse für das Verhältnis zwischen Muskelgewichten und Körpergewichten sind für die ovarektomierten Ratten ohne WBV am geringsten. Dieses Ergebnis untermauert die Hypothese, dass die Kombination aus Östrogenmangel und einem Mangel an mechanischer Stimulation eine Atrophie der Sklettmuskelzelle und eine Zunahme des Körpergewichtes 
bedingt. Jeong und Yoon konnten 2012 zeigen, dass ovarektomierte Mäuse, die ein Schwimmtraining über 6 Wochen absolvierten, eine reduzierte Menge an intramuskulärem Fett aufweisen. Zusammenfassend kam diese Arbeitsgruppe $\mathrm{zu}$ dem Ergebnis, dass ovarektomierte Mäuse ohne Schwimmtraining ein höheres Körpergewicht und mehr Fettgewebe als sham-operierte Mäuse hatten und dass ovarektomierte Mäuse mit Schwimmtraining eine geringere Zunahme des Körpergewichts, reduziertes Fettgewebe und eine reduzierte Größe der Adipozyten hatten (Jeong und Yoon 2012). Dass die Muskelfasergröße, die Muskelfaser-regeneration und das Remodeling der extrazellulären Matrix nach Immobilisation östrogensensitiv sind, konnte McClung bereits in 2006 zeigen (McClung et al. 2006).

\subsection{Analysen der Muskelflächen, Muskeldurchmesser und}

\section{Muskelfasertypen}

Das Bestimmen der Muskelfläche, des Muskeldurchmessers und der Muskelfasertypen, der jeweils drei ausgewählten Muskeln (M. gastrocnemius, M. longissimus dorsi und M. soleus), diente zur detaillierten Beurteilung des induzierten Östrogenmangels und des Effektes der horizontalen Ganzkörpervibration. Interessant scheint in dieser Untersuchung das Zusammenwirken von einem Defizit an Östrogen und der Ganzkörpervibration, da es unklar ist, ob es sich dabei um synergistische oder antagonistische Prozesse handelt.

In der Literatur zeigen sich Hinweise auf eine Zunahme der Muskelfaserdurchmesser bei Frauen, die sich in der Menopause befinden (Maltais et al. 2009). Belegt werden konnte dies ebenfalls durch das Ergebnis, dass ältere Frauen zwischen 65 und 80 Jahren eine doppelt so hohe Anzahl von nicht-kontraktilem Muskelgewebe pro Muskeleinheit im Vergleich zu jüngeren Frauen zwischen 23 und 57 Jahren aufweisen (Jubrias et al. 1997). Der Anteil an nicht-kontraktilem Muskelgewebe, welches typischerweise intramuskuläres Fettgewebe ist, ist bei postmenopausalen Frauen erhöht (Forsberg et al. 1991). Die Erklärung für diese Beobachtungen lieferte die Arbeitsgruppe Brown. Brown konnte nachweisen, dass Frauen im Vergleich zu Männern mehr Triglyceride als Glykogen zur Energiegewinnung nutzen. Dafür nutzen Frauen das Enzym Lipoproteinlipase (LPL). Die Aktivität der LPL fällt mit steigendem Alter und abnehmender Bewegung in der Sklettmuskulatur ab, so dass damit eine Zunahme des intramuskulären Fettgewebes verbunden ist (Brown 2008). Zusätzlich hat 
Östrogen einen unabhängigen Einfluss auf die LPL (Brown 2008). Postmeopausale Frauen, die keine Östrogen-Substitution erhalten, speichern weiterhin intramuskulär Lipide, können diese aber nicht mehr der ß-Oxidation zuführen. Konsekutiv kommt es zu einer Zunahme des intramuskulären Fettgewebes (Maltais et al. 2009). Die vorliegenden Ergebnisse bestätigen dies. Bei Betrachtung der Flächen und Durchmesser der glykolytischen und oxidativen Muskelzellen der Mm. gastrocnemii und Mm. longissimi dorsi im Verhältnis zu ihrem Muskelgewicht und zu ihrem Körpergewicht zeigen alle Ergebnisse signifikant erhöhte Werte für die SHAM-Gruppe. Für den M. soleus treten allerdings weder signifikante Unterschiede, noch eindeutige Tendenzen auf.

In der zusammenfassenden Betrachtung der Flächen und Durchmesser der glykolytischen und oxidativen Zellen des M. gastrocnemius fallen, wenn die Ergebnisse ins Verhältnis zum Muskeleigengewicht beziehungsweise zum Körpergewicht gesetzt werden, signifikant höhere Werte für die SHAM-Gruppe auf. Dies bedeutet, dass die SHAM-Gruppe, die weder ovarektomiert, noch mit einer Vibration behandelt worden ist, die größten glykolytischen und oxidativen Zellen im M. gastrocnemius aufweist. Dieses Ergebnis muss kritisch hinterfragt werden, denn bereits durchgeführte klinische Studien legen nahe, dass sich eine Ganzkörpervibration sehr wohl positiv auf die Beckenbodenmuskulatur von Frauen auswirkt (Stania et al. 2015). Lauper et al. konnten durch eine Ganzkörpervibration (stochastische Vibration) eine signifikante Steigerung der Beckenbodenmuskel-Aktivität im Vergleich zu einer maximalen freiwillig von Frauen durchgeführten Kontraktion erzielen (Lauper et al. 2009). Die Ergebnisse im vorliegenden Tiermodell können auch wie folgt interpretiert werden: Durch das fehlende Östrogen in allen ovarektomierten und mit einer Vibration behandelten Gruppen hat sich der glykolytische und oxidative Zellstoffwechsel unter der Muskelarbeit bei der Ganzkörpervibration so verändert, dass die Wassereinlagerungen, die bei Östrogenmangel in den Muskelzellen typischerweise auftreten, ausgeschwemmt worden sind.

Betrachtet man die Analyse für den M. longissmus dorsi, so zeigen sich signifikant kleinere Werte für die Flächen und Durchmesser der glykolytischen und oxidativen Zellen in der Gruppe OVX $+90 \mathrm{~Hz}$. Die Werte sind signifikant kleiner als in den Gruppen OVX+30 Hz, $\mathrm{OVX}+50 \mathrm{~Hz}$ und $\mathrm{OVX}+70 \mathrm{~Hz}$. Ebenfalls lässt sich eine Tendenz für die Gruppen SHAM und OVX erkennen, auch hier sind die Werte der Gruppe OVX $+90 \mathrm{~Hz}$ am geringsten (Abb. $24 \mathrm{u}$. 37, Tabelle 8). Diese Ergebnisse lassen nur den Schluss zu, dass eine horizontale Ganzkörpervibration mit $90 \mathrm{~Hz}$ ungeeignet ist, einen positiven Effekt auf die 
Rumpfmuskulatur auszuüben. Auch scheint gerade bei dieser Frequenz ein besonders antagonistischer Effekt des Östrogenmangel und der Muskelarbeit zu bestehen.

In der zusammenfassenden Betrachtung der Flächen und Durchmesser der glykolytischen und oxidativen Zellen im M. longissimus dorsi fallen, wenn die Ergebnisse in ein Verhältnis zum Körpergewicht gesetzt werden, signifikant höhere Werte für die Gruppe SHAM auf. Ihre Werte bleiben also unerreicht für alle ovarektomierten Gruppen, unabhängig von der gewählten Vibration. Der Schluss liegt also nahe, dass der Östrogenmangel und nicht die horizontale Ganzkörpervibration bei den ovarektomierten Gruppen die Ergebnisse stärker beeinflusst. Außerdem zeigt sich tendenziell die größte Anzahl oxidativer Zellen pro $\mathrm{mm}^{2}$ in der SHAM Gruppe.

Für die Anzahl der oxidativen Zellen im M. longissimus dorsi bestehen keine signifikanten Unterschiede innerhalb der ovarektomierten und mit Vibrationstherapie behandelten Gruppen, sondern lediglich tendenzielle Unterschiede. Hier zeigte die Gruppe OVX+90 Hz zwar die höchste Anzahl von oxidativen Zellen pro $\mathrm{mm}^{2}$ (Tabelle 13), aber dies darf, wie oben beschrieben, nicht fehlinterpretiert werden. Betrachtet man die Anzahl der oxidativen Zellen im Verhältnis zur Gesamtzellzahl pro $\mathrm{mm}^{2}$, zeigten sich in der Tendenz die höchsten Werte in der Gruppe OVX+30 Hz (Abb. 48, Tabelle 15). Das Verhältnis und die Anzahl von glykolytischen und oxidativen Zellen sind Gruppen-spezifisch unterschiedlich und zudem inkonsistent: Am meisten glykolytische Zellen hat die SHAM-Gruppe, oxidative Zellen findet man am häufigsten in der Gruppe OVX+30 Hz. Bei einer ausdauernden Muskelarbeit wie der 30-minütigen horizontalen Ganzkörpervibration ist der oxidative Stoffwechsel der Skelettmuskulatur gefordert (Schmidt et al. 2010). Der glykolytische Stoffwechsel wird eher für Muskelarbeiten, die nur wenige Minuten dauern, genutzt (Schmidt et al. 2010). Die horizontale Ganzkörpervibration mit $30 \mathrm{~Hz}$ wirkte sich also positiv auf die Bildung von Zellen mit einem oxidativen Stoffwechsel aus, welche überwiegend Typ-II-Fasern sind. Sie unterstützt die Fähigkeit zur ausdauernden Muskelarbeit. Über die Typ-II-Fasern (oxidative Zellen) ist bekannt, dass gerade diese eine höhere Rezeptorendichte für Östrogen besitzen (Brown 2008) und diese eigentlich in ihrer Anzahl und Größe zumindest bei postmenopausalen Frauen geringer sind (Widrick et al. 2003). Gerade der Verlust an Typ-IIFasern erschwert die Adaptation der Skelettmuskulatur nach einem absolviertem Training (Maltais et al. 2009). Somit sind die zellulären Veränderungen im Muskel nach einer $30 \mathrm{~Hz}$ Vibration als positiv zu werten. 
Das Ergebnis der vorliegenden Arbeit untermauert die These von Maltais et al., dass es weiterhin schwierig ist, den direkten Effekt des Östrogenmangels auf die Muskelfasern nachzuweisen. Der genaue Wirkmechanismus von Hormonen auf die Muskelfasern ist noch nicht ausreichend geklärt (Maltais et al. 2009). Auch ist die Rolle des Insulin-like growth factor-1 (IGF-1) auf den Aufbau von Muskelmasse noch unklar (Ciana et al. 2003). Unabhängig von hormonellen Einflüssen scheint eine Abnahme der Typ-II-Fasern zum regulären Alterungsprozess des Menschens zu gehören (Essen-Gustavsson und Borges 1986).

\subsection{Analysen der Zell- und Kapillardichte im Muskel}

Für den M. gastrocnemius lassen sich zwischen den Gruppen keine signifikanten Unterschiede im Hinblick auf die Zell- und Kapillardichte im Muskel ermitteln. Auffallend ist jedoch, dass vor allem die Gruppe OVX $+30 \mathrm{~Hz}$ die höchsten Werte sowohl für die Zellzahl, die Kapillaren als auch für deren Verhältnis zueinander aufweist (Tabelle 16). Ob eine höhere Anzahl an Kapillaren ggf. mit mehr Muskelkraft zur Beginn der Aktivität verbunden ist, wurde in der vorliegenden Arbeit nicht untersucht.

In den Analysen des M. longissimus dorsi treten keine signifikanten Unterschiede zwischen den Gruppen auf. Die höchste Anzahl an Kapillaren findet sich erstaunlicherweise in der Gruppe OVX. Beim Verhältnis zwischen Zellen und Kapillaren sind die höchsten Werte in der Gruppe $\mathrm{OVX}+70 \mathrm{~Hz} z \mathrm{zu}$ finden. Besonders interessant sind diese Ergebnisse, da Östrogen erwiesen positiv auf die Angiogenese wirkt, aber die SHAM-Gruppe keine höhere Kapillardichte o. ä. zeigt, sondern, die OVX-Gruppen hier besser abschneiden. Bei insgesamt nur tendenziellen Unterschieden in den Ergebnisen zu Kapillaren liegt für den M. longissimus dorsi die Vermutung nah, dass die horizontale Ganzkörpervibration keinen Einfluss auf die Angiogenese in diesem Rückenmuskel hat. Eine mögliche Erklärung für diesen (ausgebliebenen) Effekt mag sein, dass die Richtung der Vibration exakt parallel zur Rückenachse und damit zur Faserrichtung des M. longissimus dorsi verläuft.

In der Analyse für den M. soleus besteht die höchste Anzahl von Zellen in der Gruppe $\mathrm{OVX}+30 \mathrm{~Hz}$, die höchste Anzahl von Kapillaren und das beste Verhältnis zwischen Zellanzahl und Kapillaren findet sich in der Gruppe OVX+90 Hz. Die SHAM-Gruppe hat wiederum erstaunlicherweise trotz des vorhandenen hohen Östrogenspiegels das vergleichsweise geringste Vorkommen von Kapillaren. Auf den M. soleus scheint also die 
horizontale Ganzkörpervibration bei $90 \mathrm{~Hz}$ trotz des Östrogendefizits einen angioproliferativen Effekt zu haben, denn bei den ovarektomierten Tieren ohne Vibration ist die Anzahl der Zellen am geringsten. Es kann postuliert werden, dass durch die horizontale Ganzkörpervibration eine Zunahme der Kapillaren induziert wurde, welche einen konsekutiven Anstieg des Blutflusses und Scherkräfte in den Gefäßen bewirkte, wodurch die Angiogenese angeregt wurde (Badr et al. 2003). Das Östrogen bzw. der Mangel an Östrogen ist somit nicht verantwortlich für den Effekt der Zunahme von Kapillaren in den bei höheren Hertzzahlen vibrierten Tieren.

\subsection{Laktatdehydrogenase (LDH)-, die Citrat-Synthase (CS)- und der}

\section{Komplex I- Gehalt in den Mm. gastrocnemii, Mm. solei und Mm. longissimi dorsi}

Die drei ausgewählten Enzyme Laktatdehydrogenase (LDH), Citrat-Synthase (CS) und Komplex I gehören der Glykolyse, dem Citratzyklus und der Atmungskette an. In allen drei untersuchten Muskeln ließen sich aufgrund von hohen Standardabweichungen keine signifikanten Unterschiede, sondern nur Tendenzen zwischen den einzelnen Gruppen feststellen (Abb. 58-66, Tabelle 18).

In der Glykolyse findet der Abbau von Glucose zu Pyruvat statt. Es werden sämtliche Kohlenhydrate in dieser Weise zu Pyruvat abgebaut (Horn et al. 2005). In der Glykolyse kann Glukose zu Pyruvat (aerobe Glykolyse) oder zu Laktat (anaerobe Glykolyse) abgebaut werden. Unter Hypoxie kommt es durch die Laktatdehydrogenase (LDH) zur Reduktion des Pyruvats, so dass Laktat, welches in das Blut abgegeben wird, entsteht (Horn et al. 2005). Die niedrigsten LDH-Konzentrationen traten im M. soleus auf, dies verwundert nicht, da der M. soleus über einen überwiegend oxidativen Zellstoffwechsel verfügt (Peter et al. 1972).

Die Citrat-Synthase, die zum Citratzyklus gehört, darf als molekularer Marker interpretiert werden, mit dem die Enzymaktivität der Mitochondrien abgeschätzt werden kann (Opalka et al. 2004). Die Aktivität der Citrat-Synthase korreliert mit der Anzahl von Mitochondrien (Krasnianski et al. 2005). Die niedrigsten Konzentrationen für die Citrat-Synthase (CS) wurden für alle untersuchten Gruppen im M. longissimus dorsi dokumentiert. Danach folgen die Werte für den M. gastrocnemius und noch höhere Konzentrationen für die CS weisen alle Gruppen in der Untersuchung des M. soleus auf. Insgesamt liegen die Werte für die CS im M. gastrocnemius und M. soleus deutlich über dem der CS im M. longissimus dorsi. Für den M. 
soleus könnten diese hohen Werte durch seinen überwiegenden oxidativen Stoffwechsel erklärt werden. Der deutliche Unterschied zum M. longissimus dorsi könnte durch eine generell niedrigere oxidative Stoffwechselleistung des Muskels erklärt werden, oder der Unterschied beruht auf anderen Anforderungen der horizontalen Ganzkörpervibration an verschiedene Muskelgruppen: So gehören die Mm. gastrocnemii und solei zur Wadenmuskulatur, die senkrecht zur Vibrationsrichtung ausgerichtet ist und der $\mathrm{M}$. longissimus dorsi hingegen zur autochthonen Rückenmuskulatur, welche parallel zur horizontalen Vibration ausgerichtet ist. Die Ergebnisse zur Anzahl glykolytischer und oxidativer Zellen im M. longissimus dorsi decken sich für alle Gruppen durch Nachweis eines dominierenden glykolytischen Stoffwechsels. Dieses Ergebnis deckt sich auch mit der niedrigen Konzentration der CS im M. longissimus dorsi. Ebenso verwundert es nicht, dass der M. soleus, der wie oben bereits erwähnt überwiegend den oxidativen Stoffwechsel nutzt die höchsten Konzentrationen der CS aufweist (Peter et al. 1972).

Zur Diskussion steht sicherlich, ob die Konzentration der CS zu dem relevanten Zeitpunkt gemessen wurde, denn es existieren verschiedene Studien, in denen gezeigt wurde, dass direkt nach der Ganzkörpervibration die CS-Konzentration unverändert oder sogar vermindert ist (Ji et al. 1988). Wird die Gewebeprobe zur Konzentrationsbestimmung erst 24 Stunden nach einer akuten Muskelbelastung entnommen, so kann die CS-Konzentration um 30 \% erhöht sein (Savard et al. 1988). In den Ergebnissen zeigten sich trotz der entsprechenden Entnahme $24 \mathrm{~h}$ nach horizontaler Ganzkörpervibration keine signifikanten Unterschiede zwischen den vibrierten $(\mathrm{OVX}+30 \mathrm{~Hz}$; OVX $+50 \mathrm{~Hz}$; OVX $+70 \mathrm{~Hz}$; OVX $+90 \mathrm{~Hz})$ und nicht-vibrierten (SHAM; OVX) Gruppen.

Ähnlich verhalten sich die Ergebnisse für die Konzentration des Komplex I. Er gehört der Atmungskette an. Die Atmungskette ist die von allen oxidativen Stoffwechselprozessen genutzte letzte Passage zur Energiegewinnung; dafür werden in dieser Phase Elektronen aufgenommen (Horn et al. 2005). Die Elektronen gehören den im oxidativen Stoffwechsel reduzierten Reduktionsäquivalenten $\left(\mathrm{NADH} / \mathrm{H}^{+}\right.$und $\left.\mathrm{FADH}_{2}\right)$ an. Durch die Energie, die diese Elektronen besitzen, baut sich ein Protonengradient während der Atmungskette auf, der zur ATP-Synthese und damit zur Energiegewinnung dient (Horn et al. 2005). Somit werden die höchsten Konzentrationen für den Komplex I auch hier für den M. soleus (s.o.) erwartet. In den vorliegenden Ergebnissen zeigt sich die Konzentration des Komplex I für den M. soleus zwar nicht signifikant erhöht, aber deutlich höher als die im M. gastrocnemius oder M. 
longissimus dorsi (Tabelle 17). Die höchsten Konzentrationen für den Komplex I hat die SHAM-Gruppe. Dies könnte darauf hinweisen, dass das Östrogen einen positiven Effekt auf die Energiegewinnung in den Mitochondrien hat. Dieses Ergebnis deckt sich mit dem Wissen, dass bei Frauen in der Menopause ein Anstieg des oxidativen Stresses zu beobachten ist (Signorelli et al. 2006), denn Östrogen scheint vor oxidativem Stress zu schützen (Vina et al. 2006). Gleichzeitig kommt es durch eine Zunahme des Körpergewichts in der postmenopausalen Lebensphase zu einer Erhöhung des oxidativen Stresses (Wing et al. 1991). Oxidativer Stress bedeutet für die Mitochondrien einen Anstieg der reaktiven SauerstoffProduktion, welche wiederrum die Zellen in die Apoptose führt (Hiona und Leeuwenburgh 2008). Hinzu kommt, dass der oxidative Stress die mitochondriale DNA schädigt und dies dann $\mathrm{zu}$ einer verminderten Energiegewinnung in der Atmungskette führt (Bandy und Davison 1990). Die verminderte Energiegewinnung in der Atmungskette macht die Zelle anfälliger für die Apoptose, Muskelzellatrophie, Muskelzellnekrose und führt ggf. zur Sarkopenie (Maltais et al. 2009). Die geringste Konzentration für den Komplex I wurde für alle Gruppen erwartungsgemäß im M. longissimus dorsi ermittelt. Dieser wiederum niedrige Stoffwechselwert lässt sich, wie oben bereits diskutiert, durch eine generell niedrigere oxidative Stoffwechselleistung im M. longissimus dorsi erklären, oder es ist Ausdruck der unterschiedlichen Anforderungen der horizontalen Ganzkörpervibration an die verschiedene Muskelgruppen in Abhängigkeit von der Lage im Körper.

\subsection{Der Einfluss der horizontalen Ganzkörpervibration auf die Ratten- Tibia}

Der Zusammenhang zwischen Stimulation und einer daraus resultierenden Beeinflussung der Knochenheilung ist eine etablierte Hypothese zur Wirkungsweise der Ganzkörpervibration (Komrakova et al. 2013). Um diesen Zusammenhang im vorliegenden Projekt zu belegen, wurden in der Arbeitsgruppe die für die Tibia ermittelten Daten genutzt. Es wurden biomechanische Parameter an der Osteotomiestelle der ventralen Metaphyse sowie quantitative Parameter in Bezug auf Knochen und Kallus mittels Mikroradiographie, Histomorphometrie und Mikro-CT erhoben. Die detaillierte Analyse der Knochenwirkung der horizontalen Ganzkörpervibration findet sich in anderen Dissertationen der Arbeitsgruppe.

Die Analyse mittels Mikro-CT zeigte, dass es zwischen den Gruppen keine signifikanten Unterschiede der BMD gab. Das Knochenvolumen im Verhältnis zum Trabekelvolumen war 
in allen ovarektomierten Gruppen (OVX; OVX+30 Hz; OVX+50 Hz; OVX+70 Hz; OVX $+90 \mathrm{~Hz}$ ) unabhängig von der Vibration signifikant erniedrigt. Die Dichte von Kortikalis und Kallus war unter den Gruppen ohne signifikante Unterschiede $(\mathrm{p}>0,05)$ (Komrakova et al. 2013). Für die untersuchte Tibia gilt, dass eine horizontale Ganzkörpervibration die Kortikalis-Dicke $(\mathrm{OVX}<90 \mathrm{~Hz})$ und die Kallus-Dichte $(\mathrm{OVX}+30 \mathrm{~Hz})$ reduziert. Die Expression der alkalischen Phosphatase nahm zu $(\mathrm{OVX}+50 \mathrm{~Hz})$. Die reduzierte KortikalisDicke und Kallus-Dichte der Tibia wurde bei Tieren, welche mit Frequenzen $<90 \mathrm{~Hz}$ vibriert wurden gemessen. Diese Ergebnisse änderten sich auch nicht für die Tiere, die mit $90 \mathrm{~Hz}$ vibriert wurden (Komrakova et al. 2013). Die Dicke und die Dichte der Trabekel wurden nicht durch die mechanische Stimulation der horizontalen Ganzkörpervibration beeinflusst. Der Östrogenmangel hingegen verringerte die Kallus-Dichte und die Trabekel Eigenschaften der metaphysealen Tibia signifikant (Komrakova et al. 2013). 2014 konnten Stürmer et al. zeigen, dass eine WBV in Kombination mit Östrogen- oder Raloxifenappliaktion die Fraturheilung in osteopenischen Knochen verbessert (Stürmer et al. 2014). Die Fläche des Kallus zeigte sich in den Gruppen $(\mathrm{OVX}+70 \mathrm{~Hz})$ und $(\mathrm{OVX}+90 \mathrm{~Hz})$ im dorsalen Bereich verkleinert, im endostalen Bereich fanden wir jedoch im Vergleich zur OVX-Gruppe eine Zunahme der Kallus-Fläche in allen vibrierten Tier-Gruppen $(\mathrm{OVX}+30 \mathrm{~Hz} ; \mathrm{OVX}+50 \mathrm{~Hz} ; \mathrm{OVX}+70 \mathrm{~Hz}$; OVX+90 Hz) (Komrakova et al. 2013).

Zusammengefasst formuliert kann durch eine horizontale Ganzkörpervibration keine signifikante Verbesserung der Parameter für die Kortikalis oder den Kallus erreicht werden; hier scheint die vertikale Ganzkörpervibration überlegen zu sein (Komrakova et al. 2013). Es stellte sich vielmehr eine Verringerung der kortikalen Stärke an der ventralen Tibia und der Kallus-Fläche, sowie eine Abnahme der Kallus-Dichte im dorsalen Bereich dar. Die überwiegende Stabilisierung ist anscheinend auf den endostalen Kallus zurückzuführen (Komrakova et al. 2013). Aus Studien wissen wir, dass axiale Mikrobewegungen die Belastungs-, Kompressions- und Biegekräfte beinhalten günstige Effekte auf Frakturenden bei der Frakturheilung haben (Sarmiento et al. 1977). Scherkräfte hingegen haben einen schädigenden Effekt (Yamagishi und Yoshimura 1955). In der Analyse der Gen-Expression im Kallus fiel im Vergleich zur ovarektomierten Gruppe eine hochregulierte Expression der alkalischen Phosphatase in der Gruppe OVX $+50 \mathrm{~Hz}$ auf, welches ggf. als Verschlechterung des Zustandes eines eingeschränkten Knochenumsatzes verstanden werden kann (Komrakova et al. 2013). In der biomechanischen Untersuchung der Biegefestigkeit traten keine signifikanten Unterschiede zwischen den Gruppen auf. 
Zusammenfassend lässt sich sagen, dass auch die Ergebnisse zur Untersuchung des osteoporotischen Knochens darauf hinweisen, dass die horizontale Ganzkörpervibration keinen eindeutig positiven Effekt auf die Grunderkrankung und die Frakturheilung hat. 


\section{Zusammenfassung}

Die vorliegende Arbeit befasst sich mit der horizontalen Ganzkörpervibration mit verschiedenen Frequenzen auf ausgewählte Skelettmuskeln bei Östrogen-defizienten Sprague Dawley-Ratten. Analysiert wurde dieser Effekt anhand des etablierten Osteoporose-Modells der ovarektomierten Ratte. Die Halte- und Stützfunktion der Muskulatur darf im Hinblick auf die klinische Relevanz für uns Menschen in diesem Modell nicht vernachlässigt werden. 90 weibliche und geschlechtsreife Tiere im Alter von 3 Monaten wurden randomisiert in 6 Gruppen á 15 Tiere eingeteilt. So entstanden die folgenden Gruppen: SHAM; OVX; OVX+30 Hz; OVX+50 Hz; OVX+70 Hz; OVX+90 Hz. 75 Tiere wurden ovarektomiert, und 15 Tiere wurden SHAM-operiert. Nach 56 Tagen manifestierte sich eine Osteoporose bei den ovarektomierten Tieren. Im Folgenden wurde bei allen Ratten eine beidseitige Osteotomie der Tibia-Metaphysen mit stabiler T-Platten-Osteosynthese durchgeführt. Diese Untersuchungen sind Inhalt einer anderen Dissertationsarbeit. Ab dem 5. post-operativen Tag begann für 60 Ratten die horizontale Ganzkörpervibration in der für die jeweilige Gruppe spezifischen Frequenz. Die Vibration erfolgte über 30 Tage täglich für jeweils 15 Minuten. Danach wurden die Ratten getötet, um Blut, Uteri, Tibiae, Oberschenkelknochen, Wirbelkörper, Mm. gastrocnemii, Mm. longissimi dorsi, Mm. solei entnehmen und untersuchen zu können.

Für die Analyse der Wirkung einer osteoporotischen Stoffwechsellage auf die Skelettmuskulatur wurden den Versuchstieren die Mm. gastrocnemii und solei in toto und die Mm. longissimi dorsi partiell entnommen. Für die histologische Auswertung der drei ausgewählten Muskeln wurden $12 \mu \mathrm{m}$ dicke Schnitte zur Bestimmung der Muskelfasergröße, der Zellzahl und der Anzahl der Kapillaren angefertigt. Die Enzymaktivitäten für die Laktatdehydrogenase, Citrat-Synthase und für den Komplex I wurden mit einem Photometer gemessen. Die Enzymaktivität wurde jeweils im Verhältnis zum ebenfalls ermittelten Proteingehalt der Muskelprobe berechnet.

Beim Naßgewicht bestanden keine signifikanten Unterschiede zwischen den Muskeln (M. gatrocnemius, M. soleus) der verschiedenen Gruppen (SHAM, OVX, OVX+30 Hz, $\mathrm{OVX}+50 \mathrm{~Hz}, \mathrm{OVX}+70 \mathrm{~Hz}$ und $\mathrm{OVX}+90 \mathrm{~Hz}$ ). Tendenziell ist das Gewicht des M. gastrocnemius und des M. soleus in der SHAM-Gruppe geringer als in den übrigen Gruppen, und auch das Körpergewicht der Tiere dieser Gruppe ist im Vergleich zu den anderen Gruppen erniedrigt. Die horizontale WBV und/ oder der Östrogenmangel bewirkt eine 
Gewichtszunahme der Muskelmasse. Das Bestimmen der Muskelfläche, des Muskeldurchmessers und der Muskelfasertypen, der jeweils drei ausgewählten Muskeln (M. gastrocnemius, M. longissimus dorsi und M. soleus) pro Tier diente zu Beurteilung des Einflusses vom induzierten Östrogenmangel und des Effektes der horizontalen Ganzkörpervibration auf die Sklettmuskelzellen an sich. Setzen wir die Flächen und Durchmesser der sowohl glykolytischen als auch oxidativen Muskelzellen der $\mathrm{Mm}$. gastrocnemii und Mm. longissimi dorsi ins Verhältnis zu ihrem Muskelgewicht bzw. zu ihrem Körpergewicht, so lassen sich in allen Ergebnissen dafür signifikant erhöhte Werte für die SHAM-Gruppe ermitteln, dass heißt durch die 30 Tage horizontale Ganzkörpervibration konnte dieses Defizit nicht aufgehoben werden. Für den M. soleus treten weder signifikante Werte noch eindeutige Tendenzen im Gruppenvergleich auf. Außerdem lässt sich für die glykolytischen Zellen im M. longissimus dorsi die Tendenz erkennen, dass in der SHAMGruppe die höchste Anzahl von glykolytischen Zellen vorliegt. Betrachten wir die Anzahl der oxidativen Zellen im Verhältnis zur Zellzahl pro $\mathrm{mm}^{2}$, zeigen sich tendenziell die höchsten Werte in der Gruppe OVX $+30 \mathrm{~Hz}$. Im Ergebnis zeigen sich also die glykolytischen und oxidativen Zellen unterschiedlich.

Für die Analysen der Anzahl der Zellen und der Kapillaren pro $\mathrm{mm}^{2}$ lassen sich für den M. gastrocnemius und für den M. longissimus dorsi keine signifikanten Unterschiede zwischen den WBV-Gruppen ermitteln. Für den M. soleus liegt die höchste Zellzahl in der Gruppe $\mathrm{OVX}+30 \mathrm{~Hz}$, die höchste Anzahl von Kapillaren finden wir in der Gruppe OVX+90 Hz, dort liegen auch die höchsten Werte für das Verhältnis zwischen Zellanzahl und Kapillaren vor. Für die Anzahl der Kapillaren und deren Verhältnis zur Anzahl der Zellen konnten signifikant erniedrigte Werte für die Gruppen SHAM; OVX; OVX+30 Hz und OVX+50 Hz im Vergleich zur Gruppe OVX+90 Hz ermittelt werden.Die bei $90 \mathrm{~Hz}$ sehr stark wirkenden Scherkräfte scheinen sich positiv auf die Kapillardurchblutung und damit auf die gesamte Durchblutung auszuwirken.

In der Analyse der untersuchten für den Energiestoffwechsel relevanten Enzyme (Laktatdehydrogenase, Citrat-Synthase und Komplex I) waren keine signifikanten Unterschiede zwischen den drei ausgewählten Muskeln oder zwischen den gewählten Tiergruppen detektierbar (SHAM, OVX, OVX $30 \mathrm{~Hz}$, OVX $50 \mathrm{~Hz}$, OVX $70 \mathrm{~Hz}$ und OVX $90 \mathrm{~Hz})$. 
Abschließend lässt sich formulieren, dass die horizontale Ganzkörpervibration in den untersuchten Parametern keinen richtungsweisenden Effekt auf die Leistungsfähigkeit der Skelettmuskulatur hat. Es zeigen sich zum Teil sogar unvorteilhafte Effekte durch die Anwendung der horizontalen Ganzkörpervibration (Komrakova et al. 2013). Die vorliegenden Ergebnisse weisen darauf hin, dass die Ausrichtung, die Frequenz und die Dauer der Anwendung noch optimierbar sind und individuell für die jeweiligen Patienten ausgewählt und angepasst werden müssen, obwohl sie zum aktuellen Zeitpunkt schon als Therapie für Patienten eingesetzt wird.

\section{Summary}

The present study investigated the effect of horizontal whole-body vibration (WBV) with various frequencies on selected muscles in intact and osteopenic Sprague Dawley rats. Therefore we analyzed the effect of WBV by using the well-known ovariectomized rat model with osteopenia. In total 90 female and sexually mature rats at three months of age were randomized disposed in 6 groups with 15 animals (SHAM; OVX; OVX $30 \mathrm{~Hz}$; OVX $50 \mathrm{~Hz}$; OVX $70 \mathrm{~Hz}$ and OVX $90 \mathrm{~Hz}$ ). 56 days after ovariectomy the osteopenia occurred very equal to postmenopausal women in these rats and bilateral metaphyseal tibia osteotomy and T-plate osteosynthesis were performed. 5 days after osteotomy the WBV was started with the following groups in the selected frequencies: OVX $30 \mathrm{~Hz}$; OVX $50 \mathrm{~Hz}$; OVX $70 \mathrm{~Hz}$ and OVX $90 \mathrm{~Hz}$. We did the WBV for 30 days 30 minutes a day. After that, rats were decapitated to harvest blood samples, uteri, tibiae, femora, vertebral bodies, Mm. gastrocnemii, $\mathrm{Mm}$. longissimi dorsi and $\mathrm{Mm}$. solei for further investigations. The Mm. gastrocnemii and $\mathrm{Mm}$. solei were harvested in toto in contrast to the Mm. longissimi dorsi which were fractionally harvested. For histological analyses of muscle fibers we cut this muscle samples into serial cross sections of $12 \mu \mathrm{m}$ thickness. The investigation included the classification of muscle fibers (glycolytic type versus oxidative type), the determination of cell count, cross-sectional areas and of the capillary density. The analyses of muscle enzymes activities (LDH, CS, Complex I) were assayed by using a photometer. Every enzyme activity was estimated relative to the total protein content. For all volume weights of the in toto harvested muscles (M. gastrocnemius, M. soleus) no significant differences were found. By trend decreased weights for the M. gastrocnemius and M. soleus were detected in the intact rats (SHAM) comparted to other groups. It seems that the horizontal WBV and/ or the estrogen deficiency may responsible for a gain of muscle weight. 
The histological investigations of the selected muscles for each animal were done to evaluate the bearing of estrogen-deficiency and the effect of horizontal WBV. In (the M. gastrocnemius and M. longissimus dorsi) the ratio of cross-sectional areas (glycolytic and oxidative fibers), the muscle weights and the bodyweights respectively, showed significant increased values refer to the SHAM-group. There were no significant differences or clearly trends detected for the M. soleus, in comparison of all groups. Furthermore there is a trend for the highest number of glycolytic fibers in the M. longissimus dorsi found in the SHAM-group. The highest number of oxidative fibers in this muscle was however counted in the OVX $+30 \mathrm{~Hz}-$ group. In conclusion there is a different presentation of the glycolytic and the oxidative fibers. Capillary density showed no significant differences in the $\mathrm{M}$. gastrocnemius and $\mathrm{M}$. longissimus dorsi. The M. soleus did have the highest cell count in the group $\mathrm{OVX}+30 \mathrm{~Hz}$ and the highest capillary density was detected in the group $\mathrm{OVX}+90 \mathrm{~Hz}$, moreover in this group are the highest values refer to the relationship of cell count and capillary density. Capillary density and in relation to the cell count showed in comparison to group OVX $+90 \mathrm{~Hz}$ significant decreased values in the groups SHAM; OVX; OVX $+30 \mathrm{~Hz}$ and $\mathrm{OVX}+50 \mathrm{~Hz}$ respectively. Referred to the specified muscle enzyme activities there were no significant differences neither between the muscles nor between the study groups.

Though WBV is already used in various therapies. The results presented in here pointed out the necessity to adapt the direction, frequency and duration of the WBV to the refered desease and the individual patient. 


\section{Tabellenverzeichnis}

- Tabelle 1: Übersicht zu den verschieden Muskelfaserklassifikationen 6

- Tabelle 2 WHO-Diagnosekriterien Osteoporose 24

- Tabelle 3: Merkmale der primären Osteoporose-Typen 25

- Tabelle 4: Einteilung der Osteoporose nach ihrer Ätiologie 27

- Tabelle 5: Tiergewichte für die Gruppen: SHAM, OVX, OVX $30 \mathrm{~Hz}$, OVX $50 \mathrm{~Hz}$, OVX $70 \mathrm{~Hz}$ und OVX $90 \mathrm{~Hz}$ in Gramm 56

- Tabelle 6: Durchschnittliche tägliche Futteraufnahme der Ratten 57

- Tabelle 7: Flächen und Durchmesser glykolytischer und oxidativer Muskelfasern der Mm. gastrocnemii; Darstellung der MW/ Std. 75

- Tabelle 8: Flächen und Durchmesser glykolytischer und oxidativer Muskelfasern der Mm. longissimi; Darstellung der MW/ Std.

- Tabelle 9: Flächen und Durchmesser oxidativer Muskelfasern, der Mm. solei Darstellung der MW/ Std.

- Tabelle 10: Glykolytische Muskelfasern des M. gastrocnemius. Flächen und Gewichte; Darstellung der MW/ Std.

- Tabelle 11: Oxidative Muskelfasern des M. gastrocnemius. Flächen und Gewichte; Darstellung der MW/ Std.

- Tabelle 12: Oxidative Muskelfasern des M. soleus. Flächen und Gewichte; Darstellung der MW/ Std.

- Tabelle 13: Glykolytische Muskelfasern des M. longissimus; Darstellung der MW/ Std.

- Tabelle 14: Oxidative Muskelfasern des M. longissimus; Darstellung der MW/ Std.

\section{0}

- Tabelle 15: Verhältnisse der glykolytischen und oxidativen Zellen des M. longissimus pro $\mathrm{mm}^{2}$; Darstellung der MW/ Std.

- Tabelle 16: Zellen pro $\mathrm{mm}^{2}$, Kapillaren pro $\mathrm{mm}^{2}$, Kapillaren pro Zelle pro $\mathrm{mm}^{2}$ für die Mm. gastrocnemius, longissimus und soleus; Darstellung der MW/ Std.

88

- Tabelle 17: Aktivität der Laktatdehydrogenase, der Citrat-Synthase und des Komplexes I [U/g]; Darstellung der MW/ Std. 
- Tabelle 18: Zusammenfassung der Ergebnisse 


\section{Abbildungsverzeichnis}

Abb. 1: Aufbau der Muskulatur (http://www. medizinfo.de)

Abb. 2: Sarkomeraufbau (http://user.medunigraz.at/helmut.hinghofer-szalkay/SMer.jpg) 4

Abb.3: Reaktionsfolge in der Glykolyse (http://upload.wikimedia.org/wikipedia/commons /thumb/d/d5/Glycolysis_overview.svg/2000px-Glycolysis_overview.svg.png)

Abb. 4: Übersicht über die Atmungskette

(http://www.spektrum.de/lexika/images/ern/a058.jpg)

Abb.5: Schema der ß-Oxidation (http://www.nature.com/scitable/content/ne0000/ne0000 /ne0000/ne0000/14897250/dapoian_v2_1_2.jpg)

Abb. 6: ATPase-Färbung M. gastrocnemius (Ratte 02; SHAM)

Abb. 7: ATPase-Färbung M. soleus (Ratte 11; SHAM)

Abb. 8: ATPase-Färbung M. longissimus dorsi (Ratte 46; OVX+30 Hz)

Abb. 9: ATPase-Färbung M. soleus (Ratte 45; OVX+30 Hz)

Abb. 10: PAS-Färbung M. gastrocnemius (Ratte 14; SHAM)

Abb. 11: Laktatdehydrogenase Reaktion

Abb. 12: Gewicht des M. gastrocnemius der Ratten nach 30 Tagen WBV; Darstellung MW/

Std.

Abb. 13: Gewicht des M. soleus [mg] der Ratten nach 30 Tagen WBV; Darstellung MW/ Std.

Abb. 14: Gewicht des M. gastrocnemius [g] im Verhältnis zum Körpergewicht [g] der Ratten nach 30 Tagen WBV; Darstellung MW/ Std.

Abb. 15: Gewichte des M soleus [mg] im Verhältnis zum Körpergewicht [g] der Ratten nach 30 Tagen WBV; Darstellung MW/ Std.

Abb. 16: Gewichte der Ratten-Uteri am Tag der Tötung [mg] (Tag 98. nach Ovarektomie) der Ratten nach 30 Tagen WBV; Darstellung MW/ Std.

60

Abb. 17: Fläche der glykolytischen Muskelfasern im M. gastrocnemius $\left[\mathrm{mm}^{2}\right]$ der Ratten nach 30 Tagen WBV; Darstellung MW/ Std.

61

Abb. 18: Fläche der glykolytischen Muskelfasern $\left[\mathrm{mm}^{2}\right]$ zum Gewicht des M. gastrocnemius [g] der Ratten nach 30 Tagen WBV; Darstellung MW/ Std.

61

Abb. 19: Verhältnis der glykolytischen Muskelfasern im M. gastrocmemius [ $\left.\mathrm{mm}^{2}\right]$ zum Körpergewicht [g] der Ratten nach 30 Tagen WBV; Darstellung MW/ Std.

62

Abb. 20: Flächen der oxidativen Muskelfasern im M. gastrocnemius; der Ratten nach 30 Tagen WBV; Darstellung MW/ Std. 
Abb. 21: Flächen der oxidativen Muskelfasern $\left[\mathrm{mm}^{2}\right]$ zum Gewicht des M. gastrocnemius [g]; Darstellung MW/ Std.

Abb. 22: Flächen der oxidativen Muskelfasern $\left[\mathrm{mm}^{2}\right]$ zum Körpergewicht $[\mathrm{g}]$ der Ratten nach 30 Tagen WBV; Darstellung MW/ Std.

Abb. 23: Flächen der glykolytischen Muskelfasern $\left[\mathrm{mm}^{2}\right]$ im M. longissimus dorsi der Ratten nach 30 Tagen WBV; Darstellung MW/ Std.

64

Abb. 24: Verhältnis der glykolytischen Muskelfasern $\left[\mathrm{mm}^{2}\right]$ zum Körpergewicht $[\mathrm{g}]$ des M. longissimus dorsi der Ratten nach 30 Tagen WBV; Darstellung MW/ Std.

Abb. 25: Fläche der oxidativen Muskelfasern $\left[\mathrm{mm}^{2}\right]$ im M. longissimus dorsi der Ratten nach 30 Tagen WBV; Darstellung MW/ Std.

Abb. 26: Verhältnis der Flächen der oxidativen Muskelfasern des M. longissimus dorsi [ $\left.\mathrm{mm}^{2}\right]$ zum Körpergewicht [g] der Ratten nach 30 Tagen WBV; Darstellung MW/ Std.

66

Abb. 27: Fläche der oxidativen Muskelfasergröße $\left[\mathrm{mm}^{2}\right]$ im M. soleus der Ratten nach 30 Tagen WBV; Darstellung MW/ Std.

Abb. 28: Fläche der oxidativen Muskelfasergröße [ $\left.\mathrm{mm}^{2}\right]$ zum Gewicht des M. soleus [mg] der Ratten nach 30 Tagen WBV; Darstellung MW/ Std.

Abb. 29: Fläche der oxidativen Muskelfasergröße $\left[\mathrm{mm}^{2}\right]$ zum Körpergewicht [g] der Ratten nach 30 Tagen WBV; Darstellung MW/ Std.

68

Abb. 30: Durchmesser der glykolytischen Muskelfasern [mm] des M.gastrocnemius; der Ratten nach 30 Tagen WBV; Darstellung MW/ Std.

68

Abb. 31: Verhältnis des Durchmessers der glykolytischen Muskelfasern [mm] zum Gewicht des M. gastrocnemius [g] der Ratten nach 30 Tagen WBV; Darstellung MW/ Std.

69

Abb. 32: Verhältnis des Durchmessers der glykolytischen Muskelfasern [mm] zum Körpergewicht [g] der Ratten nach 30 Tagen WBV; Darstellung MW/ Std.

Abb. 33: Durchmesser der oxidativen Muskelfasern [mm] des M. gastrocnemius der Ratten nach 30 Tagen WBV; Darstellung MW/ Std.

Abb. 34: Verhältnis des Durchmessers der oxidativen Muskelfasern [mm] zum Gewicht des M. gastrocnemius [g] der Ratten nach 30 Tagen WBV; Darstellung MW/ Std.

Abb. 35: Verhältnis des Durchmessers der oxidativen Muskelfasern [mm] zum Körpergewicht [g] der Ratten nach 30 Tagen WBV; Darstellung MW/ Std.

Abb. 36: Durchmesser der glykolytischen Muskelfasern [mm] des M. longissimus dorsi der Ratten nach 30 Tagen WBV; Darstellung MW/ Std.

Abb. 37: Durchmesser der glykolytischen Muskelfasern [mm] zum Körpergewicht [g] des M. longissimus dorsi der Ratten nach 30 Tagen WBV; Darstellung MW/ Std. 
Abb. 38: Durchmesser der oxidativen Muskelfasern [mm] des M. longissimus dorsi der Ratten nach 30 Tagen WBV; Darstellung MW/ Std.

Abb. 39: Durchmesser der oxidativen Muskelfasern [mm] zum Körpergewicht [g] des M. longissimus dorsi der Ratten nach 30 Tagen WBV; Darstellung MW/ Std.

Abb. 40: Durchmesser der oxidativen Muskelfasern [mm] im M. soleus der Ratten nach 30 Tagen WBV; Darstellung MW/ Std.

Abb. 41: Durchmesser der oxidativen Muskelfasern [mm] des M. soleus im Verhältnis zum Gewicht des M. soleus [mg] der Ratten nach 30 Tagen WBV; Darstellung MW/ Std.

Abb. 42: Durchmesser der oxidativen Muskelfasern [mm] des M. soleus zum Körpergewicht in [g] der Ratten nach 30 Tagen WBV; Darstellung MW/ Std. 75

Abb. 43: Anzahl der glykolytischen Zellen pro $\mathrm{mm}^{2}$ im M. longissimus dorsi der Ratten nach 30 Tagen WBV; Darstellung MW/ Std.

80

Abb. 44: Anzahl der oxidativen Zellen pro $\mathrm{mm}^{2}$ im M. longissimus dorsi der Ratten nach 30 Tagen WBV; Darstellung MW/ Std.

Abb. 45: Anzahl der Gesamtzellzahl pro $\mathrm{mm}^{2}$ im M. longissimus dorsi der Ratten nach 30 Tagen WBV; Darstellung MW/ Std.

Abb. 46: Anteil der glykolytischen Zellen an der Gesamtzellzahl der Zellen in \%, pro $\mathrm{mm}^{2}$ im M. longissimus dorsi der Ratten nach 30 Tagen WBV; Darstellung MW/ Std.

Abb. 47: Anteil der oxidativen Zellen an der Gesamtzellzahl der Zellen in \%, pro $\mathrm{mm}^{2}$ im M. longissimus dorsi der Ratten nach 30 Tagen WBV; Darstellung MW/ Std.

Abb. 48: Anzahl der Muskelfasern pro $\mathrm{mm}^{2}$ des M. gastrocnemius der Ratten nach 30 Tagen WBV; Darstellung MW/ Std.

Abb. 49: Anzahl der Kapillaren pro $\mathrm{mm}^{2}$ des M. gastrocnemius der Ratten nach 30 Tagen WBV; Darstellung MW/ Std.

Abb. 50: Verhältnis der Kapillaren zur Gesamtzellzahl pro $\mathrm{mm}^{2}$ des M. gastrocnemius der Ratten nach 30 Tagen WBV; Darstellung MW/ Std.

84

Abb. 51: Anzahl der Zellen pro $\mathrm{mm}^{2}$ des M. longissimus dorsi der Ratten nach 30 Tagen WBV; Darstellung MW/ Std.

Abb. 52: Anzahl der Kapillaren pro $\mathrm{mm}^{2}$ des M. longissimus dorsi der Ratten nach 30 Tagen WBV; Darstellung MW/ Std.

Abb. 53: Verhältnis der Kapillaren zur Gesamtzellzahl pro $\mathrm{mm}^{2}$ im M. longissimus dorsi; Darstellung MW/ Std. 86

Abb. 54: Anzahl der Muskelzellen pro $\mathrm{mm}^{2}$ im M. soleus der Ratten nach 30 Tagen WBV; Darstellung MW/ Std. 
Abb. 55: Anzahl der Kapillaren pro $\mathrm{mm}^{2}$ im M. soleus der Ratten nach 30 Tagen WBV; Darstellung MW/ Std.

Abb. 56: Verhältnis der Kapillaren zur Gesamtzellzahl pro $\mathrm{mm}^{2}$ im M. soleus der Ratten nach 30 Tagen WBV; Darstellung MW/ Std.

Abb. 57: Aktivität der Lakatatdehydrogenase im M. gastrocnemius [U/g] Protein der Ratten nach 30 Tagen WBV; Darstellung MW/ Std.

Abb. 58: Aktivität der Laktatdehydrogenase im M. longissimus dorsi [U/g] Protein der Ratten nach 30 Tagen WBV; Darstellung MW/ Std.

Abb. 59: Aktivität der Laktatdehydrogenase im M. soleus [U/g] Protein der Ratten nach 30 Tagen WBV; Darstellung MW/ Std.

Abb. 60: Aktivität der Citrat-Synthase im M. gastrocnemius [U/g] Protein der Ratten nach 30 Tagen WBV; Darstellung MW/ Std.

Abb. 61: Aktivität der Citrat-Synthase im M. longissimus dorsi [U/g] Protein der Ratten nach 30 Tagen WBV; Darstellung MW/ Std.

Abb 62: Aktivität der Citrat-Synthase im M. soleus [U/g] Protein der Ratten nach 30 Tagen WBV; Darstellung MW/ Std.

Abb. 63: Aktivität des Komplex I im M. gastrocnemius [U/g] Protein der Ratten nach 30 Tagen WBV; Darstellung MW/ Std.

Abb. 64: Aktivität des Komplex I im M. longissimus dorsi [U/g] Protein der Ratten nach 30 Tagen WBV; Darstellung MW/ Std.

Abb 65: Aktivität des Komplex I im M. soleus [U/g] Protein der Ratten nach 30 Tagen WBV; Darstellung MW/ Std. 


\section{Literaturverzeichnis}

Badr I, Brown MD, Egginton S, Hudlická O, Milkiewicz M, Verhaeg J (2003): Differences in local environment determine the site of physiological angiogenesis in rat skeletal muscle. Exp Physiol $\underline{88}$ (5), 565-568

Bandy B, Davison AJ (1990): Mitochondrial mutations may increase oxidative stress: implications for carcinogenesis and aging? Free Radic Biol Med $\underline{8}$ (6), 523-539.

Baum E, Peters KM (2009): Primäre Osteoporose- leitliniengerechte Diagnostik und Therapie. Dtsch Aerztebl 33, 573-582

Brown M. (2008): Skeletal muscle and bone: effect of sex steroids and aging. Adv Physiol Educ $\underline{32}$ (2), 120-126

Bundesminesterium für Arbeit und Soziales (2007): Handbuch Ganzkörper-Vibrationen. EUHandbuch GKV Handbuch zum Thema GKV Seite 1 09/05/2007 Handbuch zum Thema Ganzkörper-Vibration Rechtlich nicht bindendes Handbuch im Hinblick auf die Umsetzung der Richtlinie 2002/44/EG über Mindestvorschriften zum Rechtlich nicht bindendes Handbuch im Hinblick auf die Umsetzung der Richtlinie 2002/44/EG über Mindestvorschriften zum Schutz von Sicherheit und Gesundheit der Arbeitnehmer vor der Gefährdung durch physikalische Einwrkungen (Vibrationen) Gefährdung durch physikalische Einwirkungen (Vibrationen). Unter Mitarbeit von Berufsgenossenschaftliches Institut für Arbeitsschutz Augustin (BGIA) SG „Vibration“ Fachausschuss „Maschinenbau Fertigungssysteme Stahlbau“ der BGZ beim Hauptverband der gewerblichen Berufsgenossenschaften St. Landesamt für Arbeitsschutz Potsdam (LAS), 1-63

Ciana P, Raviscioni M, Mussi P, Vegeto E, Que I, Parker MG (2003): In vivo imaging of transcriptionally active estrogen receptors. Nat Med $\underline{9}(1), 82-86$

Corrado A, Neve A, Macchiarola A, Gaudio A, Marucci A, Cantatore FP (2013): RANKL/OPG Ratio and DKK-1 Expression in Primary Osteoblastic Cultures from Osteoarthritic and Osteoporotic Subjects. J Rheumatol $\underline{40}$ (5), 684-694 
Dahlberg E (1982): Characterization of the cytosolic estrogen receptor in rat skeletal muscle. Biochim Biophys Acta $\underline{717}$ (1), 65-75

Decker K (2005): Georg Franz Knoop 100 Jahre ß-Oxidation der Fettsäuren. BIOspektrum 11 (02), 188-191

Duncan RL, Turner CH (1995): Mechanotransduction and the Functional Response of Bone to mechanical Strain. Calcif Tissue Int $\underline{57}$ 344-358

DVO Leitlinie Osteoporose (2014): Prophylaxe, Diagnostik und Therapie der Osteoporose bei Männern $\mathrm{ab}$ dem 60. Lebensjahr und bei postmenopausalen Frauen. Leitlinie des Dachverbands der Deutschsprachigen Wissenschaftlichen Osteologischen Gesellschaften e.V. Kurzfassung und Langfassung.

http://www.dv-osteologie.org/uploads/Leitlinie\%202014/DVO-

Leitlinie \%20Osteoporose $\% 202014 \% 20$ Kurzfassung\%20und $\% 20$ Langfassung $\% 20$ Version $\% 2$ 01a\%2012\%2001\%202016.pdf

Egginton S (2011): Physiological factors influencing capillary growth. Acta Physiol (Oxf) $\underline{202}$ (3), 225-239

Essén-Gustavsson B, Borges O (1986): Histochemical and metabolic characteristics of human skeletal muscle in relation to age. Acta Physiol Scand $\underline{126}$ (1), 107-114

Findlay JK (1986): Angeonesis in reproductive tissues. J Endocrinol 111 (3), 357-366

Fisher JS, Hasser EM, Brown M (1998): Effects of ovariectomy and hindlimb unloading on skeletal muscle. J Appl Physiol 85 (4), 1316-1321

Forsberg AM, Nilsson E, Werneman J, Bergström J, Hultman E (1991): Muscle composition in relation to age and sex. Clin Sci $\underline{81}$ (2), 249-256

Fritton JC, McLeod KJ, Rubin CT (2000): Quantifying the strain history of bone. Spatial uniformity and self-similarity of low -magnitude strains. J Biomech $\underline{33}$ (3), 317-325 
Frost HM (1997): On our age-related bone loss: insights from a new paradigm. J Bone Miner Res $\underline{12}(10), 1539-1546$

Gallasch E, Kenner T (1997): Characterisation of arm microvibration recorded on an accelerometer. Eur J Appl Physiol Occup Physiol 1997 (75), 226-232

GovindarajanP, Böcker W, El Khassawna T, Kampschulte M, Schlewitz G, Huerter B (2014): Bone Matrix, Cellularity, and Structural Changes in a Rat Model with High-Turnover Osteoporosis Induced by Combined Ovariectomy and a Multiple-Deficient Diet. Am J Pathol 184 (3), 765-777

Haas CT, Turbanski S, Kaiser I, Schmidtbleicher D (2004): Biomechanische und physiologische Effekte mechanischer Schwingungsreize beim Menschen. Deutsche Zeitschrift für Sportmedizin $\underline{55}(2), 34-43$

Hadjidakis DJ, Androulakis II (2006): Bone remodeling. Ann N Y Acad Sci 1092, 385-396. Hatori M, Hasegawa A, Adachi H, Shinozaki A, Hayashi R, Okano H (1993): The effects of walking at the anaerobic threshold level on vertebral bone loss in postmenopausal women. Calcif Tissue Int $\underline{52}(6), 411-414$

Häussler B, Gothe H, Göl D, Glaeske G, Pientka L, Felsenberg D (2007): Epidemiology, treatment and costs of osteoporosis in Germany- the BoneEVA Study. Osteoporos Int 18(1), $77-84$

Herold G: Innere Medizin. Gerd Herold (Verlag), Köln 2010

Hick C, Hartmann J: Muskelphysiologie. In Hick C, Hick A (Hrsg.): Intensivkurs Physiologie. 5. Auflage; Elsevier, Urban \& Fischer, München Jena 2006

Hiona A, Leeuwenburgh C (2008): The role of mitochondrial DNA mutations in aging and sarcopenia: implications for the mitochondrial vicious cycle theory of aging. Exp Gerontol $\underline{43}$ (1), 24-33 
Horn F, Moc I, Schneider N, Grillhösl C, Berghold S, Lindenmeier G: Stoffwechsel der Kohlenhydrate, Stoffwechsel der Lipide, Herkunft des ATP. In Horn F (Hrsg.): Biochemie des Menschen. Das Lehrbuch für das Medizinstudium. 3. Auflage; Thieme, Stuttgart 2005

Jeong S, Yoon M (2012): Swimming's prevention of ovariectomy-induced obesity through activation of skeletal-muscle PPAR $\alpha$. Int J Sport Nutr Exerc Metab 22 (1), 1-10

Ji LL, Stratman FW, Lardy HA (1988): Enzymatic down regulation with exercise in rat skeletal muscle. Arch Biochem Biophys 263 (1), 137-149

Jubrias SA, Odderson IR, Esselman PC, Conley KE (1997): Decline in isokinetic force with age: muscle cross-sectional area and specific force. Pflugers Arch 434 (3), S. 246-253

Kablar B, Rudnicki M A (2000): Skeletal muscle development in the mouse embryo. Histol Histopathol 15 (2), 649-656

Kadi F, Karlsson C, Larsson B, Eriksson J, Larval M; Billig H, Jonsdottir IH (2002): The effects of physical activity and estrogen treatment on rat fast and slow skeletal muscles following ovariectomy. J Muscle Res Cell Motil 23 (4), S. 335-339

Kahlert S, Grohé C, Karas RH, Löbbert K, Neyses L, Vetter H (1997): Effects of estrogen on skeletal myoblast growth. Biochem Biophys Res Commun 232 (2), 373-378

Kaspar D, Seidl W, Neidlinger-Wilke C, Ignatius A, Claes L (2000): Dynamic cell stretching increases human osteoblast proliferation and CICP synthesis but decreases osteocalcin synthesis and alkaline phosphatase activity. J Biomech 2000 (33), 45-51

Komrakova M, Stürmer EK, Werner C, Wicke M, Kolios L, Sehmisch S, Tezval M, Daub F, Martens T, Witzenhausen P (2010): Effect of human parathyroid hormone hPTH (1-34) applied at different regimes on fracture healing and muscle in ovariectomized and healthy rats. Bone $\underline{47}(3), 480-492$ 
Komrakova M, Sehmisch S, Tezval M, Ammon J, Lieberwirth P, Sauerhoff C, Trautmann L, Wicke M, Dullin C, Stürmer KM (2013): Identification of a Vibration Regime Favorable for Bone Healing and Muscle in Estrogen-Deficient Rats. Calcif Tissue Int 92 (6), 509-520

Krasnianski A, Deschauer M, Neudecker S, Gellerich FN, Müller T, Schoser BG, Krasnianski M, Zierz S (2005): Mitochondrial changes in skeletal muscle in amyotrophic lateral sclerosis and other neurogenic atrophies. Brain $\underline{128}$ (Pt 8), 1870-1876

Krebs HA, Johnson W A (1937): The Role of Citric Acid in Intermediate Metabolism in Animal Tissues. Enzymologia 1937 (4), 148-156

Krogh A: Anatomie und Physiologie der Capillaren. 5. Auflage; Springer, Berlin Heidelberg 1924

Kyriakides ZS, Petinakis P, Kaklamanis L, Sbarouni E, Karayannakos P, Iliopoulos D, Dontas I, Kremastinos DT (2001): Intramuscular administration of estrogen may promote angiogenesis and perfusion in a rabbit model of chronic limb ischemia. Cardiovasc Res $\underline{49}$ (3), 626-633

Lauper M, Kuhn A, Gerber R, Luginbühl H, Radlinger L (2009): Pelvic floor stimulation: What are the good vibrations? Neurourol Urodyn $\underline{28}$ (5), 405-410

Lee K, Jessop H, Suswillo R, Zaman G, Lanyon L (2003): Endocrinology: Bone adaptation requires oestrogen receptor- $\alpha$. Nature $\underline{424}$ (6947), S. 389

Lüllmann-Rauch R: Taschenlehrbuch Histologie. 3. Auflage; Thieme, Stuttgart New York 2009

Mahieu NN, Witvrouw E, Van de Voorde D, Michilsens D, Arbyn V, Van den Broecke W (2006): Improving Strength and Postural Control in Young Skiers. Whole-Body Vibration Versus Equivalent Resistance Training. J Athl Train $\underline{41}$ (3), 286-293

Maltais ML, Desroches J, Dionne IJ (2009): Changes in muscle mass and strength after menopause. J Musculoskelet Neuronal Interact $\underline{9}$ (4), S. 186-197 
Mayer H, Ammer K, Brandstätter S (2007): Ganzkörpervibration- Methoden und Indikationen. Eine Literaturübersicht. Österreichische Zeitschrift für Physikalische Medizin und Rehabilitation (17), 12-22

McClung JM, Davis JM, Wilson MA, Goldsmith EC, Carson JA (2006): Estrogen status and skeletal muscle recovery from disuse atrophy. J Appl Physiol 100 (6), 2012-2023

Meyer B: Mit ihm beginnt die eigenständige Orthopädie. Der Arzt Julius Wolff 1836-1902. In: Meyer B (Hrsg.): Porträt-Berlin von A-Z Lexikon zur Stadtentwicklung, Chronik und Gegenwart. 2. Auflage, Edition Luisenstadt, Luisenstadt 1997, 79-83

Miller SC, Wronski TJ (1993): Long-term osteopenic changes in cancellous bone structure in ovariectomized rats. Anat Rec 236 (3), 433-441

Mitchell P (1961): Coupling of phosphorylation to electron and hydrogen transfer by a chemiosmotic type of mechanism. Nature $\underline{191}, 144-148$

Moore KL, Persaud TVN, Viebahn C: Embryologie. Muskulatur. In Moore KL, Persaud TVN (Hrsg.): Entwicklungsstadien, Frühentwicklung, Organogenese, Klinik. 5. Auflage; Elsevier Urban\& Fischer, München 2007

Moran AL, Warren GL, Lowe DA (2006): Removal of ovarian hormones from mature mice detrimentally affects muscle contractile function and myosin structural distribution. J Appl Physiol $\underline{100}$ (2), 548-559

Namkung-Matthai H, Appleyard R, Jansen J, Hao Lin J, Maastricht S, Swain M, Mason RS, Murrel GA, Diwan AD, Diamond T. (2001): Osteoporosis influences the early period of fracture healing in a rat osteoporotic model. Bone $\underline{28}(1), 80-86$

Nordlund MM, Thorstensson A (2007): Strength training effects of wholw-body vibration? Scand J Med Sci Sports 17 (1), 12-17 
Opalka J R, Wicke M, Gellerich FN, Schmidt R, Rosner F, Zierz S, von Lengerken G (2004): Mitochondrial function in turkey skeletal muscle-impact on meat quality. Br Poult Sci $\underline{45}$ (3), $367-379$

Oxlund BS, Ortoft G, Andreassen TT, Oxlund H (2003): Low-Intensity, high-frequency vibration appears to prevent the decrease in strength of the femur and tibia associated with ovariectomy of adult rats. Bone $\underline{32}(1), 69-77$

Peter JB, Barnard RJ, Edgerton VR, Gillespie, CA, Stempel KE (1972): Metabolic profiles of three fiber types of skeletal muscle in guinea pigs and rabbits. Biochemistry 11 (14), 26272633

Pette D, Staron RS (2000): Myosin Isoforms, Muscle Fiber Types, and Transitions. Microsc Res Tech $\underline{50}$ (6), 500-509

Phillips SK, Rook KM, Siddle NC, Bruce SA, Woledge RC (1993): Muscle weakness in women occurs at an earlier age than in men, but strength is preserved by hormone replacement therapy. Clin Sci $\underline{84}$ (1), 95-98

Rohracher H (1962): Permanente rhythmische Mikrobewegungen des WarmblüterOrganismus (Mikrovibration). Naturwissenschaften (49), 145-150

Rubin C, Judex S, Qin YX (2006): Low-level mechanical signals and their potential as a nonpharmacological intervention for osteoporosis. Age Ageing $\underline{35}$ (2), 32-36

Sarmiento A, Schaeffer JF, Beckerman L, Latta LL, Enis J (1977): Fracture healing in the rat femora as affected by functional weight-bearing. J Bone Joint Surg Am 59 (3), 369-375

Savard R, Smith LJ, Palmer JE, Greenwood MR (1988): Site specific effects of acute exercise on muscle and adipose tissue metabolism in sedentary female rats. Physiol Behav $\underline{43}$ (1), 6571 
Schmidt RF, Lang F, Heckmann M: Kontraktionsmechanismen. In Schmidt RF, Lang F, Heckmann M (Hrsg.): Physiologie des Menschen. Mit Pathophysiologie. 31. Auflage, Springer-Medizin-Verlag Heidelberg 2010

Scott W, Stevens J, Binder-Macleod SA (2001): Human Skeltal Muscle Fiber Type Classifications. Phys Ther $\underline{81}(11), 1810-1816$

Signorelli SS, Neri S, Sciacchitano S, Di Pino L, Costa MP, Marchese G, Celotta G, Cassibba N, Pennisi G, Caschetto S (2006): Behaviour of some indicators of oxidative stress in postmenopausal and fertile women. Maturitas $\underline{53}(1), 77-82$

Simon J, Rodi IA, Stumpf PG, Sauer MV, Cohen SW, Ford LC, Bustillo M, Buster JE (1986): Polysiloxane vaginal rings and cylinders for physiologic endometrial priming in functionally agonadal women. Fertil Steril 46 (4), 619-625

Sioka C, Fotopoulos A, Georgiou A, Xourgia X, Papadopoulos A, Kalef-Ezra JA (2010): Age at menarche, age at menopause and duration of fertility as risk factors for osteoporosis. Climacteric $\underline{13}(1), 63-71$

Sitnick M, Foley AM, Brown M, Spangenburg EE (2006): Ovariectomy prevents the recovery of atrophied gastrocnemius skeletal muscle mass. J Appl Physiol 100 (1), 286-293

Slatkovska L, Alibhai SMH, Beyene J, Cheund AM (2010): Effect of whole-body vibration on BMD. A systematic review and meta- analysis. Osteoporos Int 21 (12), 1969-1980

Stania M, Chmielewska D, Kwaśna K, Smykla A, Taradaj J, Juras G (2015): Bioelectrical activity of the pelvic floor muscles during synchronous whole-body vibration - a randomized controlled study. BMC Urol $\underline{15}$ (1), S. 689

Stürmer EK, Komrakova M, Werner C, Wicke M, Kolios L, Sehmisch S, Tezval M, Utesch C, Mangal O, Zimmer S (2010): Musculoskeletal Response to Whole-Body Vibration During Fracture Healing in Intact and Ovariectomized Rats. Calcif Tissue Int $\underline{87}$ (2), 168-180 
Stürmer EK, Komrakova M, Sehmisch S, Tezval M, Dullin C, Schaefer N, Hallecker J, Stuermer KM (2014): Whole body vibration during fracture healing intensifies the effects of estradiol and raloxifene in estrogen-deficient rats. Bone 64, 187-194

Tanaka SM, Li J, Duncan RL, Yokota H, Burr DB, Turner CH (2003): Effects of broad frequency vibration on cultured osteoblasts. J Biomech $\underline{36}(1), 73-80$

Tidow G, Wiemann K (1993): Zur Interpretation und Veränderbarkeit von Kraft-Zeit-Kurven bei explosiv-ballistischen Krafteinsätzen Teil II. Deutsche Zeitschrift für Sportmedizin, 44 (4), $136-150$

Turner RT, Evans GL, Wakley GK (1994): Reduced chondroclast differentiation results in increased cancellous bone volume in estrogen-treated growing rats. Endocrinology 134 (1), $461-466$

Turner RT, Maran A, Lotinun S, Hefferan T, Evans GL, Zhang M, Sibonga JD (2001): Animal models for osteoporosis. Rev Endocr Metab Disord 2 (1), 117-127

Verschueren SM, Roelants M, Delecluse C, Swinnen S, Vanderschueren D, Boonen S (2004): Effect of 6-Month Whole Body Vibration Training on Hip Density, Muscle Strength, and Postural Control in Postmenopausal Women: A Randomized Controlled Pilot Study. J Bone Miner Res 19 (3), 352-359

Viña J, Sastre J, Pallardó FV, Gambini J, Borrás C (2006): Role of mitochondrial oxidative stress to explain the different longevity between genders. Protective effect of estrogens. Free Radic Res 40 (12), 1359-1365

Warren GL, Lowe DA, Inman CL, Orr OM, Hogan HA, Bloomfield SA, Armstrong RB (1996): Estradiol effect on anterior crural muscles-tibial bone relationship and susceptibility to injury. J Appl Physiol $\underline{80}$ (5), 1660-1665

Welsch U: Bindegewebe, Muskelgewebe. In Welsch U (Hrsg.): Lehrbuch Histologie. 3. Auflage; Elsevier, Urban\& Fischer, München 2010 
Whedon GD, Deitrick JE, Shorr E (1949): Modification of the effects of immobilisation upon metabolic and physiological functions of the normal men by the use of oscillating bed. Am J Med 6 (6), 684-711

Widrick JJ, Maddalozzo GF, Lewis D, Valentine BA, Garner DP, Stelzer JE, Shoepe TC, Snow CM (2003): Morphological and functional characteristics of skeletal muscle fibers from hormone-replaced and nonreplaced postmenopausal women. J Gerontol A Biol Sci Med. Sci $\underline{58}(1), 3-10$

Wing RR, Matthews KA, Kuller LH, Meilahn EN, Plantinga PL (1991): Weight gain at the time of menopause. Arch Intern Med 151 (1), 97-102

Wolfe RR (2006): The underappreciated role of muscle in health and disease. Am J Clin Nutr $\underline{84}(3), 475-482$

Wolff J: Das Gesetz der Transformation der Knochen. Hrsg. v. Bergmann G, Duda G. Reprint der Ausgabe Hirschwald, Berlin 1892. Pro Business, Berlin 2010

Wozniak M, Fausto A, Carron CP, Meyer DM, Hruska KA (2000): Mechanically Strained Cells of the Osteoblast Lineage Organize their Extracellular Matrix Through Unique Sites of alpha-vbeta3-Integrin Expression. J Bone Miner Res 15 (9), 1731-1745

Wronski TJ, Lowry PL, Walsh CC, Ignaszewski LA (1985): Skeletal alterations in ovariectomized rats. Calcif. Tissue Int. $\underline{37}$ (3), 324-328

Xie L, Rubin C, Judex S (2008): Enhancement of the adolescent murine musculoskeletal system using low-level mechanical vibrations. J Appl Physiol 104 (4), 1056-1062

Yamagishi M, Yoshimura Y (1955): The biomechanics of fracture healing. J Bone Joint Surg Am 37-A (5), 1035-1068

Yellowley CF, Li Z, Zhou Z, Jacob CR, Donahue HJ (2000): Functional Gap Junctions Between Osteocytic and Osteoblastic Cells. J Bone Miner Res 2000 15 (2) $)$, 209-217 


\section{Danksagung:}

An dieser Stelle möchte ich Frau Professor Dr. med. Ewa K. Stürmer für die Überlassung des Dissertations-Themas und für die kontinuierliche, zielgerichtete und sorgfältige Begleitung und Unterstützung danken. Insbesondere gilt Frau Professor Dr. med. Ewa K. Stürmer mein großer Dank für ihre sehr zeitnahen Korrekturren und ihr Vorantreiben meiner Arbeit.

Besonderer Dank gilt ebenfalls für die kontinuierliche, exzellente wissenschaftliche Unterstützung meiner Dissertation Frau Dr. rer. nat. Marina Komrakova.

Meinen herzlichsten Dank möchte ich an Frau Ramona Castro-Machguth, Frau Annette Witt, Frau Ruth Wigger und Herrn Peter Ludewig richten, ihre stets verlässliche, motivierende, engagierte, beratende, praktisch unterstützende und herzliche Art haben einen großen Beitrag an dem Entstehungsprozess meiner Dissertation geleistet. 


\section{Lebenslauf:}

Geboren am 02.01.1984 in Gelsenkirchen erlangte ich meine Allgemeine Hochschulreife 2003 am Graf-Engelbert-Gymnasium in Bochum. Danach absolvierte ich die Ausbildung zur Gesundheits- und Krankenpflegerin an der Universitätsklinik Knappschaftskrankenhaus Bochum Langendreer mit dem Abschluss des Staatsexamens.

Im Anschluss konnte ich mein Medizinstudium (10/2006-12/2012) an der Georg-AugustUniversität zu Göttingen aufnehmen. Im Sommersemester 2008 absolvierte ich den Ersten Abschnitt der Ärztlichen Prüfung. Das Klinische Studium absolvierte ich ebenfalls an der Georg-August-Universität zu Göttingen. 2010 begann ich mit meiner Arbeit an der Dissertation in der Arbeitsgrupe von Frau Prof. Dr. Ewa K. Stürmer, in der Klinik für Unfallchirurgie, Orthopädie und Plastische Chirurgie.

Studienbegleitend arbeitete ich als Gesundheits- und Krankenpflegerin in der Gynäkologie und Geburtshilfe im Agaplesion Krankenhaus Neu Bethlehem in Göttingen (2008-2011).

Nach dem Zweiten Abschnitt der Ärztlichen Prüfung (11/2012) trat ich meine Stelle als Weiterbildungsassistentin in der Allgemein-, Viszeral- und Kinderchirurgie, Abteilungsdirektor Herr Prof. Ghadimi, an der Universitätsmedizin Göttingen an, dort arbeitete ich von 04/2013 bis 03/2015. Nach meinem abgeschlossenem Common Trunk und der wissenschaftlichen Arbeit in der Arbeitsgruppe von Herrn Prof. Dr. O. Kollmar und Herrn Dr. J. E. Slotta mit den Schwerpunkten der Leberchirurgie und Lebertransplantation: Multidrug donor preconditioning (MDDP) for orthotopic rat liver transplantation wechselte ich in das Fach der Anästhesiologie.

Zunächst arbeitete ich von 05/2015 bis 04/2016 in der Klinik für Anästhesiologie, operative Intensivmedizin und Schmerztherapie, Chefarzt Herrn Dr. A. Fiehn, in den Agaplesion Diakonie Kliniken Kassel. Für meine weitere Ausbildung zur Fachärztin für Anästhesiologie arbeite ich seit 05/2016 in der Klinik für Anästhesiologie, operative Intensivmedizin und Schmerztherapie für den Abteilungsdirektor Herrn Prof. Dr. med. Dr. h.c. H. Van Aken beziehungsweise seit 10/2016 für den Abteilungsdirektor Herrn Prof. Dr. med. Alexander Zarbock am Universitätsklinikum Münster.

Münster, den 25.09.2017 